PNL-3253

UC-11

Environmental Control

Technology for

Mining, Milling, and

Refining Thorium
S. A. Weakley
D.E. Blahnik
J.K. Young
C.H. Bloomster

February 1980

Prepared for the Environmental Control Technology Division U.S. Department of Energy under Contract DE-AC06-76RLO-1830

Pacific Northwest Laboratory Operated for the U.S. Department of Energy by Battelle Memorial Institute 


\title{
NOTICE
}

This report was prepared as an account of work sponsored by the United States Government. Neither the United States nor the Department of Energy, nor any of their employees, nor any of their contractors, subcontractors, or their employees, makes any warranty, express or implied, or assumes any legal liability or responsibility for the accuracy, completeness or usefulness of any information, apparatus, product or process disclosed, or represents that its use would not infringe privately owned rights.

The views, opinions and conclusions contained in this report are those of the contractor and do not necessarily represent those of the United States Gavernment or the United States Department of Energy.

PACIFIC NORTHWEST LABORATORY

operated by

BATTELLE

for the

UNITED STATES DEPARTMENT OF ENERGY

Under Contract DE-AC06-76RLO 1830

\author{
Printed in the United States of America \\ Available from \\ National Technical Information Service \\ United States Department of Commerce \\ 5285 Pont Royal Road \\ Springfield, Virginia 22151
}

Price: Printed Copy $\$$

$\therefore$ Microfiche $\$ 3.00$

$\begin{array}{cc}\text { •Pages } & \begin{array}{c}\text { NTIS } \\ \text { Selling Price }\end{array} \\ 001-025 & \$ 4.00 \\ 026-050 & \$ 4.50 \\ 051-075 & \$ 5.25 \\ 076-100 & \$ 6.00 \\ 101-125 & \$ 6.50 \\ 126-150 & \$ 7.25 \\ 151-175 & \$ 8.00 \\ 176-200 & \$ 9.00 \\ 201-225 & \$ 9.25 \\ 226-250 & \$ 9.50 \\ 251-275 & \$ 10.75 \\ 276-300 & \$ 11.00\end{array}$


PNL -3253

33679000544140

UC-11

ENVIRONMENTAL CONTROL TECHNOLOGY FOR

MINING, MILLING, AND REFINING THORIUM
S. A. Weak ley
D. E. Blahnik
J. K. Young
C. H. Bloomster

February 1980

Prepared for the

Environmental Control Technology Division U.S. Department of Energy

under Contract DE-AC06-76RLO 1830

Pacific Northwest Laboratory

Richland, Washington 99352 
" 


\section{SUMMARY AND RECOMMENDATIONS}

In order to meet the increased demands for reactor-grade thoria $\left(\mathrm{ThO}_{2}\right)$ that a conversion to the thorium fuel cycle would require, new domestic deposits will have to be mined. This study examined the type and level of wastes that would be generated in the mining, milling, and refining of $\mathrm{ThO}_{2}$ from seven potential domestic sources of thorium. The estimated costs of the technology to control these wastes to different degrees of stringency are presented.

The incremental cost of $\mathrm{ThO}_{2}$ production for waste control could vary not only with the level of control but from site to site (see Figure 1). The maximum incremental cost of environmental control technology per pound of thoria ranges from $\$ 13.55$ at the Lemhi Pass deposit to $\$ 0.71$ at the Palmer, Michigan, deposit. The major differences between the costs at these two sites are caused by the amount of ore processed and the treatment process for the tailings from the mills and refineries. At Palmer, Michigan, more thoria would be produced and the tailings would be buried onsite by simple methods while at Lemhi Pass less thoria but more highly radioactive tailings would be produced; these tailings would be blended with asphalt and trucked to an onsite burial ground for disposal. These differences, as well as many others among the other sites, cause the environmental control technology costs to be highly site- and process-specific.

The major wastes generated at most sites would be similar in type (dust, water, etc.), but the radioactive content would vary, depending on the ore grade. The major cost would be for controlling the waste water and tailings from the mines, mills, and refineries. The type of control method that would be used depends on the water volume and its radioactivity level. Waste water control consists of tailings ponds, pond covers, beach dust spraying, and, in some cases, dewatering and material additions to immobilize the radioactive constituents. 


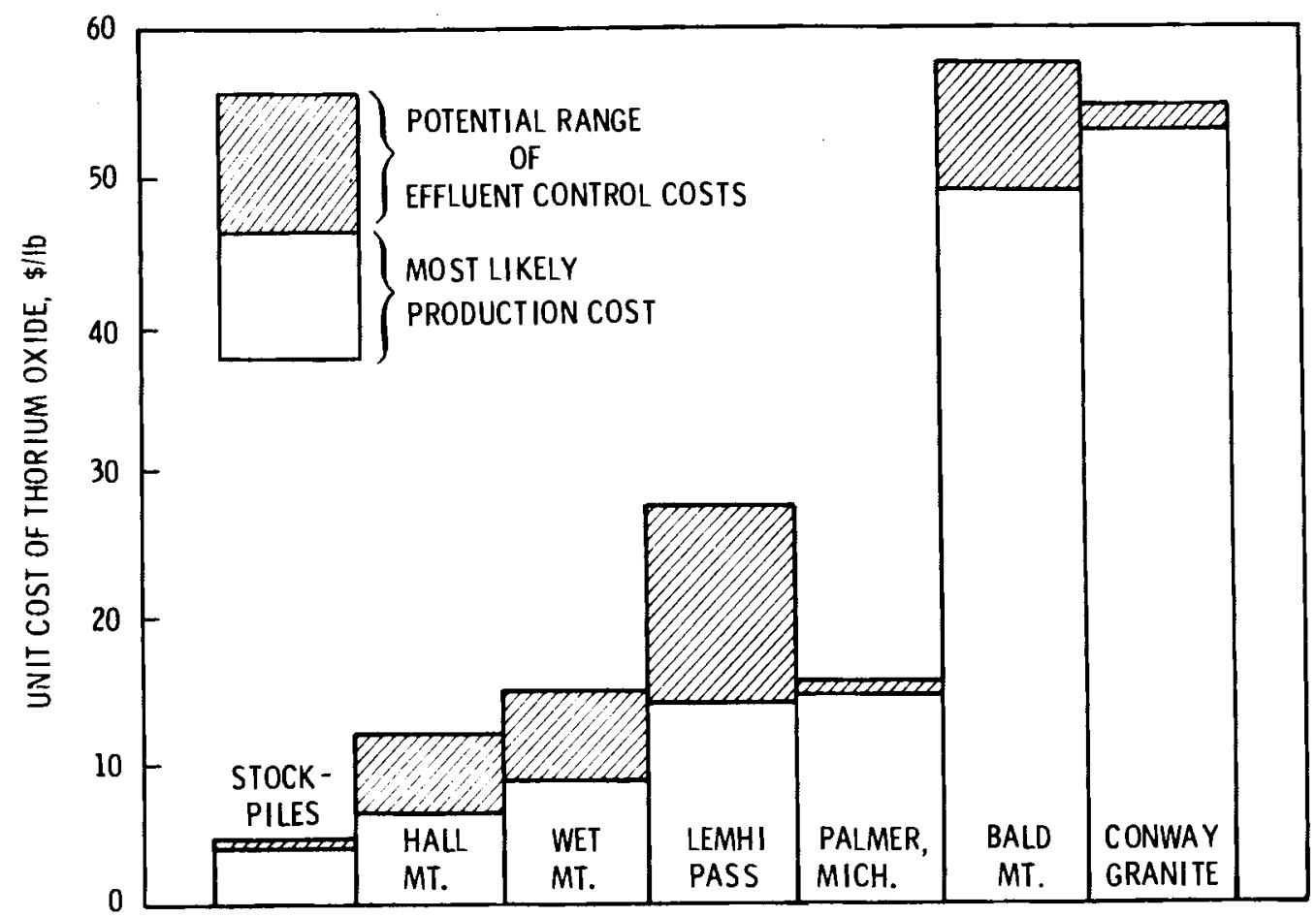

FIGURE 1. Domestic Thorium 0xide Costs

This study indicated that most of the environmental control technolgoy costs (up to about 90\%) at each site would be for the control of mill and refinery tailings. The unit costs were generally much lower in cases where the throughput rates and ore grades were higher. It could cost over an order of magnitude more to reduce the amount of a specific effluent released by the last 1 or $2 \%$.

The technologies used in this study have the potential to effectively hold the discharge of effluents to very low levels. Many of the environmental control methods used in the uranium industry should also be applicable for use in the thorium industry. It should be easier to control the offsite effluents for thorium than for uranium because the migration of thoron (radon) and its daughters is easier to prevent, due to their shorter half-lives. These shorter half-lives also reduce the radioactivity of the tailings piles substantially within 50 years. 
There is a lack of recent data dealing with industrial-scale thorium oxide production. Most of the process and production data in the literature are over two decades old with little data on the release and control of effluents. If there were a transition to a thorium fuel cycle, we recommend research to:

- obtain site-specific data from the deposit to be developed (e.g. ore analys is, hydrology, ecology, etc.),

- define flow sheet and processes for the specific sites,

- analyze the radon concentrations and retention parameters likely to be encountered in mines and tailings piles. 
. 


\section{CONTENTS}

SUMMARY AND RECOMMENDATIONS

1.0 INTRODUCTION

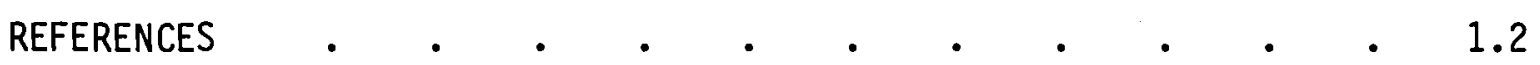

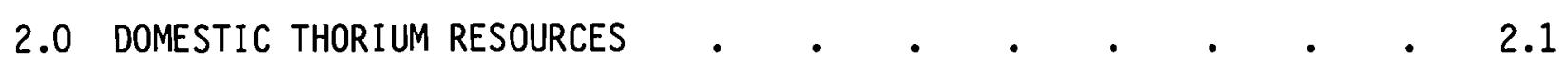

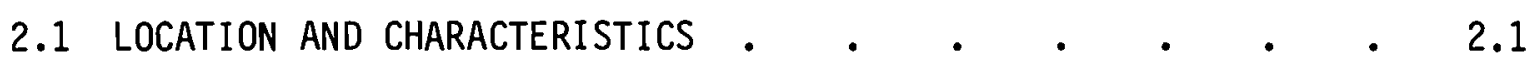

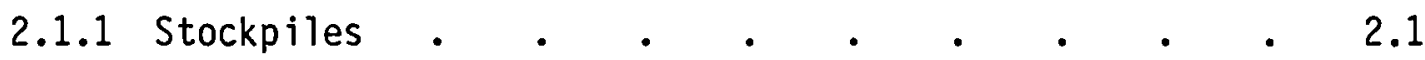

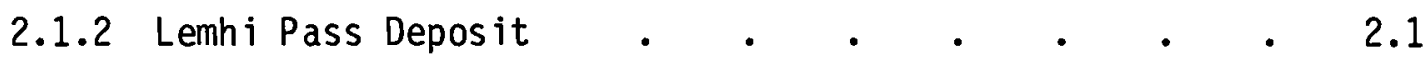

2.1.3 Wet Mountain . . . . . . . . . 2.3

2.1.4 Hall Mountain, Idaho . . . . . . . 2.3

2.1 .5 Palmer, Michigan . . . . . . . . . 2.3

2.1 .6 Bald Mountain . . . . . . . . . . . 2.4

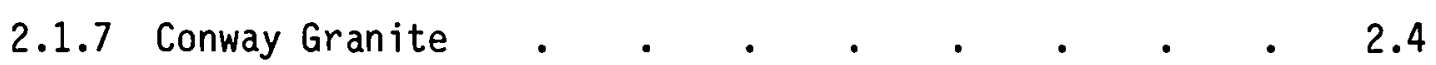

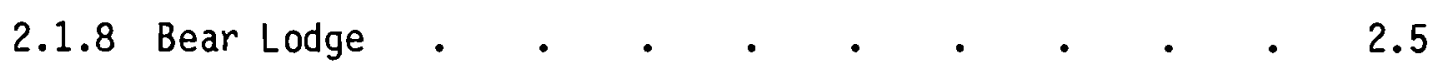

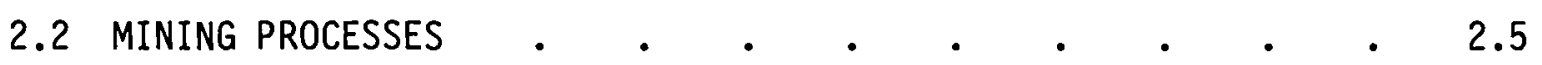

2.2.1 Underground Mining . . . . . . . . 2.5

2.2.2. Surface Mining . . . . . . . . . 2.6

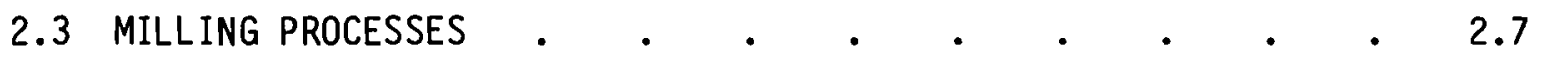

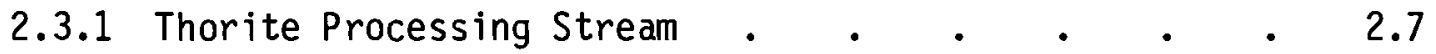

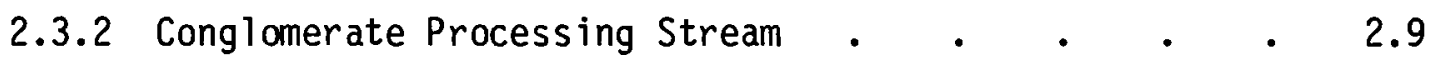

2.3.3 Granite Processing Stream . . . . . . 2.10

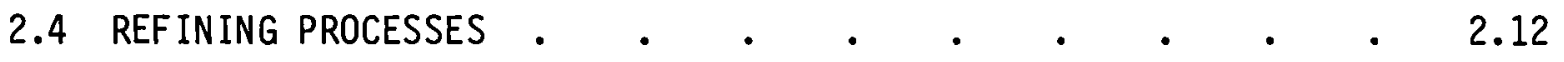

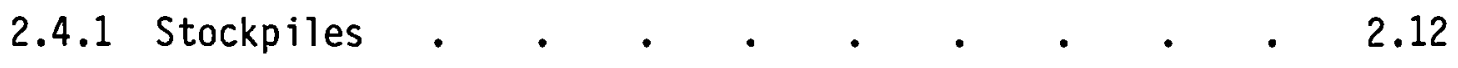

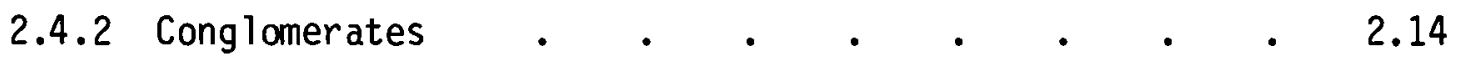


2.4 .3 Granite . . . . . . . . . . 2.16

2.5 PRODUCTION COSTS . . . . . . . . . . . . . 2.16

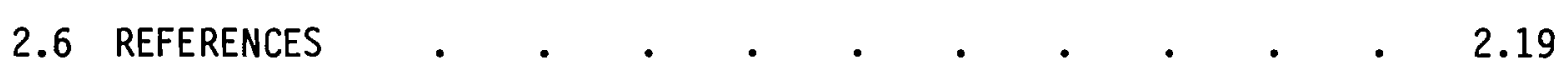

3.0 ENVIRONMENTAL IMPACTS FROM THORIUM PRODUCTION $\quad . \quad$. $\quad$ • $\quad 3.1$

3.1 CURRENT PRODUCTION

3.1.1 Mining and Milling . . . . . . . . . 3.3

3.1.2 Extraction of Thoria . . . . . . . 3.3

3.1.3 Thoria Refinement Plant $\quad$. $\quad$. $\quad . \quad$. $\quad . \quad$. 3.7

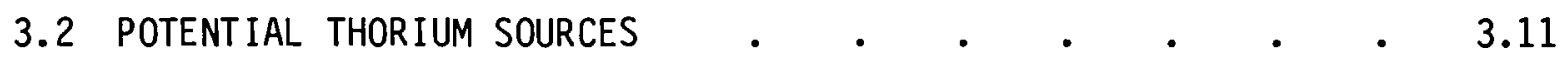

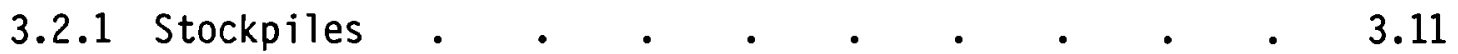

3.2.2 Lemhi Pass Deposit . . . . . . . . 3.13

3.2.3 Hall Mountain Deposit . . . . . . . . 3.19

3.2.4 Wet Mountain Deposit . . . . . . . 3.23

3.2.5 Palmer, Michigan, Deposit . • . • . . 3.28

3.2 .6 Bald Mountain Deposit . . . . . . . 3.36

3.2.7 Conway Granite Deposit • • • • . 3.43

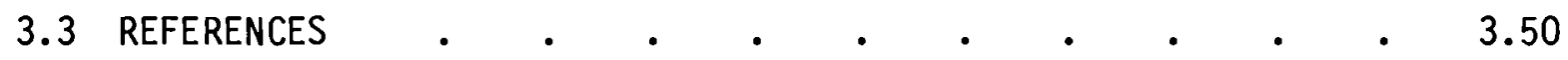

4.0 ASSESSMENT OF AVAILABLE ENVIRONMENTAL CONTROL
TECHNOLOGIES

4.1 METHODS OF ENVIRONMENTAL CONTROL FOR MINING $\quad$ • $\quad$ • $\quad$ • 4.2

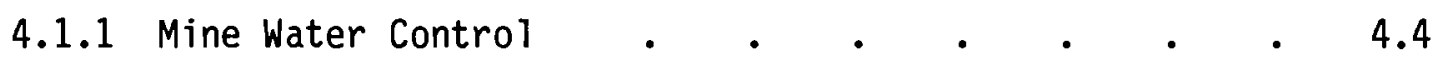

4.1.2 Ore Dust (Controlled and Uncontrolled) . . . 4.6

4.1.3 Thoron (Radon-220) Gas Control • • • • • • 4.7 
4.1.4 Control of Equipment-Generated Fumes . $\quad$ • $\quad$ - 4.9

4.2 METHODS OF ENVIRONMENTAL CONTROL FOR MILLING

AND REFINING THORIUM

4.2.1 Control of Mill Dust from Unloading,

Crushing, and Grinding Ore . . . . . . 4.10

4.2.2 Control of Dust from Drying, Ignition, and Packaging Thoria . . . . . . . 4.18

4.2.3 Control of Thoron Gas from Unloading, Crushing, and Grinding.

4.2.4 Process Fume Control . . . . . . . 4.20

4.2.5 Refinery Waste Sludge Control . . . . . 4.20

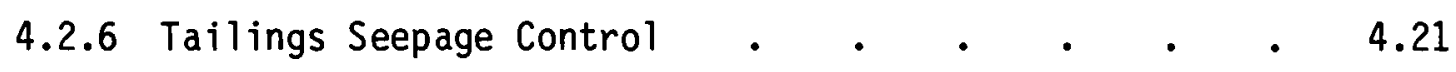

4.2.7 Tailings Pond Beach Dust Control • . . . . 4.25

4.2.8 Tailings Pond Thoron Gas Control • • • • . 4.26

4.2.9 Long-Term Stabilization of the Tailings . . . 4.26

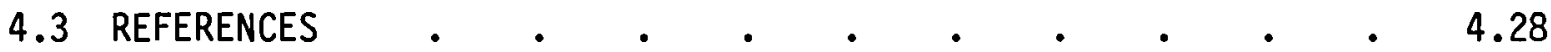

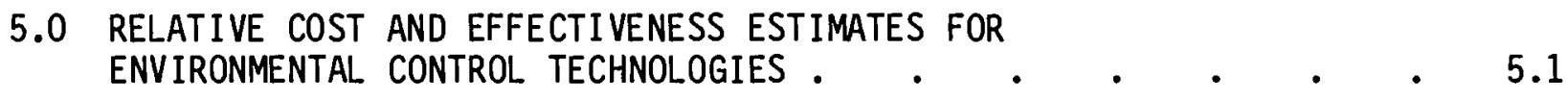

\begin{tabular}{l}
5.1 COST ESTIMATES FOR ENVIRONMENTAL CONTROL \\
TECHNOLOGIES \\
\hline
\end{tabular}

5.1 .1 Capital Installation Cost $\quad$. $\quad . \quad$. $\quad$ • 5.11

5.1 .2 Operating Costs . . . . . . . . . 5.12

5.1.3 Equivalent Annual Charge for Depreciable
Capital Investment

5.1.4 Equivalent Annual Charge for Nondepreciable
Capital Investment...
.

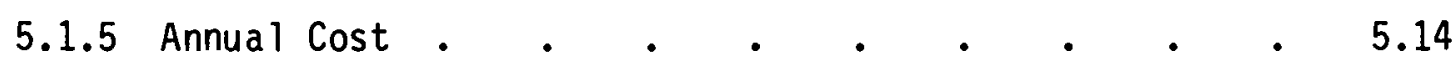

\begin{tabular}{l}
5.2 EFFECTIVENESS ESTIMATES FOR ENVIRONMENTAL CONTROL \\
TECHNOLOGIES \\
\hline
\end{tabular} 
5.2.1 Control of Airborne Dust from Productive

Equipment $. \quad . \quad . \quad . \quad . \quad$. 5.14

5.2.2 Control of Airborne Dust From Roads and

Yards . . . . . . . . . . . 5.14

5.2.3 Control of Airborne Dust From Ore Storage

Piles. . . . . . . . . . 5.14

5.2.4 Control of Airborne Dust From Tailings Beaches . . . . . . . . . 5.15

5.2.5 Mine Water Control . . . . . . . . 5.16

5.2.6 Control of Tailings Pond Seepage . . • • • • 5.16

5.2.7 Tailings Covers (at Decommissioning) • • • . 5.16

5.2.8 Refinery Waste Sludge . . . . . . . 5.18

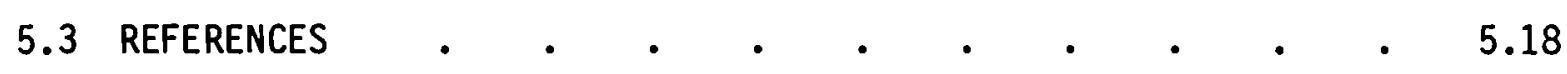

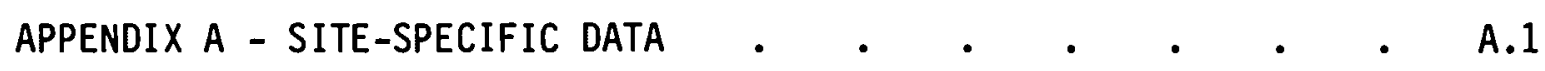

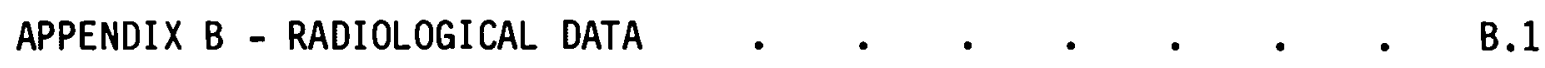

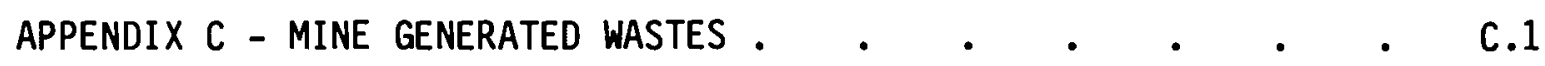

APPENDIX D - MILL AND REF INERY GENERATED WASTES • • • • • D.1

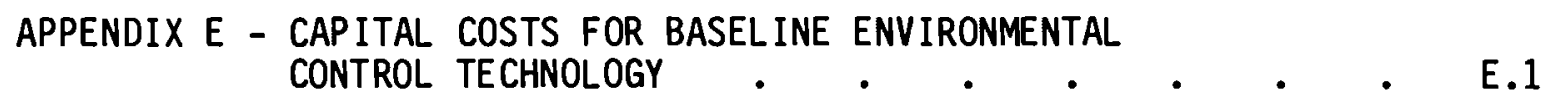

APPENDIX F - ANNUAL COSTS FOR BASELINE TECHNOLOGY • • • • F.1 


\section{FIGURES}

1 Domestic Thorium 0xide Costs . . . . . .

2.1 Map Showing the Locations of Promising Thorium

Deposits in the United States . . . . . • . 2.2

2.2A Domestic Thorium 0xide Supply Curves . • • • . . 2.17

2.2B Domestic Thorium Oxide Supply Curves . • • • • . 2.17

3.1 Main Generated Wastes Emitted from Mining and
Milling Processes at the Florida Dredge Mine

3.2 Main Generated Wastes Emitted from Extraction Process . . 3.6

3.3 Current Thorium Dioxide Refining Process . . . . . . 3.9

3.4 Stockpile Refinery Generated Wastes . • . . . 3.12

3.5 Lemhi Pass Mine and Mill/Refinery Generated Wastes . . . 3.17

3.6 Hall Mountain Mine and Mill/Refinery Generated Wastes . . . 3.20

3.7 Wet Mountain Mine and Mill/Refinery Generated Wastes . . . 3.25

3.8 Palmer, Michigan, Mine and Mill Generated Wastes . . . 3.29

3.9 Palmer, Michigan, Refinery Generated Wastes . • • . . 3.34

3.10 Bald Mountain Mine and Mill Generated Wastes . • . . 3.37

3.11 Bald Mountain Refinery Generated Wastes . . • . . 3.41

3.12 Conway Granite Mine and Mill Generated Wastes . . . . 3.44

3.13 Conway Granite Refinery Generated Wastes . . . . . 3.48

Typical Types of Wastes from Mining, Milling,
and Refining Thorium . . . . . . . 4.1

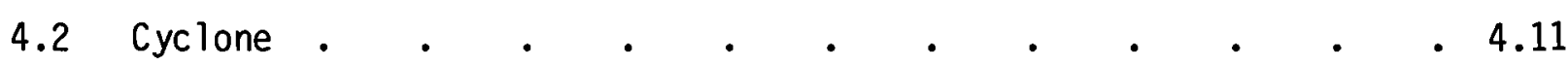

4.3 Orifice Scrubber . . . . . . . . . . . . 4.12 


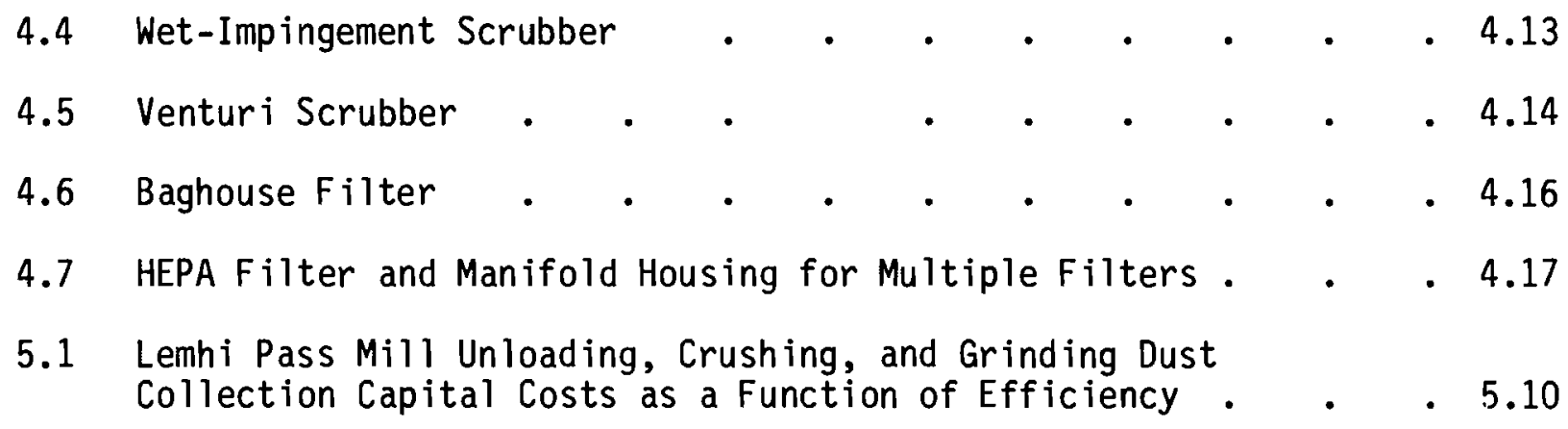




\section{$\underline{\text { TABLES }}$}

2.1 Summary of Thorium Production Costs and Reserve Estimates

3.1 Summary of Environmental Control Costs Using the Current Level of Control and Size of Operations . . . 3.2

3.2 Estimated Costs of Environmental Control Facilities and Operations for Existing Monazite Sand Mining and Milling Operations.

3.3 Estimated Capital, Annual, and Rehabilitation Costs for Environmental Control Facilities and Operations for the Extraction of Thoria from Monazite in Existing Operations

3.4 Estimated Costs of Environmental Control Facilities and Operations at a Thoria Refinement Plant . . . . 3.10

3.5 Estimated Waste Control Costs for a Stockpile Refinery

3.6 Estimated Waste Control Costs for Lemhi Pass Mine and Mill/Refinery . $. \quad . \quad . \quad . \quad . \quad . \quad . \quad . \quad . \quad 3.15$

3.7 Estimated Waste Control Costs for Hall Mountain Mine and Mill/Refinery . . . . . . . . . . 3.21

3.8 Estimated Waste Control Costs for Wet Mountain Mine and Mill/Refinery . . . . . . . . . . 3.26

3.9 Estimated Waste Control Costs for Palmer, Michigan,

3.10 Estimated Waste Control Costs for Bald Mountain Mine, Mill, and Refinery . . . . . . . . 3.38

3.11 Estimated Waste Control Costs for Conway Granite
Mine, Mill, and Refinery . . . . . . . . . 3.46

4.1 General Differences Between Thorium and Uranium
in Mining, Milling, and Refining . . . . . . . . . 4.3

4.2 Radium Decontamination Using Barium Salts $\quad$. $\quad . \quad$. $\quad$. $\quad 4.5$ 
5.1 Cost Range for Environmental Control for the Mining,

Milling, and Refining of Various Thorium Resources , . 5.2

5.2 Cost and Effectiveness of Environmental Control

Technologies at Lemhi Pass, Hall Mountain, and Wet

Mountain.

5.3 Cost and Effectiveness of Environmental Control

Technologies at Palmer, Michigan, and Bald Mountain . . 5.5

5.4 Cost and Effectiveness of Environmental Control

Technologies at Conway Granite and Stockpile Refiney . $\quad 5.7$

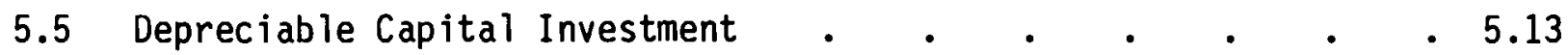

5.6 Dust Collector Efficiency Estimates . . . . . . . 5.15

5.7 Estimated Effectiveness of Various Methods of Seepage 


\subsection{INTRODUCTION}

In recent years, political opinion has prompted the reassessment of the thorium fuel cycle for nuclear power production as a deterrent to the proliferation of nuclear weapons. In a nuclear reactor, thorium breeds the fertile isotope, ${ }^{233} U$, rather than plutonium, which is bred in uranium fueled reactors. Either plutonium or uranium-233, depending on the fuel cycle, can be separated from the irradiated fuel and mixed with natural or depleted uranium $238_{U}$ to form new fuel. Conceivably, this nuclear fuel material could be diverted by terrorists or foreign governments and utilized for weapons manufacture. Unlike plutonium, however, the fissile isotope ${ }^{233} \mathrm{U}$ can only be separated from the depleted uranium by an expensive isotopic separations process. Thus, the thorium fuel cycle is attractive from a safeguards viewpoint.

If the thorium fuel cycle was adopted for nuclear power production, new thorium supply sources would have to be developed. The availability of the thorium, its cost of production, and the capability and the cost of controlling wastes from its production would be of major importance in a policy decision to implement thorium fuel cycle reactors.

The purpose of this report is to evaluate, in terms of cost and effectiveness, the various environmental control technologies that would be used to control the radioactive wastes generated in the mining, milling, and refining of thorium from domestic resources. The technologies, in order to be considered for study, had to reduce the radioactivity in the waste streams to meet Atomic Energy Commission (10 CFR 20) standards for natural thorium's maximum permissable concentration (MPC) in air and water. Further regulatory standards or licensing requirements, either federal, state, or local, were not examined. The availability and cost of producing thorium from domestic resources is addressed in a companion volume. (1)

The objectives of this study were 1) to identify the major waste streams generated during the mining, milling, and refining of reactor-grade thorium oxide from domestic resources, and 2) to determine the cost and levels of control of existing and advanced environmental control technologies for these waste streams. 
Six potential domestic deposits of thorium oxide, in addition to stockpiled thorium sludges, are discussed in this report. A seventh deposit at Bear Lodge, Wyoming, has been identified recently but no process data is available for this ore. Due to the lack of data and time constraints, the Bear Lodge deposit is not included in this study. A summary of the location and characteristics of the potential domestic thorium resources and the mining, milling, and refining processes that will be needed to produce reactor-grade thorium oxide is presented in Section 2. The wastes from existing and potential domestic thorium oxide mines, mills, and refineries are identified in Section 3. Section 3 also presents the state-of-the-art technology and the costs associated with controlling the wastes from the mines, mills, and refineries. In Section 4, the available environmental control technologies for mines, mills, and refineries are assessed. Section 5 presents the cost and effectiveness estimates for the various environmental control technologies applicable to the mine, mill, and refinery for each domestic resource.

\section{REFERENCES}

1. Young, J.K. et al. February 1980. Economics of Large-Scale Thorium Oxide Production: Assessment of Domestic Resources, PNL-3150, Pac if ic Northwest Laboratory, Richland, Washington 99352. 


\subsection{DOMESTIC THORIUM RESOURCES}

Thorium mineralization consists primarily of thorite ( $\mathrm{Th} \mathrm{SiO}_{4}$ ), mona$z i t e$, and, to a lesser degree, pyrochlore. The locations of the deposits discussed in this study are shown in Figure 2.1. Deposit characteristics and the processing techniques utilized to develop the various thorium resources are discussed in the following sections.

\subsection{LOCATION AND CHARACTERISTICS}

\subsubsection{Stockpiles}

The primary industrial stockpile for thorium is owned by W. R. Grace and Company in Chattanooga, Tennessee. Thorium sludge is currently obtained as a byproduct of monazite sand processing for rare earths and stockpiled at a rate of 250 ton/yr. An estimated back $\log$ of 1500 tons of $\mathrm{ThO}_{2}$ equivalent is contained in the ponds. The thorium sludge is reported to contain $25 \% \mathrm{ThO}_{2}$ and some uranium (assumed to be $\sim 1 \%$ ).

Government stockpiles exist at Curtis Bay, Maryland; Miamisburg, Ohio; and Fernald, Ohio. These stockpiles are primarily in the form of thorium nitrates. Approximately 800 tons of $\mathrm{ThO}_{2}$ equivalent are stored at Curtis Bay, Maryland, and another 400 tons of $\mathrm{ThO}_{2}$ equivalent are located in Miamisburg, Ohio. These stockpiles are assayed at approximately $46 \% \mathrm{ThO}_{2}$. Another 360 metric tons of $\mathrm{ThO}_{2}$ equivalent assayed at $88 \% \mathrm{ThO}_{2}$ are stored in Fernald, Ohio.

\subsubsection{Lemhi Pass Deposit}

The thorium-bearing vein deposits in the Lemhi Pass area have been described in the literature by Staatz. $(1,2)$ The Lemhi Pass quadrangle, lying astride the Continental Divide, occupies approximately $53 \mathrm{sq}$. miles in the east-central part of the Beaverhead Mountains of Idaho and Montana. Although the Lemhi Pass thorium district is much larger, the quadrangle contains the most abundant thorium veins. Veins that contain copper but no thorium also exist, as well as barren quartz veins. Staatz estimates the 


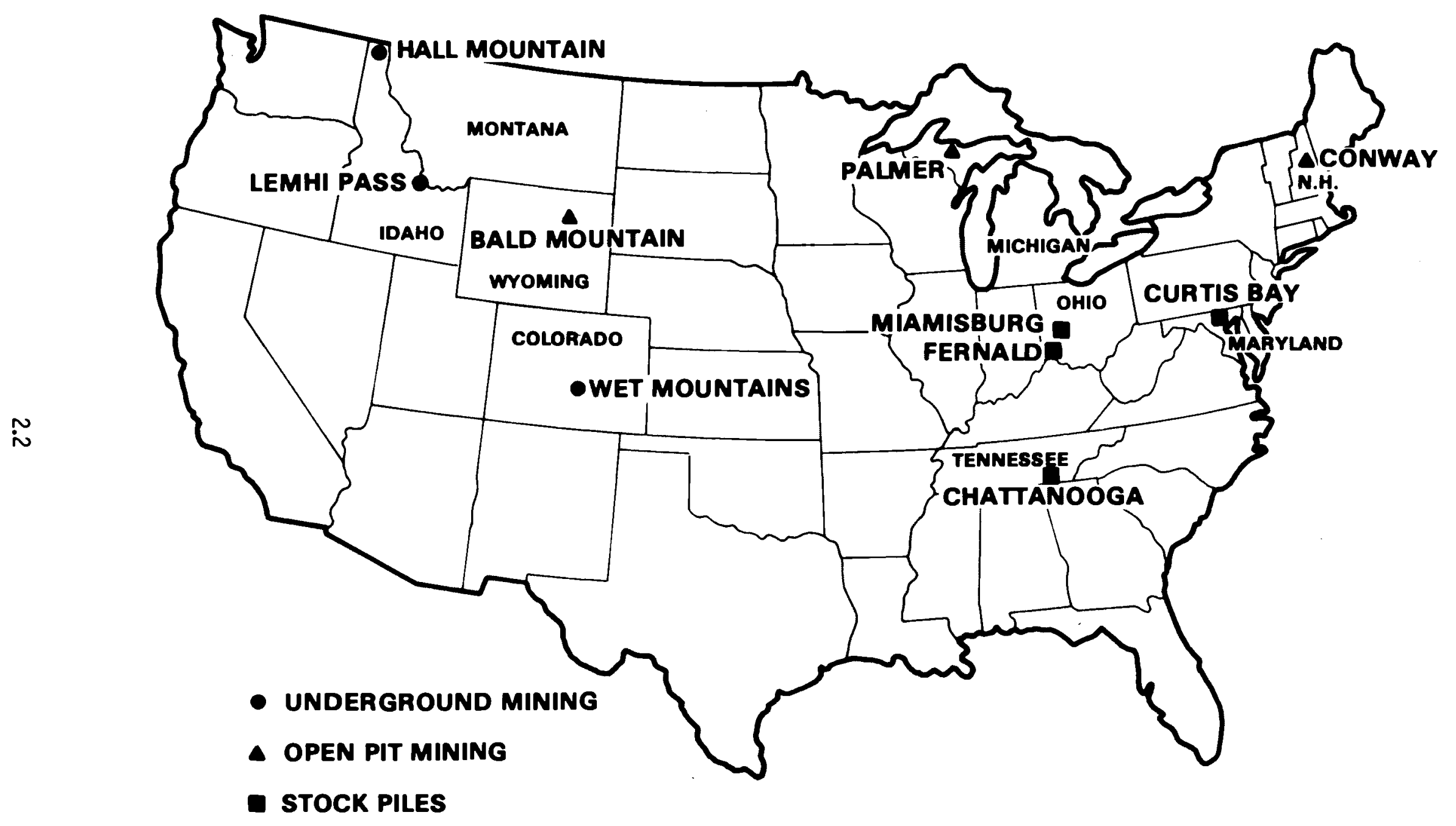

FIGURE 2.1. Map Showing the Locations of Promising Thorium Deposits in the United States 
thorium reserves at 67,700 tons of $\mathrm{ThO}_{2}$ with an additional 120,000 tons of probable and potential resources. ${ }^{(3)}$ Ten veins within the district contain $94 \%$ of these reserves.

The thorium content of some of the better-explored thorium veins ranges from $0.001 \%$ to $16.3 \%$ with an average $\mathrm{ThO}_{2}$ content of $0.4 \%$; the grade varies considerably within the veins. Although the overall rare earths content is about equal to the thorium content, the ratio of rare earths to thorium may range from $0.5: 1$ to $5.2: 1$ in the same vein.

\subsubsection{Wet Mountain}

Thorium has been identified in over 400 narrow, steeply dipping veins in a 22-mile tract of Precambrian rocks on the flank of Wet Mountain in Colorado. $(2,4,5)$

The thorium-bearing mineralization has been described as a "thorite-like mineral" and is presumed to be thorite. The $\mathrm{ThO}_{2}$ content of these vein deposits ranges from $0.02 \%$ to $12.5 \%$ with an average ore grade of $1.1 \%$. Staatz has estimated the size of these reserves at 66,900 tons of $\mathrm{ThO}_{2}$. The total probable potential resource in this district is 158,000 tons, ${ }^{(3)}$ or $46.9 \%$ of the total reserve in identified vein deposits in the U.S.

\subsubsection{Hall Mountain, Idaho}

Hall Hountain is located approximately 3 miles east of the U.S. border station at Porthill, Idaho. (6) Thorium has been identified in 11 narrow, steeply dipping veins in a half-sq. mile area. The thorium-bearing mineralization, mainly thorite, is erratic and commonly occurs along fractures. Based on geological and sample data published by Staatz, the minable ore reserve is estimated at 5210 tons of $\mathrm{ThO}_{2}$ with an average ore grade of $1.3 \%$. The probable potential resource in this district is 29,900 tons. (3) This area has $3.7 \%$ of the total identified vein deposits in the U.S.

\subsubsection{Palmer, Michigan}

The Palmer area is located in the east-central portion of Marquette County on the northern peninsula of Michigan. The deposit occupies approximately $3 \mathrm{sq}$. miles and includes the town of Palmer. The Palmer area is characterized by relatively rugged knobby topography covered by a dense forest. 
Thorium-bearing Goodrich quartzite forms the bulk of the ore deposit. This deposit contains an estimated 193,000 tons of $\mathrm{ThO}_{2}$. The thorium content is estimated at $1.06 \mathrm{lb} /$ ton $(0.06 \%)$ but ranges from 0.26 to $3.56 \mathrm{lb} /$ ton $(7)$ while the average monazite content is estimated at $14.7 \mathrm{1b} / \mathrm{ton}$. The monazite is assumed to be $8.2 \%$ thorium oxide.

The other heavy minerals associated with the quartzite are mainly hematite, magnetite, ilmenite, and rutile. No estimates of the amount of these minerals are available. The rare-earth oxide content of the monazite is approximately $46 \%$. (8) Thus, the amount of minable rare-earth oxides contained in the monazite at Palmer is estimated at over 1,000,000 tons.

\subsubsection{Bald Mountain}

Bald Mountain is located approximately 6 miles north of Sundance, Wyoming, in the Bear Lodge Mountain area (see Figure 2.1). Microscopic examination of 1400 lb of drill core from Bald Mountain showed that the principal constituents are quartz and feldspars with lesser concentrations of garnet, hematite, limonite, magnetite, ilmenite, zircon, and monazite. (9) The monazite in $20 \mathrm{million}$ tons of material is reported to average $2.51 \mathrm{~b} /$ ton of ore. A small but high-grade stratum contains 675,000 tons of ore with an average of $13.2 \mathrm{lb}$ of monazite per ton. (10) For purposes of this study, however, the monazite is assumed to be evenly distributed throughout the rock. The average grade of the monazite is reported to be $8.8 \% \mathrm{ThO}_{2} \cdot(9)$ The Bald Mountain deposit's average ore grade is assumed to be $0.013 \%$ or approximately 2.85 lb of monazite per ton of ore. Bald Mountain contains approximately 2600 tons of $\mathrm{ThO}_{2}$. Other by-products include as much as 7,700,000 tons of elements and 16,000 tons of rare-earth oxides. (11)

\subsubsection{Conway Granite}

The Conway granite of New Hampshire is a large potential source of $\mathrm{ThO}_{2}$. The deposit, occupying approximately 307 sq. miles in the White Mountains (see Figure 2.1), contains an estimated $35 \mathrm{million}$ tons of thorium and extends to a depth of at least $1000 \mathrm{ft}$. Thorium is distributed evenly in the outcrop with an average grade of $56 \pm 6 \mathrm{ppm}(0.006 \%) \mathrm{ThO}_{2} \cdot(12,13)$ 
Uranium is associated with the thorium. The uranium content is at least one-fourth that of the thorium content.

\subsubsection{Bear Lodge}

The Bear Lodge deposit--located about 6 miles north of Sundance, Wyoming, and occupying $1.5 \mathrm{sq}$. miles--contains about 228,000 tons of thorium oxide reserves. Disseminated veinlets of thorium occur in iron-manganese zones. The grade of rock containing the veinlets ranges from $46 \mathrm{ppm} \mathrm{Th0}{ }_{2}$ to 1,200 $\mathrm{ppm} \mathrm{ThO}_{2}$. The principal identified thorium-bearing minerals are brockite, monazite, and thorite. The mineralization also contains rare earths at concentrations ranging from 12,000 to $18,000 \mathrm{ppm}$ total rare-earth oxides.

\subsection{MINING PROCESSES}

\subsubsection{Underground Mining}

Underground mining is being utilized to develop the Lemhi Pass, Hall Mountain, and the Wet Mountain thorite deposits. The major steps in underground mining are discussed in the following sections.

\subsubsection{Drilling and Blasting}

Blast holes are wet drilled into the working face using pneumatic drills, loaded with explosives, and detonated. Detonation is usually at the end of each shift when miners are out of the work areas.

\subsubsection{Loading and Transporting Rock to Surface}

At the beginning of the following shift, broken rock is removed from the working face. A slusher draws the broken rock into a chute. The rock falls down the chute and is loaded by gravity feed into ore cars positioned on the haulage level. When the working face and ore haulage are on the same level, the ore is loaded into the ore cars using a mucking machine. The loaded ore cars are pulled by locomotive to a dump station outside the mine.

\subsubsection{Ground Support}

After the broken rock is removed from the working area, support is provided, if necessary, by either installing rock bolts or, in the case of weak 


\subsection{MILLING PROCESSES}

The milling processes can be divided into three groups: thorite, conglomerate, and granite processing. The stockpiled deposits do not need to be milled, only refined. The Bear Lodge deposit has not been studied in as detailed a fashion as the other deposits because of 1) a lack of information concerning the processing of this type of ore; and 2) it was not included as a deposit until late in the study. It has been estimated that the Bear Lodge ore would only need to be milled, similar to the thorite ore. Details of the other milling processes are presented below.

\subsubsection{Thorite Processing Stream}

The conceptual thorite milling process was developed based on a laboratory-scale process developed by the U.S. Bureau of Mines. (14) Thorite is milled by grinding the ore and leaching it with acid. After solvent extraction and ammonium hydroxide precipitation, the precipitate is calcined, producing reactor-grade thorium oxide.

The thorite milling process is utilized to process ores at Lemhi Pass, Hall Mountain, and Wet Mountain. The major process steps are described in the following sections. A flowsheet is contained in Appendix D.

\subsubsection{Run-of-Mine Storage}

Ore arrives at the mill by truck and is stored in piles according to grade. The ore is blended before processing to provide a constant grade for mill input. Front-end loaders transfer the ore from the storage areas to the conveyor.

\subsubsection{Crushing and Grinding}

The conveyor discharges the ore into a jaw crusher, which is in series with a cone crusher. The minus 1 in. discharge from the cone crusher is transferred to temporary storage bins. From there, the crushed ore is ground to minus 35 mesh in two $8 \mathrm{ft} \times 8 \mathrm{ft}$ ball mills. After grinding, the ore is mixed with water and transferred to the leaching tanks.

\subsubsection{Leaching}

Slurry from the grinding circuit is fed directly into the first of a series of stainless steel tanks equipped with steam heaters to maintain a 
ground, timber sets. Unmined pillars of waste rock or low-grade ore are of ten left to provide support also. Waste rock or sand fill may be brought into mined-out areas for additional support, depending on the mining method.

\subsubsection{Loading and Scanning of Rock}

Ore is loaded from skips into dump trucks on the mine surface. The dump trucks are driven through a scanner to determine ore grade then routed to the mine storage pad. Periodically, the ore is loaded from mine storage and transported to the mill.

\subsubsection{Surface Mining}

Surface mining techniques would be utilized to develop the Palmer, Michigan; Bear Lodge, Wyoming; Bald Mountain, Wyoming; and Conway Granite deposits. The major process steps are reviewed in the following sections.

\subsubsection{Removing the Overburden}

Approximately $30 \mathrm{ft}$ of overlying till must be removed before mining. The till is scraped using bulldozers, and the overburden is loaded into trucks using the front-end loaders. The overburden is then hauled to a dump adjacent to the pit. The ore is now ready to be mined.

\subsubsection{Drilling and Blasting}

Blast holes are drilled into the ore, using a downhole hamer. The blast holes are loaded with explosives and detonated.

\subsubsection{Loading the Ore}

The ore is loaded into 120 -ton electric wheel trucks using $15-$ yd $^{3}$ shove1s. Fifteen cubic yard front-end loaders are also provided to clean up around the shovels.

\subsubsection{Hauling of Ore}

The electric ore trucks transport the ore to a concentrator located approximately one-half mile from the mine. The truck is routed through a scanner to determine ore grade before it is unloaded. 
temperature of $80^{\circ} \mathrm{C}$. The slurry is mixed with sulfuric acid and agitated for about $2 \mathrm{hr}$. (14) The sulfuric acid dissolves the thorium, as well as impurities in the ore. The sulfuric acid consumption, which is a function of the ore grade and the soluble impurities, can vary from $370 \mathrm{lb} /$ ton to $650 \mathrm{lb} /$ ton of ore.

\subsubsection{Countercurrent Decantation}

The leach liquor contains approximately $60 \%$ solids, which must be removed before the solvent extraction. This is accomplished in a five-stage countercurrent decantation process. A flocculant is added to increase the settling rate of the solids. The underflow from the fifth thickener goes to the tailings pond. For a $2-\mathrm{hr}$ settling rate, a settling area of $22 \mathrm{ft}^{2} /$ ton/day is required for the thickener. (14) Final clarification is accomplished using a leaf-type pressure filter with a vacuum of 15 in. of mercury.

\subsubsection{Amine Extraction}

Thorium is extracted from the leach liquor by an organic solvent containing $10 \%$ primary amine, $5 \%$ primary decyl alcohol, and $85 \%$ kerosene. The leach liquor and organic solvent are brought into contact in seven 5,000-gal mixer/ settlers for $15 \mathrm{~min} .(14)$ The organic losses are estimated to be $0.5 \mathrm{gal} / \mathrm{ton}$ processed per hr. (14) After the thorium is extracted from the leach liquor, the leach liquor is sent to the tailings pond and the organic solution is pumped to the salt-stripping process.

\subsubsection{Salt Stripping}

The thorium is stripped from the organic solution using a premixed salt solution containing $1.5 \mathrm{M} \mathrm{NaCl}$ and $0.5 \mathrm{M} \mathrm{HCl}$ (14) The organic and the salt solution are brought into contact in stainless steel agitated tanks. The salt solution removes the thorium from the organic, then the organic is returned to the extraction step. The salt solution, containing thorium, is pumped to the reduction and neutralization process.

\subsubsection{Reduction and Neutralization}

The salt solution is neutralized with soda ash in agitated tanks to remove the thorium, and sodium hydrosulfide is added to reduce ferric 
iron. (14) The precipitate is dewatered using a disk centrifuge. The filtrate is discarded to the tailings pond.

\subsubsection{Caustic Digestion}

The dewatered precipitate is pumped to agitated tanks where the precipitate is digested with caustic soda at ambient temperature. A 2-hr residence time is required, and approximately $3 \mathrm{lb}$ of sodium hydroxide are used for each ton of ore. (14) The caustic digestion forms thorium hydroxide, which is removed from the caustic solution by filtration with a continuous rotary-drum filter. The filter--sized at approximately $4 \mathrm{ft}^{2}$ of filter area for each ton/hr processed--yields a precipitate containing $70 \%$ solids. The filtrate is pumped to the tailings pond, and the cake is discharged to a conveyor belt.

\subsubsection{Drying and Ignition}

The hydroxide cake is dried to a moisture content of $10 \%$ in a twin-screw dryer. The dryer operates with a jacket temperature of $120^{\circ} \mathrm{C}$ and a screw temperature of $154^{\circ} \mathrm{C}$. The twin-screw dryer is discharged to a rotary $k i 1 n$ where the thorium hydroxide is converted to thorium oxide. The kiln operates at $900^{\circ} \mathrm{C} .(14)$ The kiln was sized by assuming that, in normal operation, $7 \%$ of the kiln's volume is filled with thorium hydroxide. The rotary kiln discharges thorium oxide of $99+\%$ purity, which is packaged in drums for shipment to the fuel fabrication facility.

\subsubsection{Conglomerate Processing Stream}

The conceptual conglomerate monazite processing stream was developed on a laboratory scale by the U.S. Bureau of Mines. (9) In conglomerate deposits, the mineral monazite is dispersed in rock. The ore is ground to release the monazite. The ground rock is then submitted to gravity and magnetic separation to separate the monazite from the gangue rock. The concentrate is then sent to a refinery (Section 2.4 ).

The principal deposits studied are Palmer, Michigan, and Bald Mountain, Wyoming. Major process steps are described in the following sections. A flowsheet is contained in Appendix $D$. 


\subsubsection{Run-of-Mine Storage}

Ore arrives at the mill by truck and is dumped in a storage area. The ore is segregated according to grade, blended to maintain a relatively constant input to the mill, and then transferred from the storage area to the primary crusher/conveyor by means of a front-end loader.

\subsubsection{Crushing and Grinding}

The ore is initially crushed in a primary crusher and then transferred to the secondary crusher, which grinds the ore to minus 20 mesh. The discharge is screened, and the oversized particles are returned to the secondary crusher. The processed ore is stored in a crushed-ore bunker.

\subsubsection{Gravity Separation}

The crushed ore is mixed with water and is pumped to a rougher shakingtable circuit. The tails are discarded to the tails pond while the milling product is processed in the scavenger shaking-table circuit. The scavenger shaking-table concentrate is returned to the rougher circuit for reprocessing. The rougher circuit concentrate is transferred to the wet-concentrate storage pile for dewatering.

\subsubsection{Drying}

The wet concentrate is transferred from the wet-concentrate storage to a rotary dryer using an overhead crane. The concentrate is dried and discharged to the magnetic separator conveyor belt.

\subsubsection{Magnetic Separation}

The dry concentrate is processed by rougher cross-belt magnetic separators. The tails from the rougher magnetic separator are processed by smaller scavenger magnetic separators in parallel. The tails are discarded while the concentrate is recycled to the rougher magnetic separator. The final concentrate obtained is discharged to storage until it is shipped to the refinery.

\subsubsection{Granite Processing Stream}

In the U.S., granite is not currently recovered for $\mathrm{ThO}_{2}$. Laboratory beneficiation studies reveal that treating granite directly with sulfuric acid 
yields good results. $(12,13)$ The concentrate obtained is purified by solvent extraction and precipitated with ammonium hydroxide. The concentrate is packaged and sent to a refinery for further purification (Section 2.4). The only granitic deposit studied is located in Conway, New Hampshire. The major process steps are described in the following sections. A flow diagram is shown in Appendix D.

\subsubsection{Crushing and Grinding}

The mined ore is crushed to $8 \mathrm{in}$. in large gyratory crushers. The crushed ore is transported to outside stockpiles, which hold about an 8-hr supply of granite. The ore is then fed to dry, autogenous, aerofall-type mills where it is ground to minus 20 mesh.

\subsubsection{Acid Leaching}

The ground ore is agglomerated in rotating drums with 20 to 60 1b of sulfuric acid per ton of ore to produce a mix that contains $85 \%$ solids, conveyed to concrete vats, and cured for 1 to $5 \mathrm{hr}$. The ore is washed with recycle process solutions in the vats to obtain a thorium and uranium solution. The relatively small high-acid portion of the wash solution, which is obtained first, is recycled to the agglomeration operation. The next portion of the wash cycle is the pregnant liquor, which is transferred to the solvent extraction step. The latter portion of the wash solution, with a much lower concentration of thorium and uranium, is recycled to wash subsequent batches of ore. A final flush solution--containing ore tailings and water--goes then to lime neutralization and waste disposal.

\subsubsection{Solvent Extraction}

The pregnant liquor goes to a two-stage solvent extraction section. The solvent consists of $0.01 \mathrm{M}$ 1-nondecylamine and $0.01 \mathrm{M} \mathrm{N-benzy1-1-(3-ethyl-}$ penty 1)-4-ethyloctyl amine in a diluent consisting of $99 \%$ kerosene and $1 \%$ tridecanol. Thorium and uranium are then costripped from the extract with a $0.25 \mathrm{M} \mathrm{Na}_{2} \mathrm{CO}_{3}$ solution in two stages. The extraction and stripping operations are performed by standard mixer/settler equipment. 


\subsubsection{Packaging}

The thorium and uranium precipitate is filtered, dried, and stored for further refinement and separation.

\subsection{REFINING PROCESSES}

\subsubsection{Stockpiles}

The conceptual stockpiled sludge refinery utilizes solvent extraction to purify the $\mathrm{ThO}_{2}$. The thorium is precipitated as an oxalate and calcined to produce reactor-grade $\mathrm{ThO}_{2}$. The major process steps are described in the following section. A flow diagram is shown in Appendix $D$.

\subsubsection{Feed Preparation}

Sludge is dissolved in acid to obtain a solution containing $200 \mathrm{~g} / \mathrm{LTh} \mathrm{T}_{2}$. Metallic iron is then added and allowed to dissolve slowly to hinder the formation of thorium phosphate complexes. When the addition of iron is complete, nitric acid is re-introduced to achieve a concentration of $4 M$ free nitric acid. Large particles of gangue material are removed before the feed enters the solvent extraction unit. (15)

\subsubsection{Solvent Extraction}

Thorium is extracted from the acid solution using an organic solvent that contains a $50 \%$ solution of tributryl phosphate (TBP) in kerosene. The leach liquor and organic solvent are brought into contact in a 10-stage mixer/settler cascade. As the aqueous phase moves along, it loses uranium and thorium and is discharged as raffinate. The loaded solvent is then scrubbed with nitric acid and pumped to the salt-stripping process. (15)

\subsubsection{Stripping}

The thorium solution is contacted with a $1.02 \mathrm{M}$ solution of nitric acid. The thorium is removed, then the freed organic is passed on for uranium recovery. The thorium-bearing aqueous stream is discharged with a concentration of $50 \mathrm{~g} \mathrm{Th} / \mathrm{l} .{ }^{(15)}$ 


\subsubsection{Uranium Recovery}

The solvent phase is treated with sodium carbonate to remove the uranium, reacidified, and recycled. The uranium-bearing solution is sent to a tailings pond.

\subsubsection{Concentration}

A primary and secondary evaporative system is used to concentrate the thorium nitrate solution. The feed stream enters a secondary evaporative system, which consists of three boildown tanks, that concentrates the solution to about $50 \%$ of the original volume. The stream is further concentrated in a continuous single-effect evaporator to a concentration of $0.53 \mathrm{lb} \mathrm{Th/e.(16)}$

\subsubsection{Precipitation}

The thorium nitrate solution is mixed with nitric acid and heated to $45^{\circ} \mathrm{C}$ with steam. Oxalic acid is added and the solution is agitated for several minutes to facilitate the precipitation of thorium oxalate. (16)

\subsubsection{Filtration}

The slurry is filtered in a rotary vacuum filter, and an oxalate cake containing $30 \%$ to $35 \%$ water by weight is discharged. The filtrate is pumped to a plate-and-frame filter press for further clarification and then neutralized with a solution of sodium carbonate. The spent filtrate combines with the raffinate prior to liquid waste treatment. $(16)$

\subsubsection{Drying}

The oxalate cake is dried to a $10 \%$ moisture content--to avoid spattering in the calciner--in a twin-screw dryer with a jacket temperature of $120^{\circ} \mathrm{C}$ and a screw temperature of $154^{\circ} \mathrm{C}$. The thorium oxalate with a bulk density of approximately $45 \mathrm{lb} / \mathrm{ft}^{3}(16)$ is discharged into a variable-speed auger. (17)

\subsubsection{Calcination}

The oxalate cake is calcined to thorium oxide in an externally fired rotary kiln for $2 \mathrm{hr}$. Gas flowing countercurrently exits at a temperature of $820^{\circ} \mathrm{C}$. The thorium oxide product is a light, finely divided powder. (17) 


\subsubsection{Packaging}

The thorium oxide is packaged in 55-gal drums for storage or shipment.

\subsubsection{Conglomerates}

The conceptual conglomerate refining process consists of acid leaching followed by solvent extraction, caustic digestion, precipitation, and calcination. (9) The process recovers $95 \%$ of the $\mathrm{ThO}_{2}$ and produces a product of $99+\%$ purity. The major process steps are discussed below. A flow diagram is shown in Appendix D.

\subsubsection{Grinding}

The concentrate arrives from the mill by truck and is stored until processing. The concentrate, which has already been crushed to 20 mesh, contains between $1 \%$ and $6 \%$ thorite. Before leaching, the concentrate is dry ground to 100 mesh in a ball mill.

\subsubsection{Leaching}

The concentrate is mixed with 1.5 times its weight of $96 \% \mathrm{H}_{2} \mathrm{SO}_{4}$ and heated to $200^{\circ} \mathrm{C}$ in agitated tanks for $2 \mathrm{hr}$. The concentrate is then mixed with 5 parts water and agitated for $1 \mathrm{hr}$. The pregnant solution is filtered and washed with acidified water. ${ }^{(9)}$

\subsubsection{Liquid/Solid Separation}

After the acid leaching process, the pregnant solution contains $6 \%$ solids. It is flocculated with 0.2 lb of flocculate per ton of concentrate then filtered using a leaf-type pressure filter. The pregnant liquor is then transferred to the solvent extraction process.

\subsubsection{Solvent Extraction}

Thorium in the pregnant leach liquor is extracted using an organic solvent with $10 \%$ aliphatic primary amine, 5\% primary decyl alcohol (PDA), and $85 \%$ kerosene. The leach liquor and the organic solvent are brought into contact in the mixer/settler for $15 \mathrm{~min}$. The organic solution extracts the thorium from the pregnant leach solution. The barren leach solution (raffinate) is then discarded. The loaded organic is scrubbed in mixer/settlers with $0.2 \mathrm{M}$ sulfuric acid to remove the dissolved rare-earth oxides. (9) 


\subsubsection{Salt Stripping}

A salt solution is used to strip the thorium from the loaded organic. The loaded organic and the salt solution are brought into contact in three stainless steel agitated tanks. The premixed salt solution, containing $1.5 \mathrm{~N}$ sodium chloride and $0.5 \mathrm{~N}$ hydrochloric acid solution removes the thorium from the organic, which is returned to the amine extraction step, in one agitated tank. The loaded strip liquor is pumped to the neutralization process. (9)

\subsubsection{Neutralization}

The loaded strip liquor is neutralized, forming hydrous sodium and thorium sulfates, which precipitate out of solution. ${ }^{(9)}$ The barren strip liquor is then neutralized with soda ash in an agitated tank. The precipitate is dewatered using a rotary-drum filter.

\subsubsection{Caustic Digestion}

The dewatered precipitate is transferred to an agitated stainless steel tank where the precipitate is digested with caustic soda at room temperature. The caustic digestion forms hydrus thorium oxide, which is removed from the caustic solution with a continuous rotary-drum filter. ${ }^{(9)}$

\subsubsection{Drying and Ignition}

The hydrous thorium oxide is dried to $10 \%$ moisture content in a twinscrew dryer, which operates with a jacket temperature of $120^{\circ} \mathrm{C}$ and a screw temperature of $154^{\circ} \mathrm{C}$. The twin-screw dryer discharges thorium hydroxide into a rotary kiln where it is converted to thorium oxide. The kiln operates at $850^{\circ} \mathrm{C}$ and runs $7 \%$ ful1. (18) The rotary kiln discharges thoria of $99+\%$ purity. The thoria is packaged in drums and shipped to the fabrication facility.

\subsubsection{By-Product Recovery}

The raffinate from the solvent extraction phase contains the dissolved rare-earth oxides. To precipitate the rare earths, $60 \mathrm{~g} / \mathrm{l}$ of sodium sulfate is added to the raffinate. Ninety-eight percent of the rare-earth by-products are converted to the sulfate salt. The rare-earth sulfates are treated with 
caustic soda, and a rare-earth hydroxide precipitate is formed. The precipitate is dried at $140^{\circ} \mathrm{C}$. Product purity is estimated at $46 \%$ rare-earth oxides (REO). (9)

\subsubsection{Granite}

The conceptual granite refinery would be similar to the reference stockpile refinery except for the addition of an extraction cascade, which precedes the $\mathrm{ThO}_{2}$ extraction steps (see Section 2.4.1.1). The 10-stage cascade uses a $5 \%$ tributyl phosphate solvent to remove uranium from the thorium solution. The uranium recovery steps are discussed below.

\subsubsection{Uranium Recovery}

The thorium-uranium solution enters a 5-stage solvent extraction section where the aqueous is contacted with a $5 \%$ solution of TBP in kerosene. The thorium-bearing aqueous continues on to the next solvent extraction section. The organic solution enters a 5-stage scrub section where the uranium is removed from it using an aqueous $4 \mathrm{~N}$ nitric acid solution. The uranium solution is precipitated with ammonia, dewatered, and dried. The stripped organic solvent is recycled. (17)

\subsection{PRODUCTION COSTS}

Production costs for developing domestic thorium resources range from $\$ 3$ to $\$ 60$ per lb of thorium oxide $\left(\mathrm{ThO}_{2}\right)$. The supply curve (Figure $2.2 \mathrm{~A}$ and $\mathrm{B}$ ) illustrates the quantity of thorium available at a given production cost. A11 of the costs are in 1978 dollars. The production cost figures include baseline environmental control costs (discussed in Chapter 3), which are no more than $10 \%$ of the production cost (see Table 2.1) and, thus, have little effect on the cost of thorium oxide. The supply is discussed in more detail in a previous report. (19)

The low-cost resources that would be developed to satisfy near-term thorium oxide demands include the stockpiles in Fernald, Ohio; Miamisburg, Ohio; and Curtis Bay, Maryland, and the thorite deposit at Hall Mountain, Idaho. Approximately 8,000 tons of thorium oxide are available from these resources 


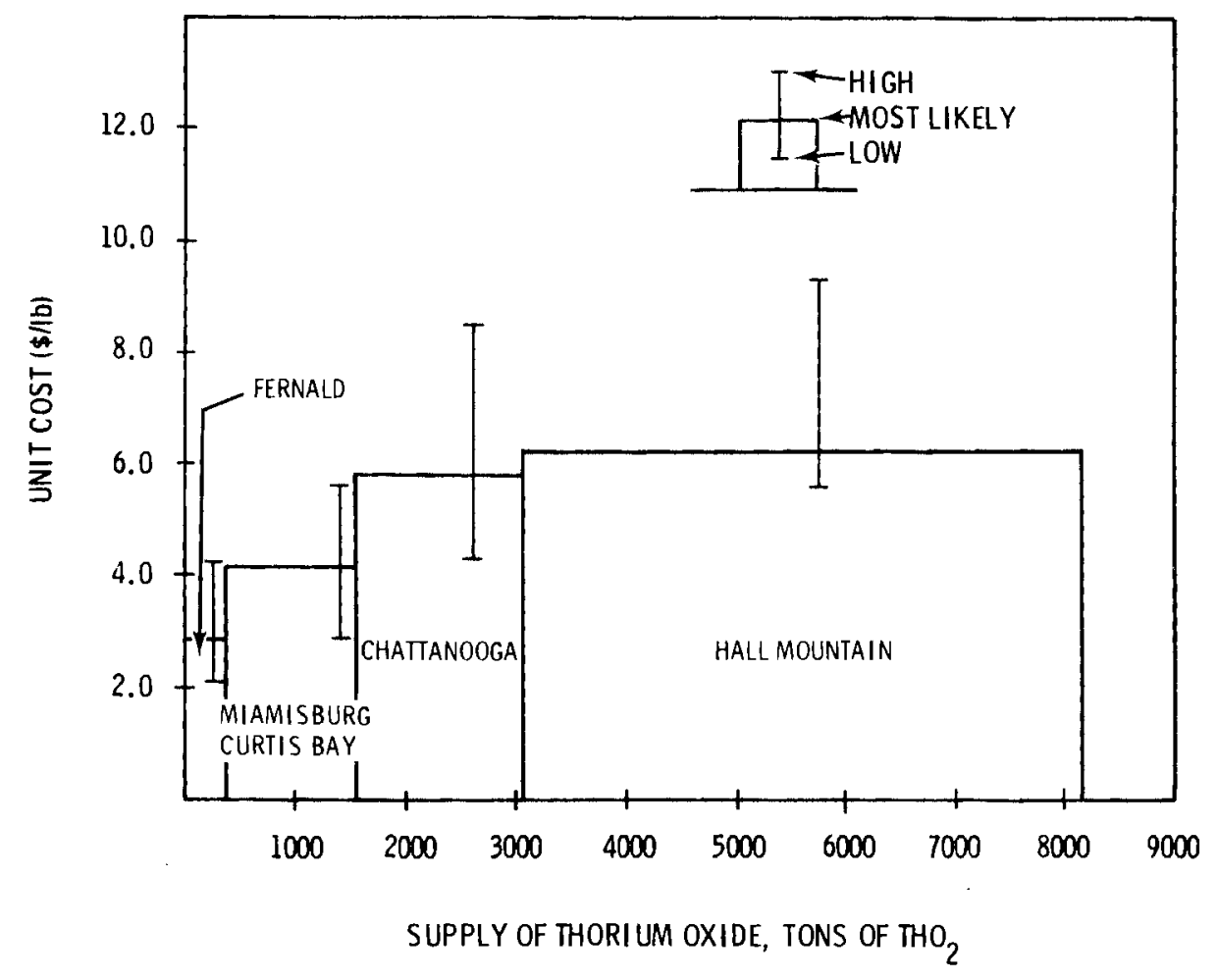

FIGURE 2.2A Domestic Thorium 0xide Supply Curves

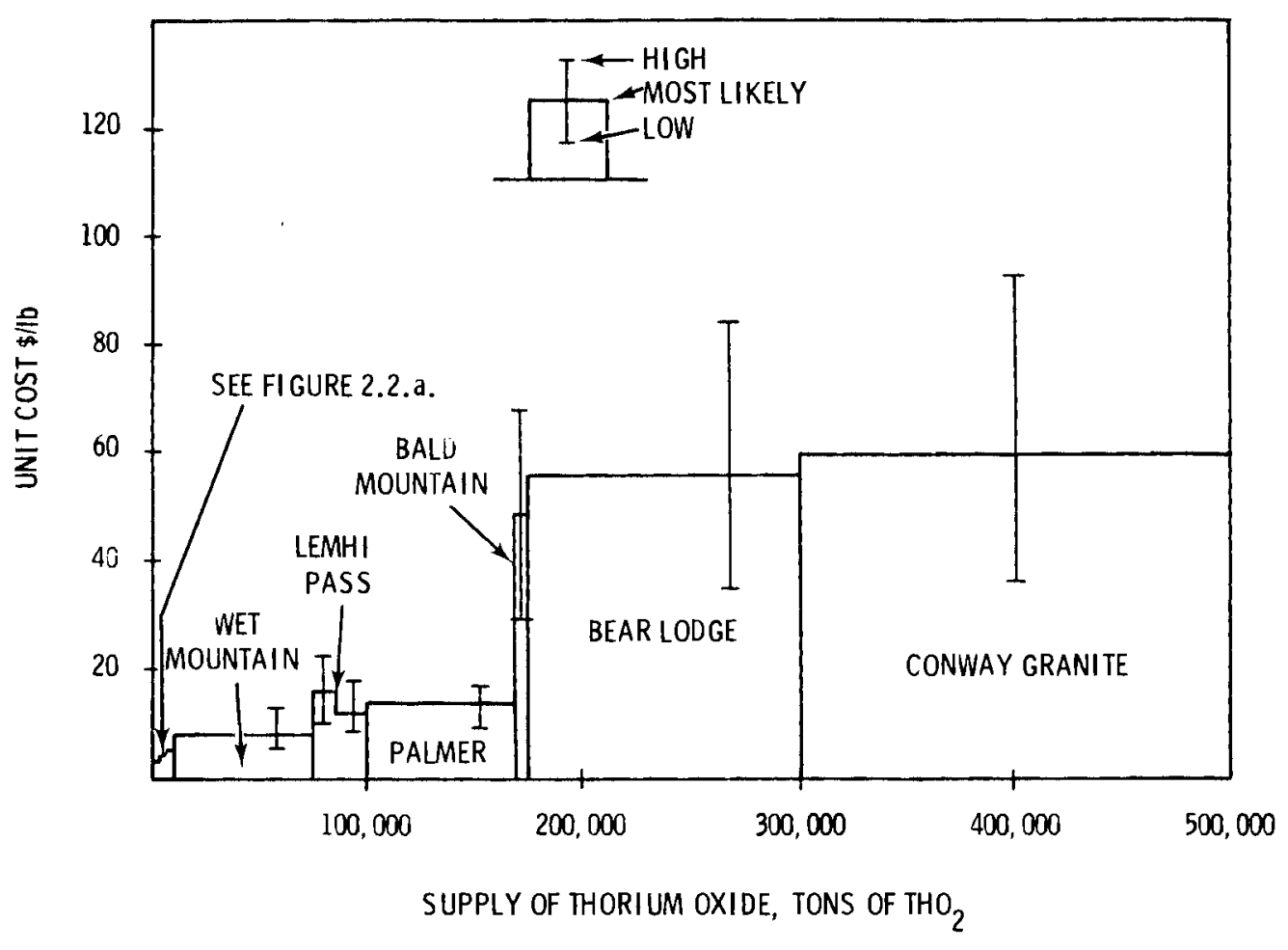

FIGURE 2.2B Domestic Thorium 0xide Supply Curves 
TABLE 2.1. Summary of Thorium Production Costs and Reserve Estimates

\begin{tabular}{|c|c|c|c|c|c|}
\hline Resource & \multicolumn{2}{|c|}{$\frac{\text { Production Costs }(\$ / 1 \mathrm{~b})}{\text { Most }}$} & $\begin{array}{l}\text { Quantity } \\
\text { Recovered } \\
\text { Tons } \mathrm{ThO}_{2} \\
\end{array}$ & $\begin{array}{c}\text { Estimated (a) } \\
\text { Quantity } \\
\text { Tons } \mathrm{ThO}_{2} \\
\text { In Deposit } \\
\end{array}$ & $\begin{array}{c}\text { Estimated } \\
\text { Minimum } \\
\text { Environmental } \\
\text { Control Cost } \\
(\% \text { of Total } \\
\text { Cost }) \\
\end{array}$ \\
\hline Fernald & 5.80 & 4.30 to 8.50 & 1,500 & 1,500 & $2.6 \%$ \\
\hline Miamisburg & 4.60 & 2.86 to 5.58 & 800 & 800 & $3.7 \%$ \\
\hline Curtis Bay & 4.60 & 2.86 to & 400 & 400 & $3.7 \%$ \\
\hline Chattanooga & 5.80 & 4.30 to 8.50 & 360 & 360 & $2.6 \%$ \\
\hline Lemhi Pass & $\begin{array}{l}15.73 \\
12.10\end{array}$ & $\begin{array}{r}10.80 \text { to } 22.90 \\
8.91 \text { to } 17.40\end{array}$ & $\begin{array}{r}9,800 \\
14,000\end{array}$ & 187,000 & $4 \%$ to $5.2 \%$ \\
\hline Hall Mountain & 6.30 & 5.60 to 9.30 & 5,000 & 35,000 & $4.4 \%$ \\
\hline Wet Mountain & 8.30 & 5.92 to 13.30 & 61,000 & 224,900 & $4.1 \%$ \\
\hline Palmer & 14.20 & 9.90 to 17.10 & 70,000 & 193,000 & $3.2 \%$ \\
\hline Bear Lodge & 57.43 & 34.20 to 84.90 & 137,000 & $1,620,000$ & Unknown \\
\hline Bald Mountain & 49.00 & 29.00 to 68.00 & 2,600 & Unknown & $8.8 \%$ \\
\hline Conway Granite & 59.32 & 36.70 to 93.70 & $u^{(b)}$ & $35,000,000$ & $0.72 \%$ \\
\hline
\end{tabular}

(a) Includes probable and potential reserves.

(b) Uncertain, depends on maximum demand.

at a cost below $\$ 10$ per $1 \mathrm{~b}$. These resources could adequately supply the thorium oxide for prototype purposes and for the initial commercialization of the thorium fuel cycle.

Over the longer term, thorium deposits at Wet Mountain, Colorado; Lemhi Pass, Idaho; and Palmer, Michigan would be developed. These deposits represent approximately 160,000 tons of thorium oxide. These resources could support thorium reactor growth and development for at least the next $50 \mathrm{yr}$ under the most likely conditions with costs ranging from $\$ 8$ to $\$ 17$ per $1 \mathrm{~b}$ of thorium oxide. 
Low-grade deposits of thorium at Bald Mountain, Wyoming; Bear Lodge, Wyoming; and Conway Granite, New Hampshire could support a thorium fuel cycle for hundreds of years at costs approximately equal to or exceeding $\$ 50$ per $1 \mathrm{~b}$ of thorium oxide. These deposits represent over 17 million tons of thorium oxide.

\subsection{REFERENCES}

1. M. H. Staatz, Geology and Description of Thorium-Bearing Veins, Lemhi Pass Quadrangle, Idaho and Montana. USGS Bulletin 1351, U.S. Government Printing Office, Washington, DC, p. 94, 1972.

2. M. H. Staatz, "Thorium Veins in the United States." Economic Geology, 69:494-507, 1974 .

3. M. H. Staatz, "Update on Thorium Resources." Proceedings of Uranium Industry Seminar, 1978, GJ0-108(78), U.S. Department of Energy, Grand Junction, Colorado, pp. 109-114,1978.

4. R. A. Christensen, et a1., Geology and Thorium Deposits of The Wet Mountains. USGS Bullet in 107-H, U.S. Government Printing Office, Washington, DC, pp. 491-535, 1961.

5. F. J. Kelly, Technical and Economic Problems of Rare Earth Metal and Thor ium Resources in Colorado, New Mexico, and Wyoming. USBM-IC-8124, U.S. Bureau of Mines, Denver, CO, p. 38, 1961 .

6. M. H. Staatz, "Thorium Rich Veins of Hall Mountain in Northernmost Idaho." Economic Geology, 67:240-248, 1972.

7. J. E. Gair, Bedrock Geology and Ore Deposits of the Palmer Quadrangle. Professional Paper 769, U.S. Geological Survey, Marquette County, MI, 1975.

8 R. C. Vickers, "Geology and Monazite Content of the Goodrich Quartzite, Palmer Area, Marquette County, Michigan." in Contributions to the Geology of Uranium, Bullet in 1030-F, U.S. Geologica1 Survey, U.S. Government Printing Office, Washington, DC, pp. 171-185, 1956.

9. S. R. Borrowman and J. B. Rosenbaum, Recovery of Thorium from a Wyoming Ore. USBM Report Inv. 5917, U.S. Bureau of Mines, Denver, C0, 1962.

10. V. R. Wilrath and D. H. Johnson, Preliminary Reconnaissance Survey for Thorium, Uranium, and Rare-Earth Oxide, Bear Lodge Mountains, Crook County, Wyoming. Trace Elements Investigations Report 172, U.S. Geological Survey, Arlington, VA, 1953. 
11. Frank W. Osterwald, et al., Mineral Resources of Wyoming. Bulletin No. 50, The Geological Survey of Wyoming, University of Wyoming, Laramie, Wyoming, p. 220, 1966.

12. F. J. Hurst, D. J. Crouse, and K. B. Brown, Recovery of Thorium and Uranium from Granitic Rocks. ORNL-3987, Oak Ridge National Laboratory, Oak Ridge, TN, 1966.

13. F. J. Hurst, et al., Estimated Costs for Recovery of Thorium and Uranium. ORNL-3988, Oak Ridge National Laboratory, Oak Ridge, TN, November 1966.

14. S. R. Borrowman and J. B. Rosenbaum, Recovery of Thorium from Ores in Colorado, Idaho, and Montana. USBM-IC-5916, U.S. Bureau of Mines, Denver, CO, 35 pp., 1961

15. R. J. Callow, The Industrial Chemistry of Lanthanons, Yttrium, Thorium, and Uranium. 1 st ed., Pergamon Press, Oxford, London, pp. 113-116, 1967.

16. Harley A. Wilhelm, "The Metal Thorium," Proceedings of Conference on Thorium, American Society for Metals, Cleveland, Ohio, pp. 72-75, 1958.

17. F. L. Cuthbert, Thorium Production Technology, Addison-Wesley Publishing Inc., Mass achusetts, p. 151.

18. H. R. Perry and C. H. Hilton, Chemical Engineering Handbook. McGraw-Hi11, New York, NY, 1973.

19. J. K. Young, et. al., Economics of Large-Scale Thorium Oxide Production: Assessment of Domest ic Resources, PNL-3150, Pacific Northwest Laboratory Richland, WA 99352. 


\subsection{ENVIRONMENTAL IMPACTS FROM THORIUM PRODUCTION}

\subsection{CURRENT PRODUCTION $(1)$}

The only domestically produced thorium at the present time is from monazite sands dredged in Florida. The thorium and rare earths are extracted in Chattanooga, Tennessee, and the thorium is refined in Jonesboro, Tennessee. Currently, only $20,000 \mathrm{lb} / \mathrm{yr}$ of reactor-grade thorium oxide $(99+\%)$ are domestically produced.

Because the beach placer deposits of Florida, which yield monazite sands, are too low-grade to be economically mined for thorium alone, thorium is produced as a by-product only and the amount produced is dependant on the market for rare earths. For these reasons, the Florida placer deposits were not included in the supply curves presented in Chapter 2. The wastes generated by a typical placer-mining operation were compilied in An Assessment of U.S. Domestic Capacity for Producing Reactor-Grade Thorium Dioxide and Controlling Associated Wastes and Effluents, PNL-2593, by W. I. Enderlin. (1) This report was used to evaluate the generated wastes from the current production processes. The environmental control costs associated with the mining, milling, extraction, and refinement of thorium dioxide presented below are estimates based on state-of-the-art technology, which may be different from what is presently used.

Table 3.1 is a summary of the estimated environmental control costs for mining, milling, extracting, and refining thorium dioxide from monazite sands. For both capital and annual costs, the generated wastes from the mining and milling operation are the most expensive to control. As noted in Table 3.1, the unit costs of environmental control assumes that the various by-products will receive no credit. The major capital costs are for the various ponds and basins used to settle and store the liquid and solid wastes. A detailed description of the generated wastes and the estimated costs of controlling them are presented in Sections 3.1.1 through 3.1.3 for current production methods. 
TABLE 3.1. Summary of Environmental Control Costs Using the Current Level of Control and Size of Operations

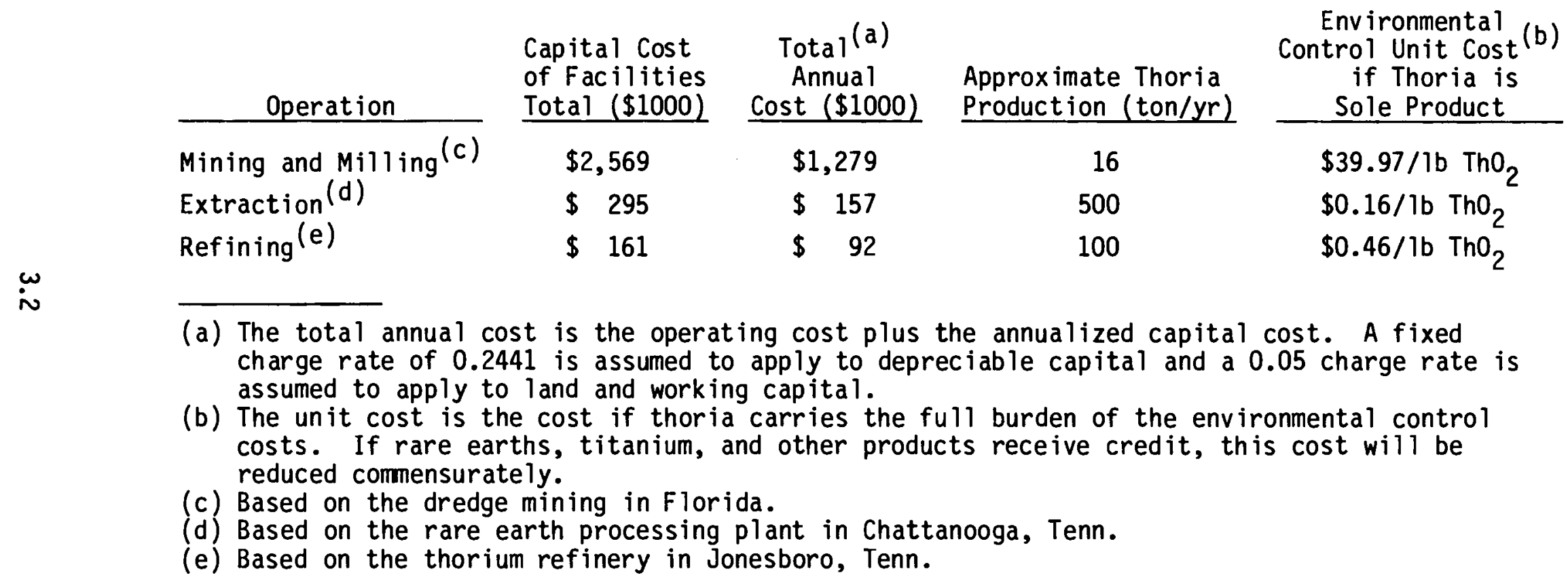




\subsubsection{Mining and Milling}

The main wastes stream generated by the mining and milling processes are shown in Figure 3.1. The processes are divided between dredging operations, the wet mill, and the dry mill. In dredging and wet milling, the major wastes--wet tailings and mine water--are sent to the dredge pond. From the dredge pond, part of the water is reused in the dredging operation and the rest is treated, settled, and discharged to a river.

The dry mill uses a variety of techniques to separate the heavy metals, monazite sand, and other products from the gangue materials and each other. The dry mill tailings are the most radioactive of the wastes generated. At this time, the only environmental control procedure consists of simply burying the tailings. In the future, these tailings may be recycled and reworked to extract the remaining monazite. The dry mill also emits fugitive dust. While not as highly radioactive as the tailings, this dust is controlled by a variety of means including general ventilation with fans and cyclone dust collectors.

The environmental control methods and costs for mining and milling monazite sands in existing operations are shown in Table 3.2. The six basins and holding ponds needed for the liquid and solid wastes account for more than half of the capital costs. When the plant ceases operation, the ponds will have to be rehabilitated at a cost of $\$ 360,000$ for 180 acres.

The equipment shown in Table 3.2 is actually being used for environmental control but the cost figures are not precise because the unconventional type of equipment used was custom built. The control equipment meets current state and federal environmental standards but will have to be updated or replaced if stricter EPA regulations are established.

\subsubsection{Extraction of Thoria}

A caustic soda attack process, shown in a simplified form in Figure 3.2, is used to concentrate the $3.8 \%$ thorium dioxide or thoria in the $95 \%$ monazite sand entering the facility to $25 \% \mathrm{ThO}_{2}$ in the thorium pond sludge. In this process, the monazite sand reacts with hot caustic soda to produce phosphate 


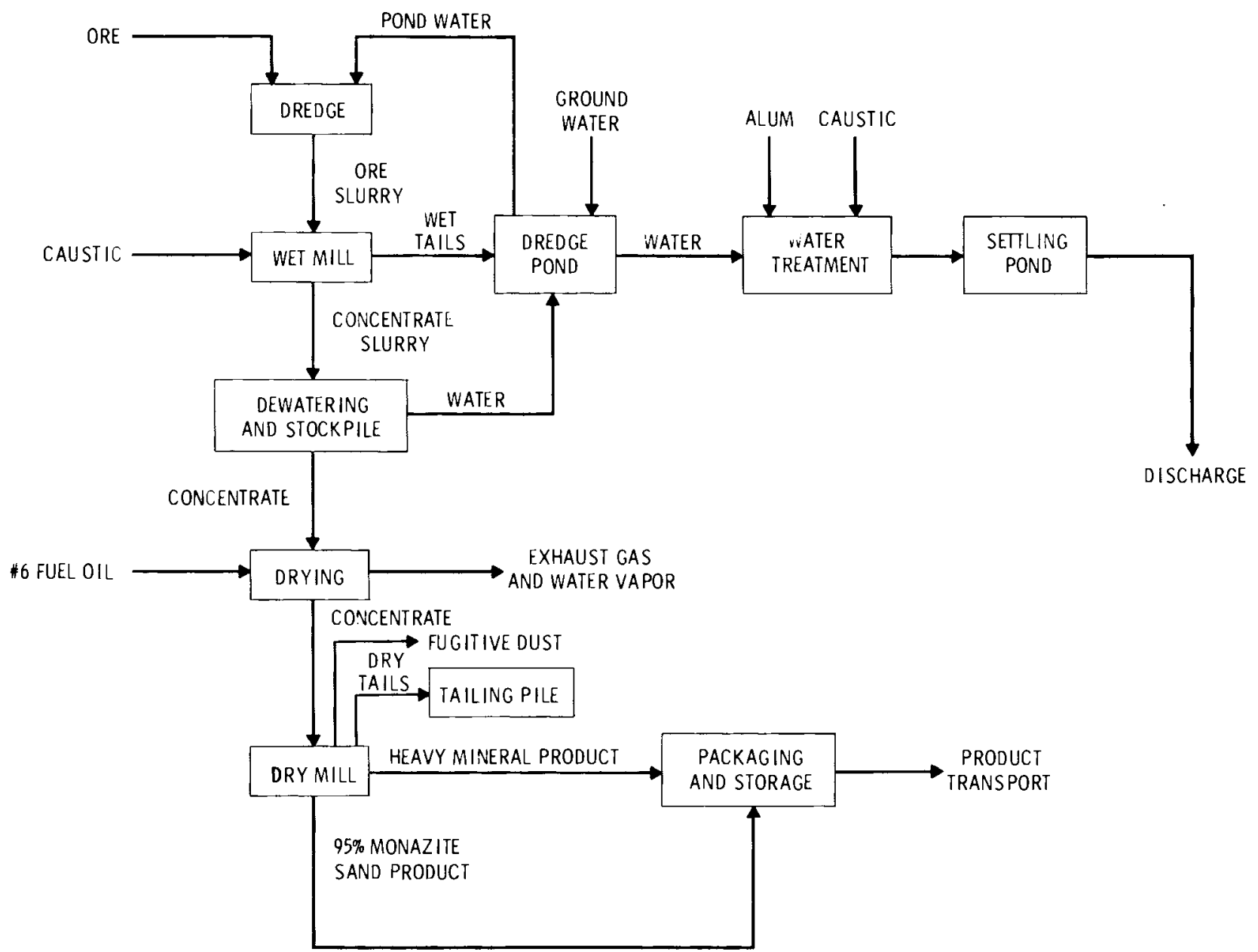

FIGURE 3.1. Main Effluents Emitted from Mining and Milling Processes 
TABLE 3.2. Estimated Costs of Environmental Control Facilities and Operations for Existing Monazite Sand Mining and Milling Operations

\section{Capital Cost Summary}

Liquid and Solid Wastes

Two 3000-gpm Pumps

Surge Storage Basin

Rapid Mix Basin

Slow Mix Basin

Two Intermediate Holding Basins

pH Adjustment System

Large Settling Pond (170 acres)

Pipe and Ditches

Auxiliary Facilities
1978 Installed

\begin{tabular}{c} 
Cost $^{(a)}(\$ 1000)$ \\
\hline$\$ 130$ \\
108 \\
54 \\
405 \\
108 \\
108 \\
510 \\
281 \\
216 \\
$\$ 1,920$
\end{tabular}

Airborne Wastes

Fans

Cyclone Dust Collectors

$\$ 30$

$\$ 113$

Contingency, Fees, and Land

\begin{tabular}{|c|c|}
\hline $\begin{array}{l}\text { Total Installation Cost } \\
10 \% \text { Contingency } \\
\text { Subtotal } \\
5 \% \text { Contractor Fee }\end{array}$ & $\begin{array}{r}\$ 2,033 \\
203 \\
\$ 2,236 \\
112 \\
\end{array}$ \\
\hline $\begin{array}{l}180 \text { Acres of Land } \\
\text { Total Capital Cost }\end{array}$ & \\
\hline
\end{tabular}

Annual Operating Cost Summary

Capital Charge

Land and Working Capital Charge

Maintenance

Operations and Overhead

Chemical Costs

Alum

Caustic

$\$ 626$

31

74

49

Miscellaneous

Power cost

Miscellaneous Supplies

Total Annual Operating Cost

35

54
$\$ 1,279$

Rehabilitation Cost Estimate

Rehabilitate 180 Acres $@ \$ 2,000 /$ acre $\$ 360$

(a) Includes complete installation as well as engineering and construction overheads. 


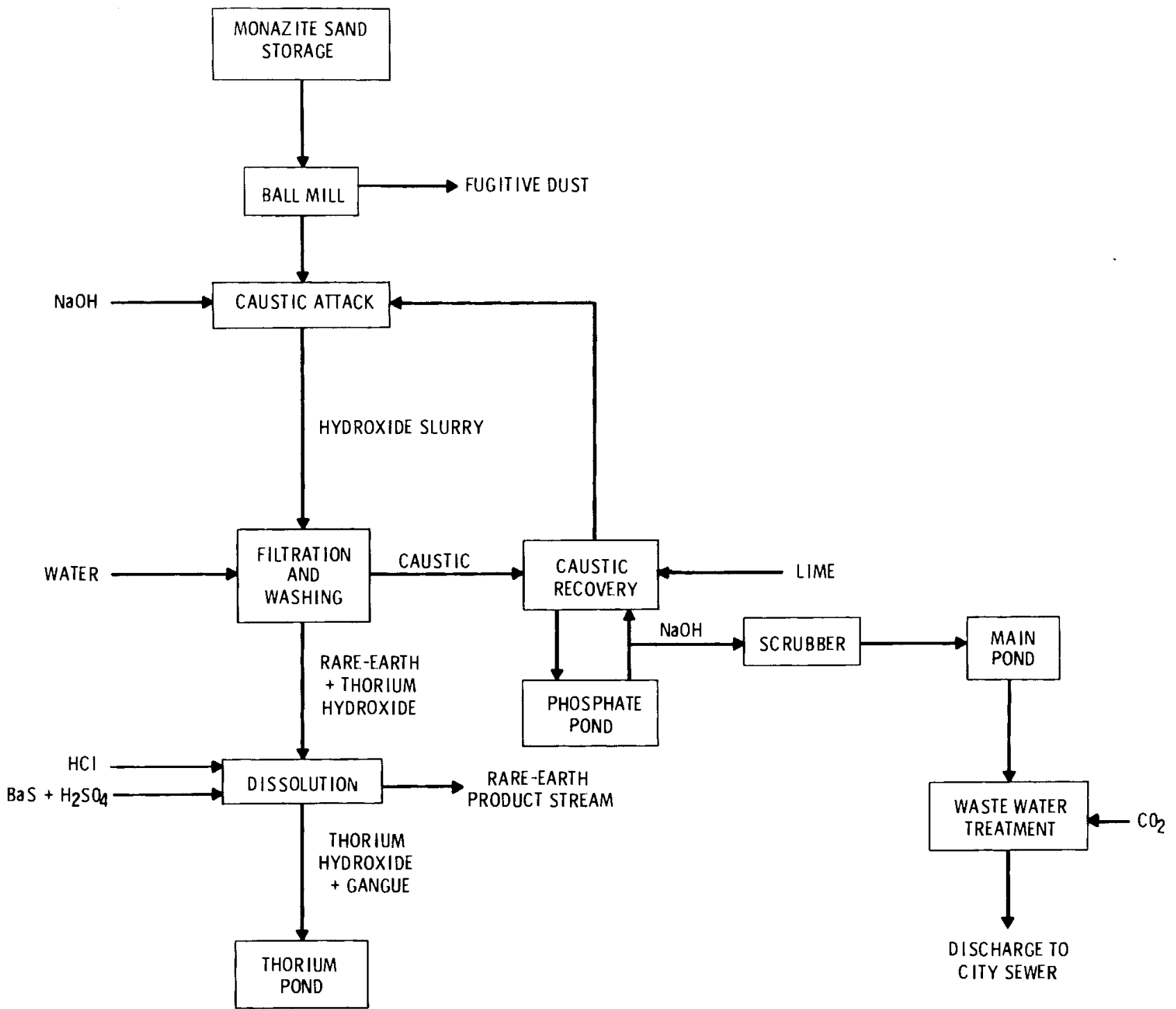

FIGURE 3.2. Main Effluents Emitted from Extraction Process 
and a mixed thorium rare-earth hydroxide. Acids are used to split the hydroxide. There are two streams from this process: thorium and gangue materials in the "waste" stream, which are pumped to the thorium pond, and the rare earths in the product stream.

The major wastes generated in the caustic recovery system are controlled in ponds. In this system, thorium oxide and other liquid wastes are stored in two ponds--the phosphate pond and the main pond. The thorium pond is the repository of the product sludge, which contains the majority of the radioactive substances. The pond systems, as shown in Table 3.3, are the most expensive items used for environmental control. They cover 12 acres of 1 and and, with the price of rehabilitating the 1and, cost $\$ 264,000$, which does not include the annual capital charge for the ponds.

The extraction process also produces dust. The ball mill is the major point of dust emission but the storage area at the beginning of the processing also has some fugitive dust emissions. The dust emission control system consists of fans and a dust collector, and, in the areas where caustic or acidic solutions are used, fume scrubbers are needed.

The location of solid waste disposal is one problem that may arise. Many states have now banned the permanent disposal of low-level radioactive substances. If these solids must be packaged for disposal offsite, the cost of onsite rehabilitation may be less than shown but the transportation costs would make this a more expensive option.

\subsubsection{Thoria Refinement Plant}

Sludge in the thorium pond at the extraction plant is refined in a refinement plant to obtain a thorium dioxide product $\left(99+\% \mathrm{ThO}_{2}\right)$. The thorium dioxide refinement process, shown in Figure 3.3, uses solvent extraction to separate thorium from the gangue and rare earths. The solvent extraction and thorium oxalate filtration sections of the process generate both liquid and solid wastes. Only one 1.5-acre waste pond is needed for the liquid and solid wastes because the sludge from the filtration unit is shipped offsite for burial at a licensed low-level burial site. 
TABLE 3.3. Estimated Capital, Annual, and Rehabilitation Costs for Environmental Control Facilities and Operations for the Extraction of Thoria from Monazite in Existing Operations

Capital Cost Summary

\begin{tabular}{|c|c|c|}
\hline Liquid and Solid Wastes & $\begin{array}{r}1978 \\
\text { Cost }(a) \\
\end{array}$ & $\begin{array}{l}\text { Installed } \\
(\$ 1000)\end{array}$ \\
\hline $\begin{array}{l}\text { 1.75-acre Thoria Pond } \\
\text { 3-acre Phosphate Pond } \\
7 \text {-acre Main Settling Pond } \\
\text { Piping System } \\
\text { pH Control } \\
\text { Auxiliary Facilities }\end{array}$ & & $\begin{array}{r}\$ 22 \\
33 \\
59 \\
22 \\
11 \\
11 \\
\$ 158\end{array}$ \\
\hline
\end{tabular}

Airborne Wastes

Two 10,000-cfm F ans

Two 10,000-cfm Plant Air and

Fume Scrubbers

One 1500-cfm F an and Dust

Collector

$\frac{14}{\$ 715}$

Contingency, Fees, and Land

Total Installation Cost

$\$ 229$

$10 \%$ Contingency

Subtotal

$\$ 23$

5\% Contractor Fee

12 Acres of Land

Total Capital Cost

Annual Operating Cost Summary

Capital Charge

Land and Working Captial Charge

$\$ 295$

Maintenance

Operating and Overhead

Carbon Dioxide

Power

Miscellaneous Supplies

Sewer Fee

$\$ 72$

4

9
7

54

8

6

$\$ 166$

Rehabilitation Cost Estimate

Rehabilitate 12 acres o $\$ 10,000 /$ acre $\$ 120$

(a) Includes complete installation plus engineering and construction overhead. 


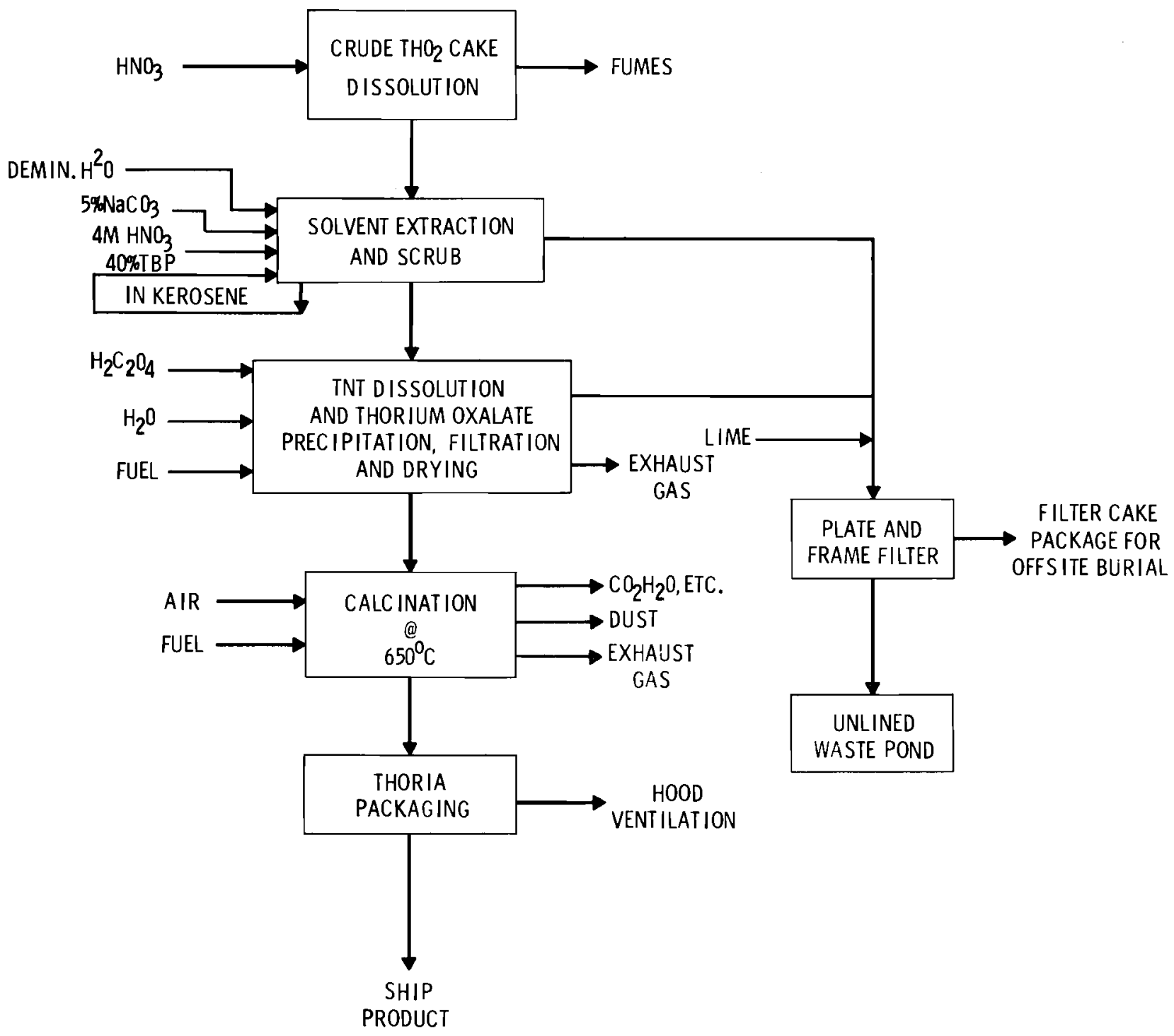

FIGURE 3.3. Current Thorium Dioxide Refining Process

The thoria refinement plant also produces some airborne wastes from calcination and thoria packaging. Dust and fumes are the major emissions. The amount of money spent for environmental control of airborne wastes at the thoria refinement $p l a n t$ is about the same as for liquid and solid waste control, as shown in Table 3.4. These control costs show that the more radioactively concentrated the dust becomes, the more costly the control methods are. Every point of dust release in the refinery must have some sort of dust collection system. 
TABLE 3.4. Estimated Costs of Environmental Control Facilities and Operations at a Thoria Refinement Plant

\section{Capital Cost Summary}

\begin{tabular}{lc} 
Liquid and Solid Wastes & $\begin{array}{c}1978 \text { Installed } \\
\text { Cost }(a)\end{array}(\$ 1000)$ \\
\hline Lime Addition Facility & $\$ 16$ \\
Plate-and-Frame Filter & 16 \\
1.5-acre Pond & 20 \\
Auxiliary Facilities & 13 \\
& $\$ 65$
\end{tabular}

Airborne Wastes

Acid Fume $F$ an and Scrubber

$\mathrm{F}$ an and Dust Collector

$\$ 22$

Packaging Hood, Fan, and HEPA Filter $(b)$

Contingency, Fees, and Land

Total Installation Cost

$10 \%$ Contingency

Subtotal

5\% Contractors Fee

2 Acres Land

Total Capital Cost

Annual Operating Cost Summary

Capital Charge

Land and Working Capital Charge

Maintenance

Operating

Lime and Miscellaneous Supplies

Power and Utilities

Package and Ship Filter Cake to Burial

Total Annual Operating Cost

Rehabilitation Cost Estimate

Rehabilitate 2 Acres @ \$23,000/acre \$46

(a) Includes complete installation plus engineering and construction overheads.

(b) High-efficiency particulate air filters (HEPA filters). 
All liquid and solid wastes pass through the plate-and-frame process before either storage in the waste pond or transportation to an offsite burial facility. The estimated cost of packaging and shipping the filter cake to this burial facility is $\$ 30,000 / y r$. After plant operations cease or when the waste pond is full, the residual sludge may have to be packaged and shipped of fsite. This cost, which is not included, might exceed $\$ 1,000,000$.

\subsection{POTENTIAL THORIUM SOURCES}

The location and characteristics of various potential domestic deposits of thorium oxide are discussed in Section 2 along with the ore mining, milling, and refinery processes. The costs given for each deposit in Section 2.5 include state-of-the-art environmental control costs. Sections 3.2.1 through 3.2.7 include detailed discussions of the types and levels of generated wastes from each process at each deposit. The costs of state-of-the-art environmental control techniques for each deposit are also presented in the following sections.

The Bear Lodge deposit is not discussed in detail in Section 3 or 5 because of inadequate information on its ore processing and because the information concerning it was received too late to develop a full analysis of the environmental effects.

\subsubsection{Stockpiles $(2,3,4)$}

Only a refinery is required to produce thorium from existing stockpiles. The stockpile refinery (see Appendix D) is designed to process $25 \% \mathrm{ThO}_{2}$ sludge, which is similar to the stockpiled sludge at the W. R. Grace and Company thorium pond in Chattanooga, Tennessee.

The various waste streams and the mass and radioactivity balances for each stream are shown in Figure 3.4. The dust stream from the drying and loading processes is the smallest waste stream, but it needs to be controlled very closely because the activity per unit mass is very high for dust from these processes. The uranium and other rare-earth impurities form another waste stream after their removal. This stream, which also contains the various daughter products of thorium, flows into the tailings pond for storage. These radioactive elements make the waste stream to the tailings pond the most radioactive in the refinery. 


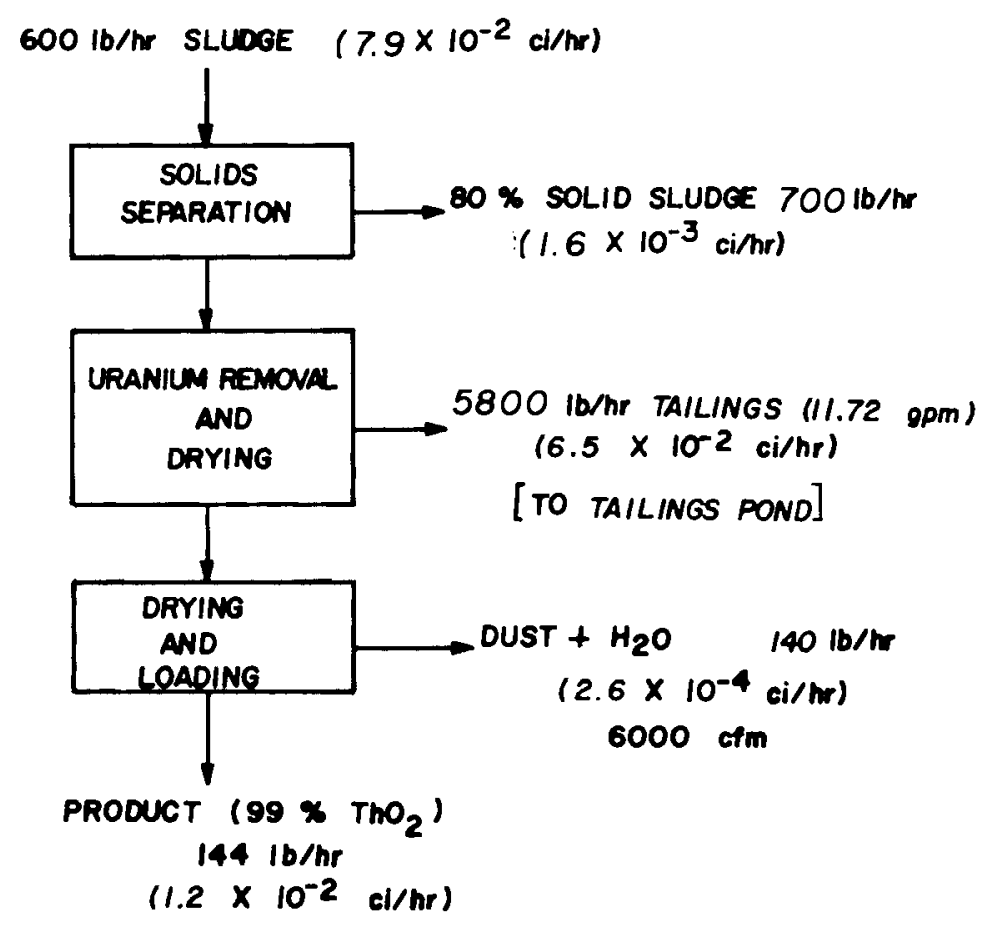

FIGURE 3.4. Stockpile Refinery Generated Wastes

At the beginning of the sludge refinement process, nitric acid is added to the entering sludge to form thorium nitrate. However, a large part of the entering sludge does not dissolve and, therefore, must be disposed of. This $80 \%$ solids stream must be buried in an approved land site.

The capital and annual costs of controlling the various waste streams are shown in Table 3.5. The waste sludge will be landfilled in a 2.5-acre claylined pit. The sludge (solid waste) will be trucked to the site in hoppers for easy handling. Transportation by hoppers is cheaper than using a conveyer system or slurry line. The drying and packaging dust (airborne wastes) will be collected by a 6000-cfm system of baghouse filters and HEPA filters in series. The solids collected from the baghouse filters will be recycled back into the main process stream. 
TABLE 3.5. Estimated Waste Control Costs for a Stockpile Refinery

\begin{tabular}{|c|c|c|c|}
\hline Generated Wastes & Type of Control & $\begin{array}{l}\text { Capital } \\
\text { Cost }(\$ 1000) \\
\end{array}$ & $\begin{array}{c}\text { Annual } \\
\text { Cost }(\$ 1000)\end{array}$ \\
\hline Waste Sludge & $\begin{array}{l}2.5 \text {-acre, clay-lined, } \\
\text { landfil1 pit with } \\
\text { trucks \& hoppers }\end{array}$ & 157.0 & 57.6 \\
\hline Liquid Waste & $\begin{array}{l}\text { 4-acre, clay-lined tailings } \\
\text { pond with no recycle system }\end{array}$ & 164.0 & 43.1 \\
\hline $\begin{array}{l}\text { Drying \& Packaging } \\
\text { Dust }\end{array}$ & $\begin{array}{l}6000 \text {-cfm bag \& HEPA } \\
\text { filter system with } \\
\text { demister }\end{array}$ & 104.0 & 45.5 \\
\hline $\begin{array}{l}\text { Tailings Pond } \\
\text { Beach Dust }\end{array}$ & $\begin{array}{l}\text { Portable chemical } \\
\text { spraying equipment }\end{array}$ & 4.0 & 2.4 \\
\hline $\begin{array}{l}\text { Tailings Pond } \\
\text { Radioactivity }\end{array}$ & $\begin{array}{l}6 \text {-ft compacted-earth } \\
\text { cover with } 6 \text { in. rock }\end{array}$ & 70.1 & 0.7 \\
\hline Total Costs & & 499 & $\overline{149}$ \\
\hline
\end{tabular}

The 4-acre, clay-core tailings pond will be the most expensive waste control measure at the refinery. The capital cost of $\$ 164,000$ includes the land cost, construction costs, and the distribution system costs. Beach dust from the tailings pond will be minimized by spraying the beach with chemicals to keep the dust level very low and to prevent of fsite contamination. As part of the decommissioning of the refinery at the end of its useful life, the pond tailings will have to be covered to contain the radioactive gases and dust.

The total capital cost of waste control for the stockpile refinery is $\$ 500,000$ while the annual cost is $\$ 150,000$, as shown in Table 3.5. Of the capital costs, $\simeq 1 / 3$ is for waste sludge disposal and $\simeq 1 / 2$ is for the tailings pond, including beach dust control and the pond cover. The above costs may be two to three times higher depending on site- or process-dependent variables. 3.2.2 Lemhi Pass Deposit (5)

\subsubsection{Mine Generated Wastes}

Solid waste generated wastes from the 1,000 ton/day Lemhi Pass mine consists of low-grade wall rock and gangue material. The ratio of waste to ore 
is $30 \mathrm{lb}$ of waste rock to 1 ton of ore. (6) Due to its low-level of radioactivity, the waste rock can be disposal of onsite.

Dust originates at two areas in the mine. It was estimated that approximately one quarter of the dust generated wastes is generated in the underground mine. Most of the dust $(\simeq 3 / 4)$ was estimated to originate in the above-ground mine operations, which include loading and transporting the mined ore to the mill and storing this ore.

The dust in the underground mine can be completely controlled by the $300,000-\mathrm{cfm}$ ventilation system required for the miners' health and safety. Dust collectors are not needed because the dust is dilute enough to release directly to the atmosphere. Thus, the cost of dust control in the underground mine is zero. The cost of the ventilation system is included as part of the mine's overall capital cost.

The above-ground dust is controlled by wetting down the roads, yards, and storage piles. To further control the dust, barriers are required around the ore storage piles. The major control costs are for these above-ground dust control measures, as shown in Table 3.6 .

The liquid wastes from the mine are influenced by a number of subsurface hydrologic conditions including the proximity of mine shafts to subsurface aquifers and the size of these aquifers. Liquid wastes are assumed to average $500 \mathrm{gpm}$ since the Lemhi Pass mine was assumed to be an intermediate (500 to $2,000 \mathrm{gpm})$ or dry mine $(<500 \mathrm{gpm})$. The average $\mathrm{ThO}_{2}$ concentration in the mine water was assumed to be $12.5 \mathrm{ppm}$. This average was based on the $\mathrm{U}_{3} \mathrm{O}_{8}$ content in mine water of a number of uranium mines since there are no thorium mines at the present time.

At the Lemhi Pass mine, the mine water is the most radioactive waste. A 2-acre settling pond on a 3-acre tract is needed to control the mine water. Containment in this pond will allow the fines to settle out.

\subsubsection{Mill/Refinery Generated Wastes}

The Lemhi Pass mill/refinery processes $0.356 \% \mathrm{ThO}_{2}$ ore from the Lemhi Pass mine and produces $99 \% \mathrm{ThO}_{2}$ powder. There are three main dust streams 
TABLE 3.6. Estimated Waste Control Costs for Lemhi Pass Mine and Mi11/Refinery(a)

\begin{tabular}{|c|c|c|c|}
\hline Generated Wastes & Type of Control & $\begin{array}{c}\text { Capital } \\
\text { Cost }(\$ 1000) \\
\end{array}$ & $\begin{array}{c}\text { Annual } \\
\text { Cost }(\$ 1000) \\
\end{array}$ \\
\hline \multicolumn{4}{|l|}{ Mine } \\
\hline Mine Water & $\begin{array}{l}\text { 2-acre settling pond, } \\
\text { ditches, etc. }\end{array}$ & 35.2 & 11.1 \\
\hline $\begin{array}{l}\text { Underground Mine } \\
\text { Dust }\end{array}$ & $300,000 \mathrm{cfm}$ ventilation & 0 & 0 \\
\hline $\begin{array}{l}\text { Above-Ground Mine } \\
\text { Dust }\end{array}$ & $\begin{array}{l}\text { Spray equipment and wind } \\
\text { barriers }\end{array}$ & 45.0 & 34.2 \\
\hline \multicolumn{4}{|l|}{ Mi11/Refinery } \\
\hline $\begin{array}{l}\text { Dust from Unload- } \\
\text { ing, Crushing, and } \\
\text { Grinding }\end{array}$ & $\begin{array}{l}26,000-c f m \text { cyclone } \\
\text { system }\end{array}$ & 19.9 & 11.6 \\
\hline $\begin{array}{l}\text { Drying and } \\
\text { Ignition Dust }\end{array}$ & $\begin{array}{l}21,000-c f m \text { wet- } \\
\text { impingement } \\
\text { scrubber system }\end{array}$ & 39.9 & 20.4 \\
\hline Packaging Dust & $\begin{array}{l}4,000-c f m \text { baghouse filter } \\
\text { system }\end{array}$ & 22.7 & 9.9 \\
\hline Liquid Waste & $\begin{array}{l}\text { Tailings pond: } 100 \text {-acre } \\
\text { clay-core dam and } \\
\text { reservoir with recycle } \\
\text { and distribution systems }\end{array}$ & 3,066 & 913.4 \\
\hline $\begin{array}{l}\text { Tailings Pond } \\
\text { Beach Dust }\end{array}$ & $\begin{array}{l}\text { Portable chemical } \\
\text { spraying equipment }\end{array}$ & 20.0 & 26.0 \\
\hline $\begin{array}{l}\text { Tailings Pond } \\
\text { Radioactivity }\end{array}$ & $\begin{array}{l}\text { 1-ft compacted earth } \\
\text { cover with } 6 \text { in. rock }\end{array}$ & 320.0 & 1.0 \\
\hline Total Costs & & $\overline{3,570.0}$ & $\overline{1,030}$ \\
\hline
\end{tabular}

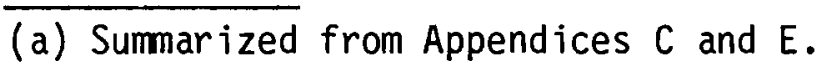


and four main liquid waste streams. The detailed calculations of the effluent streams and their levels of radioactivity are shown in Appendix $D$ and summarized in Figure 3.5 .

Airborne wastes are released as the ore from the mine is stored in piles according to grade, crushed, and ground. Dust from unloading, crushing, and grinding the ore is released at a rate of $4.55 \mathrm{lb} / \mathrm{hr}$; it has an overall radioactivity rate of $6.9 \times 10^{-6} \mathrm{Ci} / \mathrm{hr}$. The percentage of ${ }^{232} \mathrm{Th}$ in the dust is the same as the overall percentage in the ore being crushed $(0.313 \%)$. Airborne wastes are released from two other points. The drying and ignition processes release $896 \mathrm{lb} / \mathrm{hr}$ of airborne wastes, most of which is water evaporated in the kiln. Even though the amount of dust is small, it is very radioactive on a per mass basis because it is $99 \% \mathrm{ThO}_{2}$. This is also true of the dust released from the packaging operation. Only $0.02 \mathrm{lb} / \mathrm{hr}$ are emitted but the radioactivity per $\mathrm{lb}$ is $\simeq 58$ times higher than the dust from unloading, crushing, and grinding the ore.

The airborne waste streams will be controlled by several methods at varying costs. A system of fans and hoods with a 26,000-cfm capacity and a cyclone dust collector will be used to control the dust from unloading, crushing, and grinding the ore. The capital cost for this system is $\$ 19,900$ and the annual cost $\$ 11,600$. The cost of controlling the drying and ignition dust is higher because that stream is more radioactive. To control it, fans and a 21,000-cfm wet-impingement scrubber will be installed at a capital cost of $\$ 39,900$ and an annual cost of $\$ 20,400$. Although the packaging dust stream is smaller and less radioactive than the other streams on a per $\mathrm{hr}$ basis, the radioactivity is quite a bit larger on a per mass basis than any of the other streams. Because of this high radioactivity, a system of controlling very small particles is needed. The 4,000-cfm baghouse filter unit with fans and hoods will operate at a higher efficiency to ensure that little of the dust is emitted to the environment. The solids collected from all of the above dust streams are recycled back into the main flow streams. 
A. MINE

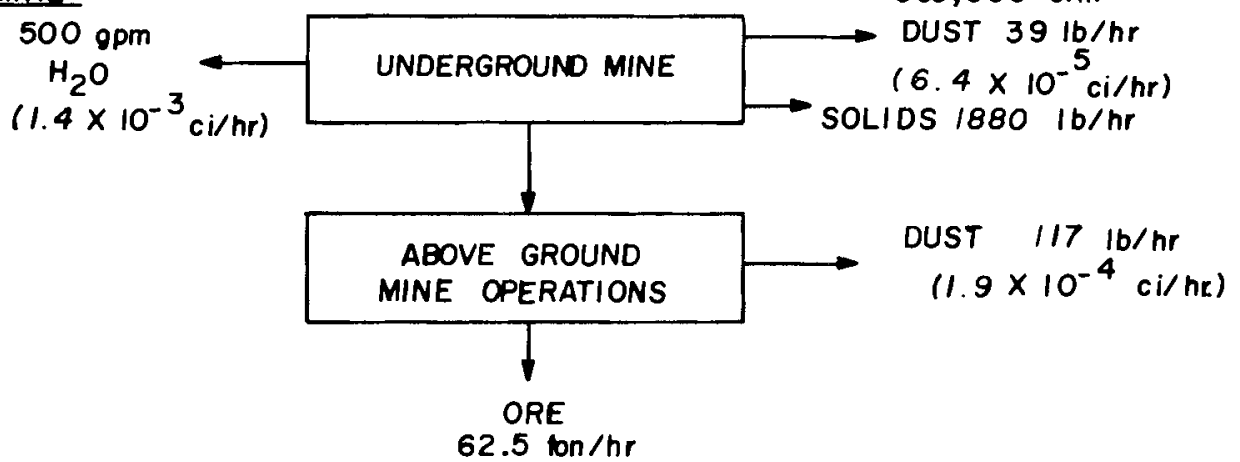

B. MILL/REFINERY
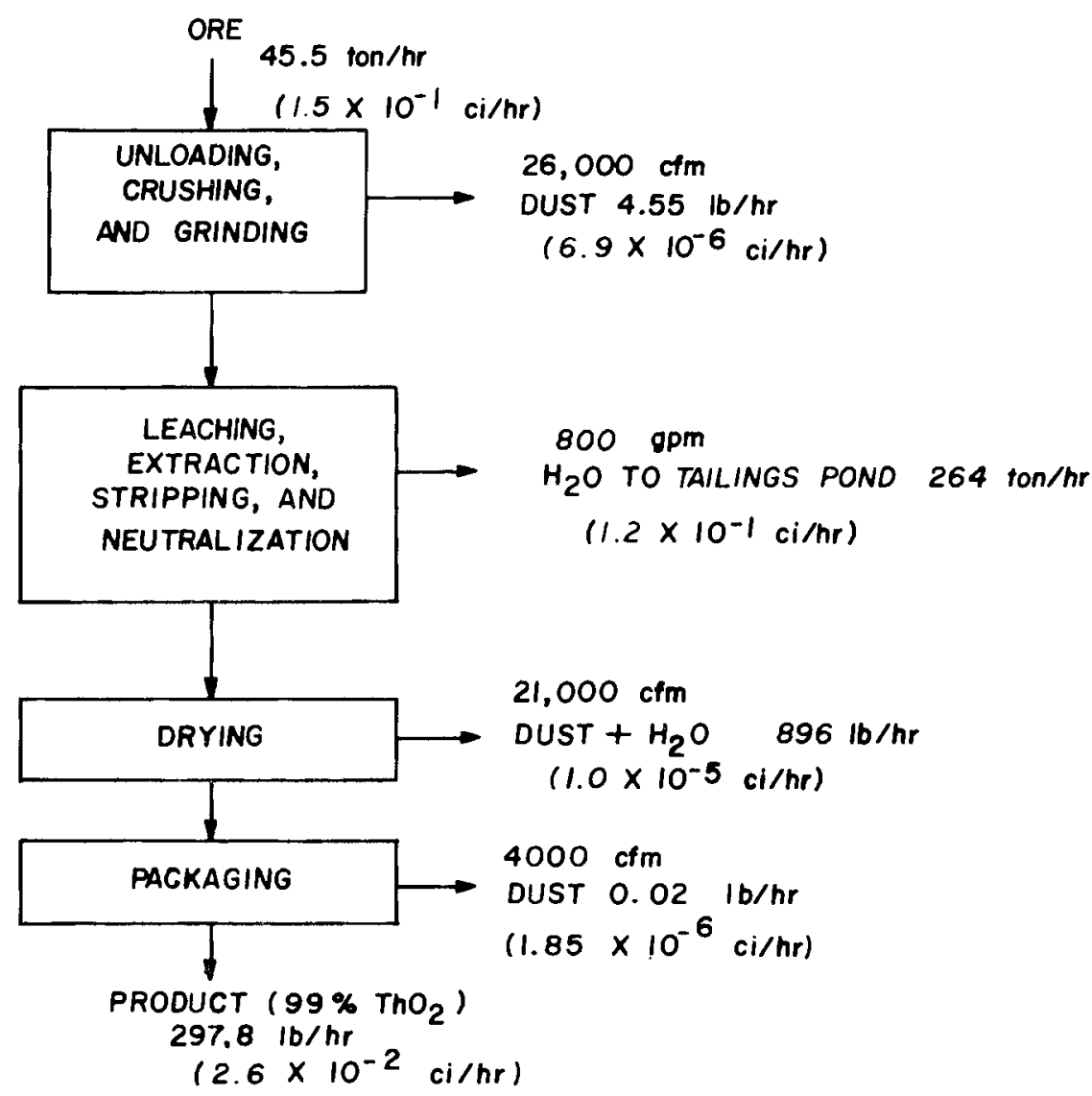

FIGURE 3.5. Lemhi Pass Mine and Mi11/Refinery Generated Wastes 
Four liquid streams flow into the central tailings pond. The largest stream is from the counter-current decantation process, and it is $45 \%$ solids. The tailings pond receives most of the radioactivity from the mill. Even the final product has less radioactivity than the tailings pond because all of the thorium daughters not emitted in the dust streams are assumed to enter the pond. All of the ${ }^{238} \mathrm{U},{ }^{235} \mathrm{U}$, and the ir daughter products are also impounded in this pond, except for the small amount released in the airborne wastes.

A 100 -acre pond is needed to contain the tailings and to allow $\simeq 1 / 4$ of the waste water to evaporate. This pond will have a clay-core dam and will need a system for spreading the tailings that precipitate from the water. There may be some seepage ( 0 to 15\%) even with a clay-core dam. About $75 \%$ of the tailings water is recycled through the mill. Before entering the mill, the recycled water will pass through a 1-acre settling pond where the remaining solids will settle out.

A detailed cost breakdown for the above tailings pond system is sumarized in Table 3.6. The capital cost of controls is $\$ 3,066,000$ and the annual cost is $\$ 913,000$. These are the major environmental control costs for the Lemhi Pass deposit; they represent greater than $85 \%$ of the total capital and annual costs. The cost of spraying the beach with chemicals and water to control the beach dust will be $\$ 26,000 / y r$; the spray equipment will cost $\$ 20,000$. When the mill is decommissioned, the tailings pond will be covered with $1 \mathrm{ft}$ of earth and $6 \mathrm{in}$. of rock. This will reduce or eliminate the thoron gas, radioactive dust, and radiation. The tailings pond covering will cost $\$ 320,000$ to install and should be sufficient to protect the environment from significant contamination.

The total capital cost of controlling environmental emissions for the entire Lemhi Pass deposit--mining through mill/refining--is $\$ 3,570,000$ and the annual cost is $\$ 1,030,000$. The cost of the tailings pond for the mill/refinery is $\approx 95 \%$ of the capital costs and $\approx 91 \%$ of the annual costs, excluding the costs of beach dust control and covering the tailings pond. 


\subsubsection{Hall Mounta in Deposit $(5)$}

\subsubsection{Mine Generated Wastes}

The mine at the Hall Mountain deposit is an underground thorite mine similar to the Lemhi Pass mine. The $1.1 \% \mathrm{ThO}_{2}$ ore grade is higher than the Lemhi Pass ore grade but less ore is mined (400 ton/day). Because of the high ore grade, the dust contains more ${ }^{232} \mathrm{Th}$ at Hall Mountain. It was assumed that $\simeq 1 / 4$ of the dust is from the underground mine and $\simeq 3 / 4$ is emitted above ground, the same as for the Lemhi Pass mine. The waste release rates from the mine operations are shown in Figure 3.6.

The solid wastes removed from the mine--gangue and wall rock--are assumed to be of such low radioactivity that their disposal onsite poses no environmental problems.

The liquid wastes at Hall Mountain are the most radioactive of the effluents released, as was the case with the Lemhi Pass deposit. For liquid wastes, we followed the assumptions used at Lemhi Pass (see Section 3.2.1). The Hall Mountain mine is half as large as the Lemhi Pass mine so the water removal was assumed to be $250 \mathrm{gpm}$. The average $\mathrm{Th}_{2}$ concentration in the mine water was assumed to be $12.5 \mathrm{ppm}$. There are, as previously mentioned, a number of subsurface conditions that may influence the flow and concentration levels in the mine water.

The mine water is the most radioactive stream from the Hall Mountain mine. To control the mine water and to settle the fines, a 1-acre settling pond is required. The total capital cost of the settling pond and associated equipment is $\$ 21,700$ while the annual cost is $\$ 9,700$.

Airborne wastes in the Hall Mountain Mine will be controlled by a $160,000-c f m$ ventilation system. No control measures will be needed for mine dust because it is sufficiently diluted by this system. Thus, the cost of controlling the mine dust is zero, as shown in Table 3.7. The cost of the ventilation system is already included as part of the overall mine cost.

The airborne wastes from the above-ground mine operations are controlled by 1) spraying waste water onto the areas of heaviest dust emissions, and 2) erecting wind barriers. These measures have a capital cost of $\$ 26,000$ and an annual cost of $\$ 22,700$. 


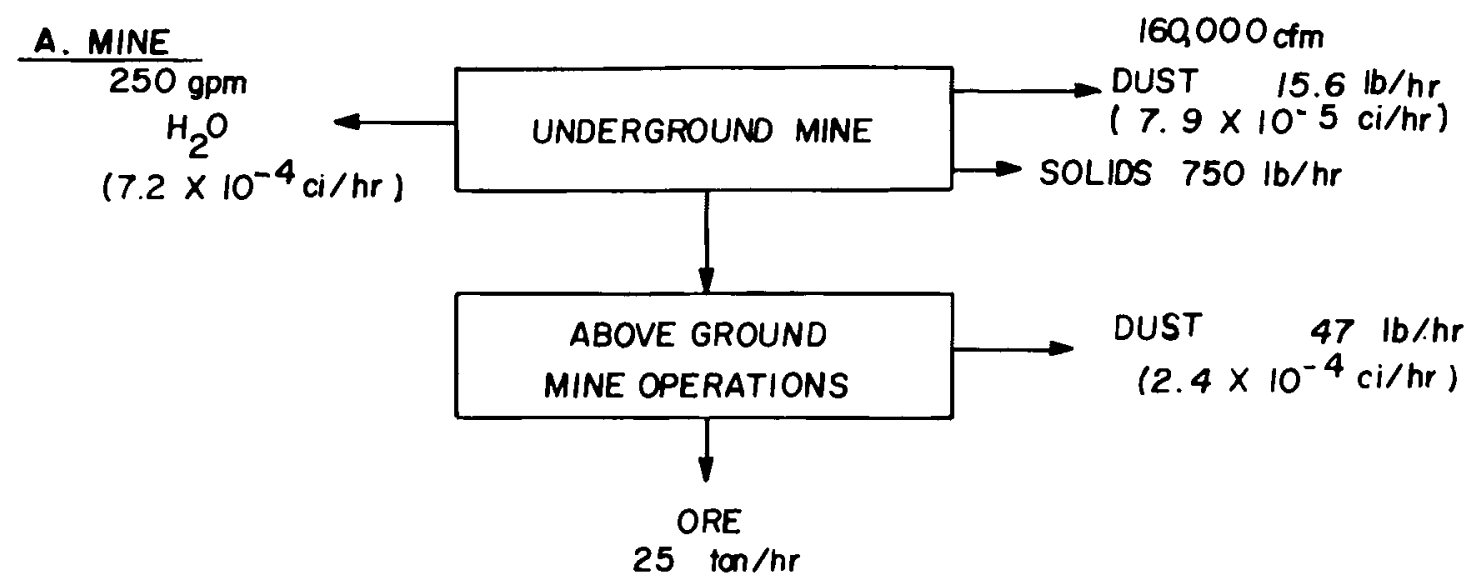

B. MILL/REFINERY

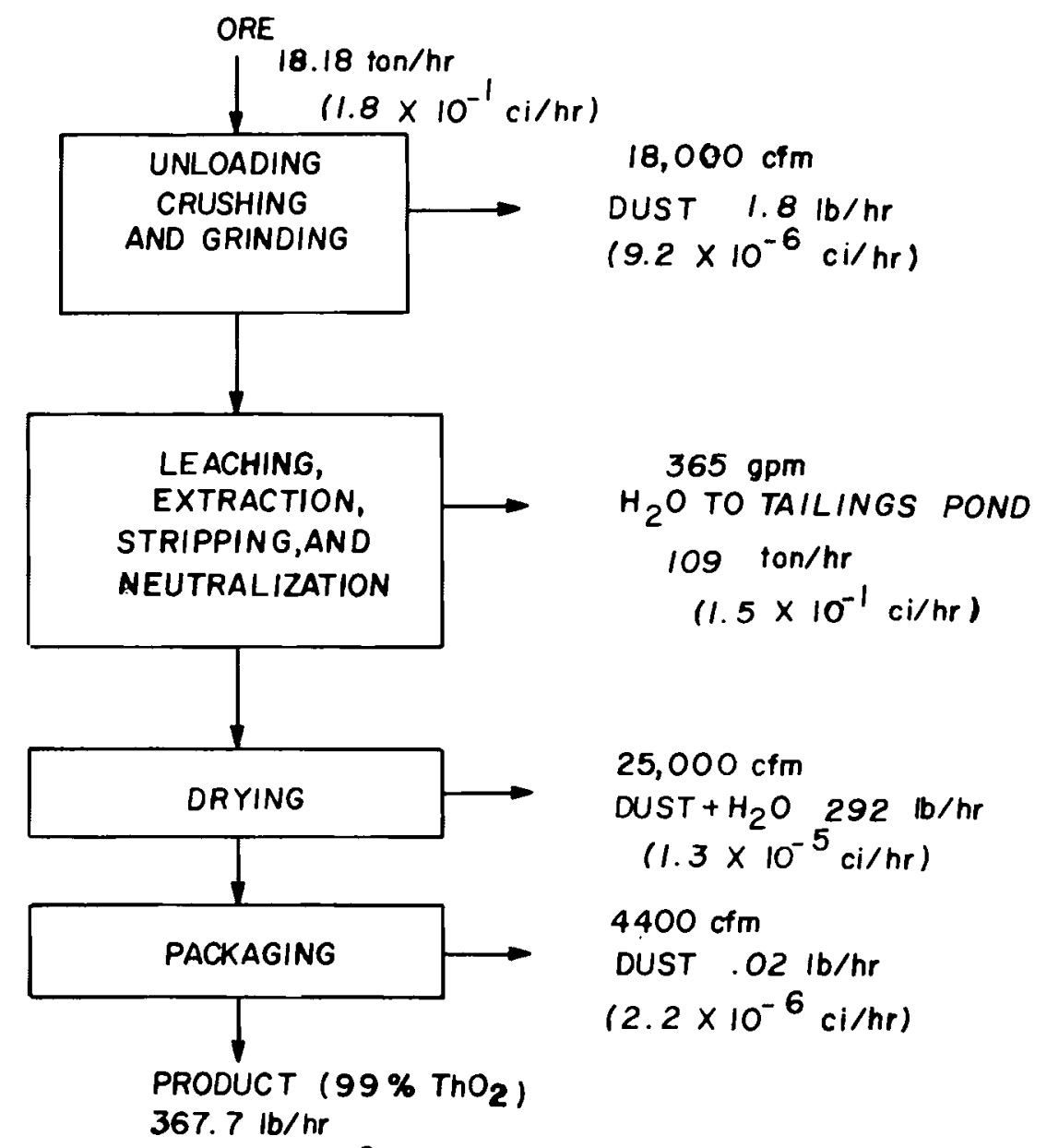

$\left(3.2 \times 10^{-2} \mathrm{ci} / \mathrm{hr}\right)$

FIGURE 3.6. Hall Mountain Mine and Mi11/Refinery Generated Wastes 
TABLE 3.7. Est imated Waste Confrol Costs for Hall Mountain Mine and Mill/Refinery(a)

\begin{tabular}{|c|c|c|c|}
\hline Generated Wastes & Type of Control & $\begin{array}{c}\text { Capital } \\
\text { Cost }(\$ 1000) \\
\end{array}$ & $\begin{array}{c}\text { Annual } \\
\text { Cost }(\$ 1000 \\
\end{array}$ \\
\hline \multicolumn{4}{|l|}{ Mine } \\
\hline Mine Water & $\begin{array}{l}\text { 1-acre settling pond, } \\
\text { ditches, etc. }\end{array}$ & 21.7 & 9.7 \\
\hline $\begin{array}{l}\text { Underground Mine } \\
\text { Dust }\end{array}$ & 160,000 -cfm ventilation & 0 & 0 \\
\hline $\begin{array}{l}\text { Above-Ground Mine } \\
\text { Dust }\end{array}$ & $\begin{array}{l}\text { Spray equipment and wind } \\
\text { barriers }\end{array}$ & 26.0 & 22.7 \\
\hline \multicolumn{4}{|l|}{ Mi11/Refinery } \\
\hline $\begin{array}{l}\text { Dust From Unload- } \\
\text { ing, Crushing, and } \\
\text { Grinding }\end{array}$ & $18,000-\mathrm{cfm}$ cyclone system & 13.5 & 10.2 \\
\hline $\begin{array}{l}\text { Drying and } \\
\text { Ignition Dust }\end{array}$ & $\begin{array}{l}25,000-c f m \text { wet- } \\
\text { impingement scrubber } \\
\text { system }\end{array}$ & 46.2 & 30.5 \\
\hline Packaging Dust & $\begin{array}{l}4400-c f m \text { baghouse filter } \\
\text { system }\end{array}$ & 24.7 & 14.3 \\
\hline Liquid Waste & $\begin{array}{l}\text { Tailings Pond: } 15 \text {-acre } \\
\text { clay-core dam and reser- } \\
\text { voir with recycle and } \\
\text { distribution }\end{array}$ & 970.0 & 450.0 \\
\hline $\begin{array}{l}\text { Tailings Pond } \\
\text { Beach Dust }\end{array}$ & $\begin{array}{l}\text { Portable chemical } \\
\text { spraying equipment }\end{array}$ & 11.5 & 16.0 \\
\hline $\begin{array}{l}\text { Tailings Pond } \\
\text { Radioactivity }\end{array}$ & $\begin{array}{l}\text { 1-ft compacted earth } \\
\text { cover with } 6 \text { in. rock }\end{array}$ & 70.1 & 10.4 \\
\hline Total Costs & & $\overline{1,180}$ & $\overline{563}$ \\
\hline
\end{tabular}

(a) Sumarized from Appendices C, E, and F. 


\subsubsection{Mill/Refinery Generated Wastes}

The Hall Mountain mi11/refinery processes $1.1 \% \mathrm{ThO}_{2}$ ore from the Hall Mountain mine and produces $99 \% \mathrm{ThO}_{2}$ powder. At the Hall Mountain mill/ refinery--like Lemhi Pass, there are three dust streams and four liquid effluent streams to be treated. The detailed calculations of the radioactivity of these streams are given in Appendix $D$ and sumarized in Figure 3.6.

The three airborne waste streams have varying release rates and levels of radioactivity. The dust from unloading, crushing, and grinding the ore is released at a rate of $1.8 \mathrm{lb} / \mathrm{hr}$ and has a radioactive release rate of $9.2 \times$ $10^{-6} \mathrm{Ci} / \mathrm{hr}$. The percentage of ${ }^{232} \mathrm{Th}$ in this dust is assumed to be the same as that in the ore being crushed $(0.968 \%)$. The drying and ignition process releases $292 \mathrm{lb} / \mathrm{hr}$ of airborne wastes. Most of this is water but the dust given off is $99 \% \mathrm{ThO}_{2}$. Of the three dust streams, this stream has the highest radioactive release rate $\left(1.3 \times 10^{-5} \mathrm{Ci} / \mathrm{hr}\right)$. The packaging dust is released at a rate of $0.02 \mathrm{lb} / \mathrm{hr}$, is $99 \% \mathrm{ThO}_{2}$, and has a radioactive release rate of $2.2 \times 10^{-6} \mathrm{Ci} / \mathrm{hr}$.

Each of the three airborne waste streams uses a different type of control. A system of fans, hoods, and an $18,000-c f m$ capacity cyclone dust collector will be used, to control the dust from unloading, crushing, and grinding. This system will cost $\$ 13,500$ installed and $\$ 10,200$ to operate annually. The drying and ignition dust stream is the largest and most radioactive of the three dust streams. It is controlled by a system consisting of fans, hoods, and a 25,000-cfm capacity wet-impingement scrubber. The control measures for this stream are the most expensive to purchase, install, and operate, as shown in Table 3.7, with a capital cost of $\$ 46,200$ and an annual cost of $\$ 30,500$. To control the packaging dust, a small particle control system is needed because of the high radioactivity per unit weight. The stream is small but 99\% $\mathrm{ThO}_{2}$. The $4400-\mathrm{cfm}$ baghouse filter system has a capital cost of $\$ 24,700$ and an annual cost of $\$ 14,300$. All of the radioactive solids removed from the dust streams will be recycled back into the mill processes from whence they came. 
Four liquid streams flow into the central tailings pond. Most of the ${ }^{232}$ Th in the tailings pond $(\simeq 91 \%)$ is from the counter-current decantation stream. The tailings pond receives most of the radioactivity from the mill because all of the thorium daughters and uranium products and daughters that are not released in the dust from unloading, crushing, and grinding the ore are impounded in the tailings pond.

A 15-acre tailings pond with a clay-core dam will be needed to allow the tailings to precipitate out and $\simeq 1 / 4$ of the water to evaporate. The other $\simeq 3 / 4$ of the water will be recycled back to the mill after passing through another small settling pond. Because of the clay-core dam, the tailings pond should keep the seepage rate low (0 to 15\%). The capital cost for the tailings pond system is $\$ 970,000, \simeq 80 \%$ of the total environmental control costs for the Hall Mountain deposit. (a)

To control the beach dust from the tailings pond, chemicals will be sprayed on the beach. The capital cost for the spray equipment is $\$ 11,500$ and the annual cost of the operation is $\$ 16,000$. To decommission the tailings pond, a cover must be placed over it. This tailings pond cover will consist of $1 \mathrm{ft}$ of compacted earth and $6 \mathrm{in}$. of rock. This should be sufficient to stop most radioactivity from seeping through to the atmosphere. The capital cost of this cover is $\$ 70,100$.

At the Hall Mountain mine and mill/refinery, the total capital cost for the environmental control of emissions is $\$ 1,180,000$ and the total annual cost is $\$ 563,000$. Waste control costs for the mill/refinery tailings pond, including the costs for tailings pond beach dust control and the tailings pond cover, are $88 \%$ of the capital cost and $84 \%$ of the annual cost.

3.2.4 Wet Mountain Deposit $(5)$

\subsubsection{Mine Generated Wastes}

The 350 ton/day mine at the Wet Mountain deposit has an underground mine similar to the Lemhi Pass and Hall Mountain mines; so the various generated

(a) See Appendices $E$ and $F$ for detailed capital and annual cost estimates. 
wastes and release points are about the same. However, variations in radioactivity and the amount of ${ }^{232}$ Th released to the environment vary with the amount and grade of the ore put through the mine. As in the other thorite mines, the underground mine operations are assumed to generate $1 / 4$ of the dust while the above-ground operations are assumed to generate $3 / 4$ of the dust. Calculations of the amount of generated wastes and the level of radioactivity in the dust are contained in Appendix $C$ and summarized in Figure 3.7.

The solid waste from the mine is of very low grade and amounts to only about 5.25 ton/day in the form of gangue and wall rock. This waste rock can be used onsite without appreciable harm to the environment.

To control the above-ground dust, water will be used to wet down roads, yards, and storage piles. Wind barriers will also be used to keep the offsite dust level low. The capital cost for this is $\$ 24,000$ and the annual cost is $\$ 20,900$. A 140,000 -cfm ventilation system will be installed in the mine, which will dilute the dust so that no other method of control is needed. The cost of this ventilation system is included in the capital cost for the mine as a whole; so the extra control costs incurred are zero.

The Wet Mountain mine water is assumed to be released at half of the release rate for the Lemhi Pass mine water, i.e., $250 \mathrm{gpm}$, which is the same as the rate for the Hall Mountain mine. The concentration is assumed to be $12.5 \mathrm{ppm} \mathrm{ThO}_{2}$, which is also the same as that of both the Lemhi Pass and Hall Mountain water. Thus, the Wet Mountain mine water is similar to the Hall Mountain mine water in terms of volume and radioactivity. The water control costs are also the same for both mines. The capital cost for a 1-acre settling pond with ditches and pumping equipment is $\$ 21,700$ with an annual cost of $\$ 9,700$, shown in Table 3.8 .

\subsubsection{Mill/Refinery Generated Wastes}

The Wet Mountain mill/refinery processes $0.96 \% \mathrm{ThO}_{2}$ ore from the wet Mountain mine and produces $99 \% \mathrm{ThO}_{2}$ powder. As in the other thorite mill/ refineries, there are three main dust streams to be treated and four liquid streams that are sent to a central tailings pond. The detailed calculations of these streams and their levels are shown in Appendix $D$ and summarized in Figure 3.7 . 
A. MINE

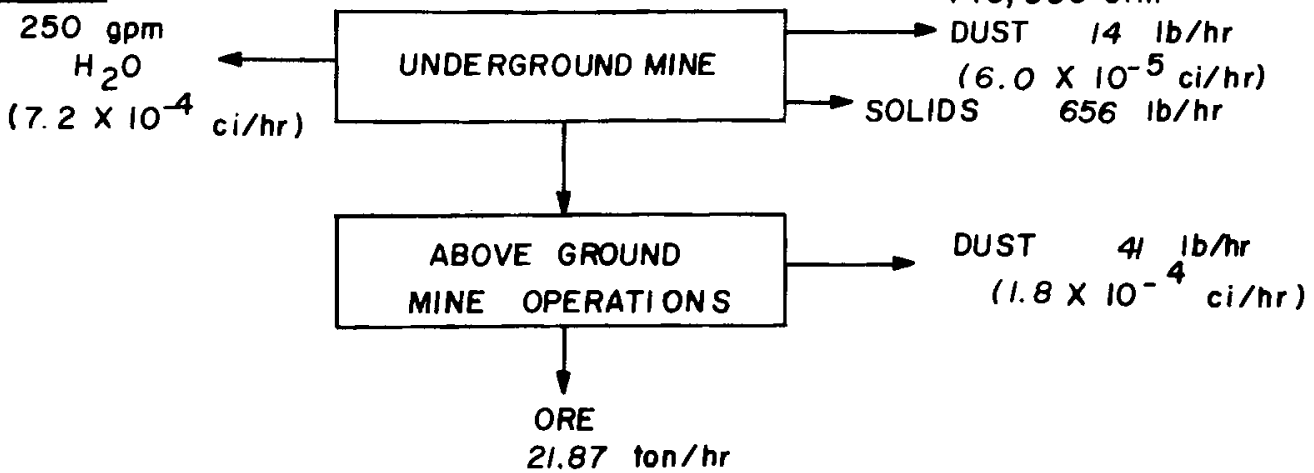

B. MILL/REFINERY

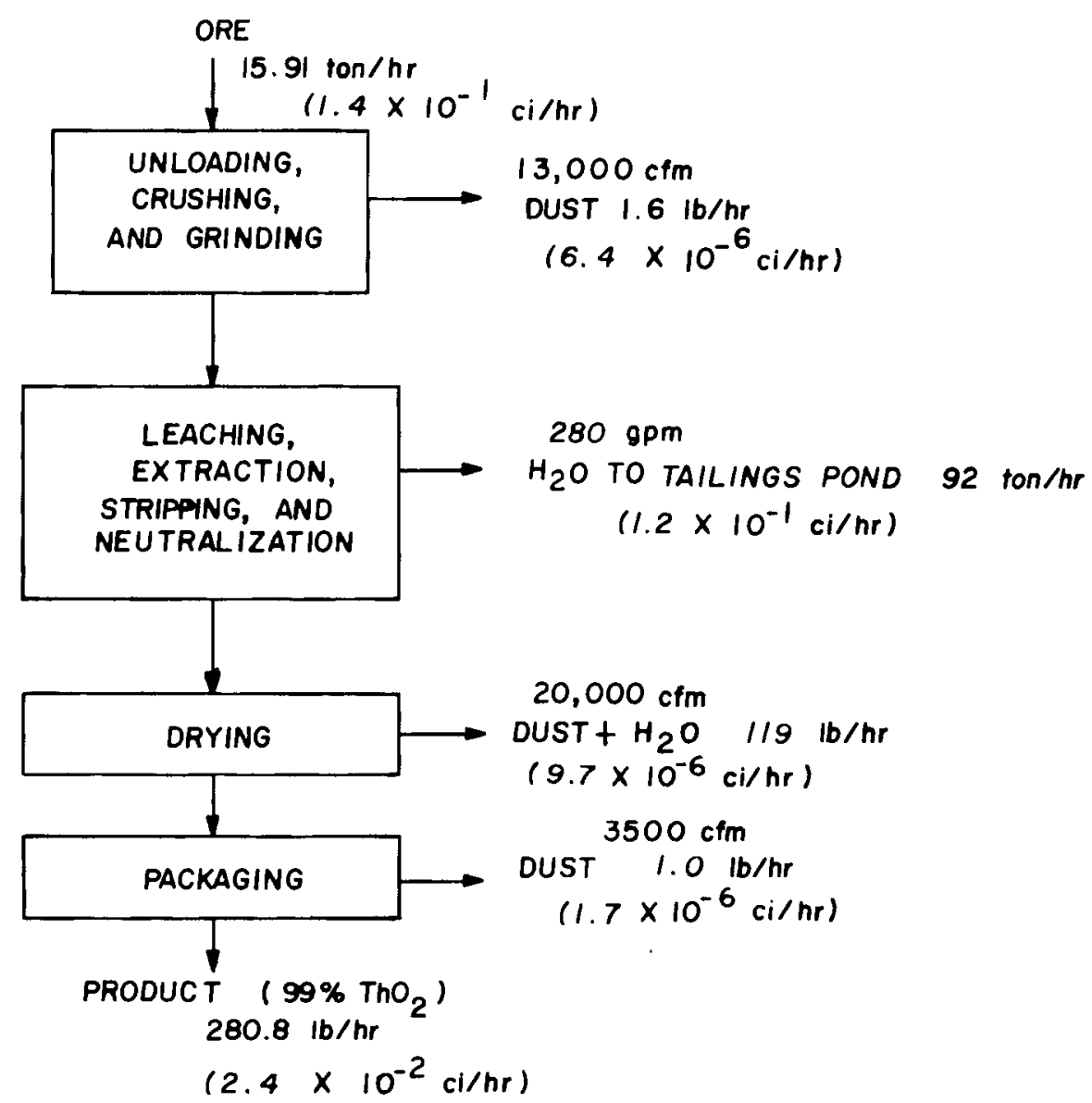

FIGURE 3.7. Wet Mountain Mine and Mi11/Refinery Generated Wastes 

TABLE 3.8. Estimated Waste Control fosts for Wet Mountain
Mine and Mill/Refinery(a)

\begin{tabular}{|c|c|c|c|}
\hline Generated Wastes & Type of Control & $\begin{array}{c}\text { Capital } \\
\text { Cost }(\$ 1000)\end{array}$ & $\begin{array}{c}\text { Annual } \\
\text { Cost }(\$ 1000) \\
\end{array}$ \\
\hline \multicolumn{4}{|l|}{ Mine } \\
\hline Mine Water & $\begin{array}{l}\text { 1-acre settling pond, } \\
\text { ditches, etc. }\end{array}$ & 21.7 & 9.7 \\
\hline Underground Mine Dust & $\begin{array}{l}140,000-c f m \text { ventila- } \\
\text { tion }\end{array}$ & 0 & 0 \\
\hline Above-Ground Mine Dust & $\begin{array}{l}\text { Spray equipment and } \\
\text { wind barriers }\end{array}$ & 24.0 & 20.9 \\
\hline \multicolumn{4}{|l|}{ Mill/Refinery } \\
\hline $\begin{array}{l}\text { Dust From Unloading, } \\
\text { Crushing, and Grinding }\end{array}$ & $\begin{array}{l}13,000-c f m \text { cyclone } \\
\text { system }\end{array}$ & 11.1 & 7.8 \\
\hline $\begin{array}{l}\text { Drying and Ignition } \\
\text { Dust }\end{array}$ & $\begin{array}{l}20,000 \text {-cfm wet- } \\
\text { impingement scrubber } \\
\text { system }\end{array}$ & 38.3 & 25.0 \\
\hline Packaging Dust & $\begin{array}{l}3,500-c f m \text { baghouse filter } \\
\text { system }\end{array}$ & 20.3 & 11.8 \\
\hline Liquid Waste & $\begin{array}{l}\text { Tailings pond: 14-acre } \\
\text { clay-core dam and } \\
\text { reservoir with } \\
\text { recycle and distribu- } \\
\text { tion systems }\end{array}$ & 902.0 & 417.0 \\
\hline $\begin{array}{l}\text { Tailings Pond Beach } \\
\text { Dust }\end{array}$ & $\begin{array}{l}\text { Portable chemical } \\
\text { spraying equipment }\end{array}$ & 10.7 & 14.7 \\
\hline $\begin{array}{l}\text { Tailings Pond Cover } \\
\text { Radioactivity }\end{array}$ & $\begin{array}{l}\text { 1-ft compacted earth } \\
\text { cover with } 6 \text { in. rock }\end{array}$ & 66.4 & 9.8 \\
\hline Total Costs & & $\overline{1,094.5}$ & $\overline{517}$ \\
\hline
\end{tabular}


The three streams of airborne wastes have various dust and radioactive release rates. The dust from unloading, crushing, and grinding the ore is assumed to have the same percentage of ${ }^{232}$ Th $(0.85 \%)$ as the ore being crushed. This dust is emitted at a rate of $1.6 \mathrm{lb} / \mathrm{hr}$ with a radioactive release rate of $6.4 \times 10^{-6} \mathrm{ci} / \mathrm{hr}$. The $119 \mathrm{lb} / \mathrm{hr}$ of airborne wastes released in the drying and ignition processes are mostly water, but the $99 \% \mathrm{ThO}_{2}$ dust emitted is very radioactive on a per unit mass basis; $0.097 \mathrm{lb} / \mathrm{hr}$ of ${ }^{232} \mathrm{Th}$ is given off in these processes. This stream has the highest radioactive release rate $\left(9.7 \times 10^{-6} \mathrm{Ci} / \mathrm{hr}\right)$ of the three dust streams in the Wet Mountain mill/refinery. The packaging dust stream is small $(0.02 \mathrm{lb} / \mathrm{hr})$, but, because of its higher concentration per $1 \mathrm{~b}$, it has a radioactive release rate of $1.7 \times 10^{-6} \mathrm{Ci} / \mathrm{hr}$ from the packaging process.

The three airborne waste streams are controlled by differing equipment at substantially different costs. A system of fans, hoods, and a 13,000-cfm cyclone dust collector will be used to control the dust from unloading, crushing, and grinding the ore. This system's capital cost is $\$ 11,100$ with an annual cost of $\$ 7,800$. The drying and ignition stream is the largest and most radioactive of the three dust streams. It will be controlled by a system of fans, hoods, and a 20,000-cfm wet-impingement scrubber with a capital cost of $\$ 38,300$ and an annual cost of $\$ 25,000$. The control measures for it are the most expensive to purchase, insta11, and operate. The packaging dust stream is smaller then the other streams but has a higher radioactivity per unit weight. For this reason, a system must be installed to control small dust particles. The system that will be used is a 3500 -cfm baghouse filter unit with a capital cost of $\$ 20,300$ and an annual cost of $\$ 11,800$. All of the solids removed in these dust control units will be recycled back into the mill.

Four liquid waste streams flow into the central tailings pond. As in the previous thorite mill/refineries, most of the ${ }^{232} \mathrm{Th}$ in the tailings pond $(\approx 91 \%)$ is from the counter-current decantation stream. The amount of radioactivity entering the tailings pond $\left(1.16 \times 10^{-1} \mathrm{Ci} / \mathrm{hr}\right)$ is $\approx 82 \%$ of the total radioactivity entering the mill/refinery. This is due, in part, to the 
assumption that all of the thorium daughters not released in the dust from unloading, crushing, and grinding the ore are impounded in the tailings pond.

A 14-acre tailings pond with a clay-core dam and an associated piping network will be required to allow the tailings to precipitate out and $\simeq 1 / 4$ of the water to evaporate. The other $\approx 3 / 4$ of the water will be recycled to the mill after passing through another small settling basin or pond. The claycore dam in the tailings pond will keep the seepage rate low (0 to 15\%). The capital cost for the tailings pond system is $\$ 902,000$ and the annual cost is $\$ 417,000$. These costs represent $\simeq 81 \%$ of the total environmental control costs for the Wet Mountain deposit.

To control the beach dust and to keep the radiation level low, the exposed tailings will be sprayed with chemicals. The capital cost of the spray equipment is $\$ 10,700$ and the annual cost is $\$ 14,700$. As in the other two $\mathrm{mill} /$ refineries, a tailings pond cover must be added as part of the decommissioning process. This tailings pond cover will consist of $1 \mathrm{ft}$ of compacted earth and 6 in. of rock, which should prevent radioactive materials from escaping to the atmosphere. The capital cost of this tailings pond cover is $\$ 66,400$.

The total capital cost for the environmental control of emissions at the Wet Mountain mine and mi1l/refinery is $\$ 1,095,000$ and the total annual cost is $\$ 517,000$, as shown in Table 3.8. The mill/refinery tailings pond is $89 \%$ of the capital cost and $85 \%$ of the annual cost, including the costs for tailings pond beach dust control and the tailings pond cover.

\subsubsection{Palmer, Michigan, Deposit (7)}

\subsubsection{Mine Generated Wastes}

The open-pit mine at Palmer, Michigan, produces $10 \mathrm{million}$ tons of ore per $\mathrm{yr}$ with an average $\mathrm{ThO}_{2}$ grade of $0.06 \%$. Of all of the waste streams shown in Figure 3.8, Part $A$, the dust from the open pit is the most radioactive waste.

The solid waste consists of 3 tons of waste rock for every 10 tons of ore mined. (8) This rock will be stored onsite; it is of such low radioactivity that there will be no harmful external environmental effects. 


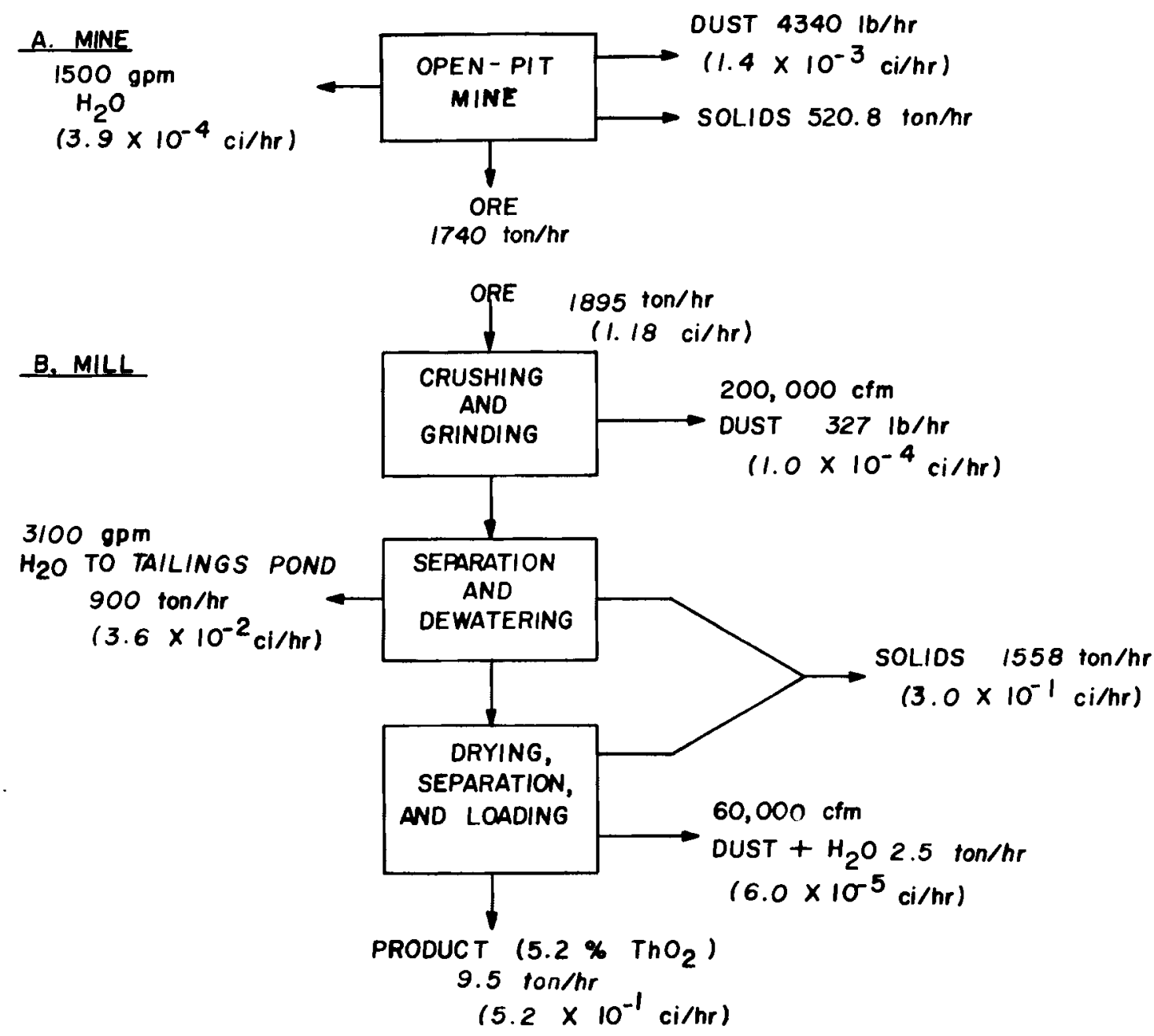

FIGURE 3.8. Palmer, Michigan, Mine and Mill Generated Wastes

About $0.125 \%$ of the ore mined or $4340 \mathrm{lb} / \mathrm{hr}$ is released as airborne wastes. (a) Because of the mine's open-pit structure, the dust will have to be controlled by careful drilling, blasting, and material-handling procedures. The roads, yards, and storage piles will be wet down by spray equipment to keep the dust levels low. The ore storage piles will have barriers built around them to protect them from the wind. The total capital cost of these dust prevention methods is $\$ 156,000$ and the annual cost is $\$ 104,000$. The majority $(\simeq 62 \%)$ of the capital cost is for the storage pile wind barriers.

(a) See Appendix $C$ for detailed generated waste calculations. 
The mine water is assumed to contain only $1 \mathrm{ppm}$ of $\mathrm{ThO}_{2}$, due to the low grade of ore. If $1,500 \mathrm{gpm}$ of mine water are pumped from the mine floor, $0.66 \mathrm{lb}$ of ${ }^{232} \mathrm{Th}$ is removed per $\mathrm{hr}$. The water removed from the mine passes through a 3-acre settling pond. After the solids have settled out in the settling pond, the water is used in the mill circuit as process water. The water can be recycled, after the solids have settled out in the settling pond, because the radioactivity is $10 \mathrm{w}, 3.9 \times 10^{-4} \mathrm{Ci} / \mathrm{hr}$. The capital cost for pumping, piping, and settling the mine water is $\$ 236,000$ and the annual cost is $\$ 101,000$.

The total capital cost of controlling mine wastes from the Palmer, Michigan, mine is $\$ 392,000$ and the annual cost is $\$ 205,000$, as shown in Table 3.9.

\subsubsection{Mi11 Generated Wastes}

The Palmer, Michigan, mill processes $0.06 \% \mathrm{ThO}_{2}$ ore from the Palmer, Michigan, mine and produces a $5.2 \% \mathrm{ThO}_{2}$ concentrate. There are two solid waste streams, two dust streams, and one liquid waste stream in the Palmer, Michigan, mill. The detailed calculations of the radioactivity in each of these streams are presented in Appendix $D$ and summarized in Figure 3.8.

The majority ( $\simeq 99 \%)$ of the solid waste generated is from the dewatering process while the rest of the solid waste is from the magnetic separation process. To dispose of these wastes, trucks will transport the solids back to the mine where they can be safely disposed of as landfil1. The solids content (80\%) of this waste stream is high because it has already been dewatered.

There are two airborne waste streams in the mill. The dust stream from unloading, crushing, and grinding the ore is generated at a rate of $327 \mathrm{lb} / \mathrm{hr}$ with a radioactive release rate of $1.0 \times 10^{-4} \mathrm{Ci} / \mathrm{hr}$. This dust stream is actually composed of two parts. The first is from the primary crusher, which processes ore 240 days/yr at a rate of $1895 \mathrm{ton} / \mathrm{hr}$. The crushed ore is then stored and processed through the rest of the mill at a rate of $1377 \mathrm{ton} / \mathrm{hr}$ for 330 days/yr. After being stored, the ore is crushed again and ground, which also contributes to the previously mentioned $327 \mathrm{lb} / \mathrm{hr}$ of dust. This figure represents the maximum dust emission value that would be released during all 
TABLE 3.9. Estimated Waste Control Costs for Palmer, Michigan, Mine, Mill, and Refinery(a)

\begin{tabular}{|c|c|c|c|}
\hline Generated Wastes & Type of Control & $\begin{array}{c}\text { Capital } \\
\text { Cost }(\$ 1000) \\
\end{array}$ & $\begin{array}{c}\text { Annual } \\
\text { Cost }(\$ 1000) \\
\end{array}$ \\
\hline \multicolumn{4}{|l|}{ Mine } \\
\hline$\overline{\text { Mine Water }}$ & $\begin{array}{l}\text { 3-acre settling pond, } \\
\text { piping and pumps to } \\
\text { mill and surface waters }\end{array}$ & 236.0 & 101.0 \\
\hline Mine Dust & $\begin{array}{l}\text { Spray equipment and ore } \\
\text { storage wind barriers }\end{array}$ & 156.0 & 104.0 \\
\hline \multicolumn{4}{|l|}{ Mill } \\
\hline $\begin{array}{l}\text { Dust from Unloading, } \\
\text { Crushing, and Grinding }\end{array}$ & $\begin{array}{l}\text { Four } 50,000-c f m \text { cyclone } \\
\text { systems }\end{array}$ & 139.0 & 87.7 \\
\hline $\begin{array}{l}\text { Dust from Drying, } \\
\text { Magnetic Separating, } \\
\text { and Loading }\end{array}$ & $\begin{array}{l}60,000 \text {-cfm wet- } \\
\text { impingement scrubber } \\
\text { system }\end{array}$ & 108.0 & 66.7 \\
\hline Liquid Waste & $\begin{array}{l}200 \text {-acre clay-lined } \\
\text { tailings pond with } \\
\text { recycle and distribu- } \\
\text { tion system to mill }\end{array}$ & $7,222.0$ & $2,290.0$ \\
\hline \multicolumn{4}{|l|}{ Refinery } \\
\hline $\begin{array}{l}\text { Dust from Unloading } \\
\text { and Grinding }\end{array}$ & $\begin{array}{l}10,000-c f m \text { baghouse filter } \\
\text { system }\end{array}$ & 49.5 & 23.9 \\
\hline $\begin{array}{l}\text { Drying and Ignition } \\
\text { Dust }\end{array}$ & $\begin{array}{l}16,000 \text {-cfm low-energy } \\
\text { venturi scrubber system }\end{array}$ & 36.9 & 25.1 \\
\hline Packaging Dust & $\begin{array}{l}3,000-\mathrm{cfm} \text { baghouse filter } \\
\text { system }\end{array}$ & 17.8 & 7.7 \\
\hline $\begin{array}{l}\text { By-Product Recovery } \\
\text { Dust }\end{array}$ & $\begin{array}{l}24,000-c f m \text { wet- } \\
\text { impingement scrubber } \\
\text { system }\end{array}$ & 44.7 & 26.9 \\
\hline Liquid Wastes & $\begin{array}{l}20-\text { acre tailings pond with } \\
\text { recycle and distribu- } \\
\text { tion systems }\end{array}$ & 993.0 & 423.0 \\
\hline $\begin{array}{l}\text { Tailings Pond Beach } \\
\text { Dust }\end{array}$ & $\begin{array}{l}\text { Portable chemical } \\
\text { spraying equipment }\end{array}$ & 6.5 & 5.8 \\
\hline $\begin{array}{l}\text { Tailings Pond } \\
\text { Radioactivity }\end{array}$ & $\begin{array}{l}\text { 6-ft compacted earth } \\
\text { cover with } 6 \text { in. rock }\end{array}$ & 254.0 & 2.5 \\
\hline Total Costs & & $\overline{9,260}$ & $\overline{3,170}$ \\
\hline
\end{tabular}

(a) Appendices $E$ and $F$ present detailed analyses of the capital and annual costs. 
of the time that the mill is operating. The percentage of ${ }^{232}$ Th in the dust is of the same as that in the ore being crushed and ground (0.053). The dust from drying, magnetic separating, and loading is released at a rate of $2.5 \mathrm{ton} / \mathrm{hr}$ of which $0.1 \mathrm{lb} / \mathrm{hr}$ is ${ }^{232} \mathrm{Th}$. The radioactive release rate for this dust stream is $6.0 \times 10^{-5} \mathrm{Ci} / \mathrm{hr}$ from all radioactive sources.

The airborne wastes are controlled by individual systems. To control the dust from unloading, crushing, and grinding, a 200,000-cfm cyclone system will be installed to collect the dust. Half of this cyclone system will be used on the primary crusher and will be shut down when it is not in use. The capital cost for these control systems is $\$ 139,000$ and the annual cost is $\$ 87,700$. The dust from drying, magnetic separating, and loading will be controlled by a 60,000-cfm wet-impingement scrubber system. The capital cost of this system is $\$ 108,000$ and the annual cost is $\$ 66,700$. All of the dust collected by the above systems will be periodically recycled from the dust collectors back into the main process stream.

The final waste stream is the liquid discharged from the dewatering process. This stream has a flow rate of $3100 \mathrm{gpm}$ and a radioactive release rate of $3.6 \times 10^{-2} \mathrm{Ci} / \mathrm{hr}$, which is higher than the two dust streams. The liquid wastes are piped to a tailings pond where the solids are allowed to precipitate. From this 200 -acre pond, $\simeq 3 / 4$ of the water is recycled to the mill for use as process water and the rest is allowed to evaporate or, if permissable, drain into the natural surface water.

The 200-acre tailings pond will have a clay core and a clay liner to keep seepage low ( 0 to $3 \%$ ) and a distribution system to spread the solids evenly throughout the pond. The total capital cost of the tailings pond, including the recycle system, is $\$ 7,220,000$ and the annual cost is $\$ 2,290,000$.

The total capital cost for the Palmer, Michigan, mill is $\$ 7,470,000$ and the total annual cost is $\$ 2,440.000$, as shown in Table 3.9. The tailings pond and recycle system costs are $\simeq 97 \%$ of the total capital cost and $\simeq 94 \%$ of the total annual cost. 


\subsubsection{Refinery Generated Wastes}

The Palmer, Michigan, refinery processes the $5.2 \% \mathrm{ThO}_{2}$ concentrate from the Palmer, Michigan, mill and produces a $99 \% \mathrm{ThO}_{2}$ powder. The detailed flowsheet and calculations of the radioactive wastes are presented in Appendix $D$ and summarized in Figure 3.9. There are four dust streams that need to be controlled and five liquid streams that empty into the central tailings pond.

The four dust streams vary in size and contain different amounts of radioactivity. The dust from unloading and grinding the concentrate is emitted at a rate of $0.95 \mathrm{lb} / \mathrm{hr}$ and has a radioactive release rate of $2.6 \times 10^{-5} \mathrm{Ci} / \mathrm{hr}$. The percentage ${ }^{232}$ Th in the dust stream is the same as that in the entering concentrate. The amount of dust from the ignition and drying process is quite small, although the stream has a release rate of $1200 \mathrm{lb} / \mathrm{hr}$ consisting mainly of steam. Only $0.8 \mathrm{lb} / \mathrm{hr}$ of ${ }^{232} \mathrm{Th}$ is released in this stream, which has a radioactive release rate from all radioactive sources of $8.0 \times 10^{5} \mathrm{Ci} / \mathrm{hr}$. The packaging dust stream has a waste release rate of only $0.16 \mathrm{lb} / \mathrm{hr}$ but, since the ${ }^{232} \mathrm{Th}$ concentration is high $(\approx 87 \%)$, the radioactive release rate $\left(1.4 \times 10^{-5} \mathrm{Ci} / \mathrm{hr}\right)$ is high on a per unit weight basis. The by-product dust is emitted in a 3.2 ton/hr stream, but most of this stream, like the ignition and drying dust stream mentioned previously, is water. Although this is the largest stream emitted, it has the lowest radioactive release rate $(3.7 \mathrm{x}$ $\left.10^{-6} \mathrm{Ci} / \mathrm{hr}\right)$. The amount of ${ }^{232} \mathrm{Th}$ is quite $10 \mathrm{w}$ in this stream $(0.0062 \mathrm{lb} / \mathrm{hr})$. The majority of the radioactivity is from the uranium and its daughter products that are being recovered as by-products.

A separate system will be used to control each of the four dust streams. To control the unloading and grinding dust, a system composed of fans, hoods, and a 10,000-cfm baghouse filter unit will be installed. The capital cost of this system is $\$ 49,5000$ and the annual cost is $\$ 23,900$. The ignition and drying dust will be controlled by a 16,000-cfm low-energy venturi scrubber system. The capital cost of this is $\$ 36,900$ and the annual cost is $\$ 25,100$. The packaging dust stream, though small, needs to be tightly controlled because of its 


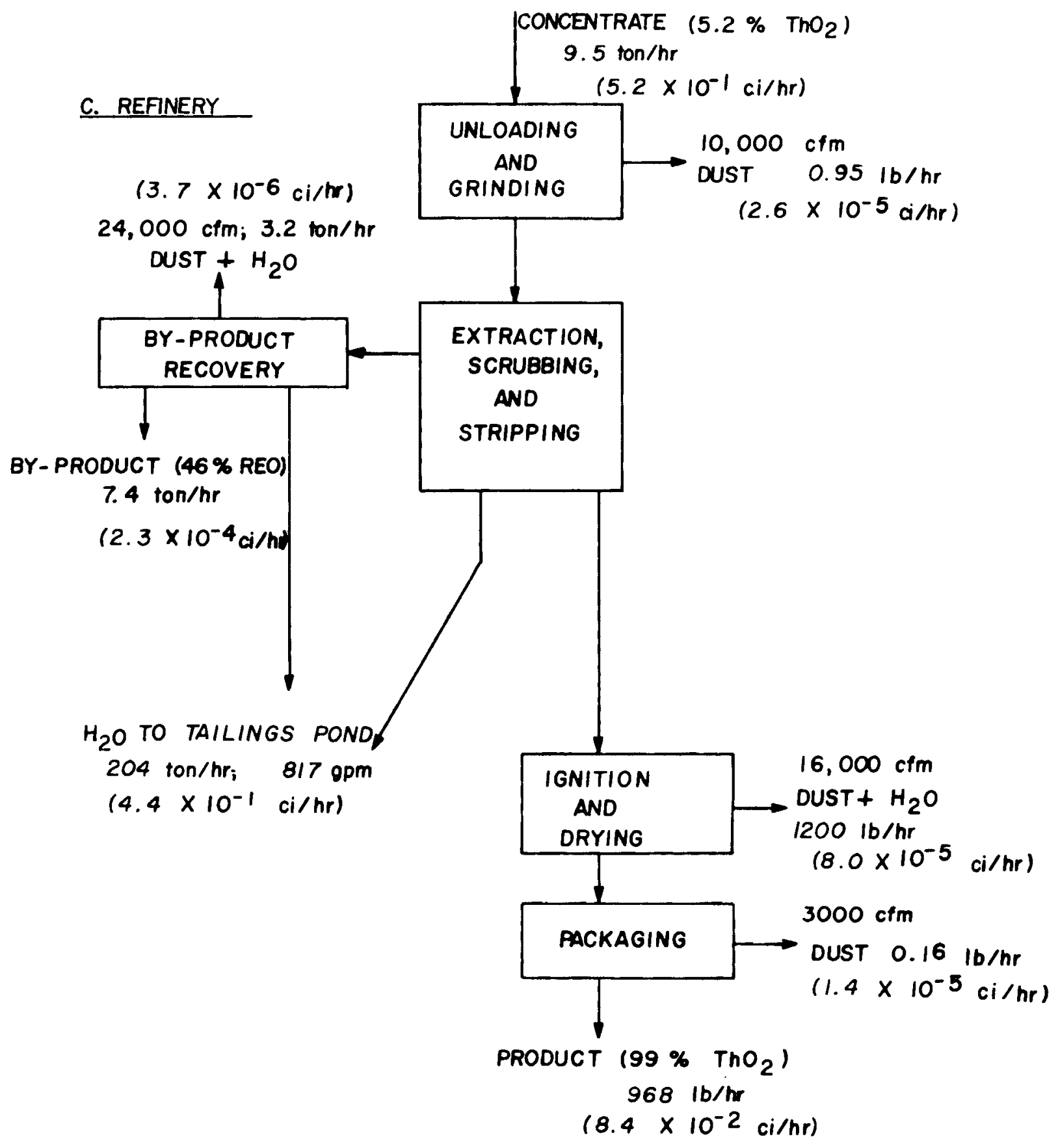

FIGURE 3.9. Palmer, Michigan, Refinery Effluents 
high radioactivity per unit weight. A 3,000-cfm baghouse filter unit will be used to control this stream with a capital cost of $\$ 17,800$ and an annual cost of $\$ 7,700$. Finally, the by-product recovery dust stream--the largest dust stream will--need a 24,000-cfm wet-impingement scrubber to control its dust. The capital cost of this system is $\$ 44,700$ and the annual cost is $\$ 26,900$.

The five filtration liquid streams all flow into the central tailings pond. The first filtration stream contains $\simeq 94 \%$ of the ${ }^{232}$ Th entering the pond. It flows into the pond at a rate of $817 \mathrm{gpm}$. The radioactive release rate of $4.4 \times 10^{-1} \mathrm{Ci} / \mathrm{hr}$ is the most radioactive of any stream, including the two product streams, leaving the refinery. The tailings pond retains $\approx 84 \%$ of the entering radioactivity. The reason for this large amount of radioactivity, compared to the other waste streams, is that most of the daughter products of thorium and uranium accumulate in the pond, as well as considerable amounts of uranium and thorium.

The proposed pond will cover 20 acres and will have a 3-ft clay core to keep the seepage rate low. The tailings pond system will also include a recycle system for $\simeq 3 / 4$ of the water. The total capital cost of the tailings pond and the associated recycle system is $\$ 993,000$ and the annual cost is $\$ 423,000$. At this tailings pond like the others, beach dust will have to be kept tied down so that the dry tailings do not enter the atmosphere. The capital cost of the equipment for beach dust control is $\$ 6,500$ and the annual cost is $\$ 5,800$. To decommission the tailings pond after the refinery is closed, a cover of $6 \mathrm{ft}$ of earth and 6 in. of rock will be placed over the pond. This should prevent any radioactive material from spreading to the external environment. The capital cost of the tailings pond cover $(\$ 254,000)$ is not incurred until after the refinery shuts down. A sinking fund with an annual cost of $\$ 2500$ would be established to pay for the cover.

The total capital cost of environmental control technology for the Palmer, Michigan, refinery is $\$ 1,400,000$ and the total annual cost is $\$ 515,000$, as shown in Table 3.9. The tailings pond, with the pond cover and beach dust control, makes up $\simeq 89 \%$ of the capital cost and $\simeq 84 \%$ of the annual cost of the refinery control equipment. The capital cost of the mill's environmental 
control methods amounts to $\simeq 81 \%$ of the total capital cost of $\$ 9,260,000$ while the mill's projected annual costs are $\simeq 77 \%$ of the Palmer, Michigan, deposit's total annual cost of $\$ 3,170,000$.

\subsubsection{Bald Mountain Deposit $(7)$}

\subsubsection{Mine Generated Wastes}

The open-pit mine at Bald Mountain, Wyoming, will produce 10,000 tons of ore per day with an average $\mathrm{ThO}_{2}$ grade of $0.00951 \%$. It will have two types of wastes generated at the mine site: dust and water, as shown in Figure 3.10.

At Bald Mountain like the Palmer, Michigan, mine, there are 3 tons of waste rock for every 10 tons of ore mined; so $125 \mathrm{ton} / \mathrm{hr}$ of waste rock are removed from the mine. It was assumed that little radiation is associated with this waste rock and that there will be no harmful effects from storing the rock onsite.

About $0.125 \%$ of the ore mined or $1040 \mathrm{lb} / \mathrm{hr}$ will potentially be released as dust. (a) At the Bald Mountain mine like the Palmer, Michigan, open-pit mine, the dust cannot be completely controlled. To keep the dust levels low, the roads, yards, and storage piles will be wet down by spray equipment and the ore storage piles will be sheltered from the wind. The total capital cost for dust control at the mine is $\$ 94,000$ and the annual cost is $\$ 71,300$. Most of the capital costs (50.2\%) are for the wind barriers. All of the costs are shown in Table 3.10.

The mine water was assumed to contain $1 \mathrm{ppm} \mathrm{Th0} \mathrm{T}_{2}$ in equilibrium with both its daughter products and $238 \mathrm{U}$ and $235_{U}$. The flow rate was assumed to be $1000 \mathrm{gpm}$, which is less then at Palmer, Michigan, because the mine is smaller and there is less precipitation. The total radioactive release rate for the mine water is $2.6 \times 10^{-4} \mathrm{Ci} / \mathrm{hr}$. (a) Since this rate is not very high, a 2-acre settling pond that will allow the solids to settle out is the only treatment method needed. The water can then be used in the mill or released to the local surface water. The capital cost for the settling pond, pipes, and pumps is $\$ 175,000$ and the annual cost is $\$ 78,300$.

(a) Refer to Appendix C for detailed calculations. 


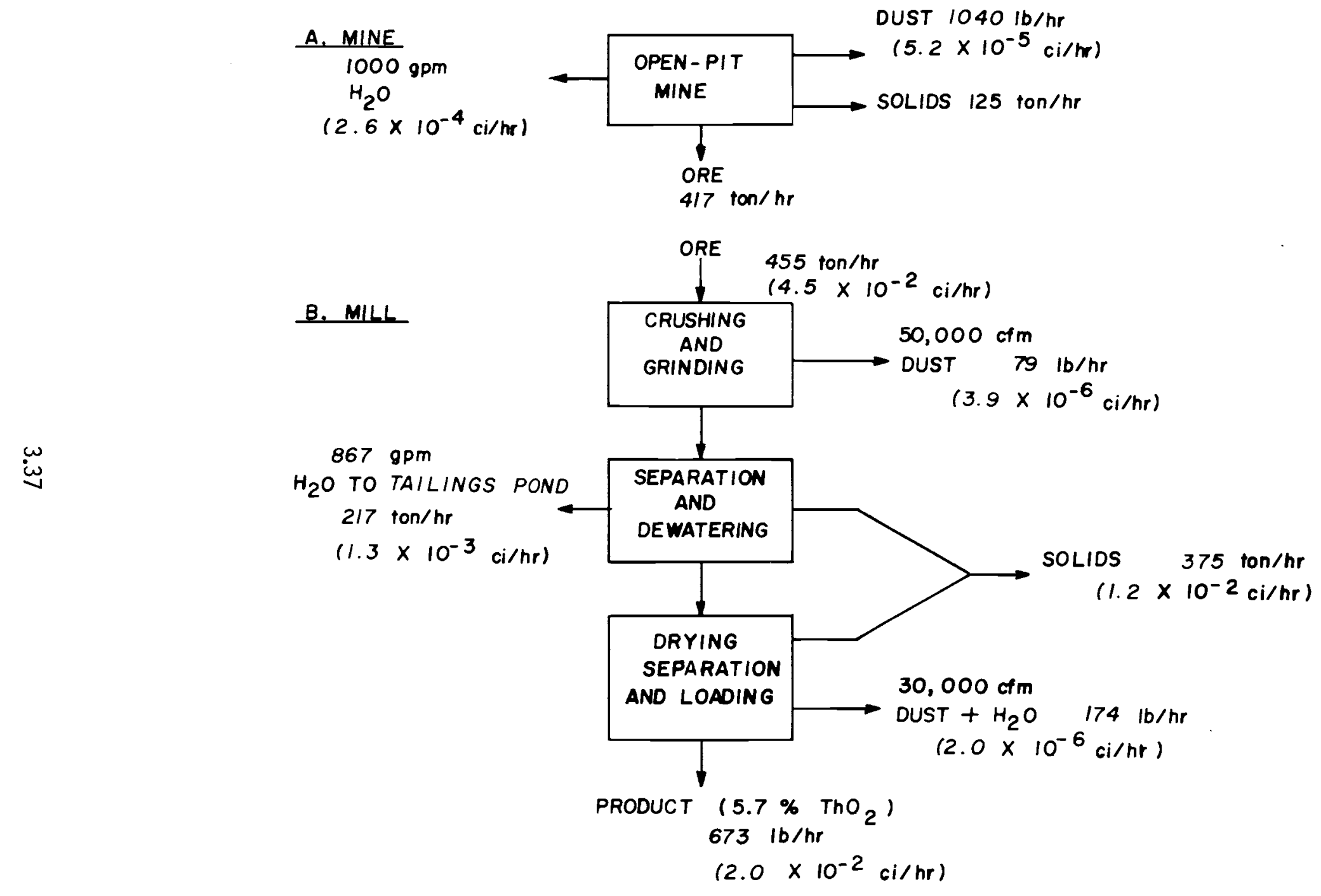

FIGURE 3.10 Bald Mountain Mine and Mi11 Effluents 
TABLE 3.10. Estimated Waste Control Costs for Bald Mountain Mine, Mill, and Refinery(a)

\begin{tabular}{|c|c|c|c|}
\hline Generated Wastes & Type of Control & $\begin{array}{c}\text { Capital } \\
\text { Cost }(\$ 1000) \\
\end{array}$ & $\begin{array}{c}\text { Annual } \\
\text { Cost }(\$ 1000)\end{array}$ \\
\hline \multicolumn{4}{|l|}{ Mine } \\
\hline$\overline{\text { Mine Water }}$ & $\begin{array}{l}\text { 2-acre settling pond, } \\
\text { piping and pumps to } \\
\text { mill and surface waters }\end{array}$ & 174.7 & 78.3 \\
\hline Mine Dust & $\begin{array}{l}\text { Spray equipment and ore } \\
\text { storage wind barriers }\end{array}$ & 94.4 & 71.3 \\
\hline \multicolumn{4}{|l|}{ Mill } \\
\hline $\begin{array}{l}\text { Dust from Unloading, } \\
\text { Crushing, and } \\
\text { Grinding }\end{array}$ & $\begin{array}{l}50,000-\mathrm{cfm} \text { cyclone } \\
\text { system }\end{array}$ & 34.7 & 26.7 \\
\hline $\begin{array}{l}\text { Dust from Drying, } \\
\text { Magnetic Separating, } \\
\text { and Loading }\end{array}$ & $\begin{array}{l}30,000 \text {-cfm wet- } \\
\text { impingement scrubber } \\
\text { system }\end{array}$ & 54.0 & 35.0 \\
\hline Liquid Waste $s$ & $\begin{array}{l}40 \text {-acre clay-lined tail } \\
\text { ings pond with recycle } \\
\text { and distribution systems }\end{array}$ & $2,350.0$ & 795.0 \\
\hline \multicolumn{4}{|l|}{ Refinery } \\
\hline $\begin{array}{l}\text { Unloading and } \\
\text { Grinding Dust }\end{array}$ & $\begin{array}{l}10,000-c f m \text { cyclone } \\
\text { system }\end{array}$ & 8.8 & 6.1 \\
\hline $\begin{array}{l}\text { Drying and Ignition } \\
\text { Dust }\end{array}$ & $\begin{array}{l}6,000-c f m \text { low-energy. } \\
\text { venturi system }\end{array}$ & 16.0 & 10.0 \\
\hline Packaging Dust & $\begin{array}{l}1,200 \text {-cfm baghouse filter } \\
\text { system }\end{array}$ & 8.2 & 4.2 \\
\hline $\begin{array}{l}\text { By-Product Recovery } \\
\text { Dust }\end{array}$ & $\begin{array}{l}15,000-\mathrm{cfm} \text { wet- } \\
\text { impingement scrubber } \\
\text { system }\end{array}$ & 30.0 & 18.7 \\
\hline Liquid Waste & $\begin{array}{l}\text { 6-acre pond clay-lined } \\
\text { tailings pond with no } \\
\text { recycle system }\end{array}$ & 209.0 & 62.1 \\
\hline $\begin{array}{l}\text { Tailings Pond Beach } \\
\text { Dust }\end{array}$ & $\begin{array}{l}\text { Portable chemical } \\
\text { spraying equipment }\end{array}$ & 4.0 & 2.6 \\
\hline $\begin{array}{l}\text { Tailings Pond } \\
\text { Radioactivity }\end{array}$ & $\begin{array}{l}6 \text {-ft compacted earth } \\
\text { cover with } 6 \text { in. rock }\end{array}$ & 96.9 & 4.8 \\
\hline Total Costs & & $\overline{3,080}$ & $\overline{1,110}$ \\
\hline
\end{tabular}
(a) Detailed calculations of the capital and annual costs are shown in
Appendices $E$ and $F$. 
The total capital cost for the mine environmental control methods and equipment at Bald Mountain is $\$ 269,000$ and the annual cost is $\$ 150,000$, as shown in Table 3.10.

\subsubsection{Mill Generated Wastes}

The Bald Mountain mill processes the $0.00951 \% \mathrm{ThO}_{2}$ ore from the Bald Mountain mine and produces a $5.7 \% \mathrm{ThO}_{2}$ concentrate. At the Bald Mountain mill like the one at Palmer, Michigan, there are two solid waste streams, two dust streams, and one liquid waste stream. The detailed calculations of the radioactivity of each of these streams are presented in Appendix $D$ and summarized in Figure 3.10 .

There are $375 \mathrm{ton} / \mathrm{hr}$ of solids returned to the mine from two areas of the mi11: the dewatering process and the magnetic separators. Most (99\%) of the ore is from the dewatering process. The waste, which is $\simeq 80 \%$ solid, will be trucked back to the mine and used as landfill.

The airborne wastes originate in three areas and combine into two streams. As in the Palmer, Michigan, mill, the dust stream from crushing and grinding the ore is composed of two parts. The first part is from the primary crusher, which emits $45.5 \mathrm{lb} / \mathrm{hr}$ and operates 240 days/yr. The second part is from the secondary crusher and grinders, which emit dust at a rate of $33 \mathrm{lb} / \mathrm{hr}$ and operate 330 days/yr. These two dust streams will be combined and treated together. The combined radioactive release rate is $3.9 \times 10^{-6} \mathrm{Ci} / \mathrm{hr}$. This rate is the maximum value emitted when both the primary and secondary crushers are operating, which is $\simeq 2 / 3$ of the time. The percentage of ${ }^{232} \mathrm{Th}$ in this dust is the same as that in the ore being crushed. The dust from drying, magnetic separating, and loading, which has a radioactive release rate of $2.0 \mathrm{x}$ $10^{-6} \mathrm{Ci} / \mathrm{hr}$, from all sources is released at a rate of $174 \mathrm{lb} / \mathrm{hr}$, of which of $3.4 \times 10^{-3} \mathrm{lb} / \mathrm{hr}$ is ${ }^{232} \mathrm{Th}$.

Two systems will be used to control the airborne waste streams. One cyclone dust collector will be used on the stream from unloading, crushing, and grinding the ore. This system will operate at 50,000 cfm and will be used for both the primary crushing operation and the secondary crushing and grinding operation. The capital cost of this system is $\$ 34,700$ and the annual cost 
is $\$ 26,700$. The dust from drying, magnetic separating, and loading will be collected by a 30,000-cfm wet-impingement scrubber system. The capital cost of this system is $\$ 54,000$ and the annual cost is $\$ 35,000$. As in the Palmer, Michigan, mill, all of the dust collected in the above systems will be periodically recycled back into the main process stream.

The liquid waste from the dewatering process is the largest and most radioactive waste stream in the mill. The liquid wastes flow into a tailings pond at a rate of $867 \mathrm{gpm}$ with a radioactive release rate of $1.3 \times 10^{-3} \mathrm{Ci} / \mathrm{hr}$. A 40-acre clay-lined settling pond will be used to allow the solids to precipitate. Approximately $3 / 4$ of the liquid will be recycled and used as process water in the mill; the rest of the water will be allowed to evaporate or drain into the surface water. The clay lining of the pond should keep the seepage rate low ( 0 to $3 \%$ ). A distribution system will be used to spread the solids evenly on the pond bottom. The total capital cost of the tailings pond, including the recycle system for the liquids and the distribution system for the solids, is $\$ 2,350,000$ and the annual cost is $\$ 795,000$.

The total capital cost of the environmental control techniques and equipment for the Bald Mountain mill is $\$ 2,440,000$ and the total annual cost is $\$ 856,000$, as shown in Table 3.10. The tailings pond and associated systems make up $\simeq 96 \%$ of the capital cost and $\simeq 93 \%$ of the annual cost of the Bald Mountain mill's environmental control expenses.

\subsubsection{Refinery Generated Wastes}

The Bald Mountain refinery processes the $5.7 \% \mathrm{ThO}_{2}$ concentrate from the Bald Mountain mill and produces a $99 \% \mathrm{ThO}_{2}$ powder. The detailed flowsheet and waste radioactivity calculations are presented in Appendix $D$ and summarized in Figure 3.11. There are four dust streams that need to be controlled and five liquid streams that empty into the central tailings pond.

The airborne wastes are divided into four dust streams. The dust from unloading and grinding the concentrate is released at the rate of $0.03 \mathrm{lb} / \mathrm{hr}$ with a radioactive release rate of $8.9 \times 10^{-7} \mathrm{Ci} / \mathrm{hr}$. The percentage of ${ }^{232} \mathrm{Th}$ in the dust is the same as that in the concentrate being unloaded and ground. 


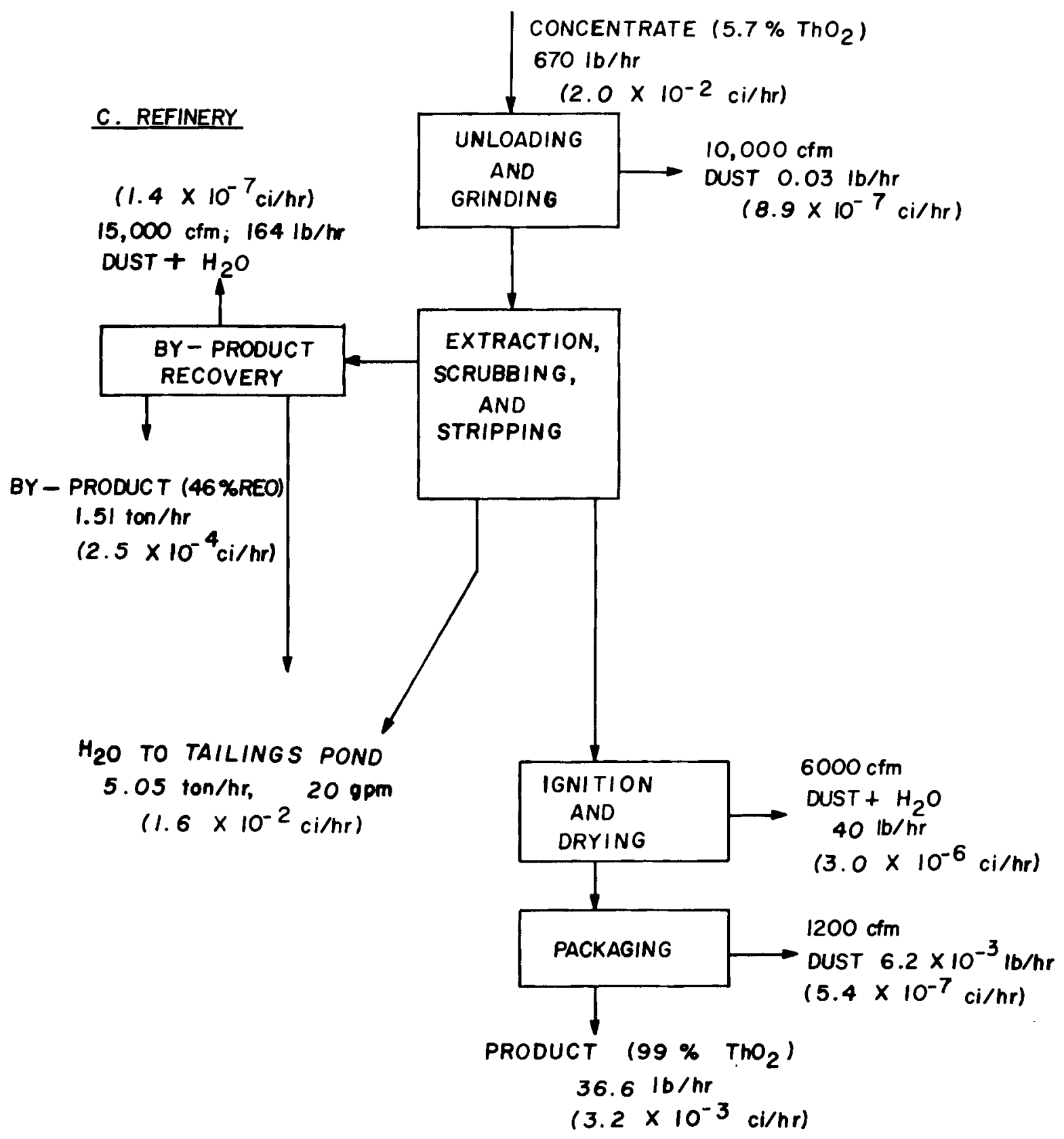

FIGURE 3.11 Bald Mountain Refinery Generated Wastes 
Only $3.0 \times 10^{-2} \mathrm{lb} / \mathrm{hr}$ of ${ }^{232} \mathrm{Th}$ is released in the ignition and drying process, even though the waste stream flow rate is $40 \mathrm{lb} / \mathrm{hr}$ with a radioactive release rate of $3.0 \times 10^{-6} \mathrm{Ci} / \mathrm{hr}$. Most of the mass is water released in the process. The packaging dust is emitted at the rate of $6.2 \times 10^{-3} \mathrm{1b} / \mathrm{hr}$, which is low, but the radioactive release rate is $5.4 \times 10^{-7} \mathrm{Ci} / \mathrm{hr}$, which is high on a per unit weight basis. The release rate is high because the dust being released is $99 \%{ }^{232} \mathrm{Th}$, the same as the product being packaged. The by-product dust is emitted at the rate of $164 \mathrm{lb} / \mathrm{hr}$. Most of this stream is water emitted when the by-product is dried. The amount of ${ }^{232} \mathrm{Th}$ emitted is $2.3 \times 10^{-4} \mathrm{lb} / \mathrm{hr}$. The total radioactive release rate of $1.4 \times 10^{-7} \mathrm{Ci} / \mathrm{hr}$ makes this the least radioactive stream in the refinery.

Each of the four airborne waste streams has a separate control system. A 10,000-cfm cyclone system will be used to control the dust from unloading and grinding the concentrate. The capital cost of this system is $\$ 8,800$ with an annual cost of $\$ 6,100$. A 6,000 -cfm low-energy venturi scrubber system will be used to control the ignition and drying dust. The capital cost of this system is $\$ 16,000$ and the annual cost is $\$ 10,000$. The packaging dust stream, though small, needs to be closely controlled because its dust is $99 \% \mathrm{ThO}_{2}$. A 1,200-cfm baghouse filter unit will be used to control this stream at a capital cost of $\$ 8,200$ and an annual cost of $\$ 4,200$. The largest dust stream, the by-product recovery dust, will be controlled by a 15,000-cfm wetimpingement scrubber. The capital cost of this system is $\$ 30,000$ with an annual cost of $\$ 18,700$. As before, all of the dust collected will be recycled back into the main process stream.

The five filtration liquid streams all flow into the central tailings pond. The first filtration stream contains $\approx 93 \%$ of the ${ }^{232}$ Th entering the pond and flows into the pond at a rate of $4 \mathrm{gpm}$. The radioactive release rate of the combined streams is $1.6 \times 10^{-2} \mathrm{ci} / \mathrm{hr}$ and is the largest of any waste stream from the refining process, including the product and by-product streams. The tailings pond retains $82 \%$ of the entering radioactivity. The pond's high radioactivity may be explained by the fact that most of the thorium and uranium daughter products, as well as considerable amounts of thorium and uranium, end up in the tailings pond. 
The proposed tailings pond is 6 acres in size with a $3-\mathrm{ft}$ clay liner to keep the seepage low (0 to 3\%). This tailings pond, unlike the Palmer, Michigan, tailings pond, has no recycle system because all of the liquid should evaporate. The total capital cost of the tailings pond at the Bald Mountain refinery is $\$ 209,000$ while the annual cost is $\$ 62,100$.

Like the other tailings ponds, the beach dust here must be controlled to minimize the release of dust via the wind. The capital cost of the equipment to keep the beach dust tied down is $\$ 4,000$ while the annual cost is $\$ 2,600$. After the refinery operation ends, the tailings pond will be covered with $6 \mathrm{ft}$ of earth and $6 \mathrm{in}$. of rock to contain the radioactive tailings. The capital cost of this tailings pond cover is $\$ 96,900$.

The total capital cost for the Bald Mountain refinery's environmental control techniques and equipment is $\$ 373,000$ while the annual cost is $\$ 109,000$, as shown in Table 3.10. The capital cost for the tailings pond, including beach dust control and pond cover, is $\simeq 57 \%$ of the annual cost of controlling the radioactive wastes. For the Bald Mountain deposit, the capital cost of the mill's environmental control methods amount to $\simeq 79 \%$ of the total capital cost of $\$ 3,080,000$ and the mill's annual costs are $\sim 76 \%$ of the total annual cost of $\$ 1,110,000$.

\subsubsection{Conway Granite Deposit $(2,3,4,9)$}

\subsubsection{Mine Generated Wastes}

The open-pit mine at the Conway Granite site in New Hampshire produces 100,000 tons of ore per day with an average $\mathrm{ThO}_{2}$ grade of $0.006 \%$. As shown in Figure 3.12, there are two radioactive waste streams leaving the mine: one airborne stream and one water stream.

There will be 2-tons of waste rock for every 10 tons of ore mined. The waste rock will be stored onsite, either in the mine or adjacent to it. It will cause no external environmental effects because the radioactivity is quite low. 
A. MINE

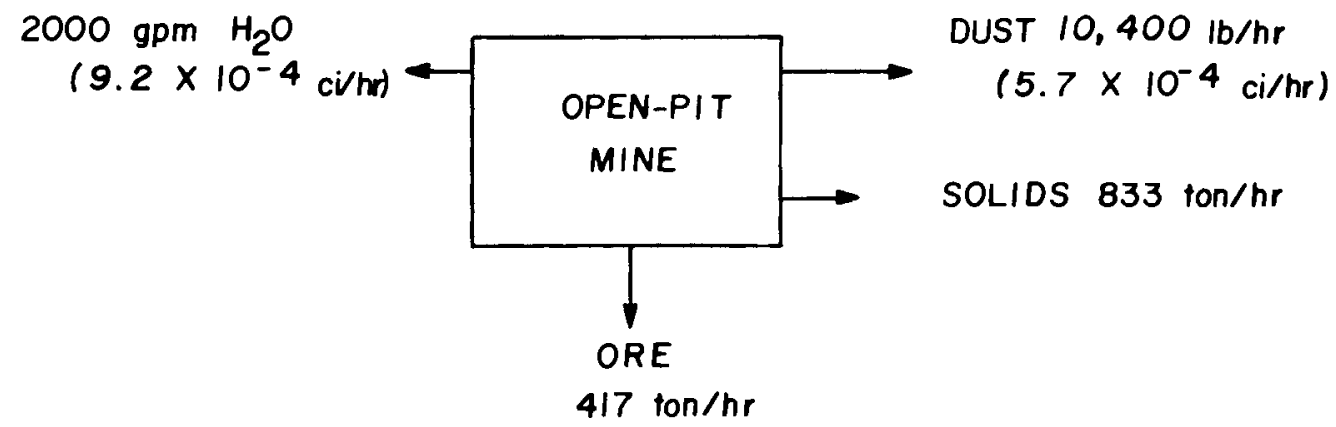

B. MILL

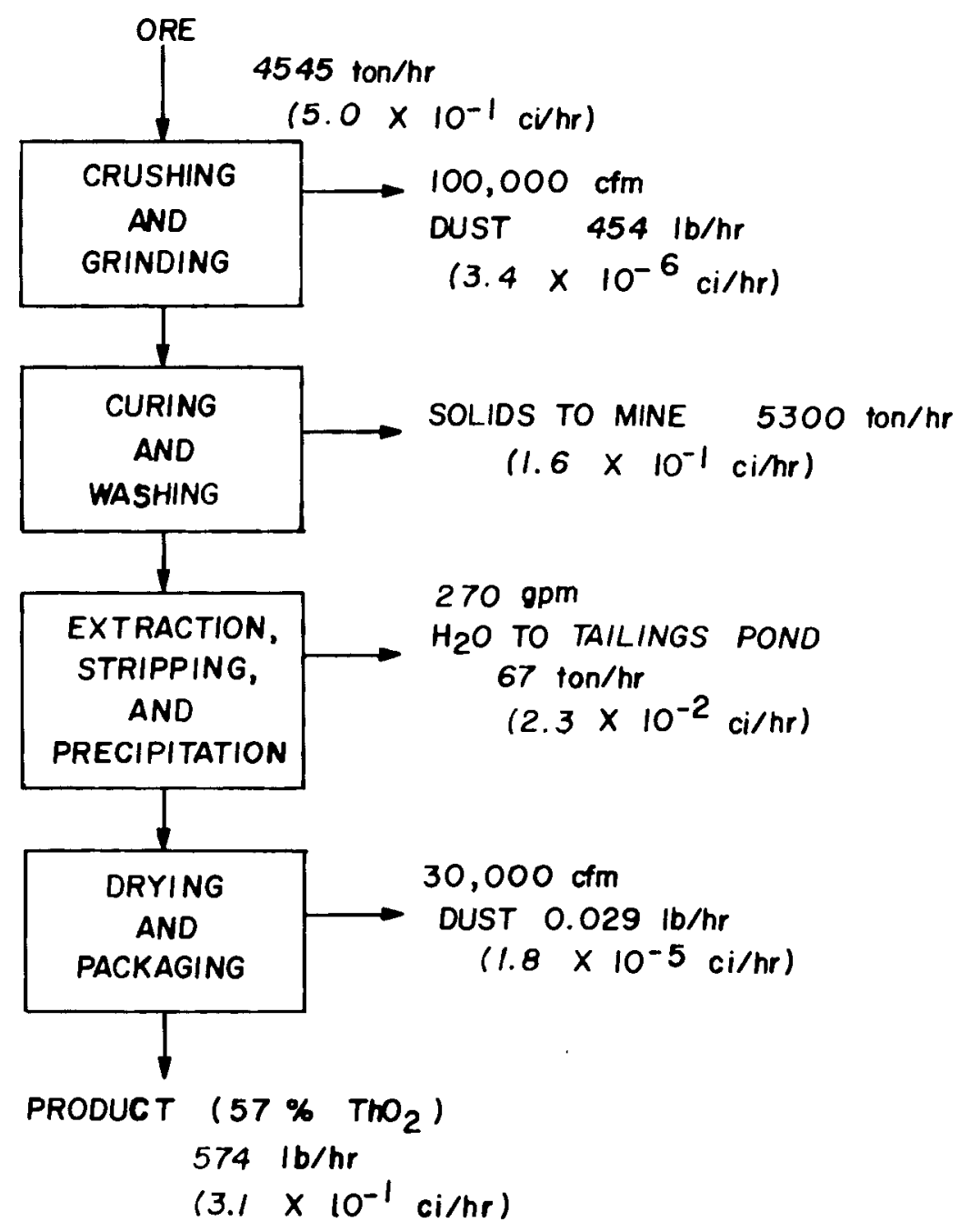

FIGURE 3.12. Conway Granite Mine and Mill Generated Wastes 
The airborne waste stream consists of $10,400 \mathrm{lb} / \mathrm{hr}$ of dust released in the mining operations if $\simeq 0.125 \%$ of the ore mined is dust. This stream has a radioactive release rate of $5.7 \times 10^{-4} \mathrm{Ci} / \mathrm{hr}$. Due to the open structure of the mine, the dust will have to be controlled by careful mining methods, wetting down the mining and transportation areas, and placing wind barriers around the ore storage piles. The capital cost of these various methods is $\$ 225,000$ and the annual cost is $\$ 169,000$. The majority $(\approx 67 \%)$ of the capital cost is for the ore storage pile wind barriers.

Because of the low grade of the ore mined, the mine water is assumed to contain only $1 \mathrm{ppm}$ of $\mathrm{ThO}_{2}$. In the water, $0.88 \mathrm{lb} / \mathrm{hr}$ of ${ }^{232} \mathrm{Th}$ is removed per $\mathrm{hr}$ from the mine assuming a flow rate of $2000 \mathrm{gpm}$. The radioactivity level is $9.2 \times 10^{-4} \mathrm{Ci} / \mathrm{hr}$, low enough for the water to be re-used in the mill after the solids are allowed to precipitate in a 4-acre settling pond. The excess water not needed in the mill may be discharged to surface waters. The capital cost for pumps, pipes, and the pond are $\$ 293,000$ while the annual cost is $\$ 153,000$.

The total capital cost of controlling the mine wastes from the Conway Granite Mine is $\$ 518,000$ with a total annual mine control cost of $\$ 322,300$ as shown in Table 3.11 .

\subsubsection{Mill Generated Wastes}

The Conway Granite mill processes $0.006 \% \mathrm{ThO}_{2}$ ore from the Conway Granite mine and produces a $57 \% \mathrm{ThO}_{2}$ concentrate. One solid stream, two dust streams, and one liquid stream come from the mill. The detailed calculations of the radioactive release rates of all of these streams are presented in Appendix $D$ and summarized in Figure 3.12 .

A large amount of solids are to be returned to the mine after being dewatered. Lime may be added to the waste stream to neutralize it so that it can be disposed of safely at the mine site. The solid waste that is to be disposed of in the mine contains $1.6 \times 10^{-1} \mathrm{Ci} / \mathrm{hr}$ of radioactivity.

The dust stream from crushing and grinding the ore is generated at a rate of $454 \mathrm{lb} / \mathrm{hr}$ with a radioactive release rate of $3.4 \times 10^{-6} \mathrm{Ci} / \mathrm{hr}$. The dust is assumed to have the same percentage of ${ }^{232} \mathrm{Th}$ as the ore being crushed. 
TABLE 3.11. Estimated Waste Control Gosts for Conway Granite Mine, Mill, and Refinery(a)

\begin{tabular}{|c|c|c|c|}
\hline Generated Wastes & Type of Control & $\begin{array}{l}\text { Capital } \\
\text { cost }(\$ 1000)\end{array}$ & $\begin{array}{c}\text { Annual } \\
\text { Cost }(\$ 1000) \\
\end{array}$ \\
\hline ine Water & $\begin{array}{l}\text { 4-acre settling pond, } \\
\text { piping and pumps to } \\
\text { mill and surface waters }\end{array}$ & 293.0 & 153.0 \\
\hline line Dust & $\begin{array}{l}\text { Spray equipment and ore } \\
\text { storage wind barriers }\end{array}$ & 225.0 & 169.0 \\
\hline $\begin{array}{l}\frac{i 1 l}{\text { ust from Unloading, }} \\
\text { rushing, and } \\
\text { rinding }\end{array}$ & $\begin{array}{l}\text { two } 50,000-\mathrm{cfm} \text { cyclone } \\
\text { systems }\end{array}$ & 69.5 & 53.0 \\
\hline $\begin{array}{l}\text { rying and Packaging } \\
\text { ust }\end{array}$ & $\begin{array}{l}30,000-c f m \text { wet- } \\
\text { impingement scrubber } \\
\text { system }\end{array}$ & 54.0 & 34.9 \\
\hline iquid Wastes & $\begin{array}{l}20 \text {-acre clay-lined tailings } \\
\text { pond with recycle and } \\
\text { distribution systems }\end{array}$ & 908.0 & 368.0 \\
\hline
\end{tabular}

\section{Refinery}

\begin{tabular}{|c|c|c|c|}
\hline Waste Sludge & $\begin{array}{l}2.5 \text {-acre clay-lined land- } \\
\text { fill pit with trucks } \\
\text { and hoppers }\end{array}$ & 179.0 & 65.5 \\
\hline $\begin{array}{l}\text { Drying and Packaging } \\
\text { Dust }\end{array}$ & $\begin{array}{l}12,000-c f m \text { baghouse filter } \\
\text { and HEPA filter system } \\
\text { with demister }\end{array}$ & 187.0 & 90.6 \\
\hline Liquid Waste & $\begin{array}{l}\text { 10-acre clay-lined tailings } \\
\text { pond with no recycle system }\end{array}$ & 327.0 & 86.0 \\
\hline $\begin{array}{l}\text { Tailings Pond Beach } \\
\text { Dust }\end{array}$ & $\begin{array}{l}\text { Portable chemical } \\
\text { spraying equipment } \\
\text { system }\end{array}$ & 4.0 & 3.1 \\
\hline $\begin{array}{l}\text { Tailings Pond } \\
\text { Radioactivity }\end{array}$ & $\begin{array}{l}6 \text {-ft compacted earth } \\
\text { cover with } 6 \text { in. rock }\end{array}$ & 146.0 & 1.4 \\
\hline Total Costs & & 5,390 &, 025 \\
\hline
\end{tabular}

(a) Detailed calculations of the capital and annual costs are shown in Appendices $E$ and $F$. 
The second dust stream, the dust from drying and packaging the ore, is a much smaller $(0.029 \mathrm{lb} / \mathrm{hr})$ but more radioactive stream $\left(1.8 \times 10^{-5} \mathrm{ci} / \mathrm{hr}\right)$. The higher radioactivity is due to the assumption that the percentage of $\mathrm{ThO}_{2}$ in the dust is the same as that in the concentrate being packaged.

Two control systems will be used to control the airborne waste streams. A system of two 50,000-cfm cyclone dust collectors will be used to control the dust from unloading, crushing, and grinding the ore. The capital cost of this system is $\$ 69,500$ while the annual cost is $\$ 53,000$. A system using a 30,000 cfm wet-impingement scrubber will be needed to control the dust from drying and packaging. The capital cost of this system is $\$ 54,000$ and the annual cost is $\$ 34,900$. All of the solids collected in the above dust control systems will be recycled back into the main mill process streams.

Liquid waste flows into the tailings pond from the precipitation and filtration process. The flow rate is $270 \mathrm{gpm}$ with radioactive release rate of $2.3 \times 10^{-2} \mathrm{Ci} / \mathrm{hr}$. A 20 -acre clay-lined pond will be used to handle this waste. Most of the liquid stream $(\simeq 3 / 4)$ will be returned to the mill for use as process water after the solids have settled out. An auxiliary settling pond will also be needed. Before the liquid is used in the mill, it will flow through the auxilary pond to ensure that all the solids have settled out. The auxilary pond will not need a pond cover when it is decommissioned because the radioactivity level is low. The clay-lining of the pond should minimize seepage $(0$ to $3 \%)$. The recycle and distribution systems will handle most of the liquids. The capital cost of the tailings pond system is $\$ 908,000$ with an annual cost of $\$ 368,000$.

The total capital cost for environmental control of emissions at the Conway Granite mill is $\$ 1,030,000$ while the annual cost is $\$ 456,000$. The mill tailings pond system makes up $\simeq 88 \%$ of the capital cost and $\approx 81 \%$ of the annual cost of controls, as shown in Table 3.11.

\subsubsection{Refinery Generated Wastes}

The Conway Granite refinery processes $57 \% \mathrm{ThO}_{2}$ concentrate and produces a $99 \% \mathrm{ThO}_{2}$ product. This refinery is similar to the stockpile refinery except that a uranium recovery system is added. There are nine waste streams: 
one solid, one dust, and seven liquid streams. The radioactivity in each of these streams is calculated in Appendix $D$ and summarized in Figure 3.13.

The waste sludge stream leaving the refinery is $80 \%$ solids and has a radioactive release rate of $6.8 \times 10^{-3} \mathrm{Ci} / \mathrm{hr}$. This stream is emitted from the refinery at a rate of $660 \mathrm{lb} / \mathrm{hr}$. Because of its radioactivity, this sludge must be buried at an approved landsite. The sludge will be trucked in hoppers to a 2.5-acre clay-lined pit. This method of disposal will be less costly than a conveyer system or slurry line. The capital cost of the sludge pit, the trucks, and the hoppers is $\$ 179,000$ and the annual cost is $\$ 65,500$.

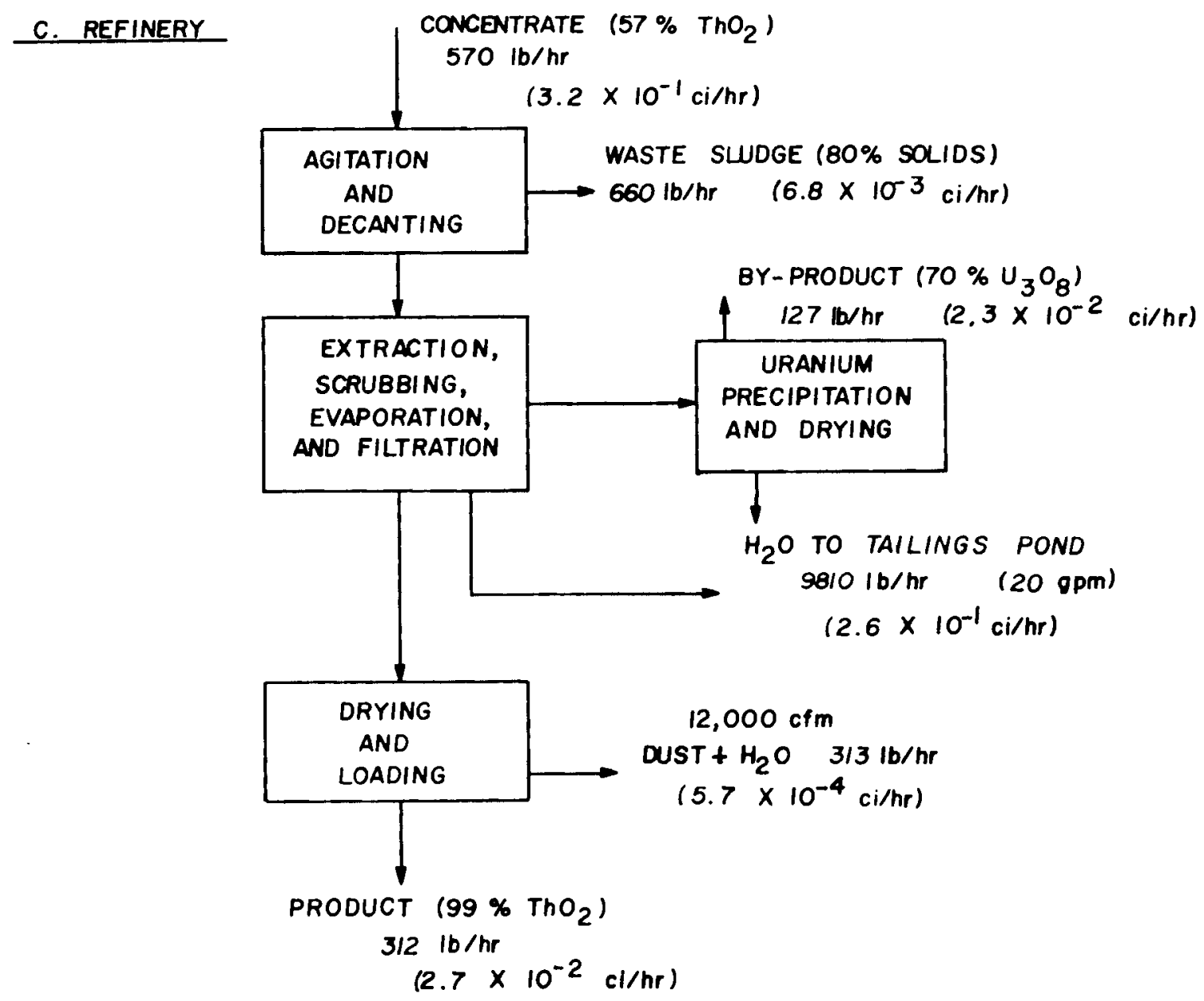

FIGURE 3.13. Conway Granite Refinery Generated Wastes 
The smallest and least radioactive waste stream is the dust stream from drying and loading the concentrate. Most of the $313 \mathrm{lb} / \mathrm{hr}$ of dust given off are water and carbon dioxide from the drying process; however, of this only $5.6 \mathrm{lb} / \mathrm{hr}$ of ${ }^{232} \mathrm{Th}$ are emitted. The $5.7 \times 10^{-4} \mathrm{Ci} / \mathrm{hr}$ radioactivity level is not as large as the levels in other streams in the refinery but, because the dust is $99 \% \mathrm{ThO}_{2}$, the stream must be closely controlled.

A $12,000-c f m$ baghouse filter system with a HEPA filter attached must be installed to control the drying and packaging dust. Because of the amount of water present in the stream being treated, a 1,200-cfm air demister must be installed for the system to operate correctly. The capital cost of the entire system is $\$ 62,300$ and the annual cost is $\$ 90,600$.

The seven liquid streams that flow into the tailings pond are more radioactive than the amount of ${ }^{232} \mathrm{Th}$ would indicate. Most of ${ }^{232} \mathrm{Th},{ }^{238} \mathrm{U}$, and $235 \mathrm{U}$ daughter products empty into this pond. The $2.6 \times 10^{-1} \mathrm{Ci} / \mathrm{hr}$ radioactive release rate is $82 \%$ that of the concentrate being processed. The liquid stream from the plate-and-frame press process has $\simeq 80 \%$ of the ${ }^{232}$ Th entering the pond in it, but, as previously mentioned, it is the daughter products that cause the pond to be highly radioactive. The total flow into the pond is $20 \mathrm{gpm}$.

The refinery tailings pond will be a 10-acre clay-lined pond without a recycle system. The water is too radioactive for it to be used as process water in the refinery. The capital cost of this tailings pond is $\$ 327,000$ while the annual cost is $\$ 86,000$. As with the other tailings ponds, the beach dust must be kept tied down with chemicals. The capital cost of the spray equipment is $\$ 4,000$ and the annual cost is $\$ 3,100$. When the refinery ceases operation, the pond must be covered with $6 \mathrm{ft}$ of earth and $6 \mathrm{in}$. of rock. The capital cost of this pond cover is $\$ 146,000$.

The total capital cost for controls at the Conway Granite refinery is $\$ 842,000$ and the annual cost is $\$ 247,000$. The tailings pond capital cost, including beach dust control and tailings pond cover, is $\approx 57 \%$ of the capital 
cost and $\simeq 37 \%$ of the annual cost for control of the generated wastes at the refinery. The capital cost for waste control from all phases of $\mathrm{ThO}_{2}$ powder production at the Conway Granite deposit is $\$ 2,390,000$ and the annual cost is $\$ 1,025,000$, as shown in Table 3.11 .

\subsection{REFERENCES}

1. W. I. Enderlin, An Assessment of U.S. Domestic Capacity for Producing Reactor-Grade Thorium Dioxide and Controlling Associated Wastes and Effluents. PNL-2593, Pacific Northwest Laboratory, RichTand, WA, February 1978.

2. R. J. Callow, The Industrial Chemistry of Lanthanons, Yttrium, Thorium and Uranium. Pergamon Press, Elmsford, NY, p. 248, 1967.

3. F. L. Cuthbert, Thorium Production Technology. Addison-Wesley, Reading, Massachusetts, 1958.

4. H. A. Wilhe $1 \mathrm{~m}$, The Metal Thorium. Proceedings of Conference on Thorium, American Society for Metals, Cleveland, $\mathrm{OH}, 1958$.

5. S. R. Borrowman and J. B. Rosenbaum, Recovery of Thorium from Ores in Colorado, Idaho, and Montana. USBM-RI-5916, U.S. Bureau of Mines, Denver, C0, 1961.

6. Golden Associates, "Appendix D: Lemhi Pass Model Mine" In Economics of Large-Scale Thorium Oxide Production: Assessment of Domestic Resources, J. K. Young, PNL-3150, Pacific Northwest Laboratory, Richland WA, 1980.

7. S. R. Borrowman and J. B. Rosenbaum, Recovery of Thorium from a Wyoming Ore. USBM-RI-5917, U.S. Bureau of Mines, Denver, CO, 1962.

8. Golden Associates, "Appendix E: Palmer, Michigan Model Mine/M:11" In Economics of Large-Scale Thorium 0xide Production: Assessment of Domestic Resources, J. K. Young, PNL-3150, Pacific Northwest Laboratory, Richland, WA, 1980.

9. F. J. Hurst, et al., Recovery of Thorium and Uranium from Granite Rocks. ORNL-3987, Oak Ridge National Laboratory, Oak Ridge, TN, 1966. 


\subsection{ASSESSMENT OF AVAILABLE ENVIRONMENTAL CONTROL TECHNOLOGIES}

The environmental control technologies available to protect the offsite environment from thorium mining, milling, and refining effluents were reviewed in the literature and through discussions with suppliers of commercial environmental control equipment. There are many methods available to control the wastes. The selection of the best methods to use will depend upon the processes employed and site-specific data. The equipment and facilities selected for environmental control will be determined during the detailed feasibility and environmental impact studies for the specific site.

The typical types of wastes that must be controlled during the mining, milling, and refining of thorium are shown in Figure 4.1. The tailings pile, which contains the bulk of the radioactivity, will be a major source of concern for offsite release of effluents during operations and after operations are terminated.

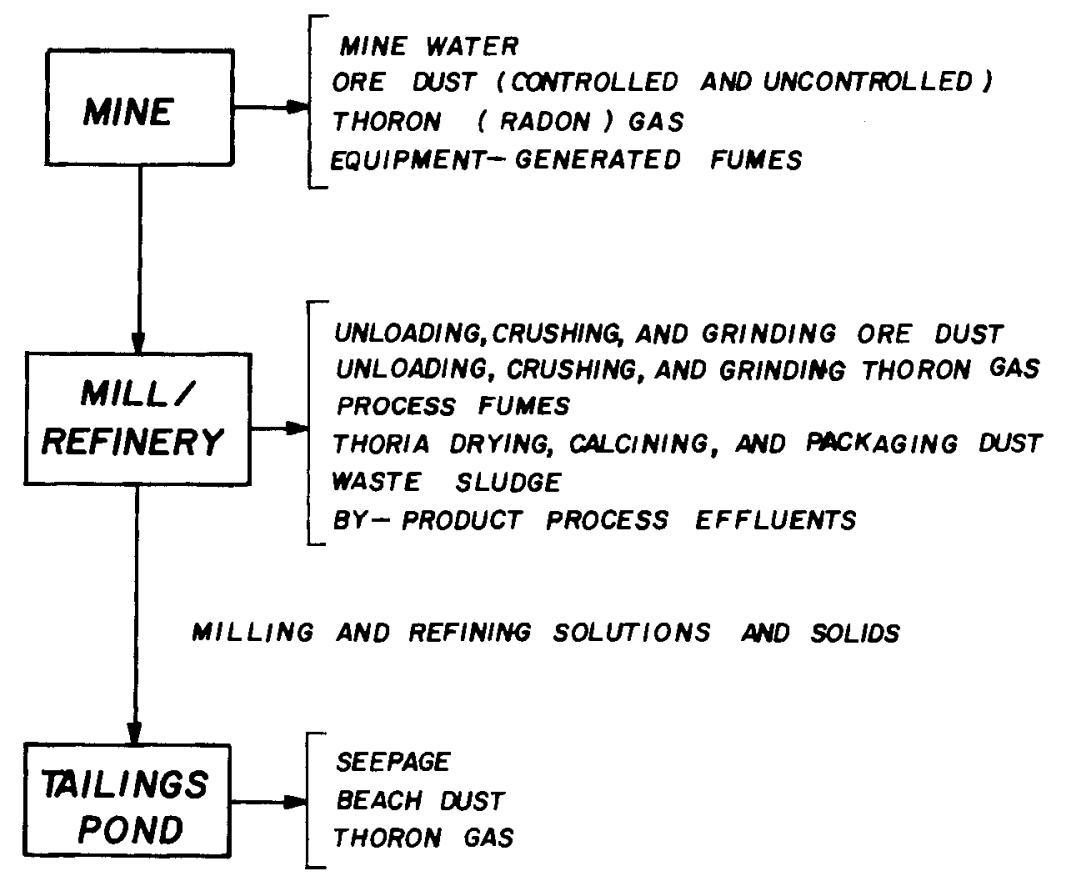

FIGURE 4.1. Typical Types of Wastes from Mining, Milling, and Refining Thorium 
Data from the uranium industry were used for most of the analys is because little information was available about environmental controls for the thorium industry. Some of the general differences between thorium and uranium are outlined in Table 4.1. Because site-specific data were lacking, all of these differences could not be factored into this study.

The thorium industry, like the uranium industry, would be associated with a wide range of processes, chemicals, by-products, locations, geologies, etc. The environmental control methods used at one site may not be suitable at another site. The various methods of controlling wastes are listed in Figure 4.1 and discussed in the following subsections.

The wastes can be controlled to different levels by methods that are in various stages of advancement. The effectiveness and costs of some of the methods are addressed in Section 5 of the report. The effectiveness and costs of the methods are site and ore specific.

\subsection{METHODS OF ENVIRONMENTAL CONTROL FOR MINING}

The thorium is mined in both underground and surface mines. The generated wastes with the largest chance of offsite release from the mine are:

- untreated mine water that can reach underground aquifers or surface waters;

- ore dust generated from drilling, blasting, and materials handling operations, and dust generated by the wind and vehicles from roads, yards, and ore storage piles;

- thoron (radon) gas released from the ore during mining, handling, and storage;

- fumes generated by the equipment (e.g., diesel engines).

The underground mine dust, the thoron released, and the fumes generated by equipment are more controllable because the mine ventilation is used to collect and channel the wastes. The methods of controlling mine water and wastes outside the underground area are similar for both types of mines. The biggest problem at the mine is the control of radon gas. In an underground 
TABLE 4.1. General Differences Between Thorium and Uranium Ores in Mining, Milling, and Refining

Thorium Ore

1. Contained in igneous rock

2. Form: nodules peppered in a rock matrix

3. High degree of grinding needed for feed material

4. High silica

5. Gravity separations difficult

6. High slime content in mill tailings effluent

7. Mineralogy, climatology, and topography are different than current uranium mines

8. High pyrite and sulfides can affect mine water $\mathrm{pH}$

9. Behavior of thoron (radon-220) not well established

10. Radium-228 and radium-224 daughters have short half-lives ( 6.7 years and 3.69 days) and require short-term control and containment.

11. Thoron (radon-220) has a short half-life (54.5 seconds). Requires less time to filter and less cover to contain.

12. Probably a greater hazard to miners
Uranium Ore

1. Contained in sedimentary rock (sandstone)

2. Form: fines coating sand kernels

3. Moderate crushing and grinding needed for feed material

4. Low silica

5. Gravity separations easier

6. High sand content in mill tailings effluent

7. Current mines mostly in arid regions

8. pH usually about 7 (neutral)

9. Radon-222 is better understood

10. Thorium-230 and radium-226 daughters have long halflives (1622 years and 75,200 years) and require long-term control and containment.

11. Radon-222 has a longer half-life (3.825 days). Requires more time to filter and greater cover to contain.

12. Probably not as great a hazard to miners 
mine, it is feasible to control thoron wastes but releases in open-pit mines are essentially impossible to control.

\subsubsection{Mine Water Control}

Standard mining practices will be used to channel the mine water in a way that will minimize the pollution due to erosion. Water treatment may be required in some cases where the turbidity, dissolved radioactive material content, acidity, or heavy metals content are high. In some thorium mines, the acidity may be higher than in uranium mines because of the ore's higher pyrite and sulfide content. The mine water can be utilized in milling and refining operations when they are located nearby and can also be used to control the release of dust from onsite roads, ore piles, materials handling, and drilling and blasting operations.

The mine water will usually be collected and possibly treated in a settling pond prior to subsequent use or discharge into natural surface waters or drainage systems. Flocculation and clarification $(1)$ can be employed, when needed, to reduce the total solids in solution, the chemical oxygen demand, and the radium. Flocculants are water-soluble organic polyelectrolytes that are sometimes used with inorganic coagulants and/or coagulant aids to agglomerate solids suspended in aqueous systems. The flocculation process collects colloidal particles into larger and more dense aggregates, which then settle more rapidly and more completely in the clarification step. The choice of the specific chemicals used in the process depends upon the characteristics of the waste.

Ion exchange ${ }^{(1)}$ can be used to collect the thorium and uranium. It also has been used to collect radium but not much is known about the process. The exchange of ions by means of a synthetic resin is a proven method of reducing the dissolved solids contained in water. Uranium has been successfully extracted from mine water and mill ore leach pulp; the technology should also be adaptable to recovering thorium.

Barium salt coprecipitation can be used in the pond to precipitate the radium out of the liquid streams. In the past, the common salts used along with a flocculant for coprecipitation of radium were $\mathrm{BaSO}_{4}, \mathrm{Ba} \mathrm{CO}_{3}$, and 
$\mathrm{BaCl}_{2}$. The relative effectiveness of barium salts is shown in Table 4.2. (2) Barium chloride has been the most effective and its product is relatively insoluble.

Lime precipitation $(1,2)$ can be used in the settling pond. The lime will help precipitate out the heavy metals and increase the pH. Neutralization with lime also tends to remove radium from the waste stream (up to $90 \%$ in highly acidic solutions).

In the unlikely event that mine water cannot be treated to meet environmental discharge requirements, it will be necessary to collect and evaporate the water with an evaporator or in a pond. The solids collected could be buried after operations cease by either covering the pond or moving them to the mill tailings pond or an approved landfill.

TABLE 4.2. Radium Decontamination Using Barium Salts(a)

\begin{tabular}{|c|c|c|c|c|c|}
\hline \multirow[b]{2}{*}{$\begin{array}{c}\text { Effluent } \\
\mathrm{pH} \\
\end{array}$} & \multirow[b]{2}{*}{ Reagent } & \multirow{2}{*}{$\begin{array}{l}\text { Reagent } \\
\text { Addition } \\
\mathrm{g} / \mathrm{e} \\
\end{array}$} & \multicolumn{2}{|c|}{ 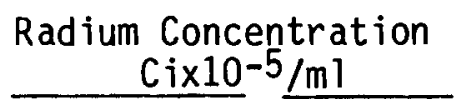 } & \multirow{2}{*}{$\begin{array}{l}\text { Radium } \\
\text { Removal } \\
\% \\
\end{array}$} \\
\hline & & & $\begin{array}{l}\text { Before } \\
\text { Treatment }\end{array}$ & $\begin{array}{c}\text { After } \\
\text { Treatment }\end{array}$ & \\
\hline \multirow[t]{8}{*}{ Neutral } & \multirow{2}{*}{$\mathrm{BaSO}_{4}$} & 0.3 & 10 & 3 & 70 \\
\hline & & 1.0 & 30 & 7 & 77 \\
\hline & \multirow{2}{*}{$\mathrm{BaCO}_{3}$} & 0.1 & 47 & 3 & 94 \\
\hline & & 0.2 & 49 & 4 & 92 \\
\hline & \multirow{4}{*}{$\mathrm{BaCl}_{2}$} & 0.03 & 80 & 2 & 97 \\
\hline & & 0.06 & 44 & 0.6 & 99 \\
\hline & & 0.1 & 40 & 0.2 & 99 \\
\hline & & 0.2 & 43 & 0.2 & 99 \\
\hline \multirow[t]{4}{*}{ Acidic } & \multirow{3}{*}{$\mathrm{BaCO}_{3}$} & 0.1 & $15^{(b)}$ & $1.8^{(c)}$ & $88^{(c)}$ \\
\hline & & 0.2 & $15^{(b)}$ & $2.0^{(c)}$ & $87^{(c)}$ \\
\hline & & 0.3 & $15^{(b)}$ & $3.0^{(c)}$ & $80^{(c)}$ \\
\hline & $\mathrm{BaCl}_{2}$ & 0.1 & $15^{(b)}$ & 0.5 to 1.5 & 90 to 97 \\
\hline
\end{tabular}

(a) Mill-scale tests, Union Carbide Corporation, Uravan, Colorado.

(b) Average several sampling periods; individual samples erratic.

c) Differences in results not considered significant. 
Some mines on the other hand, unlike the ones we studied, may be quite dry. Some uranium mines are very dry; so water must be transported to the site for drilling and blasting operations.

\subsubsection{Ore Dust (Controlled and Uncontrolled)}

\subsubsection{Controlled Ore Dust}

The dust generated in the underground mine can be categorized as controlled dust. The underground mine's ventilation system helps to control dust at safe working levels for the workers. Auxiliary exhausts can be used where drilling, blasting, and materials handling generate larger quantities of dust. Water is used to reduce the dust from drilling. Blankets and water spray curtains can also be used to tie down the dust from blasting and materials handling. The use of the latest equipment and the best standard operating procedures will help control the dust.

The dust carries with it thorium, radium, and other alpha and beta emitters. (3) The contamination levels at any place and time depend on the ore grade, the type of operations involved, moisture, ventilation, and other such factors. Generally, where low-grade ore is mined and ventilation is good, the contamination levels in uranium mines are well within the prescribed levels. Mines that produce high-grade ore have been known to have substantially higher levels of contamination. Underground contamination in thorium mines is expected to be more of a problem because the short half-life of thoron ( 54.5 seconds) will result in a greater accumulation of daughter products in the mine rooms, shafts, ventilation ducts, etc. Usually thorium mines will contain more silica than uranium mines; so the protection of workers from silicosis will be an added concern.

The dust collected and discharged through the underground mine ventilation system $c$ an be passed through dust collection equipment if it is deemed necessary. The types of dust collection equipment that could be used are discussed in Section 4.2.1. 


\subsubsection{Uncontrolled Ore Dust}

In a surface mine, the ore dust generated by the drilling, blasting, and handling operations is not as major a concern as it is underground. Use of the best equipment and best procedures will minimize the amount of dust generated.

Dust suppression is necessary for both surface and underground mines in these surface areas:

- roads

- yards

- ore stockpiles

- mine loading and mill unloading areas.

The roads and yard dust can be minimized by periodically spraying surfaces with water and chemicals. The ore stockpiles can be protected from the prevailing winds by erecting wind barriers ${ }^{(4)}$ and, if necessary, by periodically wetting them or encrusting them with chemicals. The loading and unloading areas can also be protected from the wind, and spray curtains can be used if necessary.

\subsubsection{Thoron (Radon-220) Gas Control}

In open-pit mines, there is little that can be done to control the release of thoron to the environment. The thoron is continually diluted in the air and does not build up or accumulate like it could in unventilated areas of underground mines; however, it is necessary to monitor radon in surface mines during periods of air stagnation, thermal inversions, etc. Most of the concern is about the thoron daughters because they present a hazard to the workers' health when inhaled. Underground mines must rely on ventilation systems to prevent the accumulation of thoron and its daughter products in the mine. The ventilation systems also dilute the concentration of these products with air to meet effluent discharge requirements for the mine.

The behavior of thoron, compared to radon in uranium mines, is not well understood. The physical properties of radon and thoron are the same except for the half-life variation of 3.82 days and 54.5 seconds, respectively. In underground uranium mines, ${ }^{(3)}$ the ambient concentration of radon is a function 
of barometric pressure variations, rock porosity, the volume of the water seepage, the volume of ventilation, and, to a surprisingly minor extent, ore grade. The emanation rates of radon from mine walls and rocks may be estimated to determine which control measures to use and to establish design ventilation requirements. The large quantities of ventilation air, required to meet the federal standards for radon decay products with in the mines, result in the discharge to the atmosphere of large air volumes with low radioactive concentrations. The immediate, large dilution of mine air by atmospheric air and the remote locations of the mines prevent any significant exposure to anyone. Normally, no special waste control equipment is needed to limit the discharge of radon and its decay products.

The thoron will be swept in the mine ventilation exhaust system as it is released from the mine. By continuously operating the ventilation system in the working areas, a thoron buildup can be prevented and the deposit of its daughters can be reduced.

The amount of thoron and its daughters being released to the environment via the ventilation system can be reduced by delaying the gas and filtering out the daughter particles in the exhaust system. If the air is exhausted at $500 \mathrm{ft} /$ minute, the solid daughter particles will increase by about $50 \%$ (due to the 54.5 second half-life) with in a 500-ft run of duct, shaft, drift, etc. in the ventilation system. The particulates can be collected by high-efficiency particulate-air (HEPA) filters before the air is discharged. Activated charcoal-filter delay traps could be used to collect essentially all of the thoron $(99 \%+)$. After the thoron decays to the particulate daughter products, it will be released from the carbon filter and pass to the HEPA filter where 99.97\% of the particulate will be collected. In the event that charcoal and HEPA filters are used, it will be necessary to install a baghouse filter upstream to catch the bulk of the dust.

Because of the high cost, it is probably impractical to use charcoal and HEPA filters in uranium mines. In a thorium mine, it may be practical because much less charcoal is needed and there is less of a pressure drop across the filter, reducing equipment and power costs. 


\subsubsection{Control of Equipment-Generated Fumes}

No special methods will be used in the surface mines and all equipment (e.g., diesel engine) is assumed to utilize standard exhaust systems that meet or exceed EPA requirements. In the underground mines, the equipment fumes will be collected in the mine ventilation exhaust systems and diluted with excess air to meet EPA requirements.

\subsection{METHODS OF ENVIRONMENTAL CONTROL FOR MILLING AND REF INING THORIUM}

The generated wastes from the mill/refinery complex that may be released include:

- dust in the mill from unloading, crushing, and grinding the ore;

- dust from drying, ignition, and packaging the thoria;

- thoron gas released while the ore is unloaded, crushed, and ground in the mill;

- process fumes;

- waste sludge;

- tailings pond seepage;

- tailings pond beach dust;

- radioactivity in the tailings pond after the mill/refinery closes.

Airborne dust waste from the mill/refinery operations can be controlled with well-developed equipment. The control of the thoron from crushing and grinding operations in the mill (through the use of carbon and HEPA filters) is feasible but very expensive.

Waste control at the tailings pond, both during and after operations, still poses the biggest problem. Low-cost control methods that are effective against pond water seepage during operations need to be developed, as well as methods of curtailing long-term thoron release after the mill operations cease. Even the costly methods have site-specific problems. 
4.2.1 Control of Mill Dust from Unloading, Crushing, and Grinding Ore

A large variety of well-developed equipment is available to control the waste dust. The equipment is gradually being improved and, as a result of the recent emphasis on environmental control, more special application equipment is on the market today. The application, location, ore characteristics, process selected, and other factors can determine the optimum choice of equipment. Probably no two plants will select the same equipment because of process and site-specific considerations.

The main types of dust collection equipment considered in this report are listed below. The list does not include all of the types of dust collectors that should be considered but is simply a cross section of equipment with various efficiencies. New pieces of equipment, hybrids of various types, are also coming onto the market.

In actuality, the dust collector should be selected after the process and plant layout is determined. Tests should be run with typical ore and conditions at the site to narrow down the equipment choice. Even with preliminary full-scale tests, unexpected surprises as a result of site-specific variables (e.g., ore moisture content, size fractions, climate extremes, etc.) may still occur after actual installation in the plant.

The types of dust collectors ${ }^{(5)}$ included in this study are as follows:

- Cyclone

- Orifice Scrubber

- Wet-impingement scrubber (irrigated target)

- Low-energy venturi scrubber

- High-energy venturi scrubber

- Baghouse filter

- HEPA filter

- Others.

\subsubsection{Cyclone Dust Collector}

A cyclone removes particulates from the air by converting the inlet stream into a double vortex within the cyclone. Figure 4.2 illustrates a 


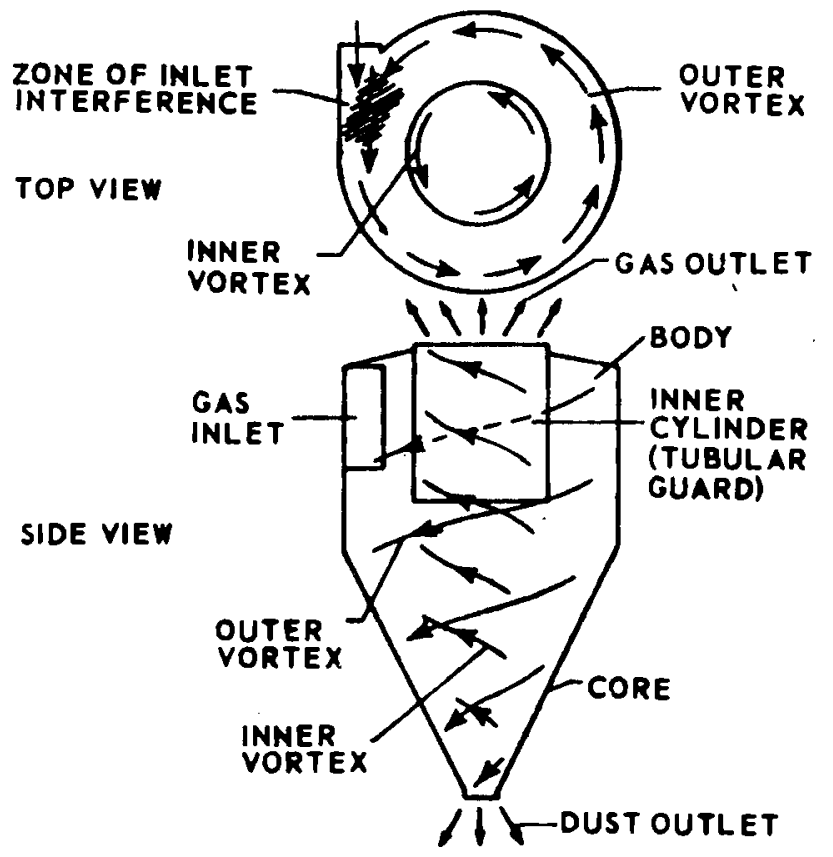

FIGURE 4.2. Cyc lone ${ }^{(6)}$

cyclone dust collector. ${ }^{(6)}$ The primary vortex is formed as the inlet gas spirals downward and causes a layer of dust to slowly swirl down the walls and collect in the bottom of the hopper. Centrifugal force is the mechanism that acts to separate the particles. After the air reaches the bottom, the vortex reverses its axial direction and passes through the outlet. Multiple cyclones are simply two or more cyclones either in series or parallel. A single cyclone will have a collection efficiency of about $50 \%$ for 5 -micron particles while multiple cyclones are up to $90 \%$ efficient.

A cyclone is simple in design and, therefore, has a relatively low cost. The collection efficiency is also relatively poor for particles below 10 microns in size. The cost of installing a 30,000-cfm cyclone is in the $\$ 0.50$ to $\$ 1.00 / \mathrm{cfm}$ range.

\subsubsection{Orifice Scrubber Dust Collector $(4,5)$}

Orifice scrubbers have been widely used in the uranium industry in the past. An example of an orifice scrubber is shown in Figure 4.3. Its principle of operation is that high-velocity air impinges on a pool of scrubbing 

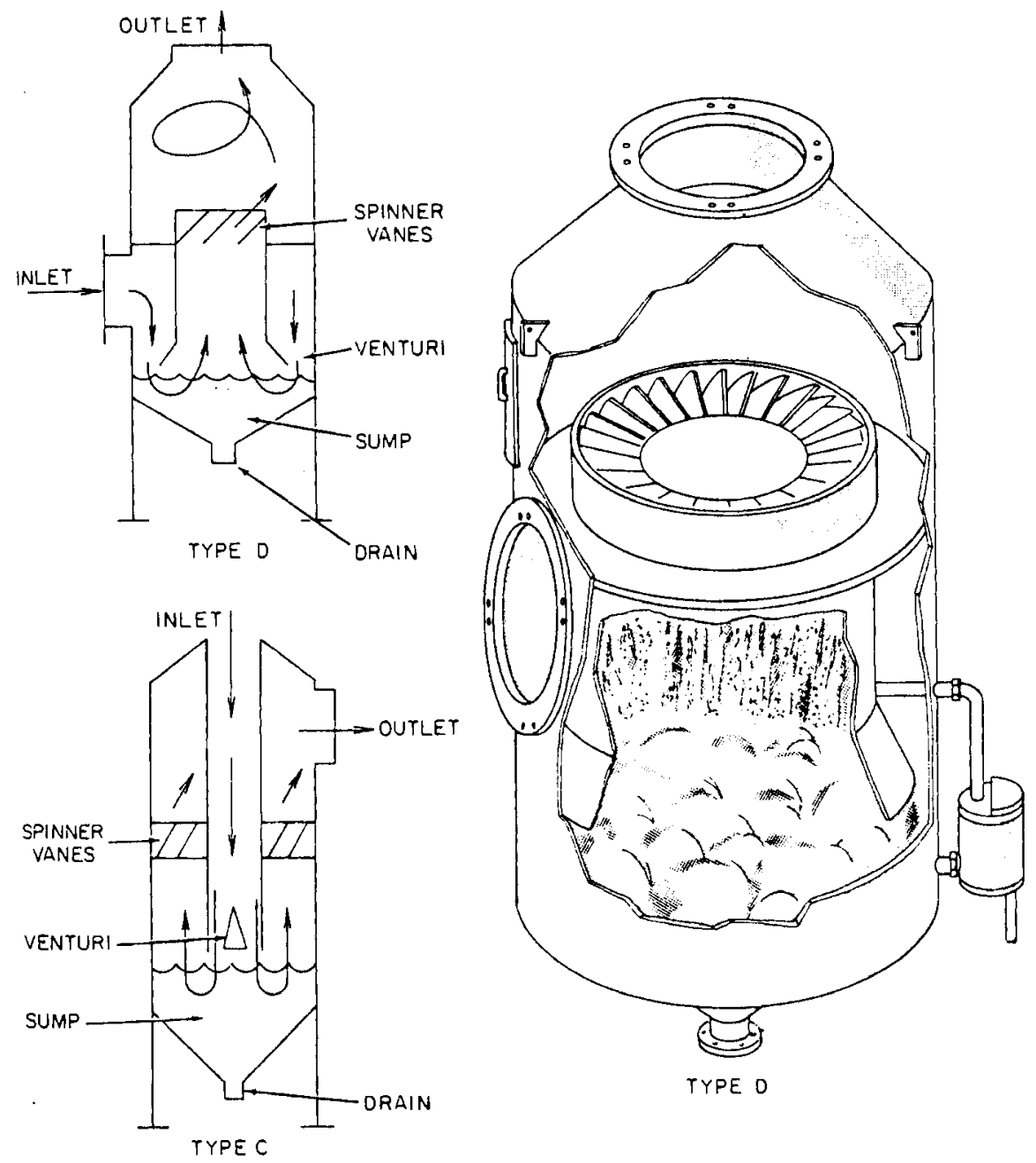

FIGURE 4.3. Orifice Scrubber (represented with permission from Environmental Engineers Handbook, Vol. 2 Air Pollution, Bela Liptak, Chilton Book Company, Radnor, Pennsylvania, 1974.

liquor. The air flows through a baffle at high velocity while carrying water in a heavy turbulent sheet. The rapid change in direction causes a centrifugal force that makes the dust particles penetrate and adhere to the water film. It has a dust collection efficiency of about $94 \%$ with 5 -micron particles. The efficiency is reduced by about $50 \%$ for 1 -micron sized particles. The installation costs range from approximately $\$ 1$ to $\$ 2 / \mathrm{cfm}$ for a 30,000 -cfm orificescrubber system. 


\subsubsection{Wet-Impingement Scrubber Dust Collector (Irrigated Target)}

Figure 4.4 demonstrates a type of wet-impingement scrubber. (7) The air stream is accelerated to a high velocity while passing through orifices, then impinged upon baffle plates. The dust particles are collected on vaned mist el iminators and are withdrawn, along with the solids collected, in the liquid overflow from the impingement plate. It has an efficiency of about $98 \%$ for 5-micron particles, which drops to about $80 \%$ for 1-micron particles. For a $30,000-\mathrm{cfm}$ unit, the cost ranges from about $\$ 1.50$ to $\$ 2.50 / \mathrm{cfm}$ installed.

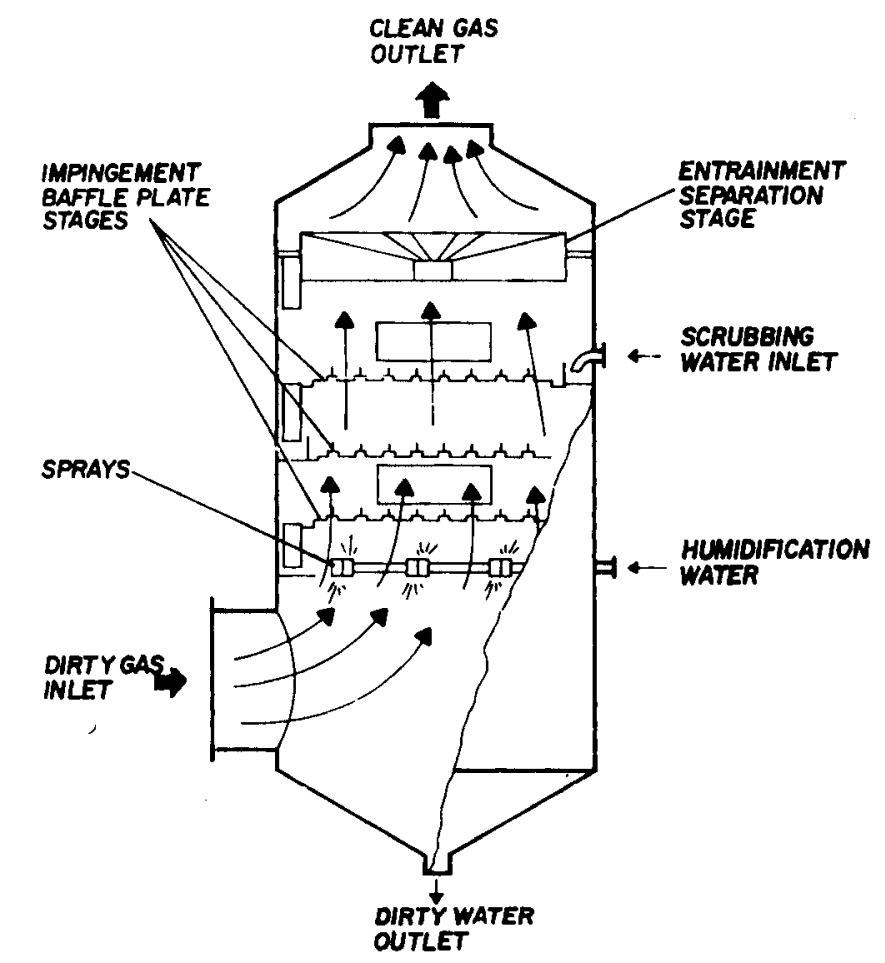

FIGURE 4.4. Wet-Impingement Scrubber (reprinted with permission from Pollution Engineering Practice Handbook, Cheremisinoff and Young, Ann Arbor Science Publishers, Inc., Ann Arbor, MI, 1976, p. 126. 


\subsubsection{Low- and High-Energy Venturi Scrubber Dust Collectors}

An example of a venturi scrubber is given in Figure 4.5 . (6) Its principle of operation is that high-velocity air impinges on the liquid stream in the throat of a venturi-shaped section and atomizes the liquid into fine droplets, on which the dust particles are collected. The gas stream continues into a cyclonic separator where the particle-laden scrubbing liquor and the air are thoroughly separated by centrifugal force to complete the cleaning operation.

Both the low-energy and high-energy units collect over 99\% of the 5-micron size particles. The low-energy units collect up to $96 \%$ of the 1 -micron size

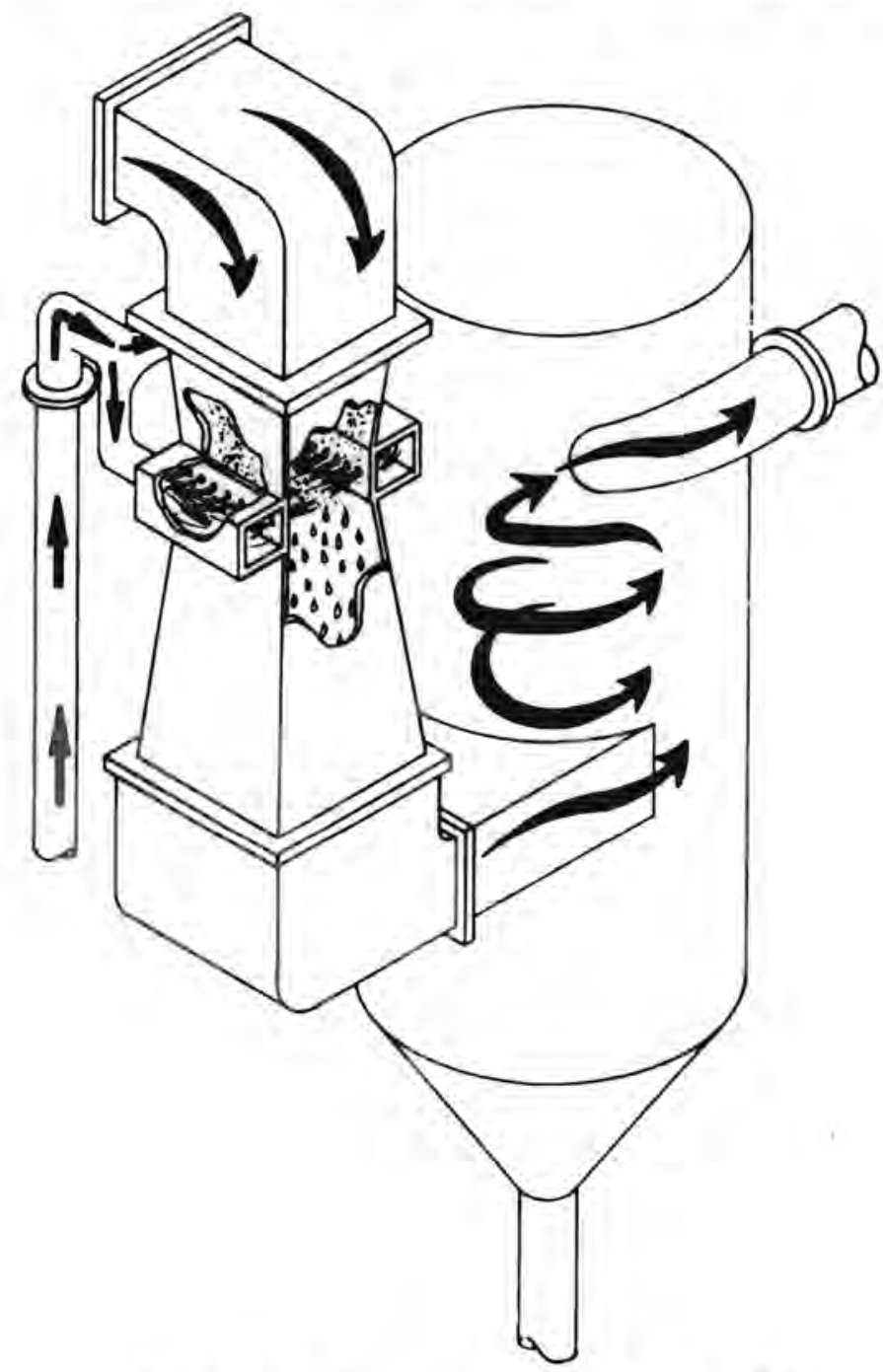

FIGURE 4.5. Venturi Scrubber (6) 
particles and the high-energy unit collect up to $98 \%$. The low-energy unit will cost in the $\$ 1.75$ to $\$ 2.75 / \mathrm{cfm}$ range. A high-energy unit costs $\$ 2$ to $\$ 3 / \mathrm{cfm}$. The operating costs are relatively high for these units. The highenergy unit is especially costly because of the large amounts of power needed to compensate for the high pressure drop across the venturi.

\subsubsection{Baghouse Filter Dust Collector}

In the baghouse filter dust collector, illustrated in Figure $4.6,(6)$ the dust-laden air flows through a porous woven or felted fabric where it deposits the particulates in the voids. The pressure drop gradually increases as the voids are filled. When it is necessary to clean the bags, this is accomplished by mechanical action such as shaking the bags or reverse air-jet pulsing. The dust falls into a hopper for subsequent disposal or recycling in the process. The particulates are collected dry and in a usable condition, so recovery in relatively easy. Bag filters operate best with relatively dry air streams. They cannot be used on such moist streams as the dryer off-gas.

Bag filters have an efficiency rating of up to $99.9 \%$; some of the bags are even very efficient in removing submicron particles from the air. The installed cost of a simple 30,000-cfm baghouse filter system with shakers is about $\$ 3$ to $\$ 5 / \mathrm{cfm}$. The costs can be substantially higher if special bags, sophisticated cleaning methods, special alloys, etc., are needed.

\subsubsection{HEPA Filter Dust Collectors}

High-efficiency particulate air (HEPA) filters, shown in Figure 4.7, can be used downstream of a baghouse filter to reduce the release of particulates by practically 100\%. Even small 0.3-micron size particles are removed with up to $99.97 \%$ efficiency. Excessive moisture, however, can impair the HEPA filter's efficiency. The periodic buildup of particulates require the removal and replacement of the HEPA filter units.

HEPA filters have been used for many years in the nuclear industry to effectively remove radioactive particulates from gas streams. Use of this type of filter in the mining industry was not found during our review.

Each HEPA filter has a capacity of about 1,000 to $3,000 \mathrm{cfm}$. For 1arge air flows, it is necessary to arrange them in a parallel battery arrangement 


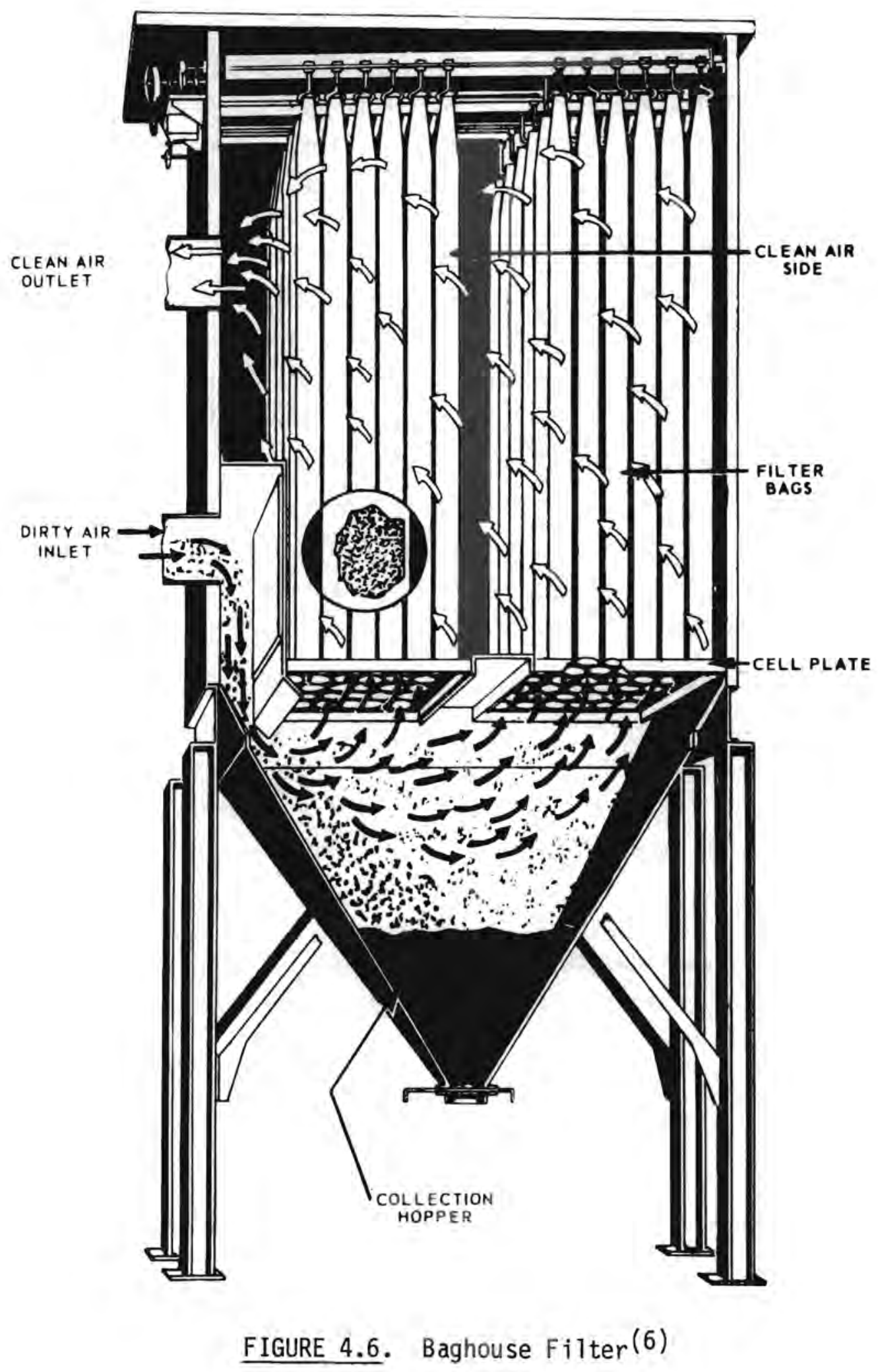




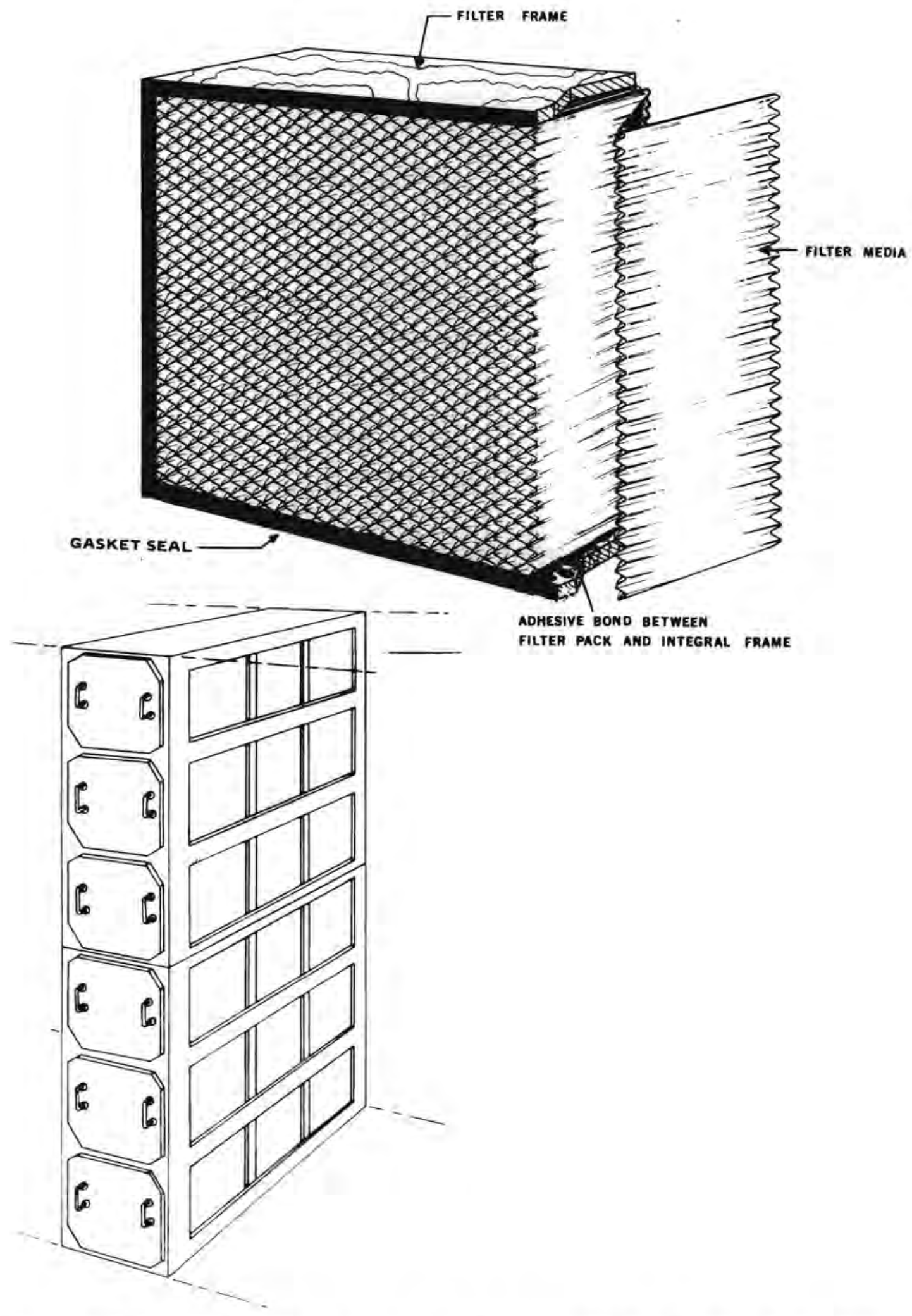

FIGURE 4.7. HEPA Filter and Manifold Housing for Multiple Filters (reprinted with permission from Flanders Air Filtration Products Catalog, Flanders Filters, Washington, NC. 
in a manifold housing, which spreads the air flow. The cost estimate for a $30,000-$ cfm unit installed would range from $\$ 6$ to $\$ 10 / \mathrm{cfm}$.

\subsubsection{Other Types of Dust Collectors}

There are many designs for each type of dust collector discussed so far; there are also many other types of dust collectors that have not been discussed. Some collectors are hybrids of different types; others are continually in the process of being designed and developed. Therefore, a more thorough review of available equipment should be made after site-specific data and ore samples are available for testing.

To select the proper dust collection equipment for a given site, it will be necessary--as a minimum--to know the following types of data:

- application

- volume, temperature, and moisture content at inlet

- inlet variations and outlet conditions

- corrosive characteristics

- particle size distribution of the dust

- dust grain loading

- physical and chemical characteristics of the material being collected

- cooling and heating requirement, if any

- scrubbing liquid characteristics and availability

- climate.

\subsubsection{Control of Dust from Drying, Ignition, and Packaging Thoria}

Essentially $100 \%$ of the daughters of thorium are removed from the thorium at this point in the process. The bulk of the particulates released from these process steps are thorium and water. While mostly water is given off in the drying and ignition steps, thoria is the only effluent exhausted from the packaging hoods.

The wet-type dust collectors such as orifice, wet-impingement, low-energy venturi, and high-energy venturi scrubbers can be used for the effluents from drying and ignition. Dry-type collectors, such as baghouse and HEPA filters, are used for the packaging operations. 
The dust in this area is more radioactive and, therefore, it is impractical to use low-efficiency collectors like cyclones. The recovery of thorium particulates in this area of the refinery will sometimes more than pay for the dust collection equipment and operations involved.

\subsubsection{Control of Thoron Gas from Unloading, Crushing, and Grinding}

Thoron gas is released when the ore is crushed and ground. It will be difficult to control without the use of a delaying mechanism. Some of the gas released will decay into daughter particulates because of thoron's short halflife. The particulates can be collected by HEPA filters and, to a smaller extent, by baghouse filters. Wet scrubbing solutions might also collect some of the particulates (tests are needed to verify how much).

Activated charcoal filters would be used to collect thoron gas from the exhaust stream. The filter system would be similar to the one mentioned earlier for the underground mine exhaust. The activated charcoal would be placed in a module made up of several stacked trays of charcoal, which could handle a 1000 -cfm air flow. These modules could be placed in a battery arrangement, similar to HEPA filters, for large air flows. Periodically, the trays would be recharged with fresh charcoal.

The charcoal filter station would be downstream from a baghouse filter, which would collect the bulk of the dust. A HEPA filter station would be placed downstream of the charcoal filters to collect thoron daughter and carbon particulates. The charcoal filter should delay up to $99+\%$ of the thoron for subsequent recovery of $99+\%$ of the daughter product in the HEPA filter.

The cost estimate for a 30,000-cfm charcoal filter system (including baghouse and HEPA filters) is in the $\$ 15$ to $\$ 30 / \mathrm{cfm}$ range. This cost may be too high a price for the small amount of thoron and its daughters collected.

Some constraints that may make it difficult to use charcoal filters are:

- The relative humidity of air stream should be $50 \%$.

- Shielding will be required because of the radioactivity.

- Charcoal beds are a potential fire hazard.

- Very limited data and experience are available for designing the system. 
An alternative to collecting thoron with carbon filters would be the use of a refrigeration trap, but this is not considered practical for large air flows because of its high cost.

\subsubsection{Process Fume Control}

The processes considered in this study do not generate sufficient fumes to warrant the use of effluent control equipment. Minor fumes will be generated from low-temperature acids, kerosene, diesel, and other chemicals, but they can be handled with conventional ventilation equipment stacks.

In cases where high-temperature acids or other chemicals are used, it will be necessary to use fume scrubbers. Venturi scrubbers, packed-bed scrubbers, or mist eliminators can be used to control the fumes. They can be installed at a cost of $\$ 1$ to $\$ 4 / \mathrm{cfm}$.

\subsubsection{Refinery Waste Sludge Control}

Some of the refineries will generate a small volume of sludge. The following alternatives were considered for handling the sludge:

- trucking the sludge to an onsite landfill lined with $3 \mathrm{ft}$ of clay (assumed as the base technology);

- blending the sludge with asphalt and trucking it to an unlined onsite landf i11; or

- shipping the sludge to a federal licensed landfill.

In all of these cases, the sludge would likely be fed into a hopper for periodic removal from the refinery. A screw conveyor could be used to remove the sludge as required for the next step. It would be relatively simple to load and unload a truck or fork lift (equipped with a dumpster) with sludge for transport to the landfill. The landfill pit would be progressively covered as it became filled and dried out.

If asphalt is blended with the sludge, the landfill operation would remain about the same but the costs would be substantially higher for the added operation and the asphalt material. The main benefit would be a more stable landfill. As an alternative, concrete could be blended with the sludge at a lower cost, but this alternative was not included in the study. 
Shipment of the sludge to a licensed burial ground involves loading the sludge into approved plastic-lined 55-gal drums. If necessary, excess solution can be absorbed by adding vermiculite or other absorbent materials to the drums. The drums are sealed and loaded onto special carrier trucks for shipment to the repository.

\subsubsection{Tailings Seepage Control}

Seepage from the tailings pond is generally minimized by a combination of proper site selection and careful design of the pond and dam. The seepage of water through the pond bottom and dam is still a common problem at many uranium tailings ponds. Seepage rates ${ }^{(8)}$ of 0 to $25 \%$ of the total input to the ponds have been reported. This seepage may be to the groundwater and/or to surface drainage. At many sites, some of the seepage is recovered in ditches or catch basins below the dam and pumped back to the pond. The newest mills have clay-core dams ${ }^{(4)}$ where seepage has not been observed. One new mill was projecting $12 \%$ to $27 \%$ seepage ${ }^{(11)}$ even with a clay-core dam. This study has assumed the use of clay-core dams as its base technology.

The geological permeability at some sites will make it necessary to line pond bottoms with clay, asphalt, rubber liners, etc., to minimize or el iminate seepage. Neutralization of acidic mill water may be required to protect some of the liners (e.g., asphalt). Some of the main factors to be considered in evaluating the pond liners are:

- resistance to subsidence of subsoil and rock,

- resistance to chemical attack from tailings fluid,

- resistance to physical penetration (man, equipment, animals, waves, wind),

- resistance to weathering (freeze-thaw, bakeout, ultraviolet light, ozone),

- liner permeability,

- liner aging,

- microbial resistance, and

- liner pressure differential effects (water head, gas generation, etc.).

In addition to geological and liner factors, the coarseness of the tailings solids can have an influence on the seepage rates. ${ }^{(11)}$ Finer particulates $\mathrm{fill}$ in voids and reduce seepage rates. Thorium mill/refineries are expected to generate a larger fraction of fines than do uranium mills. 
Other methods of reducing seepage involve dewatering the tailings and burying them as sludge or as blends with concrete or asphalt. The excess water can be eliminated by evaporation in a lined pond or an evaporator, recycled to the mill, or some combination. Residue from the excess water would be collected and processed along with the tailings at the termination of the mill's operation.

Some innovations for handling mill tailings were presented at the recent annual uranium industry seminar. (10) Additional innovations are encouraged since it is recognized that the problems of developing tailings management and disposal plans are highly site-specific.

\subsubsection{Clay-Core Dam (Base Technology)}

The base technology assumes that a dam is constructed across a natural valley or basin to impound the mill tailings and solutions. The dam is constructed of compacted borrow material with a clay core that is keyed to an impervious rock strata or clay at the base of the dam. Diversion ditches will be constructed to handle natural runoff around the impoundment. The pond bottom will be scarfed to remove topsoil that can be used in later reclamation procedures. The bottom will be contoured, smoothed--as much as practicable, and compacted. Hopefully, the site will have a native clay base.

A distribution system, such as a movable piping network, tremie rafts, a small dredge, etc., will be used to spread out the tailings and maintain a water cover on the tailings at all times. At all of the sites included in this study, a substantial amount of excess water is available to maintain a water cover over the tailings. The water cover will hold radon emanation to very low levels.

Some of the excess water (up to 80\%) will be reused in the mill after passing through an auxiliary settling pond. Extra treatment of the recycle water, such as the addition of flocculants, lime, or barium chloride, may be required but they were not included in this study's costs. 
The use of a clay-core dam should reduce seepage down to the 0 to $15 \%$ range. However, at some sites this low a seepage rate cannot be achieved even with clay-core dams. ${ }^{(11)}$ The cost for a 100-acre tailings pond, distribution system, and recycling system would be about $\$ 3,000,000$.

\subsubsection{Clay-Core Dam with Clay Liner}

This case is the same as the base technology case except a 3-ft compacted clay liner is added to the bottom and the dam interface. It is assumed that good impermeable clay is readily available within a few miles of the site. If it is not, the clay-liner option would have to be carefully studied and compared to the other options. Additives that will make some permeable clays more impermeable are being developed but there was not enough information for their costs and effectiveness to be projected. During periods of drought and hot weather, steps must be taken to prevent cracks from developing in the clay.

The addition of a clay liner should reduce the seepage rate by a factor of 5 to 10 , down to a 0 to $3 \%$ range. The cost of adding a 3-ft clay liner to a 100 -acre dam would be a minimum of about $\$ 350,000$. If the clay is mined offsite and must be shipped to the site, this will add considerably to the cost.

\subsubsection{Clay-Core Dam with Asphalt Liner}

Except for the added asphalt liner and the neutralization plant, this case is the same as the base technology case. A 2-in. asphalt liner is laid on top of a 4-in. rock base over the entire pond bottom and the dam interface. A neutralization plant has also been added to neutralize the tailings acid water before it is exposed to the asphalt. The asphalt liner should reduce the seepage to less than $1 \%$. The cost for a 100 -acre liner will be about $\$ 2,350,000$. The cost of the neutralizaton plant will be about $\$ 800,000$. The development of asphalt emulsions ${ }^{(9)}$ to line the ponds may reduce the cost of liners appreciably in the future.

\subsubsection{Clay-Core Dam with Rubber Liner}

A 60-mil multi-ply rubber (hypalon or equivalent) liner is added to the bottom and dam surfaces of the tailings pond. In this process, extra care is taken to smooth the contours of the 1 and and to remove sharp objects that 
might penetrate the liner. Venting is added where natural gas might be a problem. If the rubber liners are well cared for and protected from foot and vehicular traffic, they should provide essentially $0 \%$ leakage for the life of the mill. The cost of lining a 100-acre pond with 60 -mil hypalon would be about $\$ 3,250,000$.

\subsubsection{Dewater Tailings, Convey to Landfill}

A landfill pit well above the ground water is excavated and lined with about $3 \mathrm{ft}$ of clay. The tailings stream will pass through neutralization, thickening, and vacuum filter steps to dewater the tailings. A covered conveyor belt system carries the tailings to the landfill. The excess water is pumped to a hypalon-lined storage pond. The water is recycled to the mill after passing through an auxiliary settling pond. Solids from the storage and settling ponds are transferred to the landfill when the mill is decommissioned.

The cost of a 100-acre landfill pit to serve a 1000-tpd mill would be about $\$ 7,100,000$. If a mined-out area can be used in lieu of excavating a landfill pit, about $\$ 2,000,000$ would be saved. At some sites, using trucks to haul the dewatered tailings to the landfill might also save money. Seepage from the tailings should be less than $1 \%$ for this option.

\subsubsection{Dewater Tailings, Blend with $10 \%$ Cement, Pump to Landfill}

A clay-lined landfill pit is used in lieu of a tailings pond to dispose of the tailings. The pit is lined with $3 \mathrm{ft}$ of clay. The mill tailings stream passes through a neutralizing and thickening step where the solids are removed in a slurry. The slurry is mixed with about 1 part cement to 10 parts solids, then the slurry is pumped to the landfill where it is allowed to solidify. The decanted water from the thickener is pumped to a hypalon-lined storage pond. The water is recycled to the mill after passing through a secondary settling pond. Seepage from the original tailings effluents should be close to zero. After the mill is shut down, solids from the storage and settling pond are processed through the cement slurry plant for burial. 
For a 1000-tpd plant, the installation cost of the above system will be $\$ 5,200,000$. Annual costs will be about $\$ 3,400,000$. The use of a mined-out pit could save about $\$ 2,000,000$ in excavation costs.

\subsubsection{Dewater Tailings, Blend with 40\% Asphalt, Truck to Landfill}

Tailing solids are blended with asphalt and disposed of in an unlined landfill pit above the water table. The mill waste solutions are neutralized with slaked lime, dewatered in a thickener, and concentrated by a continuous filter. The tailing solids are blended with about $40 \%$ asphalt in an asphalt fixation plant, then the blend is hauled to the landfill by truck where it is dumped and compacted. The asphalt coats the tailing particles with a coating that is relatively impervious to leaching and thoron migration. The decanted water is processed for recycling, as in the other dewatered tailing cases.

The installation cost of the system outlined above is about $\$ 12,400,000$ for a 1000-tpd mill. If excavation can be eliminated, a cost savings of about $\$ 3,500,000$ would be achieved. The annual cost will be extremely high, about $\$ 19,000,000$, primarily due to the cost of the asphalt material.

\subsubsection{Tajlings Pond Beach Dust Control}

Beach dust will be much less of a problem in the cases where tailings solids are dewatered and buried. The water storage pond liners will have to be periodically washed down around the water's perimeter.

In the cases where tailings ponds are used, more beach surface area will be exposed and will require more treatment. Unlined and clay-lined pond beaches will have to be periodically sprayed with chemical coating agents using portable equipment to tie down the dust washed up by waves. Beaches around ponds lined with asphalt or hypalon will probabiy require hosing down with water as a minimum. The cost of portable spray equipment is estimated at about $\$ 20,000$ for a 100 -acre tailings pond. The effectiveness can be very good if the spraying is administered at the proper times.

As previously mentioned, the tailings are maintained underwater and thus there will be no exposed tailings pile to treat. The processes assumed in this study generated a large tailings solution-to-solids ratio and, since the 
sites selected were not in arid parts of the country, they must either recycle water or add hundreds of extra acres to the ponds' size to assure adequate evaporation of the water. Recycling conserves the water; so there is also enough extra water to maintain a head over the tailings despite variations in mill waste rates, seasonal evaporation rates, retention system designs, and other cyclic factors.

\subsubsection{Tailings Pond Thoron Gas Control}

The release of thoron gas from the pond during the mill's operating life will be controlled by the same methods as the tailings dust: the tailings are kept underwater and the beaches are periodically cleaned or sprayed with crusting chemicals.

After the mill ceases its operations, the pond will be allowed to evaporate, leaving the tailings exposed once again. As soon as tailings become exposed, they will be tied down with chemicals or sprayed with water for an interim period. After the tailings are sufficiently dry, they will be covered with an appropriate cover for long-term stabilization of the thoron, tailings, and radioactivity. The long-term stabilization procedures are discussed in the following section.

\subsubsection{Long-Term Stabilization of the Tailings}

After the mill ceases operation, the tailings are stabilized by covering them. However, stabilization of the tailings in the landfill cases will progress as fast as the landfill is filled.

The bulk of the radioactivity from the original mined ore is located in the tailings. This includes the radioactivity from the small percentage of thorium that was not recovered and from the daughters of thorium that were originally in equilibrium with the thorium. Uranium and its daughters may also be included at some of the sites. The daughters of thorium-232 all have much shorter half-lives than the daughters of uranium-238. Thus, it is a great deal easier to stabilize thorium mill wastes than it is to stabilize uranium mill wastes. 
Radioactivity from the original radium-228 and its daughters will be almost down to zero within $50 \mathrm{yr}$ after the pile is stabilized. At that point, the bulk of the radioactivity will come from the residual thorium and uranium (if available) and their daughters.

The shorter half-life of thoron (radon-220), 54.5 seconds, versus 3.82 days for radon-222 will allow the thorium tailings covers to be much thinner than the uranium tailings covers ( factor of 6000 difference). Except for a difference in the half-lives, radon-220 and 222 will behave the same. Therefore, where a 1-ft earth cover reduces the radon emanation from uranium tailings only a minor amount, it should reduce emanation from thorium tailings by a major amount.

The pile should be leveled just prior to being covered. The cover should be crowned slightly in the middle to allow natural drainage away from the tailings and, thus, reduce the chance of leaching radioactive constituents into the groundwater. The cover should prevent radioactive particles from migrating and reduce the emination of thoron to near background levels. The cover should also be thick enough to reduce above-ground radiation levels to as close as possible to background levels.

Besides contouring the cover to prevent the accumulation of runoff above the tailings, ditches and diversion dams should be installed to permanently control the runoff from the surrounding 1and. Most of the diversion system will be installed before the mill commences initial production.

The cover should have adequate protection from erosion by the wind and run-off water and from burrowing ground rodents. The cover can be topped with either rocks or vegetation. Rock riprap will prevent utilization of the land and protect the cover from wind erosion. Rock covers are especially suitable where moisture is inadequate to support vegetation.

Vegetation can be added to stabilize the cover, providing topsoil is also placed on the cover. Vegetation can probably be used at most of the thorium mining sites because adequate moisture is available. Care must be taken to avoid plant vegetation that will provide a path for the migration of radium 
and thoron. Where roots are likely to penetrate the tailings, it may be necessary to install a barrier such as an asphalt lining, rubber lining, or other means hostile to the growth of vegetation into the tailings.

The cover may also incorporate a rubber lining, asphalt layer, or compacted-clay layer to reduce the permeability of the cover. The use of such layers will reduce the leaching potential of the tailings and will also substantially reduce the thickness of the earth cover needed to prevent thoron emanation. The development of asphalt emulsions ${ }^{(9)}$ to cover the pond may reduce the cost of covers appreciably in the future.

In this study, a variety of covers for the tailings were considered. They included 1- to 6-ft earth covers; a 1-foot compacted clay cover, a 1-in. asphalt cover, and a 60-mil hypalon (or equivalent) impermeable cover; and a rock or vegetation topping.

Costs for a 100-acre tailings pond cover range from $\$ 320,000$ for $1 \mathrm{ft}$ of earth topped with 6 in. rock to about $\$ 4,000,000$ for $60-\mathrm{mil}$ hypalon and $6-\mathrm{ft}$ of earth, topped with 6 in. of rock.

The costs for the rock topping are higher than for the vegetation if no maintenance is required. If vegetation maintenance is required, that option will likely be the more costly in the long run. Costs will vary considerably between sites, especially if the rock or topsoil have to be mined offsite.

\subsection{REFERENCES}

1. Environmental Protection Agency, Group II, Development Document for Inter im Final and Proposed Effluent Limitation Guidelines and New Source Performance Standards for the Ore Mining and Dressing Industry, EPA 440/1-75/061, Envíronmental Protection Agency, October 1975.

2. Robert C. Merritt, The Extractive Metallurgy of Uranium, Library of Congress 71-157076, Colorado School of Mines Research Institute, Golden, C0, 1971 .

3. "Radiation Protection in Mining and Milling of Uranium and Thorium," Proceedings from International Symposium, held in Bordeaux, France, 9-11 September 1974, ISBN 92-2-101504-1, ILO Publications, CH-1211 Geneva 22, Switzer 1 and, 1976. 
4. M. B. Sears et al., Correlation of Radioactive Waste Treatment Costs and the Environmental Impact of Waste Eff Tuents in the Nuclear Fuel Cycle for Use in Establishing "As Low as Practicable" Guides - Milling of Uranium Ores, ORNL-TM-4903, Vol. 1, Oak Ridge National Laboratory, Oak Ridge TN, May 1975.

5. Bela G. Liptak, Environmental Engineers Handbook, Volume 2: Air Pollution, Chilton Book Company, Radnor, Pennsylvania, 1974.

6. Engineering-Science, Inc., Field Surveillance and Enforcement Guide for Primary Metalurgical Industries, PB-230, 898, prepared for the Environmental Protection Agency, National Technical Information Service, Springfield, VA, December 1973.

7. Cheremisinoff and Young, Polllution Engineering Practice Handbook, Ann Arbor Science Publishers, Inc., Ann Arbor, Michigan, Second Printing, 1976.

8. Donald W. Hendricks, U.S. Environmental Protection Agency, Uranium Mill Tailings Storage, Use and Disposal Problems, Paper at Conference on Uranium Mining Technology, Reno, Nevada, April 25-29, 1977.

9. P. L. Koehmstedt, J. N. Hartley, and D. K. Davis, Use of Asphalt Emulsion Sealants to Contain Radon and Radium in Uranium Tailings, BNWL-2190 Pacific Northwest Laboratory, Richland, WA 99352, January 1977.

10. John B. Martin, U.S. Nuclear Regulatory Commission, Update of NRC Uranium Mill Licensing Activities, Paper at Annual Uranium Industry Seminar, Grand Junction, Colorado, October 1978.

11. U. S. Nuclear Regulatory Commission, Operation of Bear Creek Project, Rocky Mountain Energy Company Docket No. 40-8452, PB-267 375 Nationa1 Technical Information Service, Springfield, VA, June 1977. 


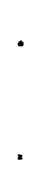




\subsection{RELATIVE COST AND EFFECTIVENESS ESTIMATES FOR ENVIRONMENTAL CONTROL TECHNOLOGIES}

The cost and effectiveness of the technologies discussed in the previous section are estimated for the mining, milling, and refining of the various thorium resources outlined in this section. These estimates can be used for preliminary planning and analys is but more accurate costs and estimates of effectiveness will have to be determined during the site-specific feasibility and environmental impact studies or during the preliminary plant design.

The estimates are based on a general review of the literature $(1,2,3,4,5)$ and augmented by discussions with sales engineers in some cases. The vendors all cautioned that, in order to make accurate $( \pm 30 \%)$ estimates, it is necessary to have an accurate assessment of process and layout, thorough ore characterization, and site-specific (e.g., climate, geology, water availability, etc.) and other data available. Preliminary laboratory and full-scale tests should also be run when practicable. Sometimes, even with thorough advance testing, some surprises occur at the startup of production. Production downtime alone may be of enough importance to sway a decision on which method or system to use.

The control methods analyzed in this study represent a cross-sectional comparision of methods in various stages of advancement. Because the technology of dust collection is well advanced, there is a wide selection of hardware designs. The dust collection methods included in this study represent a selection of some of the many methods, which range in efficiency from high to low. On the other hand, the technology for tailings storage is not as well advanced. Both conventional tailings storage methods and more advanced, but less tested, methods have been included in this study.

The estimated cost range for the seven thorium resource sites considered in this study are sumarized in Table 5.1. Details on the cost and effectiveness of various environmental control technologies are provided in Tables 5.2, 5.3 , and 5.4 .

Table 5.1 indicates that the range of costs at each site can vary by up to two orders of magnitude. The lower end of the cost spectrum represents the 
use of the most simple, least costly, and usually least effective environmental control technologies. In this study, the lowest cost represents the base technology case. The upper end of the cost spectrum utilizes the most sophisticated, most costiy, and usually most effective technologies. However, some of the more advanced and costly technologies will require testing and actual use in the field before their effectiveness can be accurately assessed. The large contingency of up to $200 \%$ can apply because geologies may have adverse variations, special materials may be required in equipment construction, or larger equipment capacities or additional equipment may be required due to the nature of the ore or processes selected.

TABLE 5.1. Cost Range for Environmental Control for the Mining, Milling, and Refining of Various Thorium Resources

\begin{tabular}{lr}
\multicolumn{1}{c}{ Location } & $\begin{array}{c}\text { Aproximate Cost Ran } \\
\text { Cost } / \text { ib of Thoria Produc }\end{array}$ \\
\cline { 3 - 4 } Lemhi Pass & $\$ 0.63$ to $\$ 40.65$ \\
Hall Mountain & $\$ 0.28$ to $\$ 16.35$ \\
Wet Mountain & $\$ 0.34$ to $\$ 18.96$ \\
Palmer, Michigan & $\$ 0.46$ to $\$ 2.13$ \\
Bald Mountain & $\$ 4.29$ to $\$ 26.22$ \\
Conway Granite & $\$ 0.43$ to $\$ 4.56$ \\
Stockpile Refinery $(c)$ & $\$ 0.15$ to $\$ 1.98$
\end{tabular}

(a) Maximum cost is for the more effective but usually more complex methods and includes up to a $200 \%$ contingency on estimates.

(b) Minimum cost represents the base technology, which is usually the most available, lowest cost, and simplest to employ (e.g., equipment constructed of mild steel, easy to move soil, good onsite availability of construction materials, no special protection from the environment, low contingency, etc.).

(c) Does not include mining and milling environmental control costs. 
TABLE 5.2. Cost and Effectiveness of Environmental Control Technologies at Lemhi Pass, Hall Mountain, and Wet Mountain

\begin{tabular}{|c|c|c|c|c|c|c|c|c|}
\hline Generated Waste and Control Method & \multicolumn{2}{|c|}{$\begin{array}{c}\text { Lemhi Pass } \\
\text { Cost Estimates(a) } \\
\text { Capital Cost Annual Cost }\end{array}$} & \multicolumn{2}{|c|}{$\begin{array}{c}\text { Hall Mountain } \\
\text { Cost Est imates(a) } \\
\text { Capital Cost Annual Cost }\end{array}$} & \multicolumn{2}{|c|}{$\begin{array}{l}\text { Wet Mountain } \\
\text { Cost Est imates }(a) \\
\end{array}$} & $\begin{array}{r}\text { Estimate of Relatjuge } \\
\text { Effectiveness }(b)\end{array}$ & $\begin{array}{l}\text { Technology } \\
\text { Conf idence } \\
\text { Level(b) } \\
\end{array}$ \\
\hline $\begin{array}{l}\text { Mine Water } \\
\text { Sett ting Pond (Base) }\end{array}$ & 35,200 & 11,100 & 21,700 & 9,700 & 21,700 & 9,700 & $30 \%$ to $90 \%$ Solids Settle & High \\
\hline Add Flocculation and Clarification & 292,700 & 123,300 & 180,200 & 94,100 & 180,200 & 94,100 & $\begin{array}{l}\text { TSS Reduced } 97 \% \text {, COD Reduced } \\
\text { by } 86 \% \text {, Radium Reduced } 99 \%\end{array}$ & High \\
\hline $\begin{array}{l}\text { Add Ion Exchange } \\
\text { Add Barium ChIoride Coprecipitation }\end{array}$ & $\begin{array}{r}473,000 \\
41,700\end{array}$ & $\begin{array}{r}163,600 \\
52,800\end{array}$ & $\begin{array}{r}288,500 \\
25,400\end{array}$ & $\begin{array}{r}135,700 \\
32,400\end{array}$ & $\begin{array}{r}288,500 \\
25,400\end{array}$ & $\begin{array}{r}135,700 \\
32,400\end{array}$ & $\begin{array}{l}\text { Recovers } 92 \% \text { of Thorium } \\
\text { Radium Reduced } 99.9 \%\end{array}$ & $\begin{array}{l}\text { Low } \\
\text { High }\end{array}$ \\
\hline $\begin{array}{l}\text { Add Lime Neutralization } \\
\text { Total If All Methods Used }\end{array}$ & $\frac{141,000}{983,600}$ & $\frac{70,500}{421,300}$ & $\frac{86,000}{601,800}$ & $\frac{52,700}{324,600}$ & $\frac{86,000}{601,800}$ & $\frac{52,700}{324,600}$ & $\begin{array}{l}\text { Precipitates Heavy Metals, Increases } \\
\text { pH, Helps Remove Radium }\end{array}$ & High \\
\hline $\begin{array}{l}\text { - Controlled Mine Ore Dust and Thoron (Underground) } \\
\text { W/0 Control Equipment (Base) } \\
\text { Add Baghouse Filter } \\
\text { Add HEPA Filter (Includes Baghouse Filter) }\end{array}$ & $\begin{array}{r}0 \\
892,000 \\
2,697,000\end{array}$ & $\begin{array}{r}0 \\
464,000 \\
1,199,000\end{array}$ & $\begin{array}{r}0 \\
522,800 \\
\mathrm{I}, 580,000\end{array}$ & $\begin{array}{r}0 \\
361,200 \\
954,300\end{array}$ & $\begin{array}{r}0 \\
466,700 \\
1,410,700\end{array}$ & $\begin{array}{r}0 \\
320,600 \\
847,600\end{array}$ & $\begin{array}{l}\text { No Dust or Thoron Reduction } \\
99.9+\% \text { Dust Reduction } \\
99.99+\% \text { Oust Reduction }\end{array}$ & $\begin{array}{l}\text { High } \\
\text { Medium }\end{array}$ \\
\hline Add Charcoal Filter (Incl. Baghouse \& HEPA Filters & s) $4,821,000$ & $1,932,000$ & $2,825,000$ & $1,558,900$ & $2,521,500$ & $1,385,900$ & $\begin{array}{l}99.99+\% \text { Dust Reduction and } \\
99+\% \text { Thoron Reduction }\end{array}$ & Low \\
\hline $\begin{array}{l}\text { - Uncontrolled Dust (Surface) } \\
\text { Spray Road, Yard and Loading/Unloading Areas (Base } \\
\text { Ore Pile Wind Barriers (Base) } \\
\text { Ore Pile Storage Buildings }\end{array}$ & $\begin{array}{l}30,000 \\
15,000 \\
60,000\end{array}$ & $\begin{array}{r}29,200 \\
5,000 \\
16,200\end{array}$ & $\begin{array}{r}17,300 \\
8,700 \\
34,600\end{array}$ & $\begin{array}{r}18,500 \\
4,200 \\
14,200\end{array}$ & $\begin{array}{r}16,000 \\
8,000 \\
32,000\end{array}$ & $\begin{array}{r}17,200 \\
3,700 \\
13,200\end{array}$ & $\begin{array}{l}30 \% \text { to } 95 \% \text { Dust Reduction } \\
20 \% \text { to } 60 \% \text { Dust Reduction } \\
80 \% \text { to } 100 \% \text { Dust Reduction }\end{array}$ & $\begin{array}{l}\text { High } \\
\text { High } \\
\text { High }\end{array}$ \\
\hline $\begin{array}{l}\text { - Mill Loading, Crushing and Grinding Dust and Thoron } \\
\text { Cyclone Dust Collector (Base) } \\
\text { Orifice Scrubber } \\
\text { Wet-Impingement Scrubber } \\
\text { Low-Energy Ventur i Scrubber } \\
\text { High-Energy Venturi Scrubber } \\
\text { Baghouse Filter } \\
\text { HEPA Filter (Includes Baghouse Filter) }\end{array}$ & $\begin{array}{r}19,900 \\
39,800 \\
47,800 \\
55,800 \\
67,700 \\
111,600 \\
337,400\end{array}$ & $\begin{array}{r}11,600 \\
21,500 \\
23,400 \\
32,600 \\
53,000 \\
51,700 \\
140,100\end{array}$ & $\begin{array}{r}13,500 \\
29,200 \\
35,100 \\
41,000 \\
49,700 \\
81,900 \\
247,700\end{array}$ & $\begin{array}{r}10,200 \\
17,900 \\
22,900 \\
29,300 \\
44,800 \\
49,100 \\
137,300\end{array}$ & $\begin{array}{l}11,100 \\
22,100 \\
26,500 \\
30,900 \\
37,600 \\
61,900 \\
187,100\end{array}$ & $\begin{array}{r}7,800 \\
13,400 \\
17,200 \\
21,800 \\
33,200 \\
36,900 \\
102,700\end{array}$ & $\begin{array}{l}50 \% \text { Dust Reduction } \\
94 \% \text { Dust Reduction } \\
97 \% \text { Dust Reduction } \\
99+\% \text { Dust Reduction } \\
99+\% \text { Dust Reduction } \\
99.9+\% \text { Dust Reduction } \\
99.99+\% \text { Dust Reduction }\end{array}$ & $\begin{array}{l}\text { High } \\
\text { High } \\
\text { High } \\
\text { High } \\
\text { High } \\
\text { High } \\
\text { Medium }\end{array}$ \\
\hline Charcoal Filter (Includes Baghouse \& HEPA Filter) & 603,100 & 228,800 & 442,700 & 223,600 & 334,400 & 172,100 & $\begin{array}{l}99.99+\% \text { Dust Reduction and } \\
99+\% \text { Thoron Reduction }\end{array}$ & Low \\
\hline $\begin{array}{l}\text { Wet-Impingement Scrubber (Base) } \\
\text { Low-Energy Venturi Scrubber } \\
\text { High-Energy Venturi Scrubber }\end{array}$ & $\begin{array}{l}39,900 \\
46,500 \\
56,500\end{array}$ & $\begin{array}{l}20,400 \\
26,800 \\
43,600\end{array}$ & $\begin{array}{l}46,200 \\
53,900 \\
65,500\end{array}$ & $\begin{array}{l}30,500 \\
39,000 \\
60,400\end{array}$ & $\begin{array}{l}38,300 \\
44,600 \\
54,200\end{array}$ & $\begin{array}{l}25,000 \\
39,100 \\
49,300\end{array}$ & $\begin{array}{l}97 \% \text { Dust Reduction } \\
99+\% \text { Dust Reduction } \\
99+\% \text { Dust Reduction }\end{array}$ & $\begin{array}{l}\text { High } \\
\text { High } \\
\text { High }\end{array}$ \\
\hline $\begin{array}{l}\text { - Refinery Packaging Dust } \\
\text { Baghause Filter (Base) } \\
\text { HEPA Filter (Includes Baghouse Filter) }\end{array}$ & $\begin{array}{l}22,700 \\
68,700\end{array}$ & $\begin{array}{r}9,900 \\
27,400\end{array}$ & $\begin{array}{l}24,700 \\
74,700\end{array}$ & $\begin{array}{l}14,300 \\
39,800\end{array}$ & $\begin{array}{l}20,300 \\
61,400\end{array}$ & $\begin{array}{l}11,800 \\
32,600\end{array}$ & $\begin{array}{l}\text { 99. } 9+\% \text { Dust Reduction } \\
99.99+\% \text { Dust Reduction }\end{array}$ & $\begin{array}{l}\text { High } \\
\text { High }\end{array}$ \\
\hline $\begin{array}{l}\text { - Tailings } \\
\text { Clay Core Dam (w/o Lining (Base) } \\
\text { Clay Core Dam } w / 3 \mathrm{ft} \text { Clay Liner } \\
\text { Clay Core Dam w/Aspha } 15 \text { tiner } \\
\text { Clay Core Dam w/Rubber }(\mathrm{c} \text { ) Liner } \\
\text { Dewater, Convey to Landf } \mathrm{i} 11 \\
\text { Dewater, Blend } w / 10 \% \text { Cement, Pump to Landfill } \\
\text { Dewater, Blend } w / 40 \% \text { Asphalt, Truck to Landf } i 11\end{array}$ & $\begin{array}{r}3,066,000 \\
3,416,000 \\
6,227,000 \\
6,296,000 \\
7,102,500 \\
6,487,400 \\
12,388,600\end{array}$ & $\begin{array}{r}913,400 \\
999,300 \\
1,866,100 \\
1,705,600 \\
2,146,200 \\
3,727,700 \\
19,203,300\end{array}$ & $\begin{array}{r}970,000 \\
1,046,700 \\
1,662,300 \\
1,677,400 \\
2,721,900 \\
2,310,100 \\
5,185,000\end{array}$ & $\begin{array}{r}449,700 \\
479,300 \\
777,400 \\
723,100 \\
1,230,600 \\
7,805,800 \\
8,527,100\end{array}$ & $\begin{array}{r}902,200 \\
974,800 \\
1,556,500 \\
1,570,800 \\
2,469,600 \\
2,107,400 \\
4,684,000\end{array}$ & $\begin{array}{r}416,900 \\
444,900 \\
669,800 \\
675,300 \\
1114,000 \\
1,622,500 \\
7,529,500\end{array}$ & $\begin{array}{l}0 \% \text { to } 15 \% \text { Seepage } \\
0 \% \text { to } 3 \% \text { Seepage } \\
0 \% \text { to } 1 \% \text { Seepage } \\
0 \% \text { to } 0.2 \% \text { Seepage } \\
0 \% \text { to } 0.1 \% \text { Seepage }(g) \\
0 \% \text { to } 0.08 \% \text { Seepage }(g) \\
0 \% \text { to } 0.06 \% \text { Seepage }\end{array}$ & $\begin{array}{l}\text { High } \\
\text { Medium } \\
\text { Low } \\
\text { High } \\
\text { Medium } \\
\text { Low } \\
\text { Low }\end{array}$ \\
\hline $\begin{array}{l}\text { - Tailings Beach Dust } \\
\text { Spraying w/Dam Case (Base) } \\
\text { Spraying w/Dewatering Case (Base) }\end{array}$ & $\begin{array}{l}20,000 \\
10,000\end{array}$ & $\begin{array}{l}26,000 \\
13,000\end{array}$ & $\begin{array}{r}11,500 \\
5,800\end{array}$ & $\begin{array}{r}16,000 \\
8,000\end{array}$ & $\begin{array}{r}10,700 \\
5,800\end{array}$ & $\begin{array}{r}14,700 \\
7,400\end{array}$ & $\begin{array}{l}50 \% \text { to } 95 \% \text { Effective } \\
50 \% \text { to } 95 \% \text { Effective }\end{array}$ & $\begin{array}{l}\text { Medium } \\
\text { Medium }\end{array}$ \\
\hline 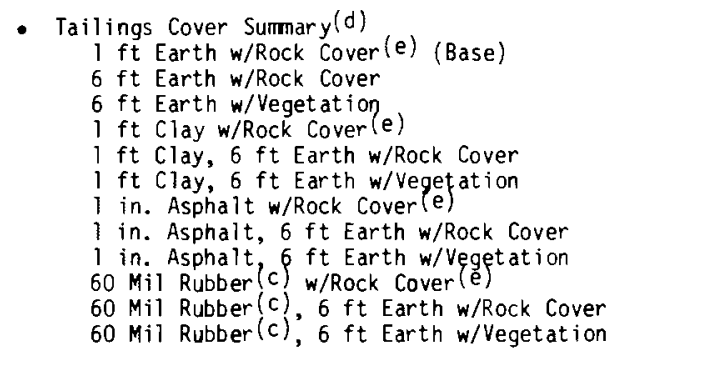 & $\begin{array}{r}320,000 \\
920,000 \\
800,000 \\
325,000 \\
1,045,000 \\
925,000 \\
1,500,000 \\
2,220,000 \\
2,100,000 \\
3,430,000 \\
4,115,000 \\
4,030,000\end{array}$ & $\begin{array}{l}1,000{ }^{f} \\
2,800 \\
2,400 \\
1,000 \\
3,200 \\
2,800 \\
4,600 \\
6,800 \\
6,400 \\
10,500 \\
12,700 \\
12,300\end{array}$ & $\begin{array}{l}70,100<f \\
201,700 \\
175,400 \\
71,200 \\
229,000 \\
202,800 \\
328,800 \\
486,600 \\
463,300 \\
751,900 \\
909,700 \\
883,400\end{array}$ & $\begin{array}{l}10,400(f \\
29,900 \\
26,000 \\
10,600 \\
34,000 \\
30,100 \\
48,800 \\
72,200 \\
68,300 \\
111,500 \\
134,900 \\
131,000\end{array}$ & $\begin{array}{l}66,400(f \\
190,400 \\
105,600 \\
67,300 \\
216,300 \\
191,500 \\
310,500 \\
459,500 \\
434,700 \\
710,000 \\
859,000 \\
834,200\end{array}$ & $\begin{array}{l}9,800(f) \\
28,200 \\
24,600 \\
10,000 \\
32,100 \\
28,400 \\
46,100 \\
68,200 \\
64,500 \\
105,300 \\
127,400 \\
123,700\end{array}$ & $\begin{array}{l}1 \text { (Base) } \\
10 \text { Times as Effective } \\
<10 \text { Times as Effective } \\
10 \text { Times as Effective } \\
20 \text { Times as Effective } \\
<20 \text { Times as Effective } \\
\text { Subject to Frost/Heaves } \\
310 \text { Times as Effective } \\
<310 \text { Times as Effective } \\
300 \text { Times as Effective } \\
310 \text { Times as Effective } \\
<310 \text { Times as Effective }\end{array}$ & $\begin{array}{l}\text { High } \\
\text { High } \\
\text { Medium } \\
\text { Medium } \\
\text { Medium } \\
\text { Medium } \\
\text { Low } \\
\text { Medium } \\
\text { Medium } \\
\text { Medium } \\
\text { Medium } \\
\text { Medium }\end{array}$ \\
\hline $\begin{array}{l}\text { Cost Summary } \\
\text { Minimum Cost } \\
\text { Maximum Cost } \\
\text { Production, Pounds 99\% Thoria } \\
\text { Minimum Cost/Pound 99\% Thoria } \\
\text { Maximum Cost/Pound } 99 \% \text { Theria }\end{array}$ & $\begin{array}{l}\$ 3,568,700 \\
\$ 23,136,500\end{array}$ & $\begin{array}{l}\$ 1,027,600 \\
\$ 21,987,100 \\
1,623,132 \quad 1 \\
\$ 0.63 / 1 \mathrm{~b} \\
\$ 13.55 / 1 \mathrm{~b}\end{array}$ & $\begin{array}{l}\$ 1,183,700 \\
\$ 10,162,100 \\
\text { los }\end{array}$ & $\begin{array}{l}\$ 563,500 \\
\$ 10,910,000 \\
2,002,000 \\
\$ 0.28 / 1 \\
\$ 5.45 / 1 \mathrm{~b}\end{array}$ & $\begin{array}{l}\$ 1,094,700 \\
\$ 9,170,100\end{array}$ & $\begin{array}{l}\$ 516,600 \\
\$ 9,659,200 \\
1,529,000 \text { lbs } \\
\$ 0.34 / 1 b \\
\$ 6.32 / 1 b\end{array}$ & & \\
\hline
\end{tabular}

Notes: (a) Costs could go up to 3 times as high for some sites because of variables in site and process characteristics.

(b) These are mostly the best estimates based upon literature written for the uranium industry and extrapolated to the thorium industry.

(c) Multi-Ply Hypalon or equivalent material. Assumptions: $6 \mathrm{ft}$ Earth reduces thoron emanation by factor of 11 from no cover.

I in. Asphalt equivalent to $60^{\prime}$ of earth cover.

(e) Radiation levels will likely be well above background initially and decay down to background levels after 50 years. Remainder of cases will

(f) Taikly be close to background at all times.

g) Includes an allowance for water storage pond leakage also. 


\section{TABLE 5.3. Cost and Effectiveness of Environmental Control Technologies}

at Palmer, Michigan, and Bald Mountain

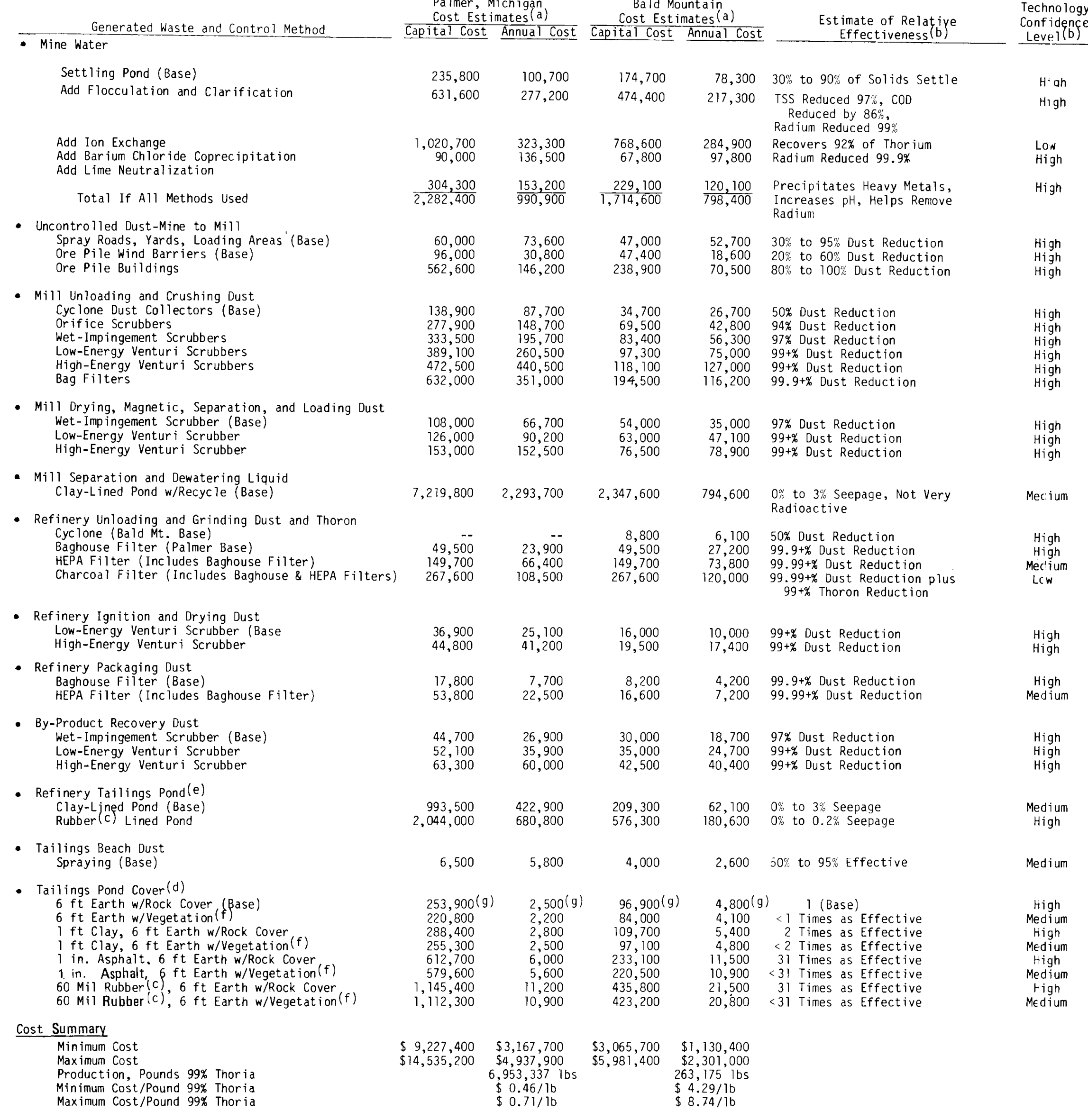

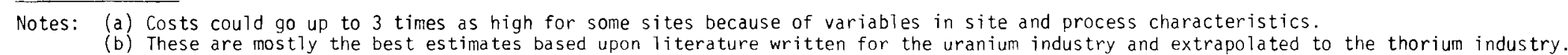
These are mostly the best estimates based upon literature written for the uranium industry and extrapolated to
The values could vary substantially by site. Full-scale tests would be required to get more accurate data.

(c) Multi-Ply Hypalon or equivalent material

(d) All of these cases eliminate release of radioactive dust unless breached some way. Also, radioactivity and thoron should be close to background levels.

(e) Only Palmer plant recycles the water to the refinery.

(f) Assumes no vegetation care is required. Slightly higher radioactivity and thoron release if roots penetrate to tailings

(g) Tailings cover capital costs are not incurred until after the refinery shuts down. A sinking fund is established to pay for the cover. 
. 
TABLE 5.4. Cost and Effectiveness of Environmental Control Technologies at Conway Granite and Stockpile Refinery

Generated Waste and Control Method

Settling Pond (Base)

Add Flocculation and Clarification

Add Ion Exchange

Add Barium Chloride Coprecipitation

Add Lime Neutralization

Total If All Methods Used

- Uncontrolled Dust

Spray Roads, Yard, Loading Areas (Base)

Ore Pile Wind Barriers (Base)

Ore Pile Buildings

- Mill Unloading, Crushing \& Grinding Dust Cyclones (Base)

- Mill Drying \& Packaging Dust Wet-Imp ingement Scrubber (Base) Low-Energy Venturi Scrubber High-Energy Venturi Scrubber

- Mill Tailings Pond

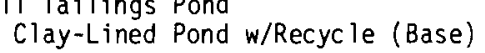

Clay-Lined Pond w/Recycle (Base)

- Refinery Waste Sludge

Truck to Clay-Lined Landfill (Base) $B$ lend w/Asphalt. Truck to Landfill Ship to Barnweli, S.C.

- Refinery Drying \& Packaging Dust Bag Filter and HEPAFilter (Base)

- Refinery Tailings Pond Clay-Ljned Evaporation Pond (Base) Rubber $(c)$ Lined Evaporation Pond

- Refinery Tailings Beach Dust Spraying (Base)

- Refinery Tails Pond Cover(d) $6 \mathrm{ft}$ Earth $w / 6$ in. Rock Cover (Base) $6 \mathrm{ft}$ Earth w/Vegetation (e) $1 \mathrm{ft}$ Clay, $6 \mathrm{ft}$ Earth w/Rock Cover $1 \mathrm{ft}$ Clay, $6 \mathrm{ft}$ Earth w/Vegetation(e) 1 in. Asphalt, $6 \mathrm{ft}$ Earth w/Rock Cover 1 in. Asphalt, $6 \mathrm{ft}$ Earth w/Vegetation $(e)$ $60 \mathrm{Mil}$ Rubber, (c) $6 \mathrm{ft}$ Earth w/Rock Cover
$60 \mathrm{Mil}$ Rubber, (c) $6 \mathrm{ft}$ Earth w/Vegetation $(\mathrm{e})$

\section{Cost Summary}

Minimum Cost

Maximum Cost

Production, Pounds $99 \%$ Thoria

Minimum Cost/Pound 99\% Thoria Maximum Cost/Pound $99 \%$ Tharia

\begin{tabular}{|c|c|}
\hline \multicolumn{2}{|c|}{$\begin{array}{l}\text { Conway Granite } \\
\text { Cost Est imates }(a)\end{array}$} \\
\hline apital Cost & Annua $\mathrm{Cos}$ \\
\hline$\$ 293,000$ & 153,200 \\
\hline 770,600 & 412,000 \\
\hline $\begin{array}{r}1,248,200 \\
110,000\end{array}$ & $\begin{array}{l}476,600 \\
240,800\end{array}$ \\
\hline 372 & 231 \\
\hline 2,793, & \\
\hline
\end{tabular}

$\begin{array}{rr}75,000 & 125,000 \\ 150,000 & 44,100\end{array}$

$\begin{array}{rr}150,000 & 44,100 \\ 950,900 & 247,900\end{array}$

$\begin{array}{rr}69,500 & 53,000 \\ 389,100 & 221,300\end{array}$

$54,000 \quad 34,900$

$\begin{array}{ll}63,000 & 45,500 \\ 76,500 & 77,300\end{array}$

$908,300 \quad 368,400$

$178,500 \quad 65,500$

$\begin{array}{rr}178,500 & 65,500 \\ 459,800 & 367,100\end{array}$

25,000

707,700

186,800

90,600

157,100

404,600
25,000

Stockpile Refinery

Capital Cost Annual Cost

$326,800 \quad 86,000$

972,900

86,000
244,700

103,700

164,000

3,100

4,000

145,800 (f)

126,800

165,600

146,600

351,900

332,900

657,800
638,800

$\$ 2,391,700$
$\$ 7,475,000$

$1,400(f)$

1,200

1,600
1,400
3,400
3,200

1,400
3,400
3,200
6,400

6,200 $70,100(f)$

60,900

79,400

70,300

168,700

159,600

315,400

306,300
57,600

323,100
466,500

45,500

\begin{tabular}{cc}
$\begin{array}{c}\text { Estimate of Relative } \\
\text { Effectiveness (b) }\end{array}$ & $\begin{array}{c}\text { Technolcgy } \\
\text { Conf idence } \\
\text { Level(t) }\end{array}$ \\
\hline
\end{tabular}

$30 \%$ to $90 \%$ Solids Settle High

TSS Reduced $97 \%$, COD Reduced by $86 \%$, High Radium Reduced 99\% $\begin{array}{ll}\text { Recovers } 92 \% \text { of Thor ium } & \text { Low } \\ \text { Radium Reduced } 99.9 \% & \text { High }\end{array}$

Precipitates Heavy Metals, Increase High pH, Helps Remove Radium

$30 \%$ to $95 \%$ Dust Reduction

$20 \%$ to $60 \%$ Dust Reduction

$80 \%$ to $100 \%$ Dust Reduction

$50 \%$ Dust Reduction

99. $9+\%$ Dust Reduction

97\% Dust Reduction

$99+\%$ Dust Reduction

$99+\%$ Dust Reduction

$0 \%$ to $3 \%$ Seepage, Not Very

Radioactive

$0 \%$ to $0.04 \%$ Seepage

$0 \%$ Seepage

99. $99+\%$ Dust Reduction

$43,100 \quad 0 \%$ to $3 \%$ Seepage

$126,600 \quad 0 \%$ to $0.2 \%$ Seepage

2,400 50\% to $95 \%$ Effective

$\begin{array}{ll}700(f) & 1 \text { (Base) } \\ 600<1 \text { Times } & \end{array}$

$600<1$ Times as Effective

8002 Times as Effective

$700<2$ Times as Effective

1,600 31 Times as Effective

,600<31 Times as Effective

$3,000<31$ Times as Effective
3,00tive

$\begin{array}{cr}\$ 1,025,200 \quad \$ 489,700 & \$ 149,200 \\ \$ 3,606,600 \quad \$ 1,322,400 & \$ 639,100 \\ 2,376,605 \text { 1bs } & 965,580 \text { 1bs } \\ \$ 0.43 / 1 \mathrm{~b} & \$ 0.15 / 1 \mathrm{~b} \\ \$ 1.52 / 7 \mathrm{~b} & \$ 0.66 / 1 \mathrm{~b}\end{array}$

Notes: (a) Costs could go up to 3 times as high for some sites because of variables in site and process characteristics.

(b) These are mostly the best estimates based upon literature written for the uranium industry and extrapolated to the thorium industry.

(d) All of these cases el iminate release of radioactive dust unless breached some way. Also, radioactivity and thoron should be close to background levels.

(e) Slightly higher radioactivity and thoron release if roots penetrate to taijings. Assumes no vegetation care is required.

(f) Tailings cover capital costs are not incurred until after the refinery shuts down. A sinking fund is established to pay for the cover. 
Tables 5.2, 5.3, and 5.4 contain estimates of the capital cost, annual cost, relative effectiveness, and technology confidence level for each generated waste and environmental control method assumed. The base technology method for each waste is identified in the tables. The cost summaries for Tables 5.2, 5.3, and 5.4 cannot be directly compared to each other because they contain data for different types of resources that use different processes.

Table 5.2 sumarizes data for underground thorite mine resources with relatively high-grade ore $(0.35 \%$ to $1.1 \%$ thoria). Lemhi Pass is more costly than Hall Mountain and Wet Mountain primarily because it has a much lower grade of thoria.

Table 5.3 summarizes the data for open-pit conglomerate mine resources with low grades of thoria $(0.0095 \%$ to $0.06 \%)$. The Palmer, Michigan, environmental control costs are much lower than at Bald Mountain because the Palmer, Michigan, operation uses a higher grade of ore and a higher throughput.

Table 5.4 compares only the Conway Granite resource refinery with the stockpile refinery. The unit environmental costs for the two refineries are essentially the same.

The effectiveness of the technologies used in this study have the potential of holding offsite discharge of effluents to very low levels. As can be observed from the tables, the more effective technologies usually cost more. An example of how costs rise with effectiveness is shown in Figure 5.1, which represents the methods for controlling dust from unloading, crushing, and grinding the ore at the Lemhi Pass mill.

\subsection{COST ESTIMATES FOR ENVIRONMENTAL CONTROL TECHNOLOGIES}

The cost estimates for all of the thorium mine sites are surmarized in Tables 5.2, 5.3, and 5.4. The capital costs include the total installation costs. The constitutent factors used are itemized in Section 5.1.1. The annual costs include a 11 of the operating costs (Section 5.1.2), allowances for annual depreciable fixed charges, and a fixed charge for 1 and and working capital, which are explained in Sections 5.1.3 and 5.1.4. Examples of calculations are provided in Appendices $E$ and $F$. 


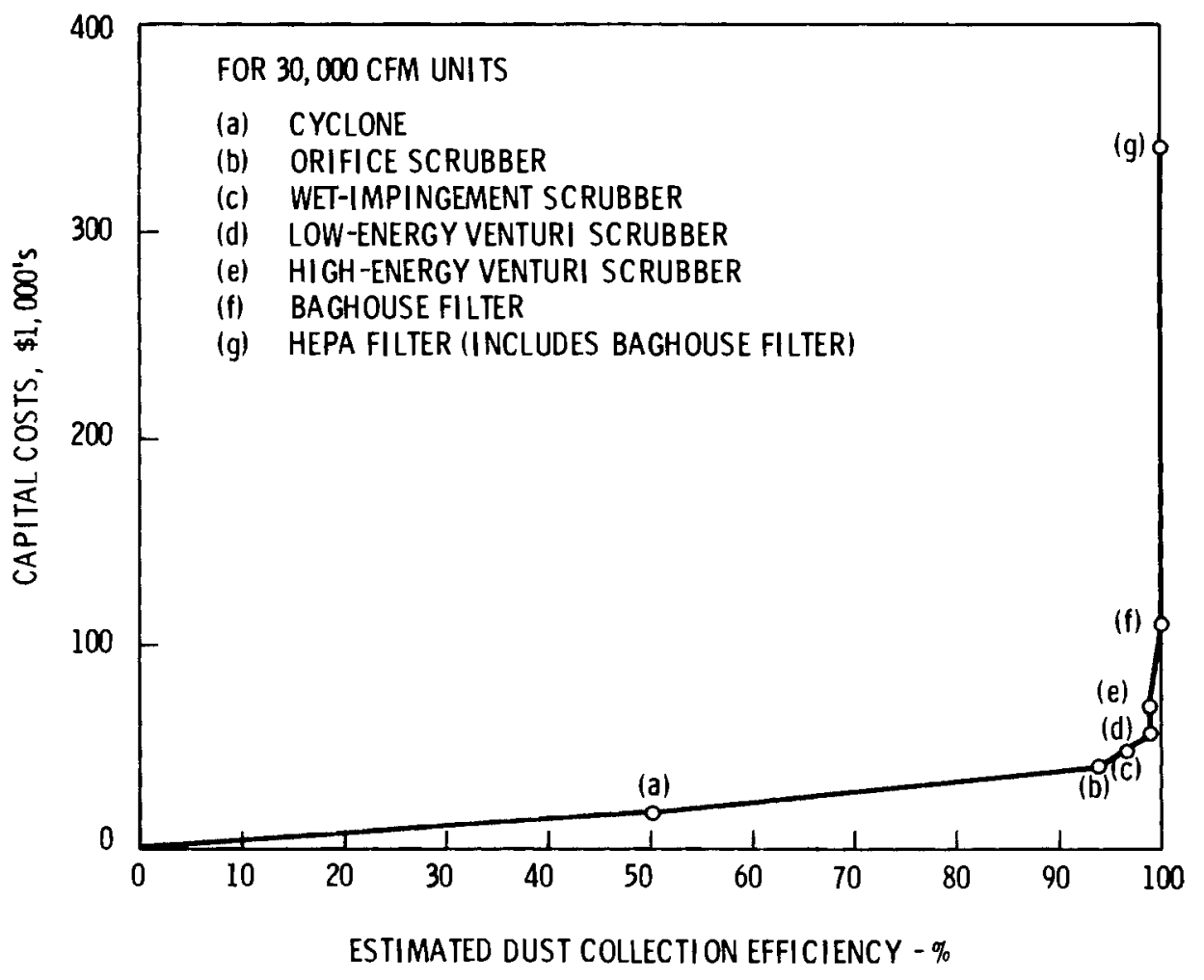

FIGURE 5.1. Lemhi Pass Mill Unloading, Crushing, and Grinding Dust Collection Capital Costs as a Function of Efficiency 


\subsubsection{Capital Installation Cost}

The capital cost of installing the equipment in this report is comprised of the following elements:

\begin{tabular}{lcc}
\multicolumn{1}{c}{ Direct Costs } & Factor $(\%)(\mathrm{a})$ \\
\cline { 1 - 1 } Purchased Equipment - Delivered & & 100 \\
Equipment Installation & 41 \\
Instrumentation and Controls & 13 \\
Piping (Installed) & 31 \\
Electrical (Installed) & $\underline{10}$
\end{tabular}

Total Direct Plant Cost

Indirect Costs

\begin{tabular}{lr}
\hline Engineering and Supervision & 32 \\
Construction Expenses & 34 \\
$\quad$ Total Indirect Plant Cost & 66 \\
Contractor's Fee (5\% of DPC \& IPC) & 13 \\
Contingency (10\% of DPC \& IPC) & $\underline{26}$ \\
Total Capital Installation Cost & $\underline{\underline{300}}$
\end{tabular}

(a) Based on the values in Reference 3 and rounded off for calculation.

The land required for a specific facility (e.g., tailings pond) is costed out at the purchase price and is included in the cost estimate. The cost of installing the items that contain no equipment (e.g., settling pond) include the costs of construction plus $20 \%$ for project costs. 


\subsubsection{Operating Costs}

The operating costs include the costs of operating labor, maintenance, materials, power, and miscellaneous items. The cost of the operating labor includes these constituents:

\begin{tabular}{lr} 
Labor & $\$ 8.70 / \mathrm{hr}$ \\
Direct Supervision and Clerical (15\% of Labor) & $1.31 / \mathrm{hr}$ \\
Laboratory Charges (15\% of Labor) & $1.31 / \mathrm{hr}$ \\
Plant Overhead & $7.05 / \mathrm{hr}$ \\
Administration Overhead & $1.76 / \mathrm{hr}$ \\
\hline Total Operating Labor Cost & $\$ 20.13 / \mathrm{hr}$
\end{tabular}

The maintenance costs were usually taken as a flat percentage ( $1 \%$ to $6 \%$ ) of the capital installation cost. Whenever possible, the man hours were estimated and costed out at $\$ 20.13 / \mathrm{hr}$, which included an allowance for replacement parts. In cases where major maintenance replacement components were required, the costs were itemized separately (e.g., filter bags for baghouses). The major materials routinely consumed in the environmental control process were also itemized and costed separately, (e.g., lime, cement, asphalt, etc.). Power consumption was estimated in terms of kilowatt hours and it was costed out at $\$ 0.03 / \mathrm{kWh}$. The miscellaneous category included contingency and other items (e.g., special supplies, parts, etc.) that were inexpensive and general in nature.

\subsubsection{Equivalent Annual Charge for Depreciable Capital Investment}

A fixed rate was applied to convert a depreciable capital investment into an equivalent annual revenue requirement. Rather than calculate a year-byyear cash flow, a single fixed charge rate is assumed to apply over the life of the facility. The fixed charge rate includes provisions for capital recovery, bond interest, return on equity, federal income tax, state income tax, property tax, and property insurance. The fixed charge rate was calculated for the facility assuming financial conditions typical for a uranium mining company. For such a company, the data in Table 5.5 were assumed. 
TABLE 5.5. Depreciable Capital Investment

(\%)

Capitalization

Debt

24

Equity

76

Bond Interest Rate

8

Return on Equity

15

Feberal Income Tax

48

State Income Tax

7

Property Tax

2.5 of Capital Cost

Property Insurance

0.5 of Capital Cost

Mine/Mill Life

Site Dependent

Depreciation

Sum-of-the-Year's-Digits Method

When the factors assumed in Table 5.5 were used, the following annual capital charge rates were calculated:

\begin{tabular}{ccc} 
Facility Life & & Rate \\
\cline { 1 - 1 } $5 \mathrm{yr}$ & & 0.3681 \\
$10 \mathrm{yr}$ & & 0.2668 \\
$12 \mathrm{yr}$ & 0.2529 \\
$14 \mathrm{yr}$ & 0.2441 \\
$20 \mathrm{yr}$ & 0.2338 \\
$28 \mathrm{yr}$ & 0.2336
\end{tabular}

The rate was simply multiplied by the capital installation cost to give the annual charge for depreciable capital.

\subsubsection{Equivalent Annual Charge for Nondepreciable Capital Investment}

The fixed charge described in Section 5.1.3 does not apply to nondepreciable assets, which include land and working capital. In this study, it was assumed that a cost equivalent to $5 \%$ of the depreciable investment would 
represent the annual 1 and and working capital charge. This cost rate was used because the charge is minor, and it simplified the many calculations performed in this study.

\subsubsection{Annual Cost}

The annual cost is the sum of the operating cost, the annual depreciable charge, and the annual nondepreciable charge. This cost provides the economic comparision between methods for total costs on an annual basis.

\subsection{EFFECTIVENESS ESTIMATES FOR ENVIRONMENTAL CONTROL TECHNOLOGIES}

The effectiveness of the various environmental control technologies can vary considerably between sites. Like the costs for control, the effectiveness estimates are order-of-magnitude-type approximations. The effectiveness estimates for all of the thorium mine, mill, and refinery sites are summarized in Tables 5.2, 5.3, and 5.4.

\subsubsection{Control of Airborne Dust from Productive Equipment}

To control the dust effluents from mine ventilation, loading, crushing, grinding, by-product recovery, drying, ignition, and packaging-type operations, the list of equipment in Table 5.6 was assumed. The list provides a guide for a preliminary relative comparison of the equipment's dust collection efficiency only. The actual efficiencies of the equipment are likely to be lower because the dust grain loadings of waste air assumed in this study are lower than needed for the equipment to perform optimally.

\subsubsection{Control of Airborne Dust From Roads and Yards}

Road and yard dust can be controlled by tying down the dust with moisture or chemicals. The frequency and amount of spraying depends on the weather, amount of usage, type of dust, type of surface, etc. If rigidly administered, the dust in these areas should be controlled with close to $100 \%$ effectiveness although costs may become prohibitive.

\subsubsection{Control of Airborne Dust From Ore Storage Piles}

The primary method of protecting the ore storage piles from wind erosion is to erect prevailing wind barriers or store the ore in buildings. With some 
TABLE 5.6. Dust Collector Efficiency Estimates (3)

\begin{tabular}{|c|c|c|}
\hline \multirow[b]{2}{*}{ Type of Equipment } & \multicolumn{2}{|c|}{ Collection Efficiency $(\%)$} \\
\hline & 5 Micron Particles $(a)$ & 1 Micron Particle \\
\hline Cyclone & 50 & -- \\
\hline Orifice Scrubber & 94 & 50 \\
\hline Wet-Impingement Scrubber & 97 & 80 \\
\hline Low-Energy Venturi Scrubber & $99+$ & 96 \\
\hline High-Energy Venturi Scrubber & $99+$ & 98 \\
\hline Baghouse Filter & $99.9+$ & $99+$ \\
\hline HEPA Filter & $99.99+$ & $99.97+$ \\
\hline
\end{tabular}

(a) This study assumed the nominal particle size for dust was 5 microns.

types of ore and localities, it may be satisfactory to keep the ore tied down with water spray or to use the spray in conjunction with barriers. It was assumed in this study that a two-sided barrier located on the side of the most prevailing winds would be $20 \%$ to $60 \%$ effective in reducing dust. If supplementary spraying were used, a greater than $60 \%$ dust reduction is possible. The dampness would also reduce the release of dust from subsequent handling operations. The use of a full-scale building is estimated to be $80 \%$ to $100 \%$ effective in holding down the dust. However, when high-grade ore is used, the building would need some ventilation to maintain low thoron levels.

\subsubsection{Control of Airborne Dust From Tailings Beaches}

In this study, plenty of water was available to maintain a water cover over the tailings. This appreciably reduces the amount of dust released from the tailings ponds and is up to $99+\%$ effective. The remaining particles that wash up onto the beach can be periodically sprayed to tie them down or washed back into the pond. If treatments are administered at the right times, up to 95\% of dust released from this source will be eliminated; however, the costs may become prohibitive as $100 \%$ effectiveness is approached. 


\subsubsection{Mine Water Control}

The effectiveness estimates for mine water control were taken from uranium mine data. (1) The estimates are as follows:

Method

Settling Pond

Add Flocculation and Clarification

Add Ion Exchanger

Add Barium Chloride Coprecipitation

Add Lime Neutralization
Effectiveness

30 to $90 \%$ of solids will settle out.

TSS are reduced by $97 \%$, COD is reduced by $86 \%$, and radium is reduced by up to $99 \%$.

Recovers up to $92 \%$ of thorium.

Radium is reduced up to $99.9 \%$.

Precipitates heavy metals, increases $\mathrm{pH}$, and helps remove up to $90 \%$ of radium.

\subsubsection{Control of Tailings Pond Seepage}

The effectiveness of various methods of depositing the tailings to control seepage are estimated in Table 5.7. The base technology in this study is the use of a clay-core dam for a tailings pond in lieu of the more traditional dams constructed out of tailings. This should reduce seepage by up to a factor of five. The effectiveness of adding a 3-ft $\mathrm{clay}$ liner to the pond bottom should reduce seepage by another factor of 5 to 10 . All of the remaining methods should essentially reduce seepage to zero, providing the liners are protected from breach by climatic effects, rodents, vehicular and animal traffic, etc. (The figures for effectiveness are best engineering judgements based upon very little available data and represent relative approximations on 7 y.)

\subsubsection{Tailings Covers (at Decommissioning)}

It will be necessary to cover the tailings in landfill pits or evaporated tailings ponds to tie down radioactive dust, reduce radioactivity levels at the surface, and reduce the emanation of thoron gas to the atmosphere. 
TABLE 5.7. Estimated Effectiveness of Various Methods of Seepage Control

Method

Clay-core dam without a lining (base)

Clay-core dam with a 3-ft clay liner

Clay-core dam with a 2-in. asphalt liner

Clay-core dam with a 60-mil rubber(a) liner

Dewater tailings and convey to clay-lined

landfill

Dewater tailings, blend with $10 \%$ cement, and pump to a clay-lined landfill

Dewater tailings, blend with $40 \%$ asphalt, and truck to an unlined landfill
Effectiveness

0 to $15 \%$ Seepage

0 to $3 \%$ Seepage

0 to $1 \%$ Seepage

0 to $0.2 \%$ Seepage

0 to $0.10 \%$ Seepage $^{(b)}$

0 to $0.08 \%$ Seepage ${ }^{(b)}$

0 to $0.06 \%$ Seepage ${ }^{(b)}$

(a) Multi-ply Hypalon or equivalent.

(b) Includes allowance for rubber-lined recycle water storage pond also. However, this pond will not contain as large an amount of radionuclides and it will be spread over a smaller area.

The thickness requirements for covers over thorium mill tailings will not be as great as for uranium mill tailings because the radioactivity levels will decay substantially after $50 \mathrm{yr}$. Also, ${ }^{220} \mathrm{Ra}$ (thoron) requires about $1 / 6000^{\text {th }}$ the thickness of ${ }^{222} \mathrm{Ra}$ for an equivalent reduction of radon emanation to the environment, due to thoron's shorter half-life (e.g., for the same gas volume, pressure, and temperature, $1 \mathrm{ft}$ of soil is as effective for reducing ${ }^{220} \mathrm{Ra}$ emanation as $6000 \mathrm{ft}$ of soil is for ${ }^{222} \mathrm{Ra}$ emanation). Therefore, the covers assumed for the tailings in this study are probably excessively thick.

The effectiveness of earth, clay, and other covers will vary from site-tosite. Past studies $(2,5)$ of uranium tailings covers estimated the relative effectiveness of various materials for the cover as: 


\begin{tabular}{lc}
\multicolumn{1}{c}{ Cover } & $\begin{array}{c}\text { Fraction of } \\
\text { Radon Emitted (a) }\end{array}$ \\
\cline { 1 - 1 } No Cover (Base) & 1 \\
$1 \mathrm{ft} \mathrm{of} \mathrm{Earth}$ & 0.7 \\
$6 \mathrm{ft}$ of Earth & 0.09 \\
$10 \mathrm{ft}$ of Earth & 0.02 \\
$60 \mathrm{ft} \mathrm{of} \mathrm{Earth}$ & 0.003 \\
$1 \mathrm{in.} \mathrm{of} \mathrm{Asphalt}$ & 0.003 \\
$60 \mathrm{mil}$ of Rubber & 0.003 \\
(Hypalon or Equiv.) & \\
\hline (a) Based upon 222Ra data for uranium tailings. \\
Values should be much lower for 220Ra.
\end{tabular}

\subsubsection{Refinery Waste Sludge}

It was assumed that if the waste sludge were not shipped to offsite burial grounds, it would be disposed of in onsite landfills well above the groundwater table. The effectiveness against seepage was estimated as follows:

Method

Truck to $c l a y-l i n e d ~ l a n d f i l 1$

Blend with asphalt and truck to landfill

Ship to approved burial site $\frac{\text { Effectiveness }}{0 \text { to } 0.4 \% \text { seepage }}$

$0 \%$ seepage

$0 \%$ seepage

\subsection{REFERENCES}

1. Environmental Protection Agency, Group II, Development Document for Interim Final and Proposed Effluent Limitation Guidelines and New Source Performance Standards for the Ore Mining and Dressing Industry, EPA 440/1-75061, U.S. Environmental Protection Agency, Washington, DC. October 1975. 
2. M. B. Sears et al., Correlation of Radioactive Waste Treatment Costs and the Environmental Impact of Waste Effluents in the Nuclear Fuel Cycle for Use in Establishing "As Low as Practicable" Guides - Milling of Uranium Ores, ORNL-TM-4903, Vol. 1, Oak Ridge National Laboratory, Oak Ridge, TN, May 1975.

3. Belga G. Liptak, Environmental Engineers Handbook: Air Pollution, Vol. 2, Chilton Book Company, Radnor, Pennsylvania, $1908919 \overline{74 .}$

4. Engineering-Science, Inc., Field Surveillance and Enforcement Guide for Primary Metallurgical Industries, PB-230, 898, prepared for Environmental Protection Agency by Engineering-Science, Inc., National Technical Information Service, Springfield, VA. 22161, December 1973.

5. U.S. Nuclear Regulatory Commission, Operation of Bear Creek Project Rocky Mountain Energy Company, Docket No. 40-8452, PB-267 375, National Technical Information Service, Springfield, VA. 22161, June 1977. 


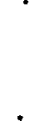


APPENDIX A

SITE-SPECIFIC DATA 
TABLE A.1. Site-Specific Data(a)

\begin{tabular}{|c|c|c|c|c|}
\hline Mine & Sludge & $\begin{array}{l}\text { Lemini } \\
\text { Pass }\end{array}$ & Mountain & Mountain \\
\hline Type & -- & Underground & Underground & Underground \\
\hline Mineral & -- & Thorite & Thorite & Thorite \\
\hline Average Grade, $\%$ & -- & 0.356 & 1.1 & 0.96 \\
\hline $\mathrm{ThO}_{2}$ Reserves, tons & -- & 67,700 & 5,210 & 66,900 \\
\hline Production, tons/day & -- & 1,000 & 400 & 350 \\
\hline $\mathrm{hr} /$ day $\times$ day $/ y r$ & -- & $16 \times 250$ & $16 \times 250$ & $16 \times 250$ \\
\hline $\begin{array}{l}\text { Dust Generated } \\
\text { Wastes }\end{array}$ & -- & $\begin{array}{l}156.16 \\
2.55 \times 10^{-4}\end{array}$ & $\begin{array}{l}62.50 \\
3.158 \times 10^{-4}\end{array}$ & $\begin{array}{l}54.69 \\
2.41 \times 10^{-4}\end{array}$ \\
\hline $\begin{array}{ll}\text { Liquid Generated } & \\
\text { Wastes } & -\mathrm{b} / \mathrm{hr} \\
& -\mathrm{gpm} \\
& -\mathrm{Ci} / \mathrm{hr}\end{array}$ & $\begin{array}{l}-- \\
-- \\
--\end{array}$ & $\begin{array}{l}250,000 \\
500 \\
1.43 \times 10^{-3}\end{array}$ & $\begin{array}{l}125,000 \\
250 \\
7.2 \times 10^{-4}\end{array}$ & $\begin{array}{l}125,000 \\
250 \\
7.2 \times 10^{-4}\end{array}$ \\
\hline $\begin{array}{ll}\text { Solid Generated } \\
\text { Wastes } & -\mathrm{lb} / \mathrm{hr}\end{array}$ & -- & 1,875 & 750 & 656.25 \\
\hline Mil1/Ref inery & & & & \\
\hline Ore in, tons/day & 6.6 & 1,000 & 400 & 350 \\
\hline Concentrate, tons/day & 1.58 & 3.28 & 4.045 & 3.0888 \\
\hline $\mathrm{hr} /$ day $\times$ day $/ \mathrm{yr}$ & $22 \times 308$ & $22 \times 250$ & $22 \times 250$ & $22 \times 250$ \\
\hline $\begin{array}{l}\text { Dust Generated } \\
\text { Wastes }\end{array}$ & $\begin{array}{l}144.64 \\
2.63 \times 10^{-4}\end{array}$ & $\begin{array}{l}900.77 \\
1.92 \times 10^{-5}\end{array}$ & $\begin{array}{l}294.14 \\
2.418 \times 10^{-5}\end{array}$ & $\begin{array}{l}120.8 \\
1.786 \times 10^{-5}\end{array}$ \\
\hline $\begin{array}{ll}\text { Liquid Generated } & \\
\text { Wastes } & -\mathrm{lb} / \mathrm{hr} \\
& -\mathrm{gpm} \\
& -\mathrm{Ci} / \mathrm{hr}\end{array}$ & $\begin{array}{l}5,859.4 \\
11.72 \\
6.47 \times 10^{-2}\end{array}$ & $\begin{array}{l}527,520 \\
801.45 \\
1.229 \times 10^{-1}\end{array}$ & $\begin{array}{l}217,660 \\
364.95 \\
1.5159 \times 10^{-1}\end{array}$ & $\begin{array}{l}184,480 \\
280.4 \\
1.58 \times 10^{-1}\end{array}$ \\
\hline $\begin{array}{l}\text { Solid Generated } \\
\text { Wastes }\end{array}$ & $\begin{array}{l}698 \\
1.59 \times 10-3\end{array}$ & $\begin{array}{l}-- \\
--\end{array}$ & -- & $\begin{array}{l}-- \\
--\end{array}$ \\
\hline
\end{tabular}

(a) Excess significant figures are shown for some numbers and were used for computational purposes only. 
TABLE A.1. (contd)

\begin{tabular}{|c|c|c|c|c|}
\hline \multicolumn{2}{|l|}{ Mine } & Palmer, MI & $\begin{array}{c}\text { Bald } \\
\text { Mountain }\end{array}$ & $\begin{array}{l}\text { Conway } \\
\text { Granite } \\
\end{array}$ \\
\hline \multicolumn{2}{|l|}{ Type } & Open-pit & Open-pit & Open-pit \\
\hline \multicolumn{2}{|l|}{ Mineral } & Conglomerate & Conglomerate & Granite \\
\hline \multicolumn{2}{|l|}{ Average Grade, $\%$} & 0.06 & 0.00951 & 0.006 \\
\hline \multicolumn{2}{|l|}{$\mathrm{ThO}_{2}$ Reserves, tons } & 193,000 & 2,600 & $35,000,000$ \\
\hline \multicolumn{2}{|l|}{ Production, tons/day } & 41,700 & 10,000 & 100,000 \\
\hline \multicolumn{2}{|l|}{$\mathrm{hr} /$ day $\times$ day/yr } & $24 \times 240$ & $24 \times 240$ & $24 \times 350$ \\
\hline Dust Generated Wastes & $\begin{array}{l}-1 b / h r \\
-C i / h r\end{array}$ & $\begin{array}{l}4,340 \\
1.36 \times 10^{-3}\end{array}$ & $\begin{array}{l}1,042 \\
5.183 \times 10^{-5}\end{array}$ & $\begin{array}{l}10,420 \\
5.743 \times 10^{-4}\end{array}$ \\
\hline Liquid Generated Wastes & $\begin{array}{l}-\mathrm{lb} / \mathrm{hr} \\
-\mathrm{gpm} \\
-\mathrm{Ci} / \mathrm{hr}\end{array}$ & $\begin{array}{l}750,000 \\
1,500 \\
3.931 \times 10^{-4}\end{array}$ & $\begin{array}{l}500,000 \\
1,000 \\
2.613 \times 10^{-4}\end{array}$ & $\begin{array}{l}1,000,000 \\
2,000 \\
9.2345 \times 10^{-4}\end{array}$ \\
\hline Solid Generated Wastes & $-1 b / h r$ & $1,041,600$ & 250,000 & $1,666,000$ \\
\hline \multicolumn{5}{|l|}{ Mill } \\
\hline \multicolumn{2}{|l|}{ Ore in, tons/day } & $\begin{array}{l}30,300 / \\
41,700\end{array}$ & $\begin{array}{l}7,272.76 / \\
10,000\end{array}$ & 100,000 \\
\hline \multicolumn{2}{|l|}{ Concentrate, tons/day } & 209.11 & 7.404 & 6.32 \\
\hline \multicolumn{2}{|l|}{$\mathrm{hr} /$ day $\times$ day $/ \mathrm{yr}$} & $22 \times 330 / 240$ & $22 \times 330 / 240$ & $22 \times 350$ \\
\hline Dust Generated Wastes & $\begin{array}{l}-1 b / h r \\
-C i / h r\end{array}$ & $\begin{array}{l}5,237.2 \\
1.625 \times 10^{-4}\end{array}$ & $\begin{array}{l}252.435 \\
5.92 \times 10^{-6}\end{array}$ & $\begin{array}{l}454.53 \\
2.119 \times 10^{-5}\end{array}$ \\
\hline Liquid Generated Wastes & $\begin{array}{l}-\mathrm{lb} / \mathrm{hr} \\
-\mathrm{gpm} \\
-\mathrm{Ci} / \mathrm{hr}\end{array}$ & $\begin{array}{l}1,800,760 \\
3,116 \\
3.65 \times 10^{-2}\end{array}$ & $\begin{array}{l}433,444 \\
866.9 \\
1.26 \times 10^{-3}\end{array}$ & $\begin{array}{l}133,420 \\
267 \\
2.3418 \times 10^{-2}\end{array}$ \\
\hline Solid Generated Wastes & $\begin{array}{l}-1 \mathrm{~b} / \mathrm{hr} \\
-\mathrm{Ci} / \mathrm{hr}\end{array}$ & $\begin{array}{l}3,115,000 \\
3.01 \times 10^{-1}\end{array}$ & $\begin{array}{l}750,520 \\
1.16 \times 10^{-2}\end{array}$ & $\begin{array}{l}11,598,920 \\
1.64 \times 10^{-1}\end{array}$ \\
\hline \multicolumn{5}{|l|}{ Refinery } \\
\hline \multicolumn{2}{|l|}{ Concentrate in, tons/day } & 209.11 & 7.37 & 6.27 \\
\hline \multicolumn{2}{|l|}{ Output, tons/day } & 10.65 & 0.403 & 3.43 \\
\hline \multicolumn{2}{|l|}{ By-product, tons/day } & 235.4 & 33.22 & 2,797 \\
\hline \multicolumn{2}{|l|}{$\mathrm{hr} /$ day $\times$ day $/ \mathrm{yr}$} & $22 \times 330$ & $22 \times 330$ & $22 \times 350$ \\
\hline Dust Generated Wastes & $\begin{array}{l}-\mathrm{lb} / \mathrm{hr} \\
-\mathrm{Ci} / \mathrm{hr}\end{array}$ & $\begin{array}{l}7,619 \\
1.24 \times 10^{-4}\end{array}$ & $\begin{array}{l}204.27 \\
4.59 \times 10^{-6}\end{array}$ & $\begin{array}{l}313.1 \\
5.7172 \times 10^{-4}\end{array}$ \\
\hline Liquid Generated Wastes & $\begin{array}{l}-\mathrm{lb} / \mathrm{hr} \\
-\mathrm{gpm} \\
-\mathrm{Ci} / \mathrm{hr}\end{array}$ & $\begin{array}{l}510,180 \\
816.72 \\
4.3656\end{array}$ & $\begin{array}{l}10,108 \\
20.216 \\
1.645 \times 10^{-2}\end{array}$ & $\begin{array}{l}9,812.5 \\
19.625 \\
2.61 \times 10^{-1}\end{array}$ \\
\hline Solid Generated Wastes & $\begin{array}{l}-\mathrm{lb} / \mathrm{hr} \\
-\mathrm{Ci} / \mathrm{hr}\end{array}$ & -- & -- & $\begin{array}{l}663 \\
6.76 \times 10^{-3}\end{array}$ \\
\hline
\end{tabular}


APPENDIX B

RADIOLOGICAL DATA 


\section{B.1 SPECIFIC ACTIVITIES}

The specific activities of ${ }^{232} \mathrm{Th},{ }^{238} \mathrm{U}$, and ${ }^{235} \mathrm{U}$ can be calculated on a $\mathrm{C} i / \mathrm{lb}$ basis as follows:

$$
\text { Specific Activity }=S A=\lambda N
$$

where $\lambda=$ the decay constant for a particular radioactive element

$\mathrm{N}=$ number of atoms per gram

$\lambda=0.693 / \mathrm{T}_{1 / 2}$

$T_{1 / 2}=$ the half-life of the element in seconds.

$$
\begin{aligned}
& \text { So } S A=\frac{(0.693) \mathrm{N}}{\mathrm{T}_{1 / 2}}=\text { discharge } / \mathrm{sec} / \mathrm{g} \\
& \text { or } S A=\frac{(0.693) \mathrm{N}}{\mathrm{T}_{1 / 2}\left(3.7 \times 10^{10}\right)}=\frac{\left(1.87297 \times 10^{-11}\right) \mathrm{N}}{\mathrm{T}_{1 / 2}}=\mathrm{Ci} / \mathrm{g}
\end{aligned}
$$

For ${ }^{232}$ Th the following specific activity can be derived:

$$
\begin{aligned}
& S A=\frac{\left(1.87297 \times 10^{-11}\right)(454 \mathrm{~g} / 1 \mathrm{~b})\left(0.6023 \times 10^{24} \mathrm{atom} / \mathrm{m}\right)}{(232.0382 \mathrm{~g} / \mathrm{m})\left(1.40 \times 10^{10} \mathrm{yr}\right)\left(3.1536 \times 10^{7} \mathrm{sec} / \mathrm{yr}\right)} \\
& S A=4.99926 \times 10^{-5} \mathrm{Ci} / 1 \mathrm{~b}
\end{aligned}
$$

For ${ }^{235} U, S A=9.731646 \times 10^{-4} \mathrm{Ci} / 1 \mathrm{~b}$, and for ${ }^{238} \mathrm{U}, \mathrm{SA}=1.51268 \times 10^{-4}$ $\mathrm{Ci} / \mathrm{lb}$.

The ${ }^{232}$ Th decay series is composed of nine daughter products, as shown in Figure B.1. These nine products have approximately nine times the activity of ${ }^{232} \mathrm{Th}$ itself. Thus, when given the specific activity of ${ }^{232} \mathrm{Th}$, we can estimate the total specific activity as being ten times as much. This was done for thorium in Appendices $C$ and $D$.

(a) Excess significant figures are shown for some numbers and were used for computational purposes only. 


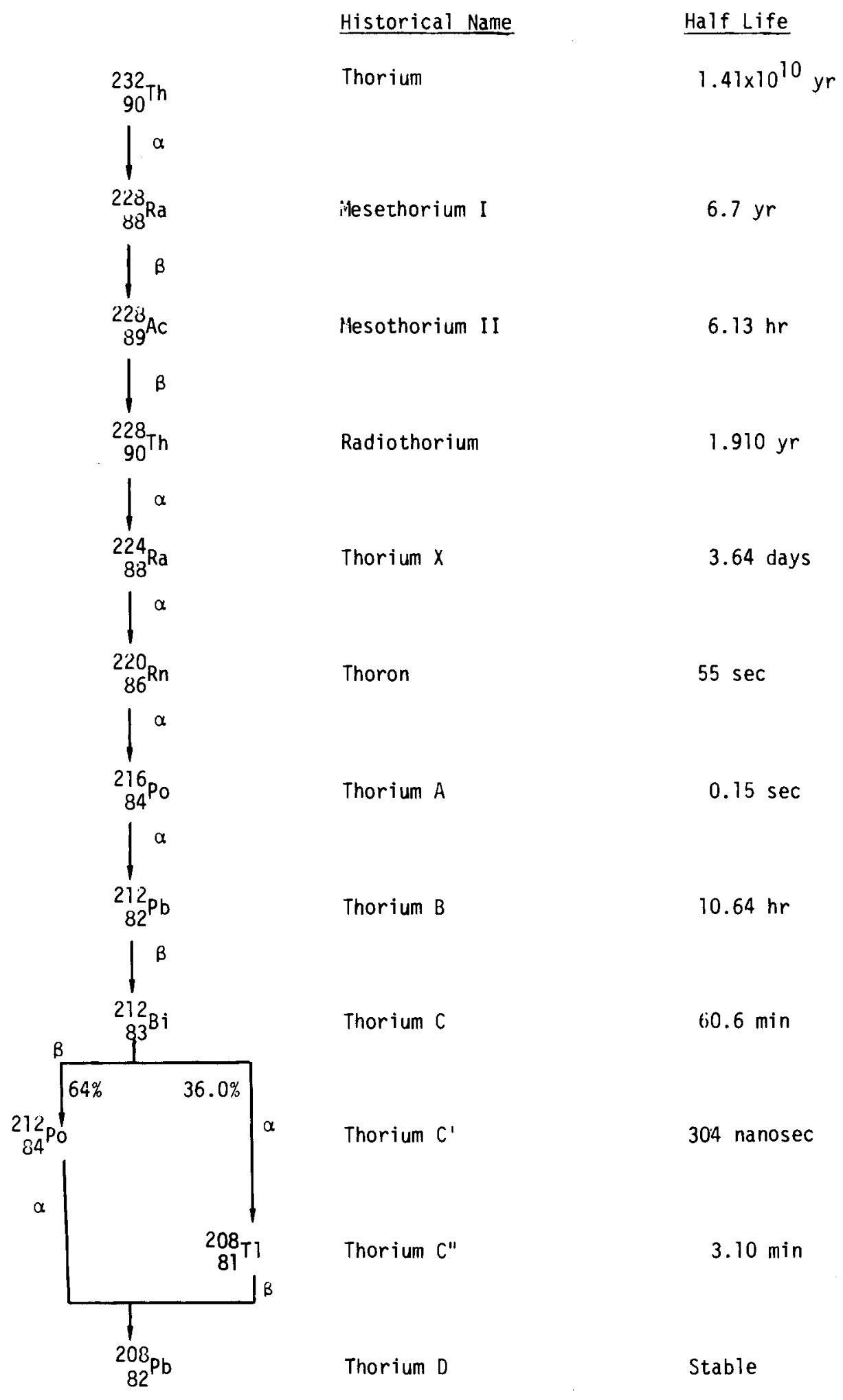

FIGURE B.1. Thorium Decay Series 


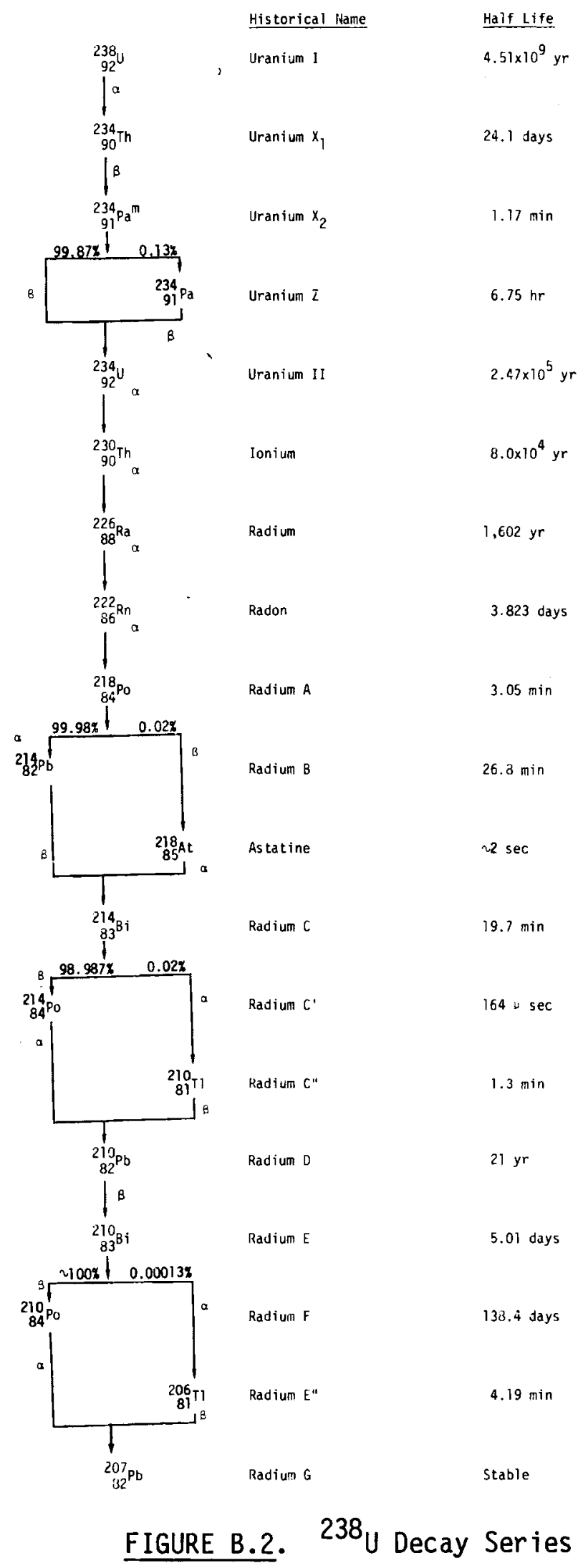

B. 3 


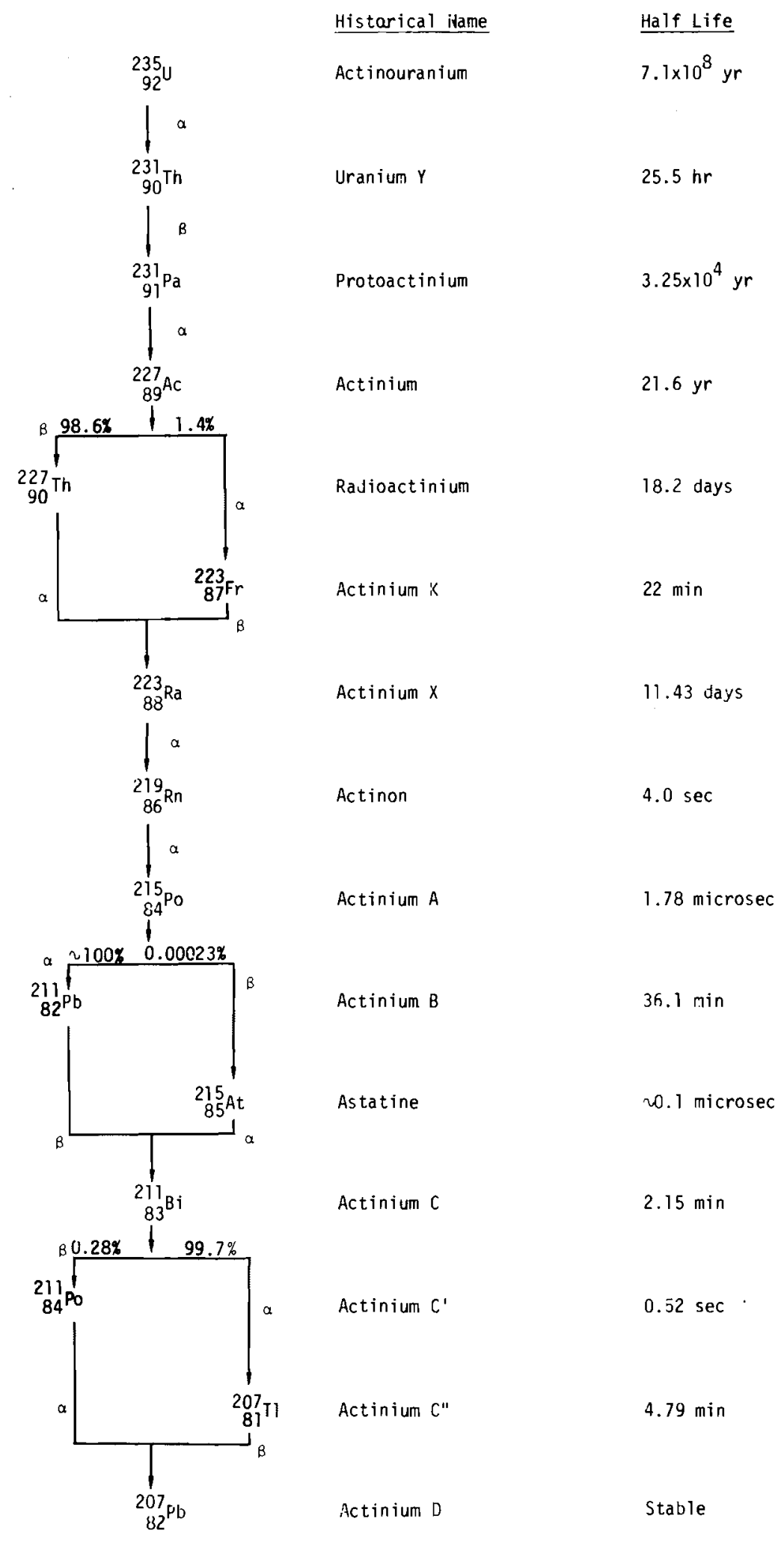

FIGURE B.3. ${ }^{235} \mathrm{U}$ Decay Series 
Figures B.2 and B. 3 show the decay series for ${ }^{238} \mathrm{U}$ and ${ }^{235} \mathrm{U}$, respectively. As shown, there are thirteen ${ }^{238} U$ daughters and ten ${ }^{235} U$ daughters. As with ${ }^{232} \mathrm{Th}$, the daughter products contribute 13 and 10 times the specific activity of ${ }^{238} U$ and ${ }^{235} U$, respectively.

\section{B.2 MAXIMUM PERMISSIBLE CONCENTRATION (MPC) AND RELATIVE RADIOTOXICITY}

The data for this part of the appendix is taken from the CRC Handbook of Radioactive Nuclides. ${ }^{(1)}$ The standards for maximum permissible concentrations (MPCS) used in this reference are based on Appendix $B$ of the U.S. Atomic Energy Commission's publication 10 CFR 20. The pertinent isotopes and their MPCs in air and water are shown in Table B.1. The MPCs shown are the limiting average concentrations in air and water that an employee may be exposed to 40 hours per week during a lifetime of employment. As seen for air, ${ }^{232} \mathrm{Th}$ and natural thorium have an MPC level of $3 \times 10^{-11} \mu \mathrm{Ci} / \mathrm{ml}$, which is less then that of uranium in any form. The same is also true for the MPC of soluble thorium in water $\left(3 \times 10^{-5} \mu \mathrm{Ci} / \mathrm{ml}\right)$. For this reason the standards used to evaluate the environmental control technologies were the natural thorium MPCs.

One of the reasons that the standards for thorium are stricter than for uranium is due to the relative radiotoxicity. As shown in Table B.2, ${ }^{232} \mathrm{Th}$ and natural thorium deliver 15 rems of radiation to the critical organ or the lung with much fewer curies than do ${ }^{235} U,{ }^{238} U$, or natural uranium. Thus, thorium is more dangerous than uranium from this point of view and the standards, as shown in Table B.1, are stricter.

\section{B.3 REFERENCES}

1. Yen Wang (ed.), Handbook of Radioactive Nuclides, The Chemical Rubber Company, Cleveland, $\mathrm{OH}, 1969$. 
TABLE B.1. Maximum Permissible Concentration of Radionuclides in Air and Water

I sotope

Natura
${ }^{232} \mathrm{Th}$

${ }^{228}$ Th

${ }^{228} \mathrm{Ra}$

228 AC

${ }^{224} \mathrm{Ra}$

$220 \mathrm{Rn}$

$212 \mathrm{pb}$

${ }^{212}{ }_{B i}$

$238 U$

$235 y$

Natural Uranium

${ }^{230}$ Th

$226 \mathrm{Ra}$

$222 \mathrm{Rn}$

$210 \mathrm{pb}$

${ }^{231} \mathrm{pa}$

${ }^{227} \mathrm{AC}$
MPC in Air, $\mu \mathrm{Ci} / \mathrm{ml}$

$3 \times 10-11$

$3 \times 10-11$

$3 \times 10-11$

$3 \times 10-11$

$9 \times 10^{-12}$

$6 \times 10^{-12}$

$7 \times 10^{-11}$

$4 \times 10^{-11}$

$8 \times 10-8$

$2 \times 10-8$

$5 \times 10^{-9}$

$7 \times 10-10$

$3 \times 10^{-7}$

$2 \times 10^{-8}$

$2 \times 10-8$

$1 \times 10^{-7}$

$2 \times 10^{-7}$

$7 \times 10^{-11}$

$1 \times 10^{-10}$

$5 \times 10^{-10}$

$1 \times 10^{-10}$

$7 \times 10^{-11}$

$6 \times 10^{-11}$

$2 \times 10^{-12}$

$1 \times 10^{-11}$

$3 \times 10^{-11}$

$5 \times 10^{-11}$

$1 \times 10-7$

$1 \times 10^{-10}$

$2 \times 10^{-10}$

$1 \times 10^{-12}$

$1 \times 10^{-10}$

$2 \times 10^{-12}$

$3 \times 10^{-11}$
MPC in Water, $\mu \mathrm{Ci} / \mathrm{ml}$

$3 \times 10^{-5}$

$3 \times 10-4$

$5 \times 10-5$

$1 \times 10-3$

$2 \times 10^{-4}$

$4 \times 10^{-4}$

$8 \times 10^{-7}$

$7 \times 10^{-4}$

$3 \times 10^{-3}$

$3 \times 10-3$

$7 \times 10-5$

$2 \times 10^{-4}$

$6 \times 10^{-4}$

$5 \times 10-4$

$1 \times 10-2$

$1 \times 10-2$

$1 \times 10^{-3}$

$1 \times 10-3$

$8 \times 10^{-4}$

$8 \times 10^{-4}$

$5 \times 10^{-4}$

$5 \times 10-4$

$5 \times 10^{-5}$

$9 \times 10^{-4}$

$4 \times 10-7$

$9 \times 10^{-4}$

$4 \times 10^{-6}$

$5 \times 10-3$

$3 \times 10^{-5}$

$8 \times 10^{-4}$

$6 \times 10^{-5}$

$9 \times 10^{-3}$ 
TABLE B.2. Relative Radiotoxicity of Radionuclides

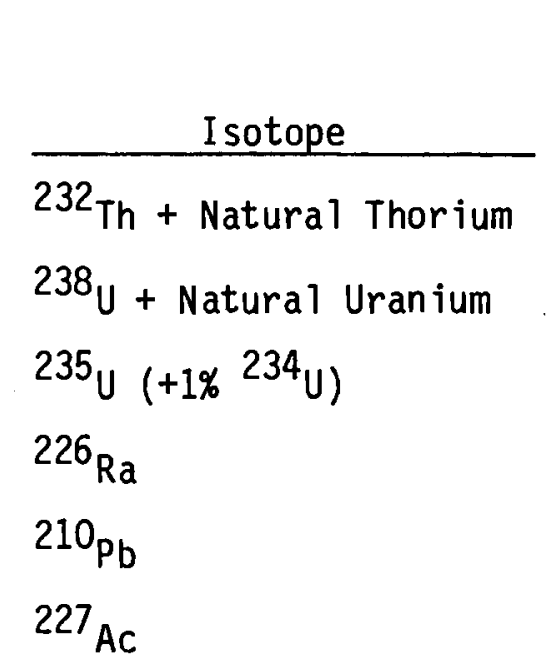

Single Inhalation, in Curies, to Give 15 rem to Critical Organ, Ci/15 rem

$$
2.25 \times 10^{-9}
$$$$
1.90 \times 10^{-7}
$$$$
1.10 \times 10^{-6}
$$$$
4.90 \times 10^{-8}
$$$$
3.20 \times 10^{-7}
$$$$
3.00 \times 10^{-9}
$$

Single Inhalation, in Curies, to Give $15 \mathrm{rem}$ to Lung, $\mathrm{Ci} / 15 \mathrm{rem}$
$2.60 \times 10^{-8}$
$3.00 \times 10^{-7}$
$2.60 \times 10^{-7}$
$1.50 \times 10^{-8}$
$5.30 \times 10^{-7}$
$6.9 \times 10^{-8}$ 
. 


\section{APPENDIX C}

MINE EFFLUENTS 


\section{APPENDIX C \\ MINE, GENERATED WASTES (a)}

\section{C.1 LEMHI PASS MINE}

\section{Airborne Generated Wastes}

The dust level $=0.1 \%$ to $0.15 \%$ of the ore mined. Only $25 \%$ of this dust is in the mine or controllable, the other $75 \%$ is generated by the loading and transportation operations. It is assumed that $0.125 \%$ of the ore mined becomes dust. This mine is a 1000 ton/day ore mine with an average grade of $0.356 \%$ $\mathrm{ThO}_{2}$.

\section{Controlled Dust}

The amounts and concentrations for the controlled dust in the mine are:

Mine dust $=(0.00125)(0.25)(1000$ tons $/$ day $)(1$ day $/ 16 \mathrm{hr})(2000 \mathrm{lb} /$ ton $)$ $=39.0 \mathrm{lb} / \mathrm{hr}$

$$
\begin{aligned}
& \mathrm{ThO}_{2}=(0.00356)(39.0)=0.13884 \mathrm{lb} / \mathrm{hr} \\
& { }^{232} \mathrm{Th}=(0.88)(0.13884)=0.12218 \mathrm{lb} / \mathrm{hr} \\
& U=(0.01)(0.12218)=1.222 \times 10^{-3} \mathrm{lb} / \mathrm{hr} \\
& 238_{U}=(0.993)\left(8.145 \times 10^{-3}\right)=1.21 \times 10^{-3} \mathrm{lb} / \mathrm{hr} \\
& 235_{U}=1.2 \times 10^{-5} \mathrm{lb} / \mathrm{hr}
\end{aligned}
$$

The activity in the mine dust is:
${ }^{232} \mathrm{Th}$
$0.12218 \mathrm{lb} / \mathrm{hr}$
$6.108 \times 10^{-6} \mathrm{Ci} / \mathrm{hr}$
$238_{U}$
$1.21 \times 10^{-3} \mathrm{lb} / \mathrm{hr}$
$1.83 \times 10^{-7} \mathrm{Ci} / \mathrm{hr}$
$235 \mathrm{U}$
${ }^{232}$ Th Daughters (9)
$1.2 \times 10^{-5} \mathrm{lb} / \mathrm{hr}$
$1.17 \times 10^{-8} \mathrm{Ci} / \mathrm{hr}$
$238_{U}$ Daughters (13)
Trace
$5.50 \times 10^{-5} \mathrm{Ci} / \mathrm{hr}$
${ }^{235} \mathrm{U}$ Daughters
Trace
$2.38 \times 10^{-6} \mathrm{Ci} / \mathrm{hr}$
Trace
$1.17 \times 10^{-7} \mathrm{Ci} / \mathrm{hr}$

This dust load is to be controlled with a ventilating system with a capacity of $300,000 \mathrm{ft}^{3} / \mathrm{min}$. The working areas will also be kept wet down to control the dust level.

(a) Excess significant figures are shown for some numbers and were used for computational purposes only. 
Uncontrolled Dust

The amounts and concentrations for uncontrolled dust in the mine are:

Uncontrolled dust $=(0.75)(0.00125)(1000$ tons $/$ day $)(1$ day $/ 16 \mathrm{hr})$ $(2000 \mathrm{lb} /$ ton $)=117.15 \mathrm{lb} / \mathrm{hr}$

$T h=(0.88)(0.00356)(117.15)=0.367 \mathrm{lb} / \mathrm{hr}$

$U=(0.01)(0.367)=3.67 \times 10^{-3} \mathrm{lb} / \mathrm{hr}$

$238 \mathrm{U}=(0.993)\left(3.67 \times 10^{-3}\right)=3.64 \times 10^{-3} \mathrm{lb} / \mathrm{hr}$

$235 \mathrm{U}=3.0 \times 10^{-5} \mathrm{lb} / \mathrm{hr}$

The activity in the uncontrolled dust is:

$\begin{array}{lll}{ }^{232} \mathrm{Th} & 0.367 \mathrm{lb} / \mathrm{hr} & 1.83 \times 10^{-5} \mathrm{Ci} / \mathrm{hr} \\ 238 \mathrm{U} & 3.64 \times 10^{-3} \mathrm{lb} / \mathrm{hr} & 5.51 \times 10^{-7} \mathrm{Ci} / \mathrm{hr} \\ { }^{235} \mathrm{U} & 3.0 \times 10^{-5} \mathrm{lb} / \mathrm{hr} & 2.92 \times 10^{-8} \mathrm{Ci} / \mathrm{hr} \\ { }^{232} \text { Th Daughters (9) } & \text { Trace } & 1.65 \times 10^{-4} \mathrm{Ci} / \mathrm{hr} \\ 238_{\mathrm{U}} \text { Daughters (13) } & \text { Trace } & 7.16 \times 10^{-6} \mathrm{Ci} / \mathrm{hr} \\ 235 \mathrm{U} \text { Daughters (10) } & \text { Trace } & 2.92 \times 10^{-7} \mathrm{Ci} / \mathrm{hr}\end{array}$

To control this dust, it may be possible to wet the major points of dust release and erect barriers. The values given above are dependent on many factors; some of which are the wind conditions, rainfall, travel distance, etc.

\section{Liquid Wastes}

Lemhi Pass could be classified as an intermediate (500 to $2000 \mathrm{gpm}$ ) or dry ( $500 \mathrm{gpm})$ mine in terms of liquid output. If $500 \mathrm{gpm}$ is assumed as an average figure, the next question is what concentration of $\mathrm{ThO}_{2}$ to assume. In uranium mines, the concentration of ${ }^{238} \mathrm{U}$ ranges from 5 to $20 \mathrm{ppm}$. If it is assumed that $\mathrm{ThO}_{2}$ behaves similarly, then the average $\mathrm{ThO}_{2}$ concentration is $12.5 \mathrm{ppm}$ or $12.5 \mathrm{mg} /$; so the amount of:

$$
\mathrm{ThO}_{2}=\frac{12.5 \mathrm{mg}}{\ell} \times \frac{1 \mathrm{~g}}{1000 \mathrm{mg}} \times \frac{1 \mathrm{lb}}{454 \mathrm{~g}} \times \frac{500 \mathrm{gal}}{\min } \times \frac{60 \mathrm{~min}}{\mathrm{hr}} \times \frac{3.79 \ell}{\mathrm{ga} 1}=3.13 \mathrm{lb} / \mathrm{hr}
$$




$$
\begin{aligned}
& { }^{232} \mathrm{Th}=2.75 \mathrm{lb} / \mathrm{hr} \\
& U=(0.01)(2.75)=2.75 \times 10^{-2} \mathrm{lb} / \mathrm{hr} \\
& 238 \mathrm{U}=(0.993)\left(2.75 \times 10^{-2}\right)=2.74 \times 10^{-2} \mathrm{lb} / \mathrm{hr} \\
& 235 \mathrm{U}=1.0 \times 10^{-4} \mathrm{lb} / \mathrm{hr}
\end{aligned}
$$

The activity in the water is:

$\begin{array}{lll}{ }^{232} \mathrm{Th} & 2.75 \mathrm{lb} / \mathrm{hr} & 1.37 \times 10^{-4} \mathrm{Ci} / \mathrm{hr} \\ 238_{\mathrm{U}} & 2.74 \times 10^{-2} \mathrm{lb} / \mathrm{hr} & 4.14 \times 10^{-6} \mathrm{Ci} / \mathrm{hr} \\ 235_{\mathrm{U}} & 1.0 \times 10^{-4} \mathrm{lb} / \mathrm{hr} & 9.73 \times 10^{-8} \mathrm{Ci} / \mathrm{hr} \\ { }^{232} \mathrm{Th} \text { Daughters (9) } & \text { Trace } & 1.23 \times 10^{-3} \mathrm{Ci} / \mathrm{hr} \\ { }^{238} \mathrm{U} \text { Daughters (13) } & \text { Trace } & 5.39 \times 10^{-5} \mathrm{Ci} / \mathrm{hr} \\ 235_{U} \text { Daughters (10) } & \text { Trace } & 9.73 \times 10^{-7} \mathrm{Ci} / \mathrm{hr}\end{array}$

Settling ponds are necessary to collect and treat this stream. Various chemicals may have to be added to settle and clean these fluids.

Solids

The solid wastes consist of the wall rock and gangue material of too low a grade to be considered ore. The ratio of waste to ore is $30 \mathrm{lb}$ waste rock/ton ore. The waste rock obtained is used onsite and has a low concentration of radioactive substances. Therefore, the external environment is not harmed appreciably. Lemhi Pass waste rock from one 1000-ton/day ore mine is 15 tons/day of waste rock. All underground mines are similar to the Lemhi Pass mine in terms of solid waste generated.

\section{C.2 HALL MOUNTAIN MINE}

\section{Airborne Generated Wastes}

The same assumptions apply here as were used for the Lemhi Pass mine. The Hall Mountain mine is a 400-ton/day underground mine with an average ore grade of $1.1 \% \mathrm{ThO}_{2}$. 


\section{Controlled Dust}

The amounts and concentrations for the controlled dust in the mine are:

Mine dust $=(0.00125)(0.25)(400$ tons $/$ day $)(1$ day $/ 16 \mathrm{hr})(2000 \mathrm{lb} /$ ton $)$ $=15.625 \mathrm{lb} / \mathrm{hr}$

${ }^{232} \mathrm{Th}=(0.88)(0.011)(15.625)=0.15125 \mathrm{lb} / \mathrm{hr}$

$U=(0.01)(0.151)=1.51 \times 10^{-3} \mathrm{lb} / \mathrm{hr}$

$238 \mathrm{U}=(0.993)\left(1.51 \times 10^{-3}\right)=1.51 \times 10^{-3} \mathrm{lb} / \mathrm{hr}$

$235 \mathrm{U}=1.1 \times 10^{-5} \mathrm{lb} / \mathrm{hr}$

The activity in the mine dust is:
${ }^{232} \mathrm{Th}$
$238_{U}$
$0.151 \mathrm{lb} / \mathrm{hr}$
$235 \mathrm{U}$
$1.499 \times 10^{-3} \mathrm{lb} / \mathrm{hr}$
$7.55 \times 10^{-6} \mathrm{Ci} / \mathrm{hr}$
${ }^{232}$ Th Daughters (9)
$238 \mathrm{U}$ Daughters (13)
$235 \mathrm{U}$ Daughters (10)
$1.1 \times 10^{-5} \mathrm{lb} / \mathrm{hr}$
$2.27 \times 10^{-7} \mathrm{Ci} / \mathrm{hr}$
$1.07 \times 10^{-8} \mathrm{Ci} / \mathrm{hr}$
Trace
$6.80 \times 10^{-5} \mathrm{Ci} / \mathrm{hr}$
Trace
$2.95 \times 10^{-6} \mathrm{Ci} / \mathrm{hr}$
Trace
$1.07 \times 10^{-7} \mathrm{Ci} / \mathrm{hr}$

The capacity of the ventilating system will be about $160,000 \mathrm{ft}^{3} / \mathrm{min}$. The working areas will be kept wet down to minimize dust levels in the mine.

\section{Uncontrolled Dust}

The amounts and concentrations of uncontrolled dust in the mine are:

Uncontrolled dust $=(0.75)(0.00125)(400$ tons $/$ day $)(1$ day $/ 16 \mathrm{hr})$

$$
(2000 / 1 \mathrm{~b} / \text { ton })=46.875 \mathrm{lb} / \mathrm{hr}
$$

${ }^{232} \mathrm{Th}$ in dust $=(0.88)(0.011)(46.875)=0.45375 \mathrm{lb} / \mathrm{hr}$

$U$ in dust $=(0.01)(0.45375)=4.5375 \times 10^{-3} \mathrm{lb} / \mathrm{hr}$

$238 \mathrm{U}$ in dust $=(0.993)\left(4.5375 \times 10^{-3}\right)=4.5057 \times 10^{-3} \mathrm{lb} / \mathrm{hr}$

${ }^{235} \mathrm{U}$ in dust $=3.18 \times 10^{-5} \mathrm{lb} / \mathrm{hr}$ 
The activity in the uncontrolled dust is:

$\begin{array}{lll}{ }^{232} \mathrm{Th} & 0.45375 \mathrm{lb} / \mathrm{hr} & 2.27 \times 10^{-5} \mathrm{Ci} / \mathrm{hr} \\ 238 \mathrm{U} & 4.5057 \times 10^{-3} \mathrm{lb} / \mathrm{hr} & 6.82 \times 10^{-7} \mathrm{Ci} / \mathrm{hr} \\ 235_{\mathrm{U}} & 3.18 \times 10^{-5} \mathrm{lb} / \mathrm{hr} & 3.09 \times 10^{-8} \mathrm{Ci} / \mathrm{hr} \\ { }^{232} \mathrm{Th} \text { Daughters (9) } & \text { Trace } & 2.04 \times 10^{-4} \mathrm{Ci} / \mathrm{hr} \\ { }^{238} \mathrm{U} \text { Daughters (13) } & \text { Trace } & 8.86 \times 10^{-6} \mathrm{Ci} / \mathrm{hr} \\ 235_{\mathrm{U}} \text { Daughters (10) } & \text { Trace } & 3.09 \times 10^{-7} \mathrm{Ci} / \mathrm{hr}\end{array}$

The best ways to minimize this condition may be to wet the dust release points and erect wind barriers.

\section{Liquid Wastes}

The Hall Mountain mine is about half as large as a Lemhi Pass mine, so a value of $250 \mathrm{gpm}$ for liquid release will be used. The concentration to be used, $12.5 \mathrm{ppm} \mathrm{Th0_{2 }}$, would also be similar. The amounts released are:

$$
\begin{aligned}
& \mathrm{Th0}_{2}=\frac{12.5 \mathrm{mg}}{\ell} \times \frac{1 \mathrm{~g}}{1000 \mathrm{mg}} \times \frac{1 \mathrm{lb}}{454 \mathrm{~g}} \times \frac{250 \mathrm{gal}}{\mathrm{min}} \times \frac{60 \mathrm{~min}}{\mathrm{hr}} \times \frac{3.79 l}{\mathrm{gaT}}=1.565 \mathrm{lb} / \mathrm{hr} \\
& { }^{232} \mathrm{Th}=(0.88)(1.565)=1.38 \mathrm{lb} / \mathrm{hr} \\
& U=1.38 \times 10^{-2} \mathrm{lb} / \mathrm{hr} \\
& 238 \mathrm{U}=(0.993)\left(1.38 \times 10^{-2}\right)=1.37 \times 10^{-2} \mathrm{lb} / \mathrm{hr} \\
& 235 \mathrm{U}=1.0 \times 10^{-4} \mathrm{lb} / \mathrm{hr}
\end{aligned}
$$

\begin{tabular}{|c|c|c|}
\hline${ }^{232} \mathrm{Th}$ & $1.38 \mathrm{lb} / \mathrm{hr}$ & $6.90 \times 10^{-5} \mathrm{Ci} / \mathrm{hr}$ \\
\hline $238 U$ & $1.37 \times 10^{-2} \mathrm{lb} / \mathrm{hr}$ & $2.07 \times 10^{-6} \mathrm{Ci} / \mathrm{hr}$ \\
\hline $235_{U}$ & $1.0 \times 10^{-4} \mathrm{lb} / \mathrm{hr}$ & $9.73 \times 10^{-8} \mathrm{Ci} / \mathrm{hr}$ \\
\hline${ }^{232}$ Th Daughters (9) & Trace & $6.21 \times 10^{-4} \mathrm{Ci} / \mathrm{hr}$ \\
\hline 238 U Daughters (13) & Trace & $2.69 \times 10^{-5} \mathrm{Ci}$ \\
\hline 235 U Daughters $(10)$ & Trace & $9.73 \times 10^{-7} \mathrm{Ci} / \mathrm{hr}$ \\
\hline
\end{tabular}

The activity in the water is: 
A settling pond will be needed to collect these wastes. Various treatment processes may be used to clean this water.

$\underline{\text { Solids }}$

There will be 6 tons/day of waste rock from the Hall Mountain mine. The waste rock will be used on site and has a low concentration of radioactive substances. This small amount will not appreciably harm the environment.

\section{C.3 WET MOUNTAIN MINE}

\section{Airborne Generated Wastes}

The assumptions used for the Lemhi Pass mine also apply here. The Wet Mountain mine is a 350-ton/day underground mine with an average ore grade of $0.96 \% \mathrm{ThO}_{2}$.

\section{Controlled Dust}

The amounts for the controlled dust in the mine are:

$$
\begin{aligned}
& \text { Mine dust }=(0.00125)(0.25)(350 \text { tons } / \text { day })(1 \text { day } / 16 \mathrm{hr})(2000 \mathrm{lb} / \text { ton }) \\
& \quad=13.67 \mathrm{lb} / \mathrm{hr} \\
& { }^{232} \mathrm{Th}=(0.88)(0.0096)(13.67)=1.155 \times 10^{-1} \mathrm{lb} / \mathrm{hr} \\
& U=(0.01)\left(0.155 \times 10^{-1}\right)=1.155 \times 10^{-3} \mathrm{lb} / \mathrm{hr} \\
& 238_{U}=(0.993)\left(1.55 \times 10^{-3}\right)=1.1469 \times 10^{-3} \mathrm{lb} / \mathrm{hr} \\
& 235 \mathrm{U}=8.1 \times 10^{-6} \mathrm{lb} / \mathrm{hr}
\end{aligned}
$$

The activity in the mine dust is:

$\begin{array}{lll}{ }^{232} \mathrm{Th} & 1.155 \times 10^{-1} \mathrm{lb} / \mathrm{hr} & 5.77 \times 10^{-6} \mathrm{Ci} / \mathrm{hr} \\ { }^{238_{\mathrm{U}}} & 1.1469 \times 10^{-3} \mathrm{lb} / \mathrm{hr} & 1.73 \times 10^{-7} \mathrm{Ci} / \mathrm{hr} \\ { }^{235} \mathrm{U} & 8.1 \times 10^{-6} \mathrm{lb} / \mathrm{hr} & 7.88 \times 10^{-9} \mathrm{Ci} / \mathrm{hr} \\ { }^{232} \text { Th Daughters (9) } & \text { Trace } & 5.19 \times 10^{-5} \mathrm{Ci} / \mathrm{hr} \\ { }^{238} \mathrm{U} \text { Daughters (13) } & \text { Trace } & 2.26 \times 10^{-6} \mathrm{Ci} / \mathrm{hr} \\ { }^{235} \mathrm{U} \text { Daughters (10) } & \text { Trace } & 7.88 \times 10^{-8} \mathrm{Ci} / \mathrm{hr}\end{array}$

The capacity of the ventilating system will be about $140,000 \mathrm{ft}^{3} / \mathrm{min}$. The dust level will be minimized considerably by keeping the working areas wet. 
Uncontrolled Dust

The amounts for uncontrolled dust in the mine are:

$$
\begin{aligned}
& \text { Uncontrolled dust }=(0.75)(0.00125)(350 \text { tons } / \text { day })(1 \text { day } / 16 \mathrm{hr}) \\
& (2000 \mathrm{lb} / \text { ton })=41.02 \mathrm{lb} / \mathrm{hr} \\
& { }^{232} \mathrm{Th}=(0.88)(0.0096)(41.02)=0.3465 \mathrm{lb} / \mathrm{hr} \\
& U=(0.01)(0.3465)=3.456 \times 10^{-3} \mathrm{lb} / \mathrm{hr} \\
& 238_{U}=(0.993)\left(3.465 \times 10^{-3}\right)=3.44 \times 10^{-3} \mathrm{lb} / \mathrm{hr} \\
& 235_{U}=2.5 \times 10^{-5} \mathrm{lb} / \mathrm{hr}
\end{aligned}
$$

\begin{tabular}{|c|c|c|c|}
\hline${ }^{232} \mathrm{Th}$ & $0.3465 \mathrm{lb} / \mathrm{hr}$ & $1.73 \times 10^{-5}$ & $\mathrm{Ci} / \mathrm{hr}$ \\
\hline $238_{U}$ & $3.44 \times 10^{-3} \mathrm{lb} / \mathrm{hr}$ & $5.20 \times 10^{-7}$ & $\mathrm{Ci} / \mathrm{hr}$ \\
\hline${ }^{235} \mathrm{U}$ & $2.5 \times 10^{-5} \mathrm{lb} / \mathrm{hr}$ & $2.43 \times 10^{-8}$ & $\mathrm{Ci} / \mathrm{hr}$ \\
\hline${ }^{232}$ Th Daughters (9) & Trace & $1.56 \times 10^{-4}$ & $\mathrm{Ci} / \mathrm{hr}$ \\
\hline${ }^{238}$ U Daughters (13) & Trace & $6.76 \times 10^{-6}$ & $\mathrm{Ci} / \mathrm{hr}$ \\
\hline $235 U$ Daughters $(10)$ & Trace & $2.43 \times 10^{-7}$ & $\mathrm{Ci} / \mathrm{hr}$ \\
\hline
\end{tabular}

The activity in the uncontrolled dust is:

The best ways to minimize this dust load are to wet down the work areas and erect barriers around the mine and loading zone.

Liquid Wastes

The Wet Mountain mine is about half as large as the Lemhi Pass mine; so a value of $250 \mathrm{gpm}$ for liquid release was used. The concentration was also similar, $12.5 \mathrm{ppm} \mathrm{ThO}_{2}$. The amounts released are:

$$
\begin{aligned}
& \mathrm{ThO}_{2}=\frac{12.5 \mathrm{mg}}{\ell} \times \frac{1 \mathrm{~g}}{1000 \mathrm{mg}} \times \frac{1 \mathrm{lb}}{454 \mathrm{~g}} \times \frac{250 \mathrm{gal}}{\mathrm{min}} \times \frac{60 \mathrm{~min}}{\mathrm{hr}} \times \frac{3.79 \ell}{\mathrm{gal}}=1.565 \mathrm{lb} / \mathrm{hr} \\
& 232 \mathrm{Th}=(0.88)(1.565)=1.38 \mathrm{lb} / \mathrm{hr} \\
& U=1.38 \times 10^{-2} \mathrm{lb} / \mathrm{hr} \\
& 238_{\mathrm{U}}=(0.993)\left(1.38 \times 10^{-2}\right)=1.37 \times 10^{-2} \mathrm{lb} / \mathrm{hr} \\
& 235_{U}=1.0 \times 10^{-4} \mathrm{lb} / \mathrm{hr}
\end{aligned}
$$


The activity in the water is the same as that for the Hall Mountain mine. As previously mentioned, a settling pond will be needed.

Solids

There are 5.25 tons/day of waste rock from the Wet Mountain mine. The waste rock will be used on site and has a low concentration of radioactive substances. This small amount will not appreciably harm the environment.

\section{C.4 PALMER, MICHIGAN, MINE}

\section{Airborne Generated Wastes}

The airborne release factors range from $0.1 \%$ to $0.15 \%$ of the ore mined. The assumed value is $0.125 \%$. The amounts for the dust released are:

$$
\begin{aligned}
\text { Dust }= & (0.00125)(10,000,000 \text { tons } / \mathrm{yr})(1 \mathrm{yr} / 240 \text { days })(1 \text { day } / 24 \mathrm{hr}) \\
& (2000 \mathrm{lb} / \text { ton })=4340 \mathrm{bb} / \mathrm{hr} \\
\mathrm{ThO}_{2}= & (0.0006)(4340)=2.60 \mathrm{lb} / \mathrm{hr} \\
{ }^{232} \mathrm{Th}= & (0.88)(2.60)=2.29 \mathrm{lb} / \mathrm{hr} \\
U= & (0.0435)(2.29)=9.96 \times 10^{-2} \mathrm{lb} / \mathrm{hr} \\
238 \mathrm{U}= & (0.993)\left(9.96 \times 10^{-2}\right)=9.89 \times 10^{-2} \mathrm{lb} / \mathrm{hr} \\
235 \mathrm{U}= & 7.0 \times 10^{-4} \mathrm{lb} / \mathrm{hr}
\end{aligned}
$$

The activity in the mine dust is:

$\begin{array}{lll}{ }^{232} \mathrm{Th} & 2.29 \mathrm{lb} / \mathrm{hr} & 1.14 \times 10^{-4} \mathrm{Ci} / \mathrm{hr} \\ 238_{\mathrm{U}} & 9.89 \times 10^{-2} \mathrm{lb} / \mathrm{hr} & 1.50 \times 10^{-5} \mathrm{Ci} / \mathrm{hr} \\ 235 \mathrm{U} & 7.0 \times 10^{-4} \mathrm{lb} / \mathrm{hr} & 6.8 \times 10^{-7} \mathrm{Ci} / \mathrm{hr} \\ { }^{232} \mathrm{Th} \text { Daughters (9) } & \text { Trace } & 1.03 \times 10^{-3} \mathrm{Ci} / \mathrm{hr} \\ { }^{238} \mathrm{U} \text { Daughters (13) } & \text { Trace } & 1.94 \times 10^{-4} \mathrm{Ci} / \mathrm{hr} \\ 235 \mathrm{U} \text { Daughters (10) } & \text { Trace } & 6.81 \times 10^{-6} \mathrm{Ci} / \mathrm{hr}\end{array}$

The dust level will be minimized by wetting down the mining area and the roads and by erecting barriers. 0ther than that, only proper methods of ore blasting and handling will lower the dust level. 


\section{Liquid Wastes}

A large portion of the waste water will be from precipitation. The concentration in the ore removed is only $0.06 \%$, so the amount in the groundwater removed is probably less than $1 \mathrm{ppm}$. All of the surface mines

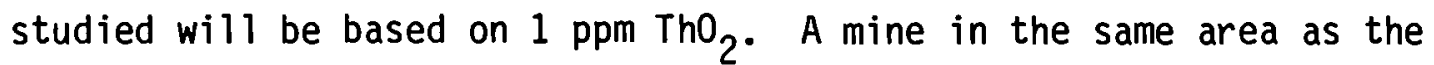
conceptual thorium oxide mine removes an average of $1500 \mathrm{gpm}$. The amounts released in the liquid wastes are:

$$
\begin{aligned}
& \mathrm{ThO}_{2}=\frac{1 \mathrm{mg}}{\ell} \times \frac{1 \mathrm{~g}}{1000 \mathrm{mg}} \times \frac{1 \mathrm{lb}}{454 \mathrm{~g}} \times \frac{1500 \mathrm{gal}}{\mathrm{min}} \times \frac{60 \mathrm{~min}}{\mathrm{hr}} \times \frac{3.79 l}{\mathrm{gaT}}=0.75 \mathrm{lb} / \mathrm{hr} \\
& { }^{232} \mathrm{Th}=(0.88)(0.75)=0.66 \mathrm{lb} / \mathrm{hr} \\
& U=(0.0435)(0.66)=0.029 \mathrm{lb} / \mathrm{hr} \\
& 238 \mathrm{U}=(0.029)(0.993)=0.0288 \mathrm{lb} / \mathrm{hr} \\
& 235 \mathrm{U}=2.0 \times 10^{-4} \mathrm{lb} / \mathrm{hr}
\end{aligned}
$$

The activity in the water is:

$$
\begin{array}{lll}
{ }^{232} \mathrm{Th} & 0.66 \mathrm{lb} / \mathrm{hr} & 3.3 \times 10^{-5} \mathrm{Ci} / \mathrm{hr} \\
{ }^{238} \mathrm{U} & 0.0288 \mathrm{1b} / \mathrm{hr} & 4.36 \times 10^{-6} \mathrm{Ci} / \mathrm{hr} \\
235 \mathrm{U} & 2.0 \times 10^{-4} \mathrm{lb} / \mathrm{hr} & 1.95 \times 10^{-7} \mathrm{Ci} / \mathrm{hr} \\
{ }^{232} \mathrm{Th} \text { Daughters (9) } & \text { Trace } & 2.97 \times 10^{-4} \mathrm{Ci} / \mathrm{hr} \\
{ }^{238} \mathrm{U} \text { Daughters (13) } & \text { Trace } & 5.66 \times 10^{-5} \mathrm{Ci} / \mathrm{hr} \\
235_{U} \text { Daughters (10) } & \text { Trace } & 1.95 \times 10^{-6} \mathrm{Ci} / \mathrm{hr}
\end{array}
$$

If the mill is located near the mine, this water stream may be used in the mill circuit. Holding ponds may be needed to allow the solids to precipitate.

\section{Solids}

The solid waste consists of overburden and waste rock from mining. This waste rock will be stored onsite, either in the pit itse lf or adjacent to it; therefore, no external environmental effects will take place. Because of the low concentration of $\mathrm{ThO}_{2}$ in the ore and the fact that the waste rock has even a lower concentration of $\mathrm{ThO}_{2}$, the radioactive effects will be minimal. 


\section{C.5 BALD MOUNTAIN MINE}

\section{Airborne Generated Wastes}

The amounts of airborne wastes released in the mine are:

$$
\begin{aligned}
& \text { Dust }=(0.00125)(10,000 \text { tons } / \text { day })(1 \text { day } / 24 \mathrm{hr})(2000 \mathrm{lb} / \text { ton }) \\
&=1042 \mathrm{lb} / \mathrm{hr} \\
& \mathrm{ThO}_{2}=(0.0000951)(1042)=9.9 \times 10^{-2} \mathrm{lb} / \mathrm{hr} \\
& 232 \mathrm{Th}=(0.88)\left(9.9 \times 10^{-2}\right)=8.71 \times 10^{-2} \mathrm{lb} / \mathrm{hr} \\
& U=(0.0435)\left(8.71 \times 10^{-2}\right)=3.79 \times 10^{-3} \mathrm{lb} / \mathrm{hr} \\
& 238 \mathrm{U}=(0.993)\left(3.79 \times 10^{-3}\right)=3.76 \times 10^{-3} \mathrm{lb} / \mathrm{hr} \\
& 235 \mathrm{U}=3.0 \times 10^{-5} \mathrm{lb} / \mathrm{hr}
\end{aligned}
$$

The activity in the mine dust is:
${ }^{232} \mathrm{Th}$
$8.71 \times 10^{-2} \mathrm{lb} / \mathrm{hr}$
$4.35 \times 10^{-6} \mathrm{Ci} / \mathrm{hr}$
$238 \mathrm{U}$
$3.76 \times 10^{-3} \mathrm{lb} / \mathrm{hr}$
$5.69 \times 10^{-7} \mathrm{Ci} / \mathrm{hr}$
$235 \mathrm{U}$
$3.0 \times 10^{-5} \mathrm{lb} / \mathrm{hr}$
$2.92 \times 10^{-8} \mathrm{Ci} / \mathrm{hr}$
${ }^{232}$ Th Daughters (9)
Trace
$3.92 \times 10^{-5} \mathrm{Ci} / \mathrm{hr}$
${ }^{238} \cup$ Daughters (13)
Trace
$7.39 \times 10^{-6} \mathrm{Ci} / \mathrm{hr}$
${ }^{235} \cup$ Daughters (10)
Trace
$2.92 \times 10^{-7} \mathrm{Ci} / \mathrm{hr}$

As mentioned for the Palmer, Michigan, mine, the best ways to minimize the dust levels are to wet down the working and transportation areas and erect wind barriers.

Liquid Wastes

It is assumed that the maximum concentration of $\mathrm{ThO}_{2}$ in the water is $1 \mathrm{ppm}$ and that the flow rate is $1000 \mathrm{gpm}$. There will be less precipitation here than in Palmer, Michigan, and the mine is also smaller. The amounts released in the liquid wastes are:

$$
\mathrm{ThO}_{2}=\frac{1 \mathrm{mg}}{\ell} \times \frac{1 \mathrm{~g}}{1000 \mathrm{mg}} \times \frac{1 \mathrm{lb}}{454 \mathrm{~g}} \times \frac{1000 \mathrm{gal}}{\mathrm{min}} \times \frac{60 \mathrm{~min}}{\mathrm{hr}} \times \frac{3.79 \ell}{\mathrm{gal}}=0.50 \mathrm{lb} / \mathrm{hr}
$$




$$
\begin{aligned}
& { }^{232} \mathrm{Th}=(0.88)(0.50)=0.44 \mathrm{lb} / \mathrm{hr} \\
& U=(0.0435)(0.44)=1.91 \times 10^{-2} \mathrm{lb} / \mathrm{hr} \\
& { }^{238} \mathrm{U}=(0.993)\left(1.91 \times 10^{-2}\right)=1.90 \times 10^{-2} \mathrm{lb} / \mathrm{hr} \\
& 235_{U}=1.0 \times 10^{-4} \mathrm{lb} / \mathrm{hr}
\end{aligned}
$$

\begin{tabular}{|c|c|c|}
\hline${ }^{232} \mathrm{Th}$ & $0.44 \mathrm{lb} / \mathrm{hr}$ & $2.2 \times 10^{-5} \mathrm{Ci} / \mathrm{hr}$ \\
\hline $238 \mathrm{U}$ & $1.9 \times 10^{-2} 1 \mathrm{~b} / \mathrm{hr}$ & $2.87 \times 10^{-6} \mathrm{Ci} / \mathrm{hr}$ \\
\hline $235_{U}$ & $1.0 \times 10^{-4} \mathrm{lb} / \mathrm{hr}$ & $9.73 \times 10^{-8} \mathrm{Ci} / \mathrm{hr}$ \\
\hline${ }^{232}$ Th Daughters (9) & Trace & $1.98 \times 10^{-4} \mathrm{Ci} / \mathrm{hr}$ \\
\hline${ }^{238}$ U Daughters (13) & Trace & $3.74 \times 10^{-5} \mathrm{Ci} / \mathrm{hr}$ \\
\hline${ }^{235} \mathrm{U}$ Daughters $(10)$ & Trace & $9.73 \times 10^{-7} \mathrm{Ci} / \mathrm{hr}$ \\
\hline
\end{tabular}

The activity in the water is:

Holding ponds or evaporation ponds will be needed to contain and treat this waste stream. If the mill is located nearby, some water may be used in it.

Solids

The waste rock and overburden will be stored onsite or adjacent to the mine. Because of this and the low concentration of radioactive substances, there should be no external environmental effects.

\section{C.6 CONWAY GRANITE MINE}

\section{Airborne Generated Wastes}

The amounts of airborne wastes released from the mine are:

$$
\begin{aligned}
\text { Dust } & =(0.00125)(100,000 \text { tons } / \text { day })(1 \text { day } / 24 \mathrm{hr})(2000 \mathrm{lb} / \text { ton }) \\
& =10,420 \mathrm{lb} / \mathrm{hr} \\
\mathrm{Th}_{2} & =(0.00006)(10,420)=0.625 \mathrm{lb} / \mathrm{hr} \\
{ }^{232} \mathrm{Th} & =(0.88)(0.625)=0.55 \mathrm{lb} / \mathrm{hr} \\
U=(0.25)(0.55)=0.1375 \mathrm{lb} / \mathrm{hr} & \\
238 U & =(0.993)(0.1375)=0.1365 \mathrm{lb} / \mathrm{hr} \\
235 \mathrm{U} & =1.0 \times 10^{-3} \mathrm{lb} / \mathrm{hr}
\end{aligned}
$$


The activity in the mine dust is:

$\begin{array}{lll}{ }^{232} \mathrm{Th} & 0.55 \mathrm{lb} / \mathrm{hr} & 2.75 \times 10^{-5} \mathrm{Ci} / \mathrm{hr} \\ { }^{238} \mathrm{U} & 0.1365 \mathrm{lb} / \mathrm{hr} & 2.06 \times 10^{-5} \mathrm{Ci} / \mathrm{hr} \\ 235 \mathrm{U} & 1.0 \times 10^{-3} \mathrm{lb} / \mathrm{hr} & 9.73 \times 10^{-7} \mathrm{Ci} / \mathrm{hr} \\ { }^{232} \mathrm{Th} \text { Daughters (9) } & \text { Trace } & 2.475 \times 10^{-4} \mathrm{Ci} / \mathrm{hr} \\ { }^{238} \mathrm{U} \text { Daughters (13) } & \text { Trace } & 2.68 \times 10^{-4} \mathrm{Ci} / \mathrm{hr} \\ 235 \mathrm{U} \text { Daughters (10) } & \text { Trace } & 9.73 \times 10^{-6} \mathrm{Ci} / \mathrm{hr}\end{array}$

As previously mentioned, the best ways to minimize the dust levels are to wet down the working and transportation areas and erect wind barriers.

Liquid Wastes

It was assumed that $1 \mathrm{ppm}$ is the maximum concentration of $\mathrm{ThO}_{2}$ in the water and that the flow rate if $2000 \mathrm{gpm}$. The large flow rate is due to the large area to be mined and the fact that the mine is in an area with high precipitation levels. The amounts released in the liquid wastes are:

$$
\begin{aligned}
& \mathrm{Th0}_{2}=\frac{1 \mathrm{mg}}{\ell} \times \frac{1 \mathrm{~g}}{1000 \mathrm{mg}} \times \frac{1 \mathrm{lb}}{454 \mathrm{~g}} \times \frac{2000 \mathrm{gal}}{\mathrm{min}} \times \frac{60 \mathrm{~min}}{\mathrm{hr}} \times \frac{3.79 \ell}{\mathrm{gaT}}=1.00 \mathrm{lb} / \mathrm{hr} \\
& 232 \mathrm{Th}=(0.88)(1.0)=0.88 \mathrm{lb} / \mathrm{hr} \\
& U=(0.25)(0.88)=0.22 \mathrm{lb} / \mathrm{hr} \\
& 238 \mathrm{U}=(0.993)(0.22)=0.218 \mathrm{lb} / \mathrm{hr} \\
& 235 \mathrm{U}=2.0 \times 10^{-3} \mathrm{lb} / \mathrm{hr}
\end{aligned}
$$

The activity in the water is:
${ }^{232} \mathrm{Th}$
$0.88 \mathrm{lb} / \mathrm{hr}$
$4.4 \times 10^{-5} \mathrm{Ci} / \mathrm{hr}$
$238 \mathrm{U}$
$0.218 \mathrm{lb} / \mathrm{hr}$
$3.3 \times 10^{-5} \mathrm{Ci} / \mathrm{hr}$
$235 \mathrm{U}$
${ }^{232}$ Th Daughters (9)
$2.0 \times 10^{-3} \mathrm{lb} / \mathrm{hr}$
$1.95 \times 10^{-6} \mathrm{Ci} / \mathrm{hr}$
${ }^{238} \mathrm{U}$ Daughters (13)
Trace
$3.96 \times 10^{-4} \mathrm{Ci} / \mathrm{hr}$
${ }^{235} \mathrm{U}$ Daughters (10)
Trace
$4.29 \times 10^{-4} \mathrm{Ci} / \mathrm{hr}$
Trace
$1.95 \times 10^{-5} \mathrm{Ci} / \mathrm{hr}$

If the mill is located near the mine, this water can be used there. Holding or evaporation ponds may also be used to control or treat the liquid wastes. 
Solids

The ratio of 2:10, waste rock to ore, applies at this mine. Thus, there are 20,000 tons/day of waste rock. This will be stored onsite, either in the mine itself or adjacent to it. Because of this and because of the low concentration of radioactive substances, there should be no external environmental effects. 

APPENDIX D

MILL AND REFINERY GENERATED WASTES 
APPENDIX D
MILL AND REFINERY GENERATED WASTES (a)

\section{D.1 GENERATED WASTES FROM STOCKPILE REFINERY}

Waste Sludge

The sludge leaves the mill at a rate of $698 \mathrm{lb} / \mathrm{hr}$, of which $80 \%$ is solids and $2.64 \mathrm{lb}$ are ${ }^{232} \mathrm{Th}$, as shown in Figure $\mathrm{D} .1$. The amount of uranium in the entering sludge is $1 \%$ of the total or $6 \mathrm{lb}$. If the same ratio as assumed between $T h$ and $U$ in the waste sludge, there is 0.12 lb of uranium in the waste sludge. The uranium is split between ${ }^{238} U$ and ${ }^{235} U$ at a ratio of:

$$
\left(\frac{0.993}{0.007}\right)\left(\frac{238 U}{235 U}\right)
$$

Thus, there are $0.1192 \mathrm{lb} / \mathrm{hr}$ of ${ }^{238} \mathrm{U}$ and $0.0008 \mathrm{lb} / \mathrm{hr}$ of ${ }^{235} \mathrm{U}$ in the waste sludge. The activity in the waste sludge stream is:
${ }^{232} \mathrm{Th}$
$2.64 \mathrm{lb} / \mathrm{hr}$
$1.32 \times 10^{-4} \mathrm{Ci} / \mathrm{hr}$
$238 \mathrm{U}$
$0.1192 \mathrm{lb} / \mathrm{hr}$
$1.88 \times 10^{-5} \mathrm{Ci} / \mathrm{hr}$
$235 \mathrm{U}$
$0.0008 \mathrm{lb} / \mathrm{hr}$
$7.79 \times 10^{-7} \mathrm{Ci} / \mathrm{hr}$
${ }^{232}$ Th Daughters (9)
Trace
$1.188 \times 10^{-3} \mathrm{Ci} / \mathrm{hr}$
238 U Daughters (13)
Trace
$2.444 \times 10^{-4} \mathrm{Ci} / \mathrm{hr}$
${ }^{235} \mathrm{U}$ Daughters (10)
Trace
$7.79 \times 10^{-6} \mathrm{Ci} / \mathrm{hr}$

This waste sludge can be disposed of by proper burial techniques at an approved site.

\section{Liquid Waste to Tailings Pond}

The following streams and respective loads are sent to a tailings pond:

Extraction and Scrubbing Stream - $1321 \mathrm{lb} / \mathrm{hr}$ containing $0.264 \mathrm{lb} / \mathrm{hr}$ ${ }^{232}$ Th with a total flow of $2.64 \mathrm{gpm}$.

Uranium Removal Stream - $1468 \mathrm{lb} / \mathrm{hr}$ with no ${ }^{232}$ Th and a total flow of $2.94 \mathrm{gpm}$.

(a) Excess significant figures are shown for some numbers and were used for computational purposes only. 


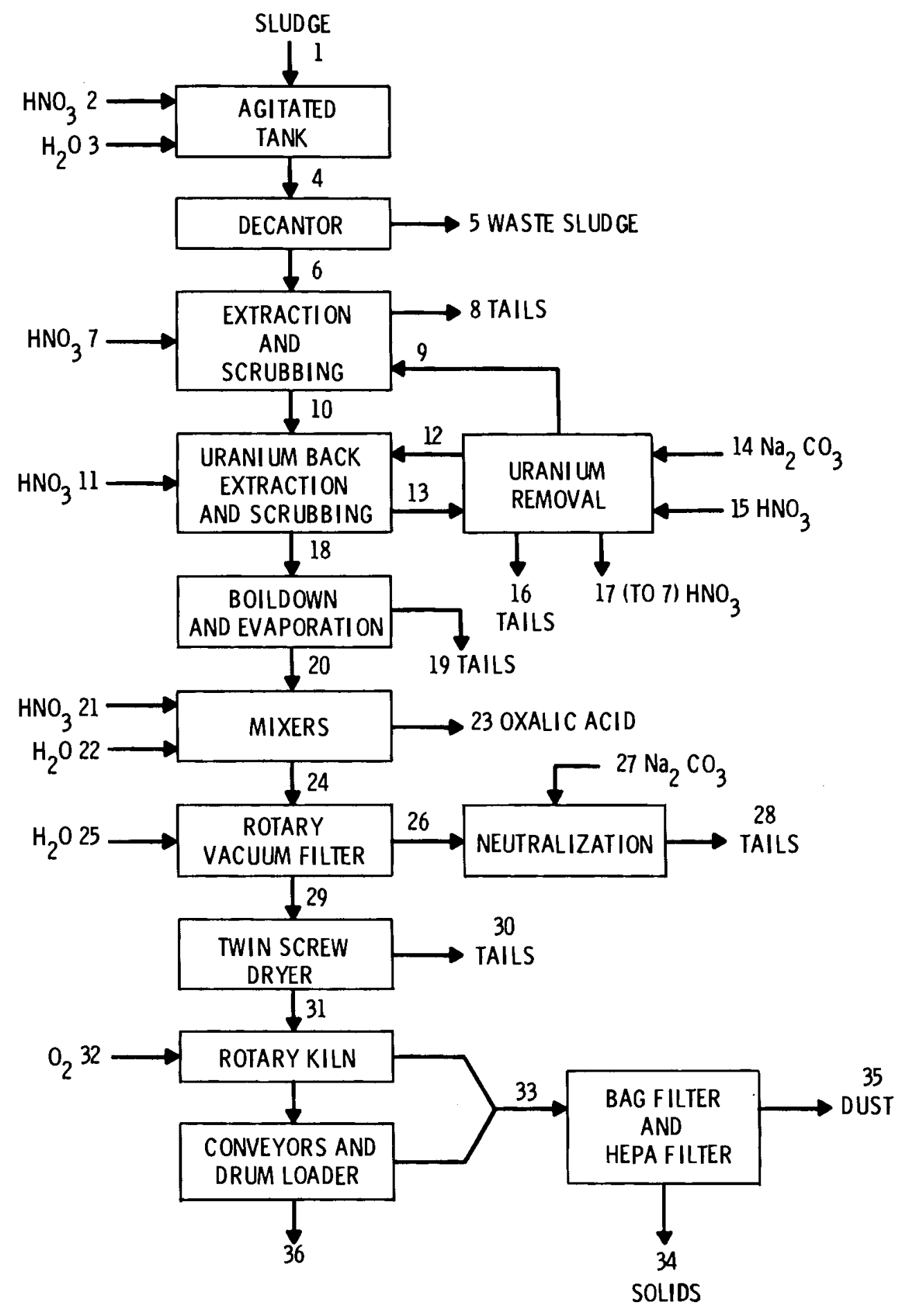

FIGURE D.1. Stockpile Refinery Flowsheet 
FIGURE D.1. Legend: Flow Streams for Stockpile Refinery

1. $600 \mathrm{lb} / \mathrm{hr}$ sludge $\mathrm{w} / 132 \mathrm{lb} / \mathrm{hr}{ }^{232} \mathrm{Th}$

2. $315 \mathrm{lb} / \mathrm{hr} \mathrm{HNO}_{3}$

3. $517 \mathrm{lb} / \mathrm{hr} \mathrm{H}_{2} \mathrm{O}$

4. $1432 \mathrm{lb} / \mathrm{hr} \mathrm{w} / 132 \mathrm{1b} / \mathrm{hr}{ }^{232} \mathrm{Th}$

5. $698 \mathrm{lb} / \mathrm{hr}$ sludge $w / 2.64 \mathrm{lb} / \mathrm{hr}{ }^{232} \mathrm{Th}$ (80\% solids)

6. $734 \mathrm{lb} / \mathrm{hr} w / 129.36 \mathrm{jb} / \mathrm{hr}{ }^{232} \mathrm{Th}$

7. $587 \mathrm{lb} / \mathrm{hr}$ of $4 \mathrm{~N} \mathrm{HNO}_{3}$

8. $1321 \mathrm{lb} / \mathrm{hr} w / 0.294 \mathrm{lb} / \mathrm{hr}{ }^{232} \mathrm{Th}$

9. $2936 \mathrm{ib} / \mathrm{hr}$

10. $2936 \mathrm{lb} / \mathrm{hr} w / 129.096 \mathrm{lb} / \mathrm{hr}{ }^{232} \mathrm{Th}$

11. $2936 \mathrm{1b} / \mathrm{hr}$ of $0.1 \mathrm{~N} \mathrm{HNO}_{3}$

12. $587 \mathrm{lb} / \mathrm{hr}$

13. $3523 \mathrm{lb} / \mathrm{hr}$

14. $1468 \mathrm{~Tb} / \mathrm{hr}$ of $\mathrm{Na}_{2} \mathrm{CO}_{3}(5 \%)$

15. $734 \mathrm{lb} / \mathrm{hr}$ of $4 \mathrm{~N} \mathrm{HNO}_{3}$

16. $1468 \mathrm{lb} / \mathrm{hr}$

17. $734 \mathrm{lb} / \mathrm{hr}$ of $\mathrm{HNO}_{3}$ to be used to make No. 7 stream

18. $2936 \mathrm{lb} / \mathrm{hr} \mathrm{w} / 129.096 \mathrm{lb} / \mathrm{hr}{ }^{232} \mathrm{Th}$
19. $2324 \mathrm{~Tb} / \mathrm{hr} \quad \mathrm{H}_{2} \mathrm{O}$

20. $612 \mathrm{lb} / \mathrm{hr} w / 129.096 \mathrm{lb} / \mathrm{hr}^{232} \mathrm{Th}$

21. $34 \mathrm{lb} / \mathrm{hr} \mathrm{HNO}_{3}$

22. $40 \mathrm{lb} / \mathrm{hr} \mathrm{H} \mathrm{H}_{2} \mathrm{O}$

23. $52 \mathrm{lb} / \mathrm{hr}$ oxalic acid

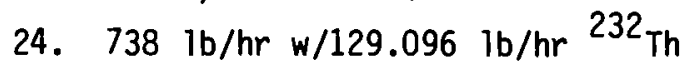

25. $133.4 \mathrm{lb} / \mathrm{hr} \mathrm{H} \mathrm{H}_{2} \mathrm{O}$

26. $494.4 \mathrm{lb} / \mathrm{hr} \mathrm{w} / 1.056 \mathrm{lb} / \mathrm{hr}{ }^{232} \mathrm{Th}$

27. $143 \mathrm{lb} / \mathrm{hr} \mathrm{Na} \mathrm{CO}_{3}$

28. $637.4 \mathrm{lb} / \mathrm{hr} \mathrm{w} / 1.056 \mathrm{lb} / \mathrm{hr}{ }^{232} \mathrm{Th}$

29. $377 \mathrm{lb} / \mathrm{hr} w / 128.04 \mathrm{lb} / \mathrm{hr}{ }^{232} \mathrm{Th}$

30. $109 \mathrm{lb} / \mathrm{hr} \mathrm{H}_{2} \mathrm{O}$

31. $268 \mathrm{lb} / \mathrm{hr} w / 128.04 \mathrm{lb} / \mathrm{hr}{ }^{232} \mathrm{Th}$

32. $20 \mathrm{lb} / \mathrm{hr} \mathrm{O}_{2}$

33. $47 \mathrm{lb} / \mathrm{hr} \mathrm{H} \mathrm{H}_{2} \mathrm{O}$ and $95 \mathrm{lb} / \mathrm{hr} \mathrm{CO}$ $\mathrm{w} / 2.64 \mathrm{lb} / \mathrm{hr}{ }^{232} \mathrm{Th}$

34. $2.614 \mathrm{lb} / \mathrm{hr}^{232} \mathrm{Th}$

35. $47 \mathrm{lb} / \mathrm{hr} \mathrm{H}_{2} \mathrm{O}$ and $95 \mathrm{lb} / \mathrm{hr} \mathrm{CO}$ $w / 0.026 \mathrm{lb} / \mathrm{hr}{ }^{232} \mathrm{Th}$

36. $144 \mathrm{lb} / \mathrm{hr} \mathrm{w} / 125.4 \mathrm{lb} / \mathrm{hr}{ }^{232} \mathrm{Th}$ 
Boildown and Evaporation Stream - $2324 \mathrm{lb} / \mathrm{hr}$ of mainly $\mathrm{H}_{2} \mathrm{O}$ with a total flow of $4.65 \mathrm{gpm}$.

Plate-and-Frame-Press Stream - $637.4 \mathrm{lb} / \mathrm{hr}$ containing $1.056 \mathrm{lb} / \mathrm{hr}{ }^{232} \mathrm{Th}$ with a total flow of $1.27 \mathrm{gpm}$.

Twin Screw Dryer Stream - $190 \mathrm{lb} / \mathrm{hr}$ mainly $\mathrm{H}_{2} \mathrm{O}$ with a total flow of $0.22 \mathrm{gpm}$.

A total of $5859.4 \mathrm{lb} / \mathrm{hr}$ flows to the tailings pond. It contains $1.32 \mathrm{lb} / \mathrm{hr}{ }^{232} \mathrm{Th}$. The total flow to the pond is $11.72 \mathrm{gpm}$. All of uranium in the entering sludge goes to the tailings pond except the amount leaving in the waste sludge stream. The amounts of uranium in the pond are:

$U$ in tailings pond $=6.0-0.12=5.88 \mathrm{lb} / \mathrm{hr}$

$238 \mathrm{U}=(0.993)(5.88)=5.838 \mathrm{lb} / \mathrm{hr}$

$235 U=(0.007)(5.88)=0.042 \mathrm{lb} / \mathrm{hr}$

The activity in the tailings pond is:

$\begin{array}{lll}232 \mathrm{Th} & 1.32 \mathrm{lb} / \mathrm{hr} & 6.60 \times 10^{-5} \mathrm{Ci} / \mathrm{hr} \\ 238 \mathrm{U} & 5.838 \mathrm{lb} / \mathrm{hr} & 8.83 \times 10^{-4} \mathrm{Ci} / \mathrm{hr} \\ 235_{\mathrm{U}} & 0.042 \mathrm{lb} / \mathrm{hr} & 4.09 \times 10^{-5} \mathrm{Ci} / \mathrm{hr} \\ 232 \mathrm{Th} \text { Daughters } & \text { Trace } & 5.18 \times 10^{-2} \mathrm{Ci} / \mathrm{hr} \\ 238 \mathrm{U} \text { Daughters (13) } & \text { Trace } & 1.1479 \times 10^{-2} \mathrm{Ci} / \mathrm{hr} \\ 235 \mathrm{U} \text { Daughters (10) } & \text { Trace } & 4.09 \times 10^{-4} \mathrm{Ci} / \mathrm{hr}\end{array}$

Drying and Loading Dust

There are $47 \mathrm{lb} / \mathrm{hr} \mathrm{H} \mathrm{H}_{2} \mathrm{O}, 95 \mathrm{lb} / \mathrm{hr} \mathrm{CO}$, and $2.64 \mathrm{lb} / \mathrm{hr}$ of ${ }^{232} \mathrm{Th}$ in the dust stream, see Figure D.1. This stream is controlled by hoods connected to a 6,000-cfm HEPA and baghouse filter system as shown. This system removes 99\% of the ${ }^{232}$ Th dust. The solid from the system is recycled back into the packaging process. There are $2.61 \mathrm{lb} / \mathrm{hr}$ of ${ }^{232} \mathrm{Th}$ solids. The other $0.026 \mathrm{lb} / \mathrm{hr}$ of ${ }^{232} \mathrm{Th}$ is emitted to the atmosphere. The activity in the stream is:
${ }^{232} \mathrm{Th}$ (solid)
$2.61 \mathrm{lb} / \mathrm{hr}$
$1.30 \times 10^{-4} \mathrm{Ci} / \mathrm{hr}$
${ }^{232}$ Th (airborne)
$0.026 \mathrm{lb} / \mathrm{hr}$
$1.30 \times 10^{-6} \mathrm{Ci} / \mathrm{hr}$
${ }^{228} \mathrm{Th}$ (solid)
Trace
$1.30 \times 10^{-4} \mathrm{Ci} / \mathrm{hr}$
${ }^{228} \mathrm{Th}$ (air)
Trace
$1.30 \times 10^{-6} \mathrm{Ci} / \mathrm{hr}$ 


\section{D.2 GENERATED WASTES FROM LEMHI PASS THORITE MILL/REFINERY}

Dust from Unloading, Crushing, and Grinding the Ore

From these processes, $4.55 \mathrm{lb} / \mathrm{hr}$ of ore are emitted in dust; of this, $0.0132 \mathrm{lb}$ is ${ }^{232} \mathrm{Th}$, as shown in Figure 0.2 . The uranium content of the dust $=(100 / 1)(T h / U)$ so $(0.0132)(0.01)=1.32 \times 10^{-4} \mathrm{lb} \mathrm{U}$. The uranium is split between ${ }^{238} \mathrm{U}$ and ${ }^{235} \mathrm{U}$ and the ratio is:

$$
\left(\frac{0.993}{0.007}\right)\left(\frac{238 U}{235 U}\right)
$$

There are $1.31 \times 10^{-4} \mathrm{lb} / \mathrm{hr}{ }^{238} \mathrm{U}$ and $1.0 \times 10^{-6} \mathrm{lb} / \mathrm{hr}{ }^{235} \mathrm{U}$. The activity in the dust stream is:
$232 \mathrm{Th}$
$238_{\mathrm{U}}$
$0.0132 \mathrm{lb} / \mathrm{hr}$
$235_{\mathrm{U}}$
$1.31 \times 10^{-4} \mathrm{lb} / \mathrm{hr}$
$6.6 \times 10^{-7} \mathrm{Ci} / \mathrm{hr}$
${ }^{232}$ Th Daughters (9)
$1.0 \times 10^{-6} \mathrm{lb} / \mathrm{hr}$
$1.98 \times 10^{-8} \mathrm{Ci} / \mathrm{hr}$
Trace
$9.75 \times 10^{-10} \mathrm{Ci} / \mathrm{hr}$
${ }^{238} \mathrm{U}$ Daughters (13)
Trace
$5.95 \times 10^{-6} \mathrm{Ci} / \mathrm{hr}$
235
U Daughters (10)
Trace
$2.58 \times 10^{-7} \mathrm{Ci} / \mathrm{hr}$
$9.75 \times 10^{-9} \mathrm{Ci} / \mathrm{hr}$

Drying and Ignition Dust

From the drying and ignition processes, $896.2 \mathrm{lb} / \mathrm{hr}$ of airborne wastes are emitted, of which $0.12 \mathrm{lb}$ are ${ }^{232} \mathrm{Th}$. The remainder is mostly $\mathrm{H}_{2} \mathrm{O}$. The activity in the stream is:
232 Th
$0.105 \mathrm{lb} / \mathrm{hr}$
$5.25 \times 10^{-6} \mathrm{Ci} / \mathrm{hr}$
${ }^{228}$ Th
Trace
$5.25 \times 10^{-6} \mathrm{Ci} / \mathrm{hr}$

The equipment that handles this dust load consists of a $21,000-\mathrm{cfm}$ wetimpingement scrubber.

Packaging Dust

From the packaging process, $0.021 \mathrm{lb} / \mathrm{hr}$ of airborne wastes are released, of which $0.0185 \mathrm{lb} / \mathrm{hr}$ are ${ }^{232} \mathrm{Th}$. The activity of the stream is: 


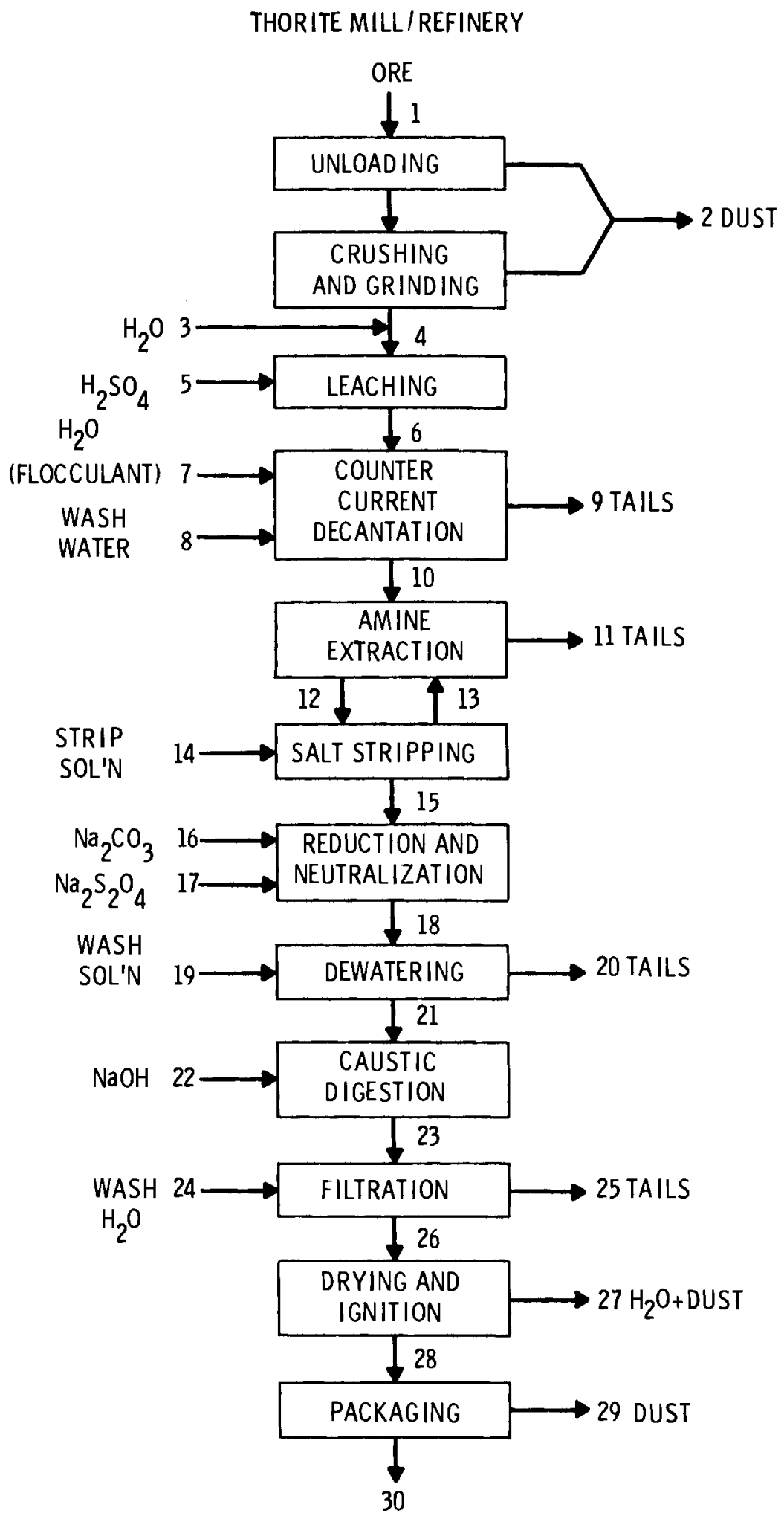

FIGURE D.2. Lemhi Pass Mill/Refinery Flowsheet

D. 6 
FIGURE D.2. Legend: Flow Streams for Lemhi Pass Mill/Refinery

1. 45.5 tons $/ \mathrm{hr}$ ore $\mathrm{w} / 285.38 \mathrm{lb} / \mathrm{hr}{ }^{232} \mathrm{Th}$

2. $4.55 \mathrm{lb} / \mathrm{hr} w / 0.0132 \mathrm{lb} / \mathrm{hr}{ }^{232} \mathrm{Th}$

3. 18.2 tons $/ \mathrm{hr} \mathrm{H}_{2} \mathrm{O}$ or $72.8 \mathrm{gpm}$

4. 63.7 tons $/ \mathrm{hr} w / 285.37 \mathrm{lb} / \mathrm{hr}{ }^{232} \mathrm{Th}$

5. $16,835 \mathrm{lb} / \mathrm{hr} \mathrm{H} \mathrm{H}_{2} \mathrm{SO}_{4}$

6. $72.12 \mathrm{lb} / \mathrm{hr} w / 285.37 \mathrm{lb} / \mathrm{hr}^{232} \mathrm{Th}$

7. 4.55 tons $/ \mathrm{hr}$ of $\mathrm{H}_{2} \mathrm{O}$ (flocculant)

8. 168.35 tons $/ \mathrm{hr}$ of wash $\mathrm{H}_{2} \mathrm{O}$

9. $45 \%$ solids -63.39 tons $/ \mathrm{hr}$ solids $\mathrm{w} / 20.86 \mathrm{lb} / \mathrm{hr}{ }^{232} \mathrm{Th}$ $55 \%$ solution - 77.475 tons/hr solution $w / 2.45 \mathrm{lb} / \mathrm{hr}{ }^{232} \mathrm{Th}$

10. 104.155 tons $/ \mathrm{hr} w / 262.06 \mathrm{lb} / \mathrm{hr}{ }^{232} \mathrm{Th}$

11. 104.155 tons $/ \mathrm{hr} w / 1.64 \mathrm{lb} / \mathrm{hr}{ }^{232} \mathrm{Th}$

12. $19.5 \mathrm{tons} / \mathrm{hr} \mathrm{w} / 260.42 \mathrm{lb} / \mathrm{hr}{ }^{232} \mathrm{Th}$

13. 19.5 tons/hr of stripped organic

14. 12.7 tons $/ \mathrm{hr}$ of strip solution

15. 12.7 tons $/ \mathrm{hr} w / 260.42 \mathrm{lb} / \mathrm{hr}{ }^{232} \mathrm{Th}$

16. $590.5 \mathrm{lb} / \mathrm{hr} \mathrm{Na} \mathrm{CO}_{3}$

17. $9.35 \mathrm{lb} / \mathrm{hr} \mathrm{Na} \mathrm{S}_{2} \mathrm{O}_{4}$

18. $13 \mathrm{tons} / \mathrm{hr} w / 260.42 \mathrm{lb} / \mathrm{hr}{ }^{232} \mathrm{Th}$

19. 3.16 tons $/ \mathrm{hr}$ of wash solution $\left(3 \% \mathrm{Na}_{2} \mathrm{SO}_{4}\right)$

20. 12.49 tons $/ \mathrm{hr} w / 0.55 \mathrm{lb} / \mathrm{hr}{ }^{232} \mathrm{Th}$

21. 3.67 tons $/ \mathrm{hr} w / 259.87 \mathrm{lb} / \mathrm{hr}{ }^{232} \mathrm{Th}$

22. $95.5 \mathrm{ib} / \mathrm{hr}$ of $\mathrm{NaOH}$

23. 3.72 tons $/ \mathrm{hr} w / 259.87 \mathrm{lb} / \mathrm{hr}{ }^{232} \mathrm{Th}$

24. 3.177 tons $/ \mathrm{hr}$ of wash $\mathrm{H}_{2} \mathrm{O}$

25. 6.25 tons $/ \mathrm{hr} w / 0.0273 \mathrm{lb} / \mathrm{hr}{ }^{232} \mathrm{Th}$

26. 0.597 tons $/ \mathrm{hr} w / 259.84 \mathrm{lb} / \mathrm{hr}{ }^{232} \mathrm{Th}$

27. $896.2 \mathrm{lb} / \mathrm{hr} w / 0.105 \mathrm{lb} / \mathrm{hr}{ }^{232} \mathrm{Th}$

28. $297.8 \mathrm{lb} / \mathrm{hr} w / 259.735 \mathrm{lb} / \mathrm{hr}{ }^{232} \mathrm{Th}$

29. $0.021 \mathrm{lb} / \mathrm{hr} w / 0.0185 \mathrm{lb} / \mathrm{hr}{ }^{232} \mathrm{Th}$

30. $297.8 \mathrm{lb} / \mathrm{hr} \mathrm{w} / 259.72 \mathrm{lb} / \mathrm{hr}{ }^{232} \mathrm{Th}$ 

${ }^{232} \mathrm{Th}$
$0.0185 \mathrm{lb} / \mathrm{hr}$
$9.25 \times 10^{-7} \mathrm{Ci} / \mathrm{hr}$
${ }^{228}$ Th
Trace
$9.25 \times 10^{-7} \mathrm{Ci} / \mathrm{hr}$

Liquid Waste to Tailings Pond

The following streams and respective loads are sent to a tailings pond:

Counter Current Decantation Stream - $45 \%$ solids $=63.39$ tons $/ \mathrm{hr}$ containing $20.86 \mathrm{lb} / \mathrm{hr}{ }^{232} \mathrm{Th}$ and 77.475 tons/hr of solution containing $2.45 \mathrm{lb} / \mathrm{hr}^{232} \mathrm{Th}$ with a total flow of $309.9 \mathrm{gpm}$.

Amine Extraction Stream - 104.155 tons/hr containing $1.64 \mathrm{lb} / \mathrm{hr}$ ${ }^{232}$ Th with a total flow of $416.6 \mathrm{gpm}$.

Dewatering Stream - 12.49 tons/hr containing $0.55 \mathrm{lb} / \mathrm{hr}{ }^{232}$ Th with a total flow of $49.95 \mathrm{gpm}$.

Filtration Stream - 6.25 tons/hr containing $0.0273 \mathrm{lb} / \mathrm{hr}{ }^{232} \mathrm{Th}$ with a total flow of $25.0 \mathrm{gpm}$.

The total amount of liquid waste sent to the tailings pond $=$ 263.76 tons/hr containing $25.527 \mathrm{lb} / \mathrm{hr}{ }^{232} \mathrm{Th}$. The total flow to the pond is $801.45 \mathrm{gpm}$. All of the uranium in the entering ore goes to the tailings pond except the amount emitted as dust from the unloading, crushing, and grinding stage. The amounts of uranium are:

Total uranium in entering ore $=(0.01)(285.38 \mathrm{lb} / \mathrm{hr})=2.854 \mathrm{lb} / \mathrm{hr}$

$U$ in tailings pond $=2.854-\left(1.32 \times 10^{-4}\right)=2.85391 \mathrm{~b} / \mathrm{hr}$

$$
\begin{aligned}
& { }^{238} U=(0.993)(2.8539)=2.834 \mathrm{lb} / \mathrm{hr} \\
& 235 \mathrm{U}=(0.007)(2.8539)=0.020 \mathrm{lb} / \mathrm{hr}
\end{aligned}
$$

The activity in the tailings pond is:

$\begin{array}{lll}{ }^{232} \mathrm{Th} & 25.527 \mathrm{lb} / \mathrm{hr} & 1.276 \times 10^{-3} \mathrm{Ci} / \mathrm{hr} \\ { }^{238_{\mathrm{U}}} & 2.834 \mathrm{lb} / \mathrm{hr} & 4.287 \times 10^{-4} \mathrm{Ci} / \mathrm{hr} \\ { }^{235_{\mathrm{U}}} & 0.02 \mathrm{lb} / \mathrm{hr} & 1.945 \times 10^{-5} \mathrm{Ci} / \mathrm{hr} \\ { }^{232} \mathrm{Th} \text { Daughters } & \text { Trace } & 1.1541 \times 10^{-1} \mathrm{Ci} / \mathrm{hr} \\ { }^{238_{U}} & \text { Trace } & 5.573 \times 10^{-3} \mathrm{Ci} / \mathrm{hr} \\ 235_{U} \text { Daughters (13) } & \text { Trace } & 1.945 \times 10^{-4} \mathrm{Ci} / \mathrm{hr}\end{array}$




\section{D.3 GENERATED WASTES FROM HALL MOUNTAIN THORITE MILL/REFINERY}

Dust from Unloading, Crushing, and Grinding the Ore

From these processes, $1.818 \mathrm{lb} / \mathrm{hr}$ of ore are emitted in dust; of this, $0.0176 \mathrm{lb} / \mathrm{hr}$ is ${ }^{232} \mathrm{Th}$, as shown in Figure $\mathrm{D} .3$. The uranium content of the dust is $(0.01)(U / T h)$; so $(0.01)\left(1.76 \times 10^{-2}\right)=1.76 \times 10^{-4} \mathrm{lb} / \mathrm{hr} U$. The uranium is split between ${ }^{238} U$ and $235 U$ and the ratio is:

$$
\left(\frac{0.993}{0.007}\right)\left(\frac{238_{U}}{235 U}\right)
$$

so $1.75 \times 10^{-4} \mathrm{lb} / \mathrm{hr} 238 \mathrm{U}$ and $1.0 \times 10^{-6} \mathrm{lb} / \mathrm{hr}{ }^{235} \mathrm{U}$ are emitted. The activity in the dust stream is:

$\begin{array}{lll}232 \mathrm{Th} & 1.76 \times 10^{-2} \mathrm{lb} \mathrm{hr} & 8.80 \times 10^{-7} \mathrm{Ci} / \mathrm{hr} \\ 238 \mathrm{U} & 1.75 \times 10^{-4} \mathrm{lb} / \mathrm{hr} & 2.65 \times 10^{-8} \mathrm{Ci} / \mathrm{hr} \\ 235 \mathrm{U} & 1.0 \times 10^{-6} \mathrm{lb} / \mathrm{hr} & 9.73 \times 10^{-10} \mathrm{Ci} / \mathrm{hr} \\ 232 \mathrm{Th} \text { Daughters (9) } & \text { Trace } & 7.92 \times 10^{-6} \mathrm{Ci} / \mathrm{hr} \\ 238_{\mathrm{U}} \text { Daughters (13) } & \text { Trace } & 3.44 \times 10^{-7} \mathrm{Ci} / \mathrm{hr} \\ 235 \mathrm{U} \text { Daughters (10) } & \text { Trace } & 9.73 \times 10^{-6} \mathrm{Ci} / \mathrm{hr}\end{array}$

Drying and Ignition Dust

These processes emit $292.3 \mathrm{lb} / \mathrm{hr}$ of airborne wastes, of which $0.1275 \mathrm{lb} / \mathrm{hr}$ is ${ }^{232} \mathrm{Th}$. The remainder is mostly $\mathrm{H}_{2} \mathrm{O}$. The activity in the stream is:
${ }^{232} \mathrm{Th}$
$0.1275 \mathrm{lb} / \mathrm{hr}$
$6.375 \times 10^{-6} \mathrm{Ci} / \mathrm{hr}$
${ }^{228} \mathrm{Th}$
Trace
$6.375 \times 10^{-6} \mathrm{Ci} / \mathrm{hr}$

\section{Packaging Dust}

This process emits $0.0227 \mathrm{lb} / \mathrm{hr}$ of airborne wastes of which $0.0225 \mathrm{lb} / \mathrm{hr}$ is ${ }^{232} \mathrm{Th}$. The activity of the dust stream is: ${ }^{232} \mathrm{Th}$
$0.0225 \mathrm{lb} / \mathrm{hr}$
$1.125 \times 10^{-6} \mathrm{Ci} / \mathrm{hr}$
${ }^{228} \mathrm{Th}$
Trace
$1.125 \times 10^{-6} \mathrm{Ci} / \mathrm{hr}$ 


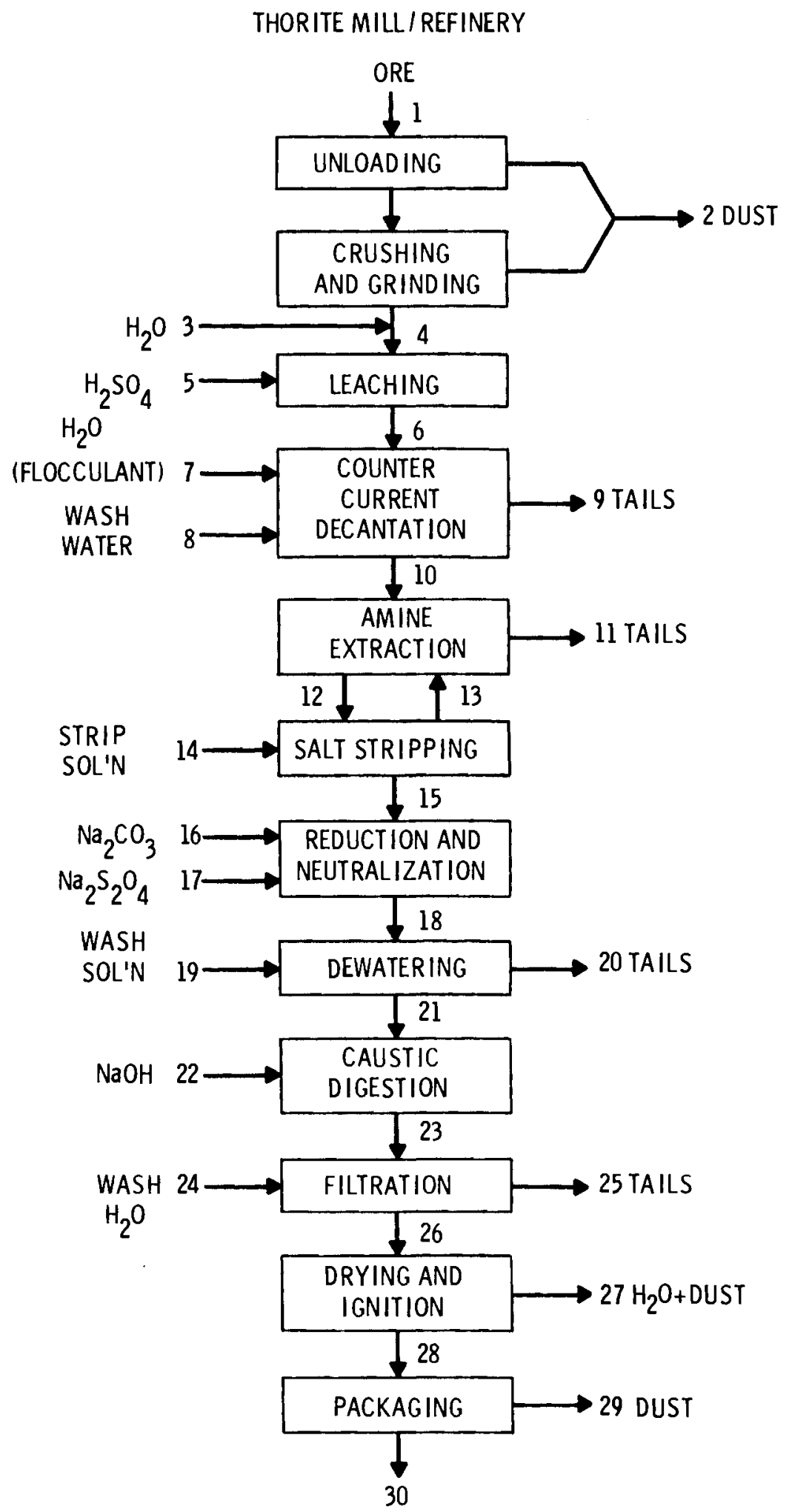

FIGURE D.3. Hall Mountain Mill/Refinery Flowsheet 
FIGURE D.3. Legend: Flow Streams for Hall Mountain Mill/Refinery

1. 18.18 tons $/ \mathrm{hr}$ ore $\mathrm{w} / 352 \mathrm{1b} / \mathrm{hr}{ }^{232} \mathrm{Th}$

2. $1.818 \mathrm{lb} / \mathrm{hr} \mathrm{w} / 1.76 \times 10^{-2} \mathrm{lb} / \mathrm{hr}{ }^{232} \mathrm{Th}$

3. 7.272 tons $/ \mathrm{hr} \mathrm{H}_{2} \mathrm{O}$ or $29.08 \mathrm{gpm}$

4. 25.451 tons $/ \mathrm{hr} \mathrm{w} / 351.98 \mathrm{lb} / \mathrm{hr}{ }^{232} \mathrm{Th}$

5. $6726.6 \mathrm{lb} / \mathrm{hr} \mathrm{H} \mathrm{H}_{2} \mathrm{SO}_{4}$

6. 28.814 tons $/ \mathrm{hr} w / 351.98 \mathrm{lb} / \mathrm{hr}{ }^{232} \mathrm{Th}$

7. 1.818 tons of $\mathrm{H}_{2} \mathrm{O}$ (flocculant)

8. 67.3 tons of wash water

9. $45 \%$ solution -17.604 tons $/ \mathrm{hr}$ solids $w / 25.73 \mathrm{lb} / \mathrm{hr}{ }^{232} \mathrm{Th}$ $55 \%$ solution - 20.38 tons $/ \mathrm{hr}$ solution $\mathrm{w} / 3.045 \mathrm{lb} / \mathrm{hr}{ }^{232} \mathrm{Th}$

10. 59.948 tons $/ \mathrm{hr} w / 323.205 \mathrm{lb} / \mathrm{hr}^{232} \mathrm{Th}$

11. 59.948 tons $/ \mathrm{hr} w / 2.02 \mathrm{lb} / \mathrm{hr}{ }^{232} \mathrm{Th}$

12. 5.42 tons $/ \mathrm{hr} w / 321.185 \mathrm{lb} / \mathrm{hr}{ }^{232} \mathrm{Th}$

13. 5.42 tons/hr of stripped organic

14. 7.39 tons $/ \mathrm{hr}$ of strip solution

15. 7.39 tons $/ \mathrm{hr} w / 321.185 \mathrm{lb} / \mathrm{hr}{ }^{232} \mathrm{Th}$

16. $363.6 \mathrm{lb} / \mathrm{hr} \mathrm{Na} \mathrm{CO}_{3}$

17. $5.454 \mathrm{lb} / \mathrm{hr} \quad \mathrm{Na}_{2} \mathrm{~S}_{2} \mathrm{O}_{2}$

18. 7.57 tons $/ \mathrm{hr} w / 321.185 \mathrm{lb} / \mathrm{hr}{ }^{232} \mathrm{Th}$

19. 1.818 tons $/ \mathrm{hr}$ of wash solution $\left(3 \% \mathrm{Na}_{2} \mathrm{SO}_{4}\right)$

20. 7.269 tons $/ \mathrm{hr} w / 0.680 \mathrm{lb} / \mathrm{hr}{ }^{232} \mathrm{Th}$

21. 2.119 tons $/ \mathrm{hr} w / 320.505 \mathrm{lb} / \mathrm{hr}{ }^{232} \mathrm{Th}$

22. $54.54 \mathrm{lb} / \mathrm{hr}$ of $\mathrm{NaOH}$

23. 2.146 tons $/ \mathrm{hr} w / 320.505 \mathrm{lb} / \mathrm{hr}{ }^{232} \mathrm{Th}$

24. 1.818 tons $/ \mathrm{hr}$ of wash $\mathrm{H}_{2} \mathrm{O}$

25. 3.634 tons $/ \mathrm{hr} w / 0.035 \mathrm{lb} / \mathrm{hr}{ }^{232} \mathrm{Th}$

26. 0.330 tons $/ \mathrm{hr} w / 320.47 \mathrm{lb} / \mathrm{hr}{ }^{232} \mathrm{Th}$

27. $292.3 \mathrm{lb} / \mathrm{hr} w / 0.1275 \mathrm{lb} / \mathrm{hr}{ }^{232} \mathrm{Th}$

28. $367.7 \mathrm{lb} / \mathrm{hr} w / 320.3425 \mathrm{lb} / \mathrm{hr}{ }^{232} \mathrm{Th}$

29. $0.0227 \mathrm{lb} / \mathrm{hr} w / 0.0225 \mathrm{lb} / \mathrm{hr}{ }^{232} \mathrm{Th}$

30. $367.7 \mathrm{lb} / \mathrm{hr} w / 320.32 \mathrm{lb} / \mathrm{hr}{ }^{232} \mathrm{Th}$ 


\section{Liquid Waste to Tailings Pond}

The following streams and respective loads are sent to a tailings pond:

Counter Current Decantation Stream - $45 \%$ solids $=17.60$ tons $/ \mathrm{hr}$ containing $25.73 \mathrm{lb} / \mathrm{hr}{ }^{232} \mathrm{Th} ; 55 \%$ solution $=20.38 \mathrm{ton} / \mathrm{hr}$ containing $3.045 \mathrm{lb} / \mathrm{hr}{ }^{232} \mathrm{Th}$; the total flow is $81.52 \mathrm{gpm}$.

Amine Extraction Stream - 59.948 tons/hr containing $2.02 \mathrm{lb} / \mathrm{hr}$ ${ }^{232}$ Th with a total flow of $239.79 \mathrm{gpm}$.

Dewatering Stream -7.269 tons $/ \mathrm{hr}$ containing $0.680 \mathrm{lb} / \mathrm{hr}{ }^{232} \mathrm{Th}$ with a total flow of $29.1 \mathrm{gpm}$.

Filtration Stream - 3.634/tons/hr containing $0.035 \mathrm{lb} / \mathrm{hr}{ }^{232} \mathrm{Th}$ with a total flow of $14.54 \mathrm{gpm}$.

The total amount sent to the tailings pond is 108.83 tons/hr containing $31.51 \mathrm{lb} / \mathrm{hr}{ }^{232} \mathrm{Th}$. The total flow to the pond is $364.95 \mathrm{gpm}$. All of the uranium in the entering ore goes to the tailings pond except for the amount emitted as dust from the unloading, crushing, and grinding stage. The amounts of uranium are:

Total uranium in entering ore $=(0.01)(352 \mathrm{lb} / \mathrm{hr})=3.52 \mathrm{lb} / \mathrm{hr}$

$U$ in tailings pond $=3.52-\left(1.76 \times 10^{-4}\right)=3.5198 \mathrm{lb} / \mathrm{hr}$

$$
\begin{aligned}
& { }^{238} U=(0.993)(3.5198)=3.4952 \mathrm{lb} / \mathrm{hr} \\
& 235 U=2.46 \times 10^{-2} \mathrm{lb} / \mathrm{hr}
\end{aligned}
$$

The activity in the tailings pond is:

$\begin{array}{lll}{ }^{232} \mathrm{Th} & 31.51 \mathrm{lb} / \mathrm{hr} & 1.575 \times 10^{-3} \mathrm{Ci} / \mathrm{hr} \\ { }^{238_{\mathrm{U}}} & 3.4952 \mathrm{lb} / \mathrm{hr} & 5.29 \times 10^{-4} \mathrm{Ci} / \mathrm{hr} \\ { }^{235} \mathrm{U} & 2.46 \times 10^{-2} \mathrm{lb} / \mathrm{hr} & 2.39 \times 10^{-5} \mathrm{Ci} / \mathrm{hr} \\ { }^{232} \mathrm{Th} \text { Daughters } & \text { Trace } & 1.42 \times 10^{-1} \mathrm{Ci} / \mathrm{hr} \\ { }^{238_{\mathrm{U}} \text { Daughters (13) }} & \text { Trace } & 6.87 \times 10^{-3} \mathrm{Ci} / \mathrm{hr} \\ { }^{235} \mathrm{U} \text { Daughters (10) } & \text { Trace } & 2.39 \times 10^{-4} \mathrm{Ci} / \mathrm{hr}\end{array}$




\section{D.4 GENERATED WASTES FROM WET MOUNTAIN THORITE MILL/REFINERY}

Dust from Unloading, Crushing, and Grinding the Ore

This stream contains $1.6 \mathrm{lb} / \mathrm{hr}$ of ore in its dust; of this, $0.0123 \mathrm{lb} / \mathrm{hr}$ is ${ }^{232} \mathrm{Th}$. The uranium content of the dust is $(100 / 1)(\mathrm{Th} / \mathrm{U})$; so $(0.0123)$ $(0.01)=1.232 \times 10^{-4} \mathrm{lb} / \mathrm{hr} U$. The uranium is split between ${ }^{238} \mathrm{U}$ and $235 \mathrm{U}$ and the ratio is:

$$
\left(\frac{0.993}{0.007}\right)\left(\frac{238 U}{235 U}\right)
$$

There are $1.22 \times 10^{-4} \mathrm{lb}{ }^{238} \mathrm{U}$ and $8.6 \times 10^{-7} \mathrm{lb}{ }^{235} \mathrm{U}$. The activity in the dust stream is:

\begin{tabular}{|c|c|c|}
\hline${ }^{232} \mathrm{Th}$ & $0.0123 \mathrm{lb} / \mathrm{hr}$ & $6.15 \times 10^{-7} \mathrm{Ci} / \mathrm{hr}$ \\
\hline $238 U$ & $1.22 \times 10^{-4} \mathrm{lb} / \mathrm{hr}$ & $1.845 \times 10^{-8} \mathrm{Ci} / \mathrm{hr}$ \\
\hline $235_{U}$ & $8.6 \times 10^{-7} \mathrm{lb} / \mathrm{hr}$ & $8.37 \times 10^{-10} \mathrm{Ci} / \mathrm{hr}$ \\
\hline${ }^{232}$ Th Daughters (9) & Trace & $5.535 \times 10^{-6} \mathrm{Ci} / \mathrm{hr}$ \\
\hline 238 U Daughters (13) & Trace & $2.3985 \times 10^{-7} \mathrm{Ci} / \mathrm{hr}$ \\
\hline $235 \mathrm{U}$ Daughters (10) & Trace & $8.37 \times 10^{-9} \mathrm{Ci} / \mathrm{hr}$ \\
\hline
\end{tabular}

Drying and Ignition Dust

The dust stream from these processes contains $119.2 \mathrm{lb} / \mathrm{hr}$ of airborne wastes, of which $0.0972 \mathrm{lb} / \mathrm{hr}$ is ${ }^{232} \mathrm{Th}$, as shown in Figure 0.4 . The remainder is mostly $\mathrm{H}_{2} \mathrm{O}$. The activity in the stream is:
${ }^{232} \mathrm{Th}$
$0.0972 \mathrm{lb} / \mathrm{hr}$
$4.86 \times 10^{-6} \mathrm{Ci} / \mathrm{hr}$
${ }^{228}$ Th Daughters
Trace
$4.86 \times 10^{-6} \mathrm{Ci} / \mathrm{hr}$

\section{Packaging Dust}

The packaging process emits $0.0197 \mathrm{lb} / \mathrm{hr}$ of airborne wastes of which $0.0172 \mathrm{lb} / \mathrm{hr}$ are ${ }^{232} \mathrm{Th}$. The activity in the stream is:
232 Th
$0.0172 \mathrm{lb} / \mathrm{hr}$
$8.60 \times 10^{-7} \mathrm{Ci} / \mathrm{hr}$
${ }^{228} \mathrm{Th}$
Trace
$8.60 \times 10^{-7} \mathrm{Ci} / \mathrm{hr}$ 
THORITE MILL/REFINERY

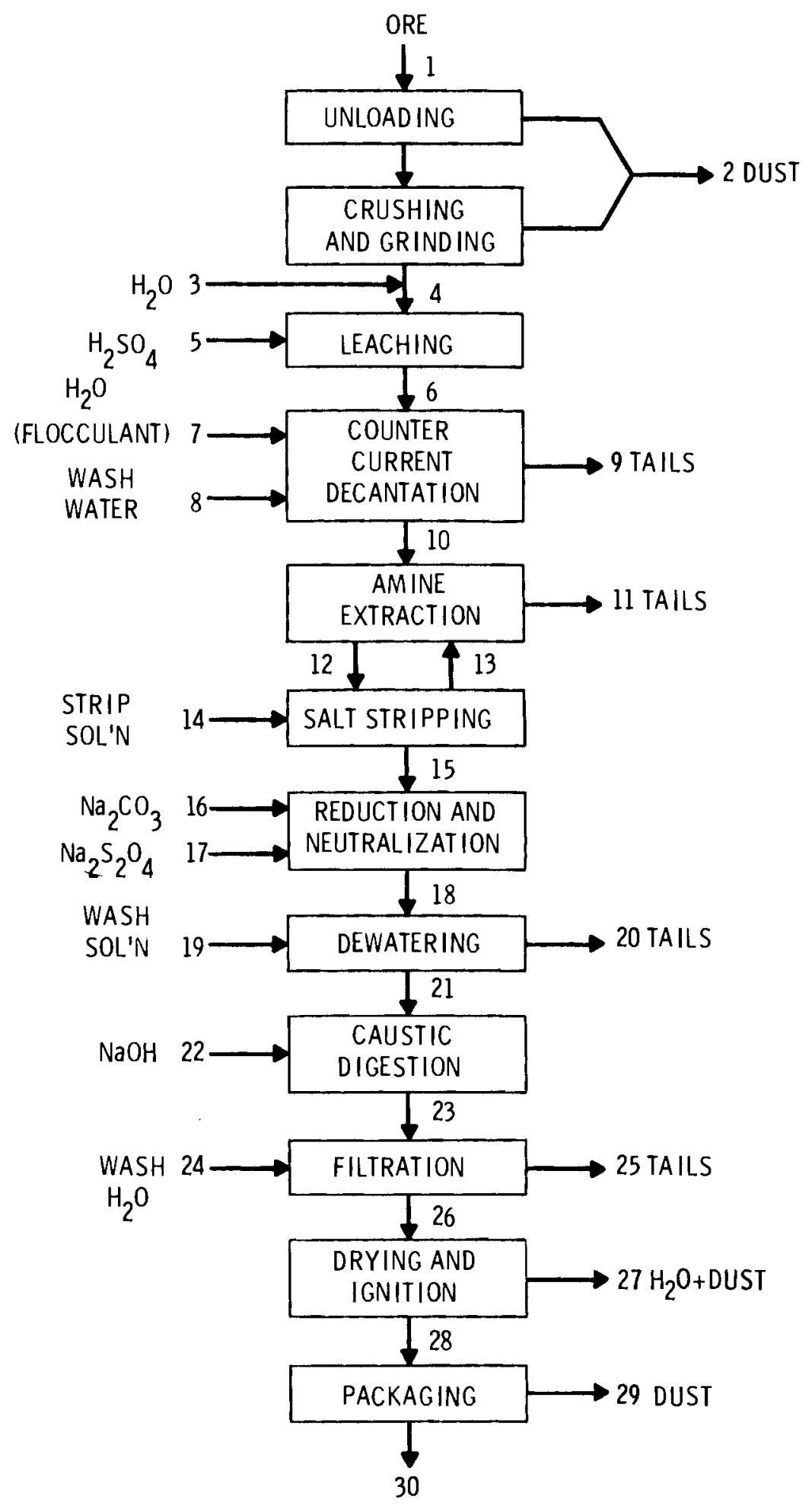

FIGURE D.4. Wet Mounta in Mill/Refinery Flowsheet 
FIGURE D.4. Legend: Flow Streams for Wet Mountain Mill/Refinery

1. 15.91 tons $/ \mathrm{hr}$ ore $w / 268.84 \mathrm{lb} / \mathrm{hr}{ }^{232} \mathrm{Th}$

2. $1.6 \mathrm{lb} / \mathrm{hr} \mathrm{w} / 0.0123 \mathrm{lb} / \mathrm{hr}{ }^{232} \mathrm{Th}$

3. 6.36 tons $/ \mathrm{hr} \mathrm{H}_{2} \mathrm{O}$ or $25.46 \mathrm{gpm}$

4. 22.27 tons $/ \mathrm{hr} w / 268.83 \mathrm{lb} / \mathrm{hr}{ }^{232} \mathrm{Th}$

5. $5887 \mathrm{lb} / \mathrm{hr} \mathrm{H}_{2} \mathrm{SO}_{4}$

6. 25.21 tons $/ \mathrm{hr} w / 268.83 \mathrm{lb} / \mathrm{hr}{ }^{232} \mathrm{Th}$

7. 1.6 tons of $\mathrm{H}_{2} \mathrm{O}$ ( f l occulant)

8. 58.87 tons of wash $\mathrm{H}_{2} \mathrm{O}$

9. $45 \%$ solids -22.16 tons $/ \mathrm{hr}$ solids $\mathrm{w} / 19.65 \mathrm{lb} / \mathrm{hr}{ }^{232} \mathrm{Th}$ $55 \%$ solution - 27.09 tons $/ \mathrm{hr}$ solution $\mathrm{w} / 2.325 \mathrm{lb} / \mathrm{hr}{ }^{232} \mathrm{Th}$

10. 36.43 tons $/ \mathrm{hr} w / 243.85 \mathrm{lb} / \mathrm{hr}{ }^{232} \mathrm{Th}$

11. 36.43 tons $/ \mathrm{hr} w / 1.55 \mathrm{lb} / \mathrm{hr}{ }^{232} \mathrm{Th}$

12. 6.82 tons $/ \mathrm{hr} w / 245.3 \mathrm{lb} / \mathrm{hr}{ }^{232} \mathrm{Th}$

13. 6.82 tons $/ \mathrm{hr}$ of stripped organic

14. 4.44 tons $/ \mathrm{hr}$ of strip solution

15. 4.44 tons $/ \mathrm{hr} w / 245.3 \mathrm{lb} / \mathrm{hr}{ }^{232} \mathrm{Th}$

16. $206.48 \mathrm{lb} / \mathrm{hr} \mathrm{Na}_{2} \mathrm{CO}_{3}$

17. $3.27 \mathrm{lb} / \mathrm{hr} \mathrm{Na} \mathrm{S}_{2} \mathrm{O}_{4}$

18. 4.55 tons $/ \mathrm{hr} \mathrm{w} / 245.3 \mathrm{lb} / \mathrm{hr}{ }^{232} \mathrm{Th}$

19. 1.10 tons $/ \mathrm{hr}$ of wash solution

20. 4.37 tons $/ \mathrm{hr} w / 0.52 \mathrm{lb} / \mathrm{hr}{ }^{232} \mathrm{Th}$

21. 1.28 tons $/ \mathrm{hr} w / 244.78 \mathrm{lb} / \mathrm{hr}{ }^{232} \mathrm{Th}$

22. $33.4 \mathrm{lb} / \mathrm{hr}$ of $\mathrm{NaOH}$

23. 1.30 tons $/ \mathrm{hr} w / 244.78 \mathrm{lb} / \mathrm{hr}{ }^{232} \mathrm{Th}$

24. 1.09 tons $/ \mathrm{hr}$ of wash $\mathrm{H}_{2} \mathrm{O}$

25. 2.19 tons $/ \mathrm{hr} w / 0.0264 \mathrm{lb} / \mathrm{hr}{ }^{232} \mathrm{Th}$

26. 400 tons $/ \mathrm{hr} w / 244.75 \mathrm{lb} / \mathrm{hr}{ }^{232} \mathrm{Th}$

27. $119.2 \mathrm{lb} / \mathrm{hr} w / 0.0972 \mathrm{lb} / \mathrm{hr}{ }^{232} \mathrm{Th}$

28. $280.8 \mathrm{lb} / \mathrm{hr} w / 244.66 \mathrm{lb} / \mathrm{hr}{ }^{232} \mathrm{Th}$

29. $0.0197 \mathrm{lb} / \mathrm{hr} w / 0.0172 \mathrm{lb} / \mathrm{hr}{ }^{232} \mathrm{Th}$

30. $280.8 \mathrm{lb} / \mathrm{hr} \mathrm{w} / 244.64 \mathrm{lb} / \mathrm{hr}{ }^{232} \mathrm{Th}$ 


\section{Liquid Waste to Tailings Pond}

The following streams and respective loads are sent to a tailings pond:

Counter Current Decantation Stream - $45 \%$ solids $=22.16$ tons $/ \mathrm{hr}$ containing $19.65 \mathrm{lb} / \mathrm{hr}{ }^{232} \mathrm{Th}$, and $27.09 \mathrm{ton} / \mathrm{hr}$ of solution containing $2.325 \mathrm{lb} / \mathrm{hr}{ }^{232} \mathrm{Th}$; total flow is $108.4 \mathrm{gpm}$.

Amine Extraction Stream - 36.43 tons/hr containing $1.55 \mathrm{lb} / \mathrm{hr}$ ${ }^{232}$ Th with a total flow of $145.7 \mathrm{gpm}$.

Dewatering Stream -4.37 tons $/ \mathrm{hr}$ containing $0.52 \mathrm{lb} / \mathrm{hr}{ }^{232} \mathrm{Th}$ with a total flow of $17.5 \mathrm{gpm}$.

Filtration Stream - 2.19/tons/hr containing $0.0264 \mathrm{lb} / \mathrm{hr}{ }^{232} \mathrm{Th}$ with a total flow of $8.76 \mathrm{gpm}$.

The total amount sent to the tailings pond is 92.24 tons/hr containing $24.07 \mathrm{lb} / \mathrm{hr}{ }^{232} \mathrm{Th}$. The total flow to the pond is $280.4 \mathrm{gpm}$. All of the uranium in the entering ore goes to the tailings pond except the amount emitted as dust from the unloading, crushing, and grinding stage. The amounts of uranium are:

Total uranium in entering ore $=(0.01)(236.84 \mathrm{lb} / \mathrm{hr})=2.6884 \mathrm{lb} / \mathrm{hr}$

$U$ in tailings pond $=2.6884-\left(1.232 \times 10^{-4}\right)=2.6883 \mathrm{lb} / \mathrm{hr}$

$$
\begin{aligned}
& 238 U=(0.993)(2.6883)=2.669 \mathrm{lb} / \mathrm{hr} \\
& 235_{U}=(0.007)(2.6883)=0.0193 \mathrm{lb} / \mathrm{hr}
\end{aligned}
$$

The activity in the tailings pond is:

$\begin{array}{lll}{ }^{232} \mathrm{Th} & 24.07 \mathrm{lb} / \mathrm{hr} & 1.20 \times 10^{-3} \mathrm{Ci} / \mathrm{hr} \\ { }^{238} \mathrm{U} & 2.669 \mathrm{lb} / \mathrm{hr} & 4.04 \times 10^{-4} \mathrm{Ci} / \mathrm{hr} \\ { }^{235} \mathrm{U} & 0.0193 \mathrm{lb} / \mathrm{hr} & 1.88 \times 10-5 \mathrm{Ci} / \mathrm{hr} \\ { }^{232} \mathrm{Th} \text { Daughters } & \text { Trace } & 1.087 \times 10^{-1} \mathrm{Ci} / \mathrm{hr} \\ { }^{238_{\mathrm{U}}} & 5.25 \times 10^{-3} \mathrm{Ci} / \mathrm{hr} \\ { }^{235} \mathrm{U} \text { Daughters (13) } & \text { Trace } & 1.88 \times 10^{-4} \mathrm{Ci} / \mathrm{hr}\end{array}$




\section{D.5 GENERATED WASTES FROM PALMER, MICHIGAN, ORE MILL}

Dust from Unloading, Crushing, and Grinding the Ore

The unloading, crushing, and grinding areas of the mill emit $327.2 \mathrm{lb} / \mathrm{hr}$ of ore dust; of this, $0.172 \mathrm{lb} / \mathrm{hr}$ is ${ }^{232} \mathrm{Th}$, and shown in Figure 0.5 . The uranium content of the dust is $(23 / 1)(T h / U)$; so $(0.0435)(0.172)=7.478 \times$ $10^{-3} \mathrm{lb} / \mathrm{hr} \mathrm{U}$. The uranium is split between ${ }^{238} \mathrm{U}$ and ${ }^{235} \mathrm{U}$ and the ratio is:

$$
\left(\frac{0.993}{0.007}\right)\left(\frac{238_{U}}{235 U}\right)
$$

Thus, there are $7.426 \times 10^{-3} \mathrm{lb}{ }^{238} \mathrm{U}$ and $5.20 \times 10^{-5} \mathrm{lb} / \mathrm{hr}{ }^{235} \mathrm{U}$. The activity in the dust stream is:

$\begin{array}{lll}{ }^{232} \mathrm{Th} & 0.172 \mathrm{lb} / \mathrm{hr} & 8.60 \times 10^{-6} \mathrm{Ci} / \mathrm{hr} \\ 238_{\mathrm{U}} & 7.426 \times 10^{-3} \mathrm{lb} / \mathrm{hr} & 1.12 \times 10^{-6} \mathrm{Ci} / \mathrm{hr} \\ 235_{\mathrm{U}} & 5.20 \times 10^{-5} \mathrm{lb} / \mathrm{hr} & 5.06 \times 10^{-8} \mathrm{Ci} / \mathrm{hr} \\ 232_{\mathrm{Th}} \text { Daughters (9) } & \text { Trace } & 7.74 \times 10^{-5} \mathrm{Ci} / \mathrm{hr} \\ 238_{\mathrm{U}} \text { Daughters (13) } & \text { Trace } & 1.46 \times 10^{-5} \mathrm{Ci} / \mathrm{hr} \\ 235_{\mathrm{U}} \text { Daughters (10) } & \text { Trace } & 5.06 \times 10^{-7} \mathrm{Ci} / \mathrm{hr}\end{array}$

Dust from Drying, Magnetic Separating, and Loading

These processes emit 2.455 tons/hr of airborne effluents, of which $0.101 \mathrm{lb} / \mathrm{hr}$ are ${ }^{232} \mathrm{Th}$; the remainder is mostly $\mathrm{H}_{2} \mathrm{O}$. The uranium content of the dust is $(0.0435)(U / T h)$; so $(0.101)(0.0435)=4.4 \times 10^{-3} \mathrm{lb} / \mathrm{hr} U$, which can be broken down into:

$$
\begin{aligned}
& 238 U=(0.993)\left(4.4 \times 10^{-3}\right)=4.369 \times 10^{-3} \mathrm{lb} / \mathrm{hr} \\
& 235 U=3.1 \times 10^{-5} \mathrm{lb} / \mathrm{hr}
\end{aligned}
$$

The activity in the dust stream is:
${ }^{232} \mathrm{Th}$
$0.101 \mathrm{lb} / \mathrm{hr}$
$238 \mathrm{U}$
$4.369 \times 10^{-3} \mathrm{lb} / \mathrm{hr}$
$5.05 \times 10^{-6} \mathrm{Ci} / \mathrm{hr}$
$235 \mathrm{U}$
$3.1 \times 10^{-5} \mathrm{lb} / \mathrm{hr}$
$6.61 \times 10^{-7} \mathrm{Ci} / \mathrm{hr}$
$3.02 \times 10^{-8} \mathrm{Ci} / \mathrm{hr}$ 


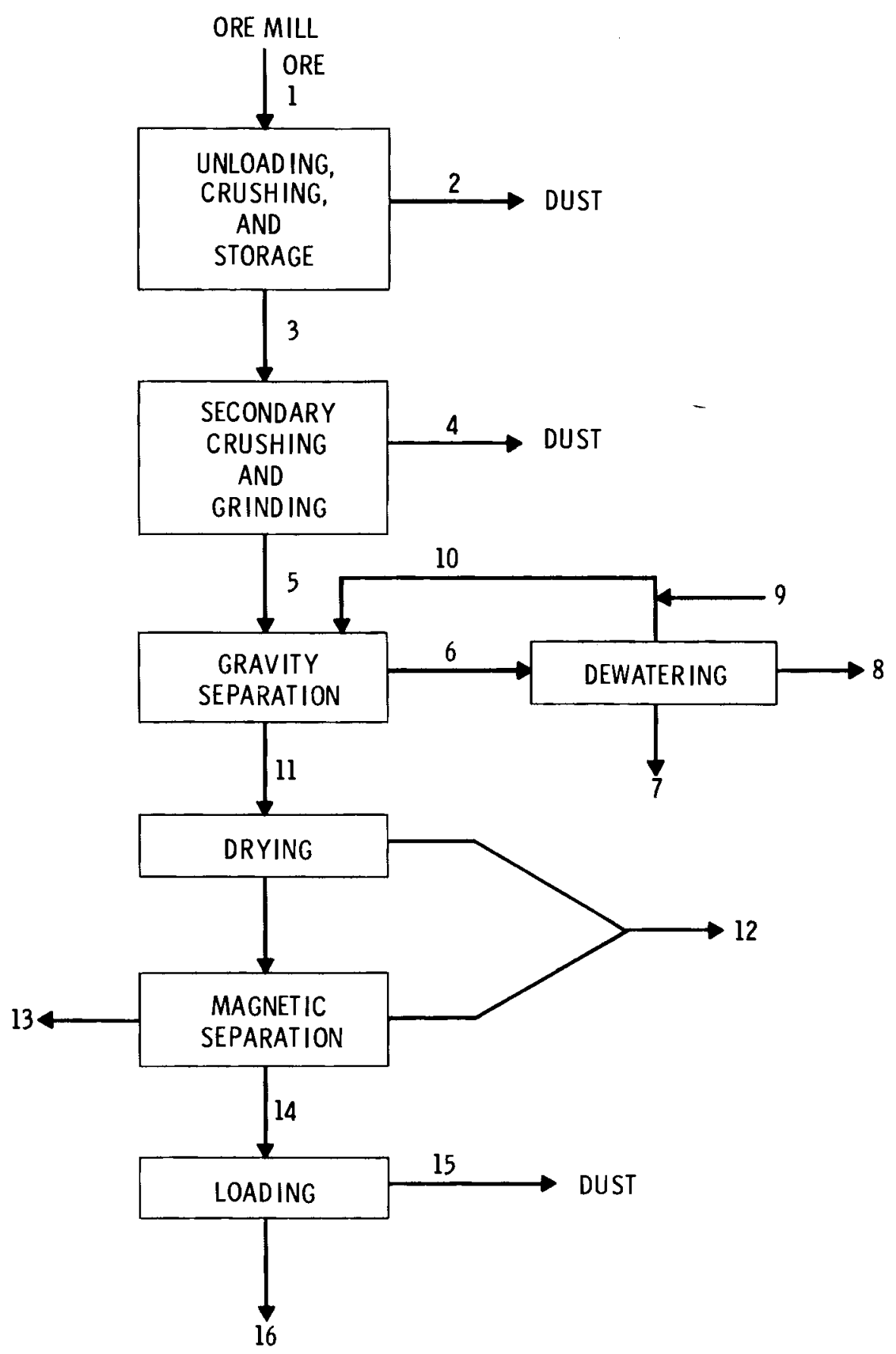

FIGURE D.5. Palmer, Michigan, Mill Flowsheet 
FIGURE D.5. Legend: Flow Streams for Palmer, Michigan, Ore Mill

1. 1895.45 tons $/ \mathrm{hr}$ ore $\mathrm{w} / 0.98912 \mathrm{ton} / \mathrm{hr}{ }^{232} \mathrm{Th}$

2. $189.545 \mathrm{lb} / \mathrm{hr} w / 0.0989 \mathrm{lb} / \mathrm{hr}{ }^{232} \mathrm{Th}$

3. 1377.27 tons $/ \mathrm{hr}$ ore $\mathrm{w} / 0.7187 \mathrm{ton} / \mathrm{hr}{ }^{232} \mathrm{Th}$

4. $137.7 \mathrm{lb} / \mathrm{hr} w / 0.073 \mathrm{lb} / \mathrm{hr}{ }^{232} \mathrm{Th}$

5. 1377.20 tons $/ \mathrm{hr} 0.7187 \mathrm{ton} / \mathrm{hr}{ }^{232} \mathrm{Th}$

6. 8656.96 tons $/ \mathrm{hr} \mathrm{H} \mathrm{H}_{2} \mathrm{O}$ and 1347.04 tons $/ \mathrm{hr}$ ore $\mathrm{w} / 0.2762 \mathrm{ton} / \mathrm{hr}{ }^{232} \mathrm{Th}$

7. 311.13 tons $/ \mathrm{hr} \mathrm{H}_{2} \mathrm{O}$ and 1225.78 tons $/ \mathrm{hr}$ ore $w / 0.2488 \mathrm{ton} / \mathrm{hr}{ }^{232} \mathrm{Th}$

8. 779.12 tons $/ \mathrm{hr} \mathrm{H}_{2} \mathrm{O}$ and 121.26 tons $/ \mathrm{hr}$ ore $\mathrm{w} / 0.0274 \mathrm{ton} / \mathrm{hr}{ }^{232} \mathrm{Th}$

9. 1092.65 tons $/ \mathrm{hr} \mathrm{H}_{2} \mathrm{O}$

10. 8659.36 tons $/ \mathrm{hr} \mathrm{H}_{2} \mathrm{O}$

11. 2.40 tons $/ \mathrm{hr} \mathrm{H} \mathrm{H}_{2} \mathrm{O}$ and 30.16 tons $/ \mathrm{hr}$ ore $\mathrm{w} / 0.4425 \mathrm{ton} / \mathrm{hr}{ }^{232} \mathrm{Th}$

12. 2.40 tons $/ \mathrm{hr} \mathrm{H} \mathrm{H}_{2} \mathrm{O}$ and $109.98 \mathrm{lb} / \mathrm{hr}$ ore $\mathrm{w} / 0.057 \mathrm{lb} / \mathrm{hr}{ }^{232} \mathrm{Th}$

13. 20.60 tons $/ \mathrm{hr} w / 8.40 \mathrm{lb} / \mathrm{hr}{ }^{232} \mathrm{Th}$

14. 9.505 tons $/ \mathrm{hr} w / 876.5 \mathrm{lb} / \mathrm{hr}$

15. $0.95 \mathrm{lb} / \mathrm{hr} w / 0.044 \mathrm{lb} / \mathrm{hr}{ }^{232} \mathrm{Th}$

16. 9.505 tons $/ \mathrm{hr} w / 876.5 \mathrm{lb} / \mathrm{hr}$
${ }^{232}$ Th Daughters (9)
Trace
$4.544 \times 10^{-5} \mathrm{Ci} / \mathrm{hr}$
$238_{U}$ Daughters (13)
Trace
$8.59 \times 10^{-6} \mathrm{Ci} / \mathrm{hr}$
$235 \mathrm{U}$ Daughters $(10)$
Trace
$3.02 \times 10^{-7} \mathrm{Ci} / \mathrm{hr}$

Liquid Waste to Evaporation Pond

The total amount of liquid waste sent to an evaporation pond is 799.12 tons $/ \mathrm{hr} \mathrm{H}_{2} \mathrm{O}$ containing 121.26 tons $/ \mathrm{hr}$ ore and 0.0274 tons $/ \mathrm{hr}{ }^{232} \mathrm{Th}$. It also contains uranium in these amounts:

Uranium content of waste $=(0.0274)(0.0435)=2.38 \mathrm{lb} / \mathrm{hr} \mathrm{U}$

$238 U=(0.993)(2.38)=2.37 \mathrm{lb} / \mathrm{hr}$

$235_{U}=0.01 \mathrm{ib} / \mathrm{hr}$ 
The activity in the evaporation pond is:

$\begin{array}{lll}232 \mathrm{Th} & 54.8 \mathrm{lb} / \mathrm{hr} & 2.74 \times 10^{-3} \mathrm{Ci} / \mathrm{hr} \\ 238 \mathrm{U} & 2.37 \mathrm{lb} / \mathrm{hr} & 3.59 \times 10^{-4} \mathrm{Ci} / \mathrm{hr} \\ 235 \mathrm{U} & 0.01 \mathrm{lb} / \mathrm{hr} & 9.73 \times 10^{-6} \mathrm{Ci} / \mathrm{hr} \\ 232 \mathrm{Th} \text { Daughters (9) } & \text { Trace } & 2.47 \times 10^{-2} \mathrm{Ci} / \mathrm{hr} \\ 238_{\mathrm{U}} \text { Daughters (13) } & \text { Trace } & 4.66 \times 10^{-3} \mathrm{Ci} / \mathrm{hr} \\ 235 \mathrm{U} \text { Daughters (10) } & \text { Trace } & 9.73 \times 10^{-4} \mathrm{Ci} / \mathrm{hr}\end{array}$

Solid Waste Returned To Mine

The following two streams are returned to the mine for disposal:

Dewatered Ore Waste - 1536.91 tons/hr ( $80 \%$ solids) containing $497.6 \mathrm{lb} / \mathrm{hr}$ ${ }^{232} \mathrm{Th}$.

Ore from Magnetic Separation - 20.60 tons/hr containing $8.4 \mathrm{lb} / \mathrm{hr}{ }^{232} \mathrm{Th}$.

The total amount returned to mine is 1557.51 tons/hr containing 506.0 $\mathrm{lb} / \mathrm{hr}{ }^{232} \mathrm{Th}$ and contains these amounts of uranium:

$$
\begin{aligned}
& \text { Uranium content }=(0.0435)(506.0)=22.0 \mathrm{lb} / \mathrm{hr} \\
& 238_{U}=(0.993)(22.0)=21.85 \mathrm{lb} / \mathrm{hr} \\
& 235 U=0.15 \mathrm{lb} / \mathrm{hr}
\end{aligned}
$$

The activity in the solid waste is:

$\begin{array}{lll}{ }^{232} \mathrm{Th} & 506.0 \mathrm{lb} / \mathrm{hr} & 2.53 \times 10^{-2} \mathrm{Ci} / \mathrm{hr} \\ { }^{238} \mathrm{U} & 22.0 \mathrm{lb} / \mathrm{hr} & 3.328 \times 10^{-3} \mathrm{Ci} / \mathrm{hr} \\ 235 \mathrm{U} & 0.15 \mathrm{lb} / \mathrm{hr} & 1.46 \times 10^{-4} \mathrm{Ci} / \mathrm{hr} \\ { }^{232} \mathrm{Th} \text { Daughters (9) } & \text { Trace } & 2.277 \times 10^{-1} \mathrm{Ci} / \mathrm{hr} \\ { }^{238} \mathrm{U} \text { Daughters (13) } & \text { Trace } & 4.326 \times 10^{-3} \mathrm{Ci} / \mathrm{hr} \\ 235 \mathrm{U} \text { Daughters (10) } & \text { Trace } & 1.46 \times 10^{-4} \mathrm{Ci} / \mathrm{hr}\end{array}$




\section{D.6 GENERATED WASTES FROM PALMER, MICHIGAN, MILL/REFINERY}

Dust from Unloading, and Grinding

These processes emit $0.9505 \mathrm{lb} / \mathrm{hr}$ of airborne wastes, of which $0.044 \mathrm{lb} / \mathrm{hr}$ is ${ }^{232} \mathrm{Th}$. The uranium content of the dust is $(0.0435)(\mathrm{U} / \mathrm{Th})$; so $(0.0435)(0.044)=1.913 \times 10^{-3} \mathrm{lb} / \mathrm{hr} \mathrm{U}$. The uranium is split between ${ }^{238} \mathrm{U}$ and $235 \mathrm{U}$ and the ratio is:

$$
\left(\frac{0.993}{0.007}\right)\left(\frac{238 U}{235 U}\right)
$$

There are $1.90 \times 10^{-3} \mathrm{lb} / \mathrm{hr} 238 \mathrm{U}$ and $1.30 \times 10^{-5} \mathrm{lb} / \mathrm{hr}{ }^{235} \mathrm{U}$. The activity in the dust stream is:
${ }^{232} \mathrm{Th}$
$0.044 \mathrm{lb} / \mathrm{hr}$
$2.20 \times 10^{-6} \mathrm{Ci} / \mathrm{hr}$
$238 \mathrm{U}$
$1.9 \times 10^{-3} \mathrm{lb} / \mathrm{hr}$
$2.87 \times 10^{-7} \mathrm{Ci} / \mathrm{hr}$
$235 \mathrm{U}$
$1.3 \times 10^{-5} \mathrm{lb} / \mathrm{hr}$
$1.265 \times 10^{-8} \mathrm{Ci} / \mathrm{hr}$
${ }^{232}$ Th Daughters (9)
Trace
$1.98 \times 10^{-5} \mathrm{Ci} / \mathrm{hr}$
${ }^{238} \mathrm{U}$ Daughters (13)
Trace
$3.73 \times 10^{-6} \mathrm{Ci} / \mathrm{hr}$
${ }^{235} U$ Daughters (10)
Trace
$1.265 \times 10^{-7} \mathrm{Ci} / \mathrm{hr}$

Dust from Ignition and Drying

The ignition and drying processes emit $1218 \mathrm{lb} / \mathrm{hr}$ of airborne wastes, of which $0.803 \mathrm{lb} / \mathrm{hr}$ are ${ }^{232} \mathrm{Th}$. The remainder is mostly $\mathrm{H}_{2} \mathrm{O}$, as shown in Figure D.6. The activity in the stream is:
${ }^{232} \mathrm{Th}$
$0.803 \mathrm{lb} / \mathrm{hr}$
$4.01 \times 10^{-5} \mathrm{Ci} / \mathrm{hr}$
${ }^{228} \mathrm{Th}$
Trace
$4.01 \times 10^{-5} \mathrm{Ci} / \mathrm{hr}$

\section{Packaging Dust}

The packaging process emits $0.1596 \mathrm{lb} / \mathrm{hr}$ of airborne wastes of which $0.139 \mathrm{Jb} / \mathrm{hr}$ are ${ }^{232} \mathrm{Th}$. The activity of the stream is:
${ }^{232} \mathrm{Th}$
$0.139 \mathrm{lb} / \mathrm{hr}$
$6.95 \times 10^{-6} \mathrm{Ci} / \mathrm{hr}$
${ }^{228} \mathrm{Th}$
Trace
$6.95 \times 10^{-6} \mathrm{Ci} / \mathrm{hr}$ 


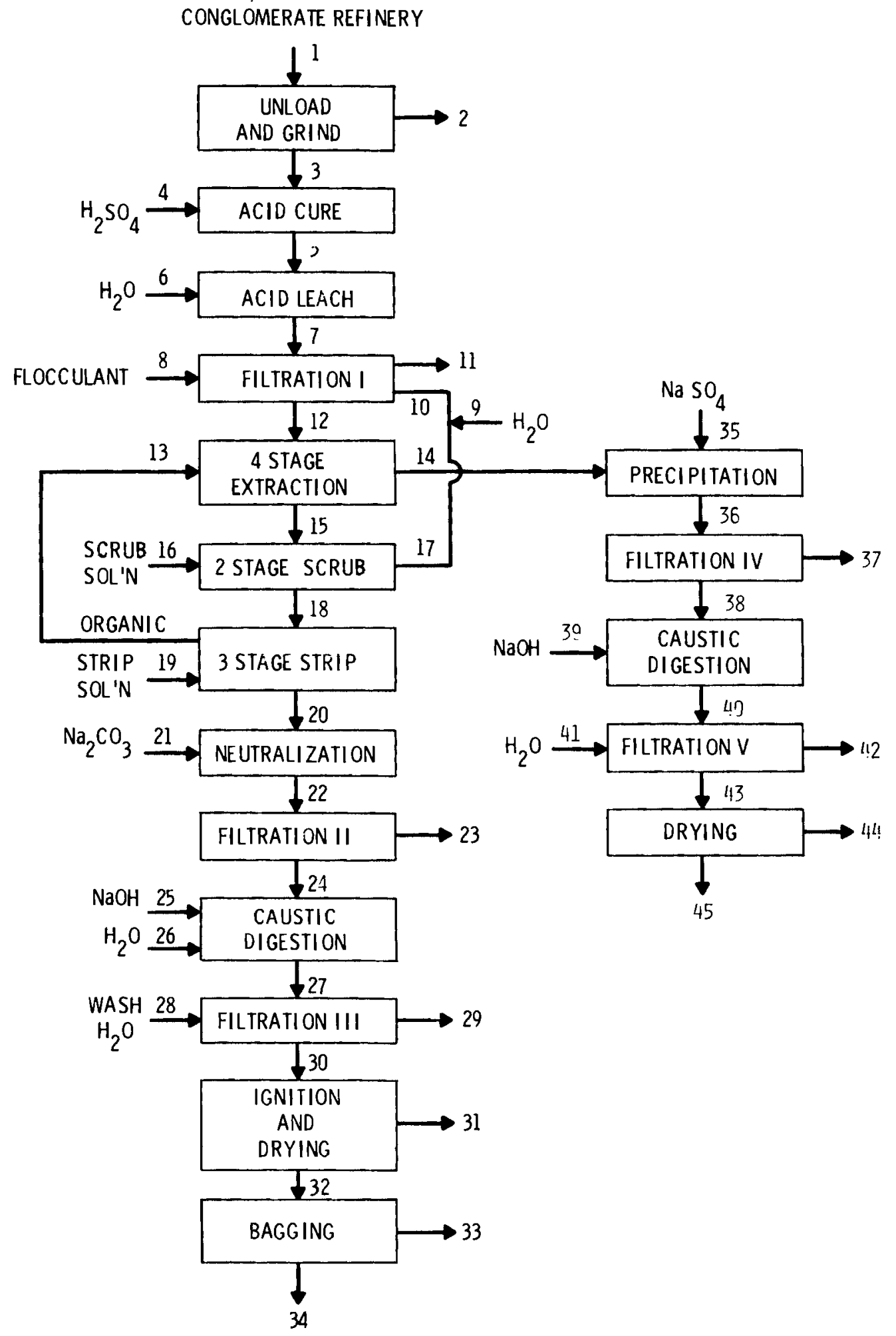

FIGURE D.6. Palmer, Michigan, Refinery Flowsheet 
FIGURE D.6. Legend: Flow Streams for Palmer, Michigan, Refinery

1. 9.505 tons $/ \mathrm{hr}$ concentrate $w / 876.48$ $1 \mathrm{~b} / \mathrm{hr}{ }^{232} \mathrm{Th}$

2. $0.9505 \mathrm{lb} / \mathrm{hr} w / 0.044 \mathrm{lb} / \mathrm{hr}{ }^{232} \mathrm{Th}$

3. 9.505 tons $/ \mathrm{hr} w / 876.436 \mathrm{lb} / \mathrm{hr}{ }^{232} \mathrm{Th}$

4. 16.01 tons $/ \mathrm{hr} \mathrm{H}_{2} \mathrm{SO}_{4}$

5. 25.51 tons $/ \mathrm{hr} w / 876.436 \mathrm{lb} / \mathrm{hr}^{232} \mathrm{Th}$

6. 47.525 tons $/ \mathrm{hr} \mathrm{H}_{2} \mathrm{O}$

7. 73.035 tons $/ \mathrm{hr} w / 876.436 \mathrm{lb} / \mathrm{hr}{ }^{232} \mathrm{Th}$

8. $1.90 \mathrm{lb} / \mathrm{hr}$ flocculant

9. 24.71 tons $/ \mathrm{hr} \mathrm{H} \mathrm{H}_{2} \mathrm{O}$

10. 48.47 tons $/ \mathrm{hr}$ wash solution $w / 0.7788$ $1 \mathrm{~b} / \mathrm{hr}{ }^{232} \mathrm{Th}$

11. 26.46 tons $/ \mathrm{hr} w / 30.254 \mathrm{lb} / \mathrm{hr}{ }^{232} \mathrm{Th}$

12. $121 / 505$ tons $/ \mathrm{hr} w / 846.96 \mathrm{lb} / \mathrm{hr}{ }^{232} \mathrm{Th}$

13. 71.29 tons $/ \mathrm{hr}$ organic (10\% JM-T, $5 \%$ PDA, 85\% kerosene)

14. 121.505 tons $/ \mathrm{hr} w / 1.55 \mathrm{lb} / \mathrm{hr}{ }^{232} \mathrm{Th}$

15. 71.29 tons $/ \mathrm{hr} w / 845.41 \mathrm{lb} / \mathrm{hr}{ }^{232} \mathrm{Th}$

16. 23.76 tons $/ \mathrm{hr}$ of scrub solution $\left(0.2 \mathrm{M} \mathrm{H}_{2} \mathrm{SO}_{4}\right)$

17. 23.76 tons $/ \mathrm{hr} w / 0.779 \mathrm{lb} / \mathrm{hr}{ }^{232} \mathrm{Th}$

18. 71.29 tons $/ \mathrm{hr} w / 844.63 \mathrm{lb} / \mathrm{hr}{ }^{232} \mathrm{Th}$

19. 38.02 tons/hr strip solution (1.5M NaCl, 0.5M HCl)

20. 38.02 tons $/ \mathrm{hr} w / 844.63 \mathrm{lb} / \mathrm{hr}{ }^{232} \mathrm{Th}$
21. 0.9505 ton $/ \mathrm{hr} \mathrm{Na}_{2} \mathrm{CO}_{3}$

22. 38.9705 tons $/ \mathrm{hr} w / 844.63 \mathrm{lb} / \mathrm{hr}{ }^{232} \mathrm{Th}$

23. 38.02 tons $/ \mathrm{hr} w / 0.779 \mathrm{lb} / \mathrm{hr}{ }^{232} \mathrm{Th}$

24. $0.9505 \mathrm{ton} / \mathrm{hr} w / 843.85 \mathrm{lb} / \mathrm{hr}$

25. $285.15 \mathrm{lb} / \mathrm{hr} \mathrm{NaOH}$

26. 1.90 tons $/ \mathrm{hr} \mathrm{H}_{2} \mathrm{O}$

27. 2.993 tons $/ \mathrm{hr} w / 843.85 \mathrm{lb} / \mathrm{hr}{ }^{232} \mathrm{Th}$

28. 1.90 tons $/ \mathrm{hr}$ wash solution

29. 3.80 tons $/ \mathrm{hr} w / 0.080 \mathrm{lb} / \mathrm{hr}{ }^{232} \mathrm{Th}$

30. 1.093 tons $/ \mathrm{hr} w / 843.77 \mathrm{lb} / \mathrm{hr}{ }^{232} \mathrm{Th}$

31. 0.609 tons $/ \mathrm{hr} w / 0.803 \mathrm{lb} / \mathrm{hr}{ }^{232} \mathrm{Th}$

32. $968.0 \mathrm{lb} / \mathrm{hr} w / 842.967 \mathrm{lb} / \mathrm{hr}{ }^{232} \mathrm{Th}$

33. $0.1596 \mathrm{lb} / \mathrm{hr} w / 0.139 \mathrm{lb} / \mathrm{hr}{ }^{232} \mathrm{Th}$

34. $967.84 \mathrm{lb} / \mathrm{hr} w / 842.831 \mathrm{lb} / \mathrm{hr}{ }^{232} \mathrm{Th}$

35. 5.7 tons $/ \mathrm{hr} \mathrm{NaSO}$

36. 127.205 tons $/ \mathrm{hr} w / 1.55 \mathrm{lb} / \mathrm{hr}{ }^{232} \mathrm{Th}$

37. 94.9 tons $/ \mathrm{hr} w / 1.05 \mathrm{lb} / \mathrm{hr}^{232} \mathrm{Th}$

38. 32.3 tons $/ \mathrm{hr} w / 0.50 \mathrm{lb} / \mathrm{hr}{ }^{232} \mathrm{Th}$

39. 9.1 tons $/ \mathrm{hr} \mathrm{NaOH} \mathrm{(30 \% )}$

40. 41.4 tons $/ \mathrm{hr} w / 0.50 \mathrm{lb} / \mathrm{hr}{ }^{232} \mathrm{Th}$

41. 10.2 tons $/ \mathrm{hr} \mathrm{H}_{2} \mathrm{O}$

42. 41.0 tons $/ \mathrm{hr} w / 0.11 \mathrm{lb} / \mathrm{hr}{ }^{232} \mathrm{Th}$

43. 10.6 tons $/ \mathrm{hr} w / 0.39 \mathrm{lb} / \mathrm{hr}{ }^{232} \mathrm{Th}$

44. 3.2 tons $/ \mathrm{hr} w / 0.0062 \mathrm{lb} / \mathrm{hr}{ }^{232} \mathrm{Th}$

45. 7.4 tons $/ \mathrm{hr} w / 0.384 \mathrm{lb} / \mathrm{hr}{ }^{232} \mathrm{Th}$ (46\% REO) 
The activity in the stream is:
${ }^{232} \mathrm{Th}$
$0.139 \mathrm{lb} / \mathrm{hr}$
$6.95 \times 10^{-6} \mathrm{Ci} / \mathrm{hr}$
${ }^{228} \mathrm{Th}$
Trace
$6.95 \times 10^{-6} \mathrm{Ci} / \mathrm{hr}$

Drying and Packaging Dust from By-Product Recovery System

These processes emit 3.2 tons $/ \mathrm{hr}$ of airborne wastes, of which 0.0062 $\mathrm{lb} / \mathrm{hr}$ are ${ }^{232} \mathrm{Th}$. The remainder is mostly $\mathrm{H}_{2} \mathrm{O}$, This dust stream also contains uranium in these amounts:

Uranium content of dust $=(0.0435)(0.0062)=2.696 \times 10^{-4} \mathrm{lb} / \mathrm{hr}$. $238 \mathrm{U}=(0.993)\left(2.696 \times 10^{-4}\right)=2.68 \times 10^{-4} \mathrm{lb} / \mathrm{hr}$ $235 \mathrm{U}=1.6 \times 10^{-6} \mathrm{lb} / \mathrm{hr}$

The activity of the stream is:

$\begin{array}{lll}{ }^{232} \mathrm{Th} & 0.0062 \mathrm{lb} / \mathrm{hr} & 3.10 \times 10^{-7} \mathrm{Ci} / \mathrm{hr} \\ { }^{238} \mathrm{U} & 2.68 \times 10^{-4} \mathrm{lb} / \mathrm{hr} & 4.05 \times 10^{-8} \mathrm{Ci} / \mathrm{hr} \\ 235_{\mathrm{U}} & 1.6 \times 10^{-6} \mathrm{lb} / \mathrm{hr} & 1.56 \times 10^{-9} \mathrm{Ci} / \mathrm{hr} \\ { }^{232} \mathrm{Th} \text { Daughters (9) } & \text { Trace } & 2.79 \times 10^{-6} \mathrm{Ci} / \mathrm{hr} \\ { }^{238} \mathrm{U} \text { Daughters (13) } & \text { Trace } & 5.27 \times 10^{-7} \mathrm{Ci} / \mathrm{hr} \\ 235_{\mathrm{U}} \text { Daughters (10) } & \text { Trace } & 1.56 \times 10^{-8} \mathrm{Ci} / \mathrm{hr}\end{array}$

Liquid Waste to Tailings Pond

The following streams and respective loads are sent to a tailings pond:

Filtration I Stream - 26.46 tons/hr containing $30.254 \mathrm{lb} / \mathrm{hr}{ }^{232} \mathrm{Th}$ with a total flow of $105.8 \mathrm{gpm}$.

Filtration II Stream - 38.02 tons $/ \mathrm{hr}$ containing $0.779 \mathrm{lb} / \mathrm{hr}{ }^{232} \mathrm{Th}$ with a total flow of $152 \mathrm{gpm}$.

Filtration III Stream - 3.80 tons/hr containing $0.080 \mathrm{lb} / \mathrm{hr}{ }^{232} \mathrm{Th}$ with a total flow of $15.2 \mathrm{gpm}$.

Filtration IV Stream - 94.9 tons/hr containing $1.05 \mathrm{lb} / \mathrm{hr}{ }^{232} \mathrm{Th}$ with a total flow of $379.6 \mathrm{gpm}$.

Filtration V Stream - 41.0 tons $/ \mathrm{hr}$ containing $0.11 \mathrm{lb} / \mathrm{hr}{ }^{232} \mathrm{Th}$ with a total flow of $16.4 \mathrm{gpm}$. 
The total amount of liquid waste sent to the tailings pond is 204.18 tons $/ \mathrm{hr}$ containing $32.273 \mathrm{lb} / \mathrm{hr}{ }^{232} \mathrm{Th}$. The total flow to the pond is $816.72 \mathrm{gpm}$. All of the uranium in the entering ore goes to the tailings pond except for the amount emitted as dust and as a by-product. The amounts of uranium are:

Total uranium in entering ore $=(0.0435)(876.48)=38.10783 \mathrm{lb} / \mathrm{hr}$. Uranium in by-product $=(0.0435)(0.384)=1.6696 \times 10^{-2} \mathrm{lb} / \mathrm{hr}$ Uranium in tailings pond $=38.108-\left(1.6696 \times 10^{-2}\right)+(1.913 \times$ $\left.10^{-3}\right)+\left(2.696 \times 10^{-4}\right)=38.089 \mathrm{lb} / \mathrm{hr}$ $238 U=(0.993)(38.089)=37.82 \mathrm{lb} / \mathrm{hr}$ $235 \mathrm{U}=0.269 \mathrm{bb} / \mathrm{hr}$

A11 of the ${ }^{232}$ Th daughters end up in the tailings pond except those emitted with the dust or in the by-product. The activity in the tailings pond is:

$\begin{array}{lll}{ }^{232} \mathrm{Th} & 32.273 \mathrm{lb} / \mathrm{hr} & 1.6134 \times 10^{-3} \mathrm{Ci} / \mathrm{hr} \\ { }^{238} \mathrm{U} & 37.82 \mathrm{lb} / \mathrm{hr} & 5.721 \times 10^{-4} \mathrm{Ci} / \mathrm{hr} \\ 235_{\mathrm{U}} & 0.269 \mathrm{lb} / \mathrm{hr} & 2.618 \times 10^{-6} \mathrm{Ci} / \mathrm{hr} \\ { }^{232} \mathrm{Th} \text { Daughters } & \text { Trace } & 3.5198 \times 10^{-1} \mathrm{Ci} / \mathrm{hr} \\ { }^{238_{\mathrm{U}}} \text { Daughters (13) } & \text { Trace } & 7.437 \times 10^{-2} \mathrm{Ci} / \mathrm{hr} \\ 235_{\mathrm{U}} \text { Daughters (10) } & \text { Trace } & 2.618 \times 10^{-3} \mathrm{Ci} / \mathrm{hr}\end{array}$




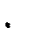




\section{D.7 GENERATED WASTES FROM BALD MOUNTAIN ORE MILL}

Dust from Unloading, Crushing, and Grinding

In the unloading, crushing, and grinding areas of the mill, $78.515 \mathrm{lb} / \mathrm{hr}$ of ore dust are released; of this, $6.551 \times 10^{-3} \mathrm{lb} / \mathrm{hr}$ is ${ }^{232} \mathrm{Th}$, as shown in Figure D.7. The uranium content of the dust is $(0.0435)\left(6.55 \times 10^{-3}\right)=$ $2.848 \times 10^{-4} \mathrm{lb} / \mathrm{hr}$. The uranium is split between ${ }^{238} \mathrm{U}$ and ${ }^{235} \mathrm{U}$ and the ratio is:

$$
\left(\frac{0.993}{0.007}\right)\left(\frac{238_{U}}{235 U}\right)
$$

There are $2.828 \times 10^{-4} \mathrm{lb} / \mathrm{hr}{ }^{238} \mathrm{U}$ and $2.0 \times 10^{-6} \mathrm{lb} / \mathrm{hr}{ }^{235} \mathrm{U}$. The activity in the dust stream is:

$\begin{array}{lll}232 \mathrm{Th} & 6.55 \times 10^{-3} \mathrm{lb} / \mathrm{hr} & 3.27 \times 10^{-7} \mathrm{Ci} / \mathrm{hr} \\ 238 \mathrm{U} & 2.828 \times 10^{-4} \mathrm{lb} / \mathrm{hr} & 4.28 \times 10^{-8} \mathrm{Ci} / \mathrm{hr} \\ 235 \mathrm{U} & 2.0 \times 10^{-6} \mathrm{lb} / \mathrm{hr} & 1.95 \times 10^{-9} \mathrm{Ci} / \mathrm{hr} \\ 232 \mathrm{Th} \text { Daughters (9) } & \text { Trace } & 2.95 \times 10^{-6} \mathrm{Ci} / \mathrm{hr} \\ 238_{\mathrm{U}} \text { Daughters (13) } & \text { Trace } & 5.56 \times 10^{-7} \mathrm{Ci} / \mathrm{hr} \\ 235 \mathrm{U} \text { Daughters (10) } & \text { Trace } & 1.95 \times 10^{-8} \mathrm{Ci} / \mathrm{hr}\end{array}$

Dust from Drying, Magnetic Separating, and Loading

These processes release $173.92 \mathrm{lb} / \mathrm{hr}$ of airborne wastes, of which $3.414 \mathrm{x}$ $10^{-3} \mathrm{lb} / \mathrm{hr}$ are ${ }^{232} \mathrm{Th}$. The remainder is mostly $\mathrm{H}_{2} \mathrm{O}$. The wastes also contain uranium in these amounts:

Uranium content of dust $=(0.0435)\left(3.414 \times 10^{-3}\right)=1.48 \times 10^{-4} \mathrm{lb} / \mathrm{hr}$ $238 \mathrm{U}=(0.993)\left(1.48 \times 10^{-4}\right)=1.474 \times 10^{-4} \mathrm{lb} / \mathrm{hr}$ $235 \mathrm{U}=6.0 \times 10^{-7} \mathrm{lb} / \mathrm{hr}$

The activity in the dust stream is:
${ }^{232} \mathrm{Th}$
$3.414 \times 10^{-3} \mathrm{lb} / \mathrm{hr}$
$1.71 \times 10^{-7} \mathrm{Ci} / \mathrm{hr}$
$238_{U}$
$1.474 \times 10^{-4} \mathrm{lb} / \mathrm{hr}$
$2.23 \times 10^{-8} \mathrm{Ci} / \mathrm{hr}$
$235 \mathrm{U}$
$6.0 \times 10^{-7} \mathrm{lb} / \mathrm{hr}$
$5.84 \times 10^{-10} \mathrm{Ci} / \mathrm{hr}$ 


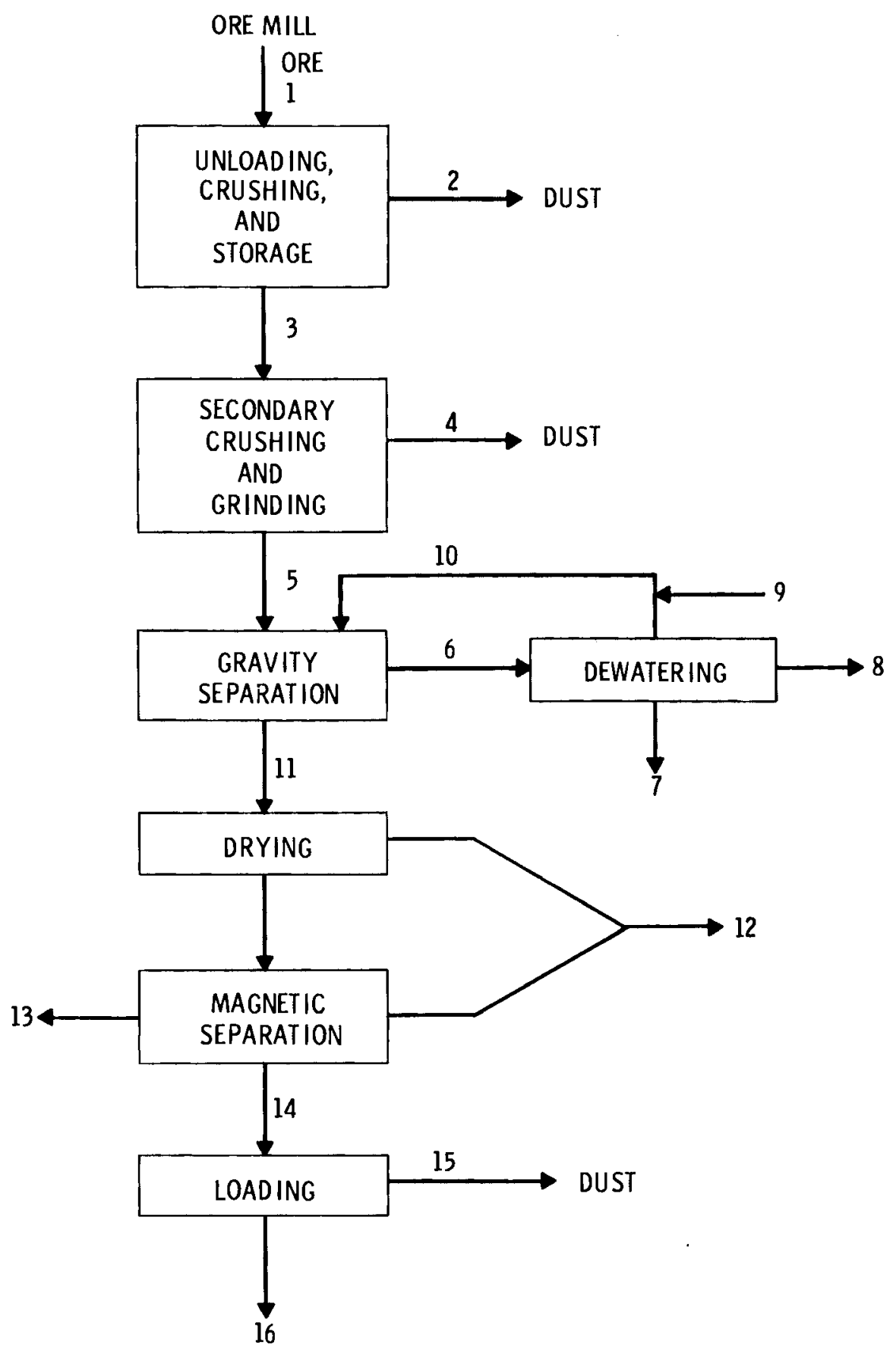

FIGURE D.7. Bald Mountain Mill Flowsheet 
FIGURE D.7. Legend: Flow Streams for Bald Mountain Mill

1. 454.55 tons $/ \mathrm{hr}$ ore $w / 76.08 \mathrm{ton} / \mathrm{hr}{ }^{232} \mathrm{Th}$

2. $45.455 \mathrm{lb} / \mathrm{hr} w / 3.784 \times 10^{-3} \mathrm{lb} / \mathrm{hr}{ }^{232} \mathrm{Th}$

3. 330.58 tons $/ \mathrm{hr} w / 55.33 \mathrm{lb} / \mathrm{hr}{ }^{232} \mathrm{Th}$

4. $33.06 \mathrm{lb} / \mathrm{hr} w / 2.767 \times 10^{-3} \mathrm{lb} / \mathrm{hr}{ }^{232} \mathrm{Th}$

5. 330.56 tons $/ \mathrm{hr} w / 55.33 \mathrm{lb} / \mathrm{hr}{ }^{232} \mathrm{Th}$

6. 2078.435 tons $/ \mathrm{hr} \mathrm{H}_{2} \mathrm{O}$ and 329.492 tons $/ \mathrm{hr}$ ore $\mathrm{w} / 21.25 \mathrm{lb} / \mathrm{hr}{ }^{232} \mathrm{Th}$

7. 74.70 tons $/ \mathrm{hr} \mathrm{H}_{2} \mathrm{O}$ and 299.83 tons/hr ore w/19.14 1b/hr ${ }^{232} \mathrm{Th}$

8. 187.06 tons $/ \mathrm{hr} \mathrm{H}_{2} \mathrm{O}$ and 29.662 tons $/ \mathrm{hr}$ ore $\mathrm{w} / 2.111 \mathrm{lb} / \mathrm{hr}{ }^{232} \mathrm{Th}$

9. 261.845 tons $/ \mathrm{hr} \mathrm{H}_{2} \mathrm{O}$

10. 2078.52 tons $/ \mathrm{hr} \mathrm{H}_{2} \mathrm{O}$

11. $170 \mathrm{lb} / \mathrm{hr} \mathrm{H} \mathrm{H}_{2} \mathrm{O}$ and $1.068 \mathrm{tons} / \mathrm{hr}$ ore $\mathrm{w} / 34.08 \mathrm{lb} / \mathrm{hr}{ }^{232} \mathrm{Th}$

12. $170 \mathrm{lb} / \mathrm{hr} \mathrm{H}_{2} \mathrm{O}$ and $3.89 \mathrm{lb} / \mathrm{hr}$ ore $\mathrm{w} / 2.024 \times 10^{-3} \mathrm{lb} / \mathrm{hr}{ }^{232} \mathrm{Th}$

13. $1459 \mathrm{lb} / \mathrm{hr}$ ore $\mathrm{w} / 0.326 \mathrm{lb} / \mathrm{hr}{ }^{232} \mathrm{Th}$

14. $673.11 \mathrm{lb} / \mathrm{hr}$ ore $\mathrm{w} / 33.75 \mathrm{lb} / \mathrm{hr}{ }^{232} \mathrm{Th}$

15. $0.03 \mathrm{lb} / \mathrm{hr}$ ore $\mathrm{w} / 1.39 \times 10^{-3} \mathrm{lb} / \mathrm{hr}{ }^{232} \mathrm{Th}$

16. $673.08 \mathrm{lb} / \mathrm{hr} \mathrm{w} / 33.75 \mathrm{lb} / \mathrm{hr}$

$\begin{array}{lll}{ }^{232} \text { Th Daughters }(9) & \text { Trace } & 1.54 \times 10^{-6} \mathrm{Ci} / \mathrm{hr} \\ { }^{238} \mathrm{U} \text { Daughters }(13) & \text { Trace } & 2.90 \times 10^{-7} \mathrm{Ci} / \mathrm{hr} \\ { }^{235} \mathrm{U} \text { Daughters }(10) & \text { Trace } & 5.84 \times 10^{-9} \mathrm{Ci} / \mathrm{hr}\end{array}$

Liquid Waste to Evaporation Pond

The liquid wastes sent to an evaporation pond total 187.06 tons $/ \mathrm{hr} \mathrm{H}_{2} \mathrm{O}$. They contain 29.662 tons/hr ore, $2.112 \mathrm{lb} / \mathrm{hr}{ }^{232} \mathrm{Th}$, and these amounts of uranium:

Uranium content of waste $=(0.0435)(2.112)=9.183 \times 10^{-2} \mathrm{lb} / \mathrm{hr}$

${ }^{238} U=(0.993)\left(9.183 \times 10^{-2}\right)=9.119 \times 10^{-2} \mathrm{lb} / \mathrm{hr}$

$235 \mathrm{U}=6.4 \times 10^{-4} \mathrm{lb} / \mathrm{hr}$ 
The activity in the evaporation pond is:

$\begin{array}{lll}{ }^{232} \mathrm{Th} & 2.112 \mathrm{lb} / \mathrm{hr} & 1.06 \times 10^{-4} \mathrm{Ci} / \mathrm{hr} \\ 238_{\mathrm{U}} & 9.119 \times 10^{-2} \mathrm{lb} / \mathrm{hr} & 1.38 \times 10^{-5} \mathrm{Ci} / \mathrm{hr} \\ 235_{\mathrm{U}} & 6.4 \times 10^{-4} \mathrm{lb} / \mathrm{hr} & 6.23 \times 10^{-7} \mathrm{Ci} / \mathrm{hr} \\ 232 \mathrm{Th} \text { Daughters (9) } & \text { Trace } & 9.54 \times 10^{-4} \mathrm{Ci} / \mathrm{hr} \\ 238_{\mathrm{U}} \text { Daughters (13) } & \text { Trace } & 1.79 \times 10^{-4} \mathrm{Ci} / \mathrm{hr} \\ 235_{\mathrm{U}} \text { Daughters (10) } & \text { Trace } & 6.23 \times 10^{-6} \mathrm{Ci} / \mathrm{hr}\end{array}$

Solid Waste Returned To Mine

The following two streams are returned to the mine for disposal:

Dewatered Ore Waste - 374.53 tons/hr ( $80 \%$ solids) containing $19.14 \mathrm{lb} / \mathrm{hr}$ ${ }^{232} \mathrm{Th}$.

Ore from Magnetic Separation - $1459 \mathrm{lb} / \mathrm{hr}$ containing $0.326 \mathrm{lb} / \mathrm{hr}{ }^{232} \mathrm{Th}$.

The total amount returned to the mine is 375.26 tons/hr containing $19.47 \mathrm{lb} / \mathrm{hr}{ }^{232} \mathrm{Th}$ and these amounts of uranium:

Uranium content $=(0.0435)(19.47)=0.8465 \mathrm{lb} / \mathrm{hr}$

$238 \mathrm{U}=(0.993)(0.8465)=0.8406 \mathrm{lb} / \mathrm{hr}$

$235 \mathrm{U}=5.9 \times 10^{-3} \mathrm{lb} / \mathrm{hr}$

The activity in the solid waste is:

$\begin{array}{lll}{ }^{232} \mathrm{Th} & 19.47 \mathrm{lb} / \mathrm{hr} & 9.73 \times 10^{-4} \mathrm{Ci} / \mathrm{hr} \\ { }^{238} \mathrm{U} & 0.8406 \mathrm{lb} / \mathrm{hr} & 1.27 \times 10^{-4} \mathrm{Ci} / \mathrm{hr} \\ 235 \mathrm{U} & 5.9 \times 10^{-3} \mathrm{lb} / \mathrm{hr} & 5.74 \times 10^{-6} \mathrm{Ci} / \mathrm{hr} \\ { }^{232} \mathrm{Th} \text { Daughters (9) } & \text { Trace } & 8.76 \times 10^{-3} \mathrm{Ci} / \mathrm{hr} \\ 238_{\mathrm{U}} \text { Daughters (13) } & \text { Trace } & 1.65 \times 10^{-3} \mathrm{Ci} / \mathrm{hr} \\ 235 \mathrm{U} \text { Daughters (10) } & \text { Trace } & 5.74 \times 10^{-5} \mathrm{Ci} / \mathrm{hr}\end{array}$




\section{D.8 GENERATED WASTES FROM BALD MOUNTAIN REFINERY}

Unloading and Grinding Dust

As shown in Figure $\mathrm{D} .8,0.03 \mathrm{lb} / \mathrm{hr}$ of airborne wastes are emitted, of which $1.50 \times 10^{-3} \mathrm{lb} / \mathrm{hr}$ is ${ }^{232} \mathrm{Th}$. The uranium content of the dust is $(0.0435)(\mathrm{U} / \mathrm{Th})$; so that amounts of uranium are:

$$
\begin{aligned}
& U=(0.0435)\left(1.50 \times 10^{-3}\right)=6.52 \times 10^{-5} \mathrm{lb} / \mathrm{hr} \\
& 238 \mathrm{U}=(0.993)\left(6.52 \times 10^{-5}\right)=6.47 \times 10^{-5} \mathrm{lb} / \mathrm{hr} \\
& 235 \mathrm{U}=5.0 \times 10^{-7} \mathrm{lb} / \mathrm{hr}
\end{aligned}
$$

The activity in the dust stream is:
${ }^{232} \mathrm{Th}$
$1.5 \times 10^{-3} \mathrm{lb} / \mathrm{hr}$
$7.5 \times 10^{-8} \mathrm{Ci} / \mathrm{hr}$
$238 \mathrm{U}$
$6.47 \times 10^{-5} \mathrm{lb} / \mathrm{hr}$
$9.79 \times 10^{-9} \mathrm{Ci} / \mathrm{hr}$
$235 \mathrm{U}$
$5.0 \times 10^{-7} \mathrm{lb} / \mathrm{hr}$
$4.86 \times 10^{-10} \mathrm{Ci} / \mathrm{hr}$
${ }^{232}$ Th Daughters (9)
238 U Daughters (13)
Trace
$6.75 \times 10^{-7} \mathrm{Ci} / \mathrm{hr}$
$235 \cup$ Daughters $(10)$
Trace
$1.27 \times 10^{-7} \mathrm{Ci} / \mathrm{hr}$
Trace
$4.86 \times 10^{-9} \mathrm{Ci} / \mathrm{hr}$

\section{Ignition and Drying Dust}

These processes release $40.23 \mathrm{lb} / \mathrm{hr}$ of airborne wastes, of which $3.03 \times$ $10^{-2} \mathrm{~Tb} / \mathrm{hr}$ is ${ }^{232} \mathrm{Th}$; the remainder is mostly $\mathrm{H}_{2} \mathrm{O}$. The activity in the dust stream is:
${ }^{232} \mathrm{Th}$
$3.03 \times 10^{-2} \mathrm{lb} / \mathrm{hr}$
$1.51 \times 10^{-6} \mathrm{Ci} / \mathrm{hr}$
${ }^{228} \mathrm{Th}$
Trace
$1.51 \times 10^{-6} \mathrm{Ci} / \mathrm{hr}$

Packaging Dust

Packaging releases $6.2 \times 10^{-3} \mathrm{lb} / \mathrm{hr}$ of airborne wastes, of which $5.4 \times 10^{-3} \mathrm{lb} / \mathrm{hr}$ is ${ }^{232} \mathrm{Th}$. The activity in the stream is:
${ }^{232} \mathrm{Th}$
$5.4 \times 10^{-3} \mathrm{lb} / \mathrm{hr}$
$2.70 \times 10^{-7} \mathrm{Ci} / \mathrm{hr}$
${ }^{228} \mathrm{Th}$
Trace
$2.70 \times 10^{-7} \mathrm{Ci} / \mathrm{hr}$

Drying and Packaging Dust from By-Product Recovery System

This dust stream carries $164 \mathrm{lb} / \mathrm{hr}$ of airborne wastes, of which $2.3 \times 10^{-4} \mathrm{lb} / \mathrm{hr}$ is $\mathrm{ThO}_{2}$; the remainder is mostly $\mathrm{H}_{2} \mathrm{O}$. This stream also contains uranium in these amounts: 


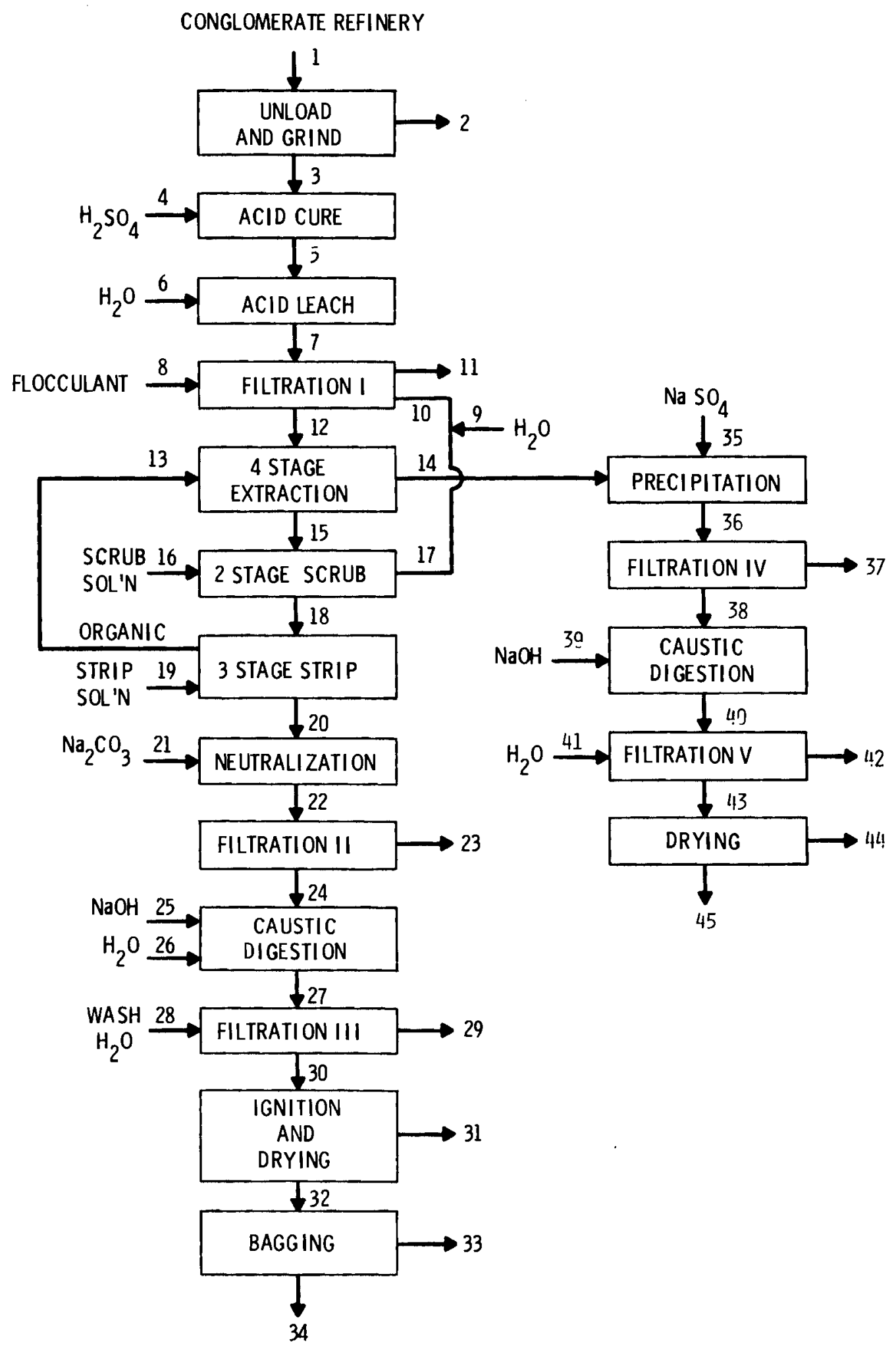

FIGURE D.8. Bald Mountain Refinery Flowsheet 


\section{FIGURE D.8. Legend: Flow Streams for Bald Mountain Refinery}

1. $670 \mathrm{lb} / \mathrm{hr}$ ore $\mathrm{w} / 33.60 \mathrm{lb} / \mathrm{hr}{ }^{232} \mathrm{Th}$

2. $0.03 \mathrm{lb} / \mathrm{hr} w / 1.50 \times 10^{-3} \mathrm{lb} / \mathrm{hr}{ }^{232} \mathrm{Th}$

3. $670 \mathrm{lb} / \mathrm{hr} \mathrm{w} / 33.60 \mathrm{lb} / \mathrm{hr}{ }^{232} \mathrm{Th}$

4. $1128 \mathrm{lb} / \mathrm{hr} \mathrm{H}_{2} \mathrm{SO}_{4}$

5. $1798 \mathrm{lb} / \mathrm{hr} \mathrm{w/33.60} \mathrm{\textrm {lb } / \mathrm { hr }}{ }^{232} \mathrm{Th}$

6. 1.675 tons $/ \mathrm{hr} \mathrm{H}_{2} \mathrm{O}$

7. 2.574 tons $/ \mathrm{hr} w / 33.60 \mathrm{lb} / \mathrm{hr}^{232} \mathrm{Th}$

8. $6.7 \times 10^{-2} \mathrm{lb} / \mathrm{hr}$ flocculant

9. $1738 \mathrm{ib} / \mathrm{hr} \mathrm{H} \mathrm{H}_{2} \mathrm{O}$

10. 1.71 tons $/ \mathrm{hr}$ wash solution $w / 3.00 \times 10^{-2} \mathrm{lb} / \mathrm{hr}{ }^{232} \mathrm{Th}$

11. $1865 \mathrm{lb} / \mathrm{hr} w / 1.13 \mathrm{lb} / \mathrm{hr}{ }^{232} \mathrm{Th}$

12. 3.352 tons $/ \mathrm{hr} w / 32.50 \mathrm{ib} / \mathrm{hr}^{232} \mathrm{Th}$

13. 2.51 tons $/ \mathrm{hr}$ organic (10\% JM-T, 5\% PDA, 85\% kerosene)

14. 3.352 tons $/ \mathrm{hr} w / 0.481 \mathrm{lb} / \mathrm{hr}{ }^{232} \mathrm{Th}$

15. 2.51 tons $/ \mathrm{hr} w / 32.019 \mathrm{lb} / \mathrm{hr}{ }^{232} \mathrm{Th}$

16. $1682 \mathrm{lb} / \mathrm{hr}$ of scrub solution $\left(0.2 \mathrm{M} \mathrm{H}_{2} \mathrm{SO}_{4}\right)$

17. $1682 \mathrm{lb} / \mathrm{hr} w / 3.00 \times 10^{-2} \mathrm{lb} / \mathrm{hr}{ }^{232} \mathrm{Th}$

18. 2.51 tons $/ \mathrm{hr} w / 31.989 \mathrm{lb} / \mathrm{hr}{ }^{232} \mathrm{Th}$

19. 1.34 tons $/ \mathrm{hr}$ strip solution (1.5 M NaCl, $0.5 \mathrm{M} \mathrm{HCl}$ )

20. 1.34 tons $/ \mathrm{hr} w / 31.989 \mathrm{lb} / \mathrm{hr}^{232} \mathrm{Th}$

21. $66.803 \mathrm{lb} / \mathrm{hr} \mathrm{Na} \mathrm{CO}_{3}$
22. 1.37 tons $/ \mathrm{hr} w / 31.989 \mathrm{lb} / \mathrm{hr}^{232} \mathrm{Th}$

23. 1.34 tons $/ \mathrm{hr} w / 2.915 \times 10^{-2} \mathrm{lb} / \mathrm{hr}{ }^{232} \mathrm{Th}$

24. $66.803 \mathrm{lb} / \mathrm{hr} w / 31.96 \mathrm{lb} / \mathrm{hr}{ }^{232} \mathrm{Th}$

25. $10.05 \mathrm{lb} / \mathrm{hr} \mathrm{NaOH}$

26. $134.1 \mathrm{ib} / \mathrm{hr} \mathrm{H} \mathrm{H}_{2} \mathrm{O}$

27. $210.95 \mathrm{lb} / \mathrm{hr} w / 31.96 \mathrm{lb} / \mathrm{hr}{ }^{232} \mathrm{Th}$

28. $134.1 \mathrm{lb} / \mathrm{hr}$ wash solution

29. $268.2 \mathrm{ib} / \mathrm{hr} w / 3.02 \times 10^{-3} \mathrm{lb} / \mathrm{hr}{ }^{232} \mathrm{Th}$

30. $76.85 \mathrm{lb} / \mathrm{hr} \mathrm{w} / 31.95 \mathrm{lb} / \mathrm{hr}{ }^{232} \mathrm{Th}$

31. $40.22 \mathrm{lb} / \mathrm{hr} w / 3.03 \times 10^{-2} \mathrm{lb} / \mathrm{hr}{ }^{232} \mathrm{Th}$

32. $36.62 \mathrm{lb} / \mathrm{hr} w / 31.919 \mathrm{lb} / \mathrm{hr}^{232} \mathrm{Th}$

33. $6.2 \times 10^{-3} \mathrm{lb} / \mathrm{hr} w / 5.4 \times 10^{-3} \mathrm{lb} / \mathrm{hr}$

34. $36.62 \mathrm{lb} / \mathrm{hr} w / 31.91 \mathrm{lb} / \mathrm{hr}{ }^{232} \mathrm{Th}$

35. $402.7 \mathrm{lb} / \mathrm{hr} \mathrm{NaSO}$

36. 3.553 tons $/ \mathrm{hr} w / 0.481 \mathrm{lb} / \mathrm{hr}{ }^{232} \mathrm{Th}$

37. 1.597 tons $/ \mathrm{hr} w / 3.93 \times 10^{-2} \mathrm{lb} / \mathrm{hr}{ }^{232} \mathrm{Th}$

38. 1.956 tons $/ \mathrm{hr} w / 0.4417^{232} \mathrm{Th}$

39. $643 \mathrm{lb} / \mathrm{hr} \mathrm{NaOH}(30 \%)$

40. 2.2775 tons $/ \mathrm{hr} w / 0.4417 \mathrm{lb} / \mathrm{hr}^{232} \mathrm{Th}$

41. $722 \mathrm{lb} / \mathrm{hr} \mathrm{H} \mathrm{H}_{2} \mathrm{O}$

42. 1.05 tons $/ \mathrm{hr} \mathrm{w} / 1.48 \times 10^{-2} \mathrm{ib} / \mathrm{hr}{ }^{232} \mathrm{Th}$

43. 1.59 tons $/ \mathrm{hr} w / 0.427 \mathrm{lb} / \mathrm{hr}{ }^{232} \mathrm{Th}$

44. $164 \mathrm{lb} / \mathrm{hr} \mathrm{w} / 2.3 \times 10^{-4} \mathrm{lb} / \mathrm{hr}{ }^{232} \mathrm{Th}$

45. 1.51 tons $/ \mathrm{hr} w / 0.4268 \mathrm{lb} / \mathrm{hr}{ }^{232} \mathrm{Th}$ (46\% REO) 
Uranium content of dust $=(0.0435)\left(2.3 \times 10^{-4}\right)=1.0 \times 10^{-5} \mathrm{lb} / \mathrm{hr}$

$$
\begin{aligned}
& { }^{238} U=(0.993)\left(1.0 \times 10^{-5}\right)=9.93 \times 10^{-6} \mathrm{lb} / \mathrm{hr} \\
& 235 U=7.0 \times 10^{-8} \mathrm{lb} / \mathrm{hr}
\end{aligned}
$$

The activity in the dust stream is:

$\begin{array}{lll}{ }^{232} \mathrm{Th} & 2.3 \times 10^{-4} \mathrm{lb} / \mathrm{hr} & 1.15 \times 10^{-8} \mathrm{Ci} / \mathrm{hr} \\ 238 \mathrm{U} & 9.93 \times 10^{-6} \mathrm{lb} / \mathrm{hr} & 1.50 \times 10^{-9} \mathrm{Ci} / \mathrm{hr} \\ 235 \mathrm{U} & 7.0 \times 10^{-8} \mathrm{lb} / \mathrm{hr} & 6.81 \times 10^{-11} \mathrm{Ci} / \mathrm{hr} \\ { }^{232} \mathrm{Th} \text { Daughters (9) } & \text { Trace } & 1.035 \times 10^{-7} \mathrm{Ci} / \mathrm{hr} \\ 238 \mathrm{U} \text { Daughters (13) } & \text { Trace } & 1.95 \times 10^{-8} \mathrm{Ci} / \mathrm{hr} \\ 235 \mathrm{U} \text { Daughters (10) } & \text { Trace } & 6.81 \times 10^{-10} \mathrm{Ci} / \mathrm{hr}\end{array}$

Liquid Waste to Tailings Pond

The following streams and respective loads are sent to a tailings pond:

Filtration I Stream - $1865 \mathrm{lb} / \mathrm{hr}$ containing $1.13 \mathrm{lb} / \mathrm{hr}{ }^{232} \mathrm{Th}$ with a total flow of $3.73 \mathrm{gpm}$.

Filtration II Stream - 1.34 tons/hr containing $2.915 \times 10^{-2} \mathrm{lb} / \mathrm{hr}$ ${ }^{232}$ Th with a total flow of $5.36 \mathrm{gpm}$.

Filtration III Stream - $268.2 \mathrm{lb} / \mathrm{hr}$ containing $3.02 \times 10^{-3} \mathrm{lb} / \mathrm{hr}$ ${ }^{232}$ Th with a total flow of $0.536 \mathrm{gpm}$.

Filtration IV Stream - 1.597 tons/hr containing $3.93 \times 10^{-2} \mathrm{lb} / \mathrm{hr}$ ${ }^{232}$ Th with a total flow of $6.39 \mathrm{gpm}$.

Filtration $V$ Stream - 1.05 tons $/ \mathrm{hr}$ containing $1.48 \times 10^{-2} \mathrm{lb} / \mathrm{hr}$ ${ }^{232}$ Th with a total flow of $4.20 \mathrm{gpm}$.

The total amount of liquid waste sent to the tailings pond is 5.054 tons $/ \mathrm{hr}$ containing $1.216 \mathrm{lb} / \mathrm{hr}$. The total flow to the pond is $20.216 \mathrm{gpm}$. All of the uranium in the entering ore goes to the tailings pond except for the amount emitted as dust and as a by-product. The amounts of uranium are:

Total uranium in entering ore $=(0.0435)(33.60)=1.4608 \mathrm{lb} / \mathrm{hr}$ Uranium in by-product $=(0.0435)(0.4268)=1.86 \times 10^{-2} \mathrm{lb} / \mathrm{hr}$ 
Uranium in tailings pond $=1.4608\left(1.86 \times 10^{-2}\right)+\left(6.52 \times 10^{-5}\right)+$ $\left(1.0 \times 10^{-5}\right)=1.4421 \mathrm{lb} / \mathrm{hr}$

$238_{U}=(0.993)(1.4421)=1.432 \mathrm{lb} / \mathrm{hr}$

$235 \mathrm{U}=1.01 \times 10^{-2} \mathrm{lb} / \mathrm{hr}$

A11 of the ${ }^{232}$ Th daughter products end up in the tailings pond except those emitted as dust, in the by-product, and as ${ }^{228} \mathrm{Th}$ in the product. The activity in the tailings pond is:

$\begin{array}{lll}{ }^{232} \mathrm{Th} & 1.216 \mathrm{lb} / \mathrm{hr} & 6.08 \times 10^{-5} \mathrm{Ci} / \mathrm{hr} \\ 238_{\mathrm{U}} & 1.432 \mathrm{1b} / \mathrm{hr} & 2.17 \times 10^{-4} \mathrm{Ci} / \mathrm{hr} \\ 235_{\mathrm{U}} & 1.01 \times 10^{-2} \mathrm{1b} / \mathrm{hr} & 9.83 \times 10^{-6} \mathrm{Ci} / \mathrm{hr} \\ 232 \mathrm{Th} \text { Daughters } & \text { Trace } & 1.3328 \times 10^{-2} \mathrm{Ci} / \mathrm{hr} \\ 238 \mathrm{U} \text { Daughters (13) } & \text { Trace } & 2.82 \times 10^{-3} \mathrm{Ci} / \mathrm{hr} \\ 235 \mathrm{U} \text { Daughters (10) } & \text { Trace } & 9.83 \times 10^{-6} \mathrm{Ci} / \mathrm{hr}\end{array}$





\section{D.9 GENERATED WASTES FROM CONWAY GRANITE MILL}

Dust from Unloading, Crushing, and Grinding the Ore

This stream carries $454.5 \mathrm{lb} / \mathrm{hr}$ of airborne wastes, of which $2.4024 \times 10^{-3} \mathrm{lb} / \mathrm{hr}$ are ${ }^{232} \mathrm{Th}$, and shown in Figure 0.9 . The uranium content of the dust $=(0.25)\left(2.4024 \times 10^{-3}\right)=6.006 \times 10^{-4} \mathrm{lb} / \mathrm{hr}$. The uranium is split between $238 \mathrm{U}$ and $235 \mathrm{U}$ and the ratio is:

$$
\left(\frac{0.993}{0.007}\right)\left(\frac{238 u}{235 u}\right)
$$

There are $5.964 \times 10^{-4} \mathrm{lb} / \mathrm{hr}{ }^{238} \mathrm{U}$ and $4.2 \times 10^{-6} \mathrm{lb} / \mathrm{hr}{ }^{235_{U}} \mathrm{U}$ emitted. The activity of the dust stream is:
${ }^{232} \mathrm{Th}$
$2.4024 \times 10^{-3} \mathrm{lb} / \mathrm{hr}$
$1.201 \times 10^{-7} \mathrm{Ci} / \mathrm{hr}$
$238 \mathrm{U}$
$5.964 \times 10^{-4} \mathrm{lb} / \mathrm{hr}$
$9.022 \times 10^{-8} \mathrm{Ci} / \mathrm{hr}$
$235 \mathrm{U}$
$4.2 \times 10^{-6} \mathrm{lb} / \mathrm{hr}$
$4.087 \times 10^{-9} \mathrm{Ci} / \mathrm{hr}$
${ }^{232}$ Th Daughters (9)
Trace
$1.081 \times 10^{-6} \mathrm{Ci} / \mathrm{hr}$
$238 \mathrm{U}$ Daughters (13)
Trace
$1.1728 \times 10^{-6} \mathrm{Ci} / \mathrm{hr}$
$235 \cup$ Daughters (10)
Trace
$9.022 \times 10^{-7} \mathrm{Ci} / \mathrm{hr}$

Drying and Packaging Dust

These processes release $0.029 \mathrm{lb} / \mathrm{hr}$ of airborne wastes, of which $0.01455 \mathrm{lb} / \mathrm{hr}$ are ${ }^{232} \mathrm{Th}$; the amount of uranium is $3.939 \times 10^{-3} \mathrm{lb} / \mathrm{hr}$; so $238 \mathrm{U}=3.912 \times 10^{-3} \mathrm{lb} / \mathrm{hr}$ and $235 \mathrm{U}=2.7 \times 10^{-5} \mathrm{lb} / \mathrm{hr}$. The activity in the dust stream is:
${ }^{232} \mathrm{Th}$
$167.96 \mathrm{lb} / \mathrm{hr}$
$8.387 \times 10^{-3} \mathrm{Ci} / \mathrm{hr}$
$238 \mathrm{U}$
$36.49 \mathrm{Ib} / \mathrm{hr}$
$5.520 \times 10^{-3} \mathrm{Ci} / \mathrm{hr}$
$235 \mathrm{U}$
$0.26 \mathrm{lb} / \mathrm{hr}$
$2.53 \times 10^{-4} \mathrm{Ci} / \mathrm{hr}$
${ }^{232}$ Th Daughters (9)
Trace
$7.548 \times 10^{-2} \mathrm{Ci} / \mathrm{hr}$
238 Daughters (13)
Trace
$7.176 \times 10^{-2} \mathrm{Ci} / \mathrm{hr}$
235 Daughters $(10)$
Trace
$2.53 \times 10^{-3} \mathrm{Ci} / \mathrm{hr}$ 


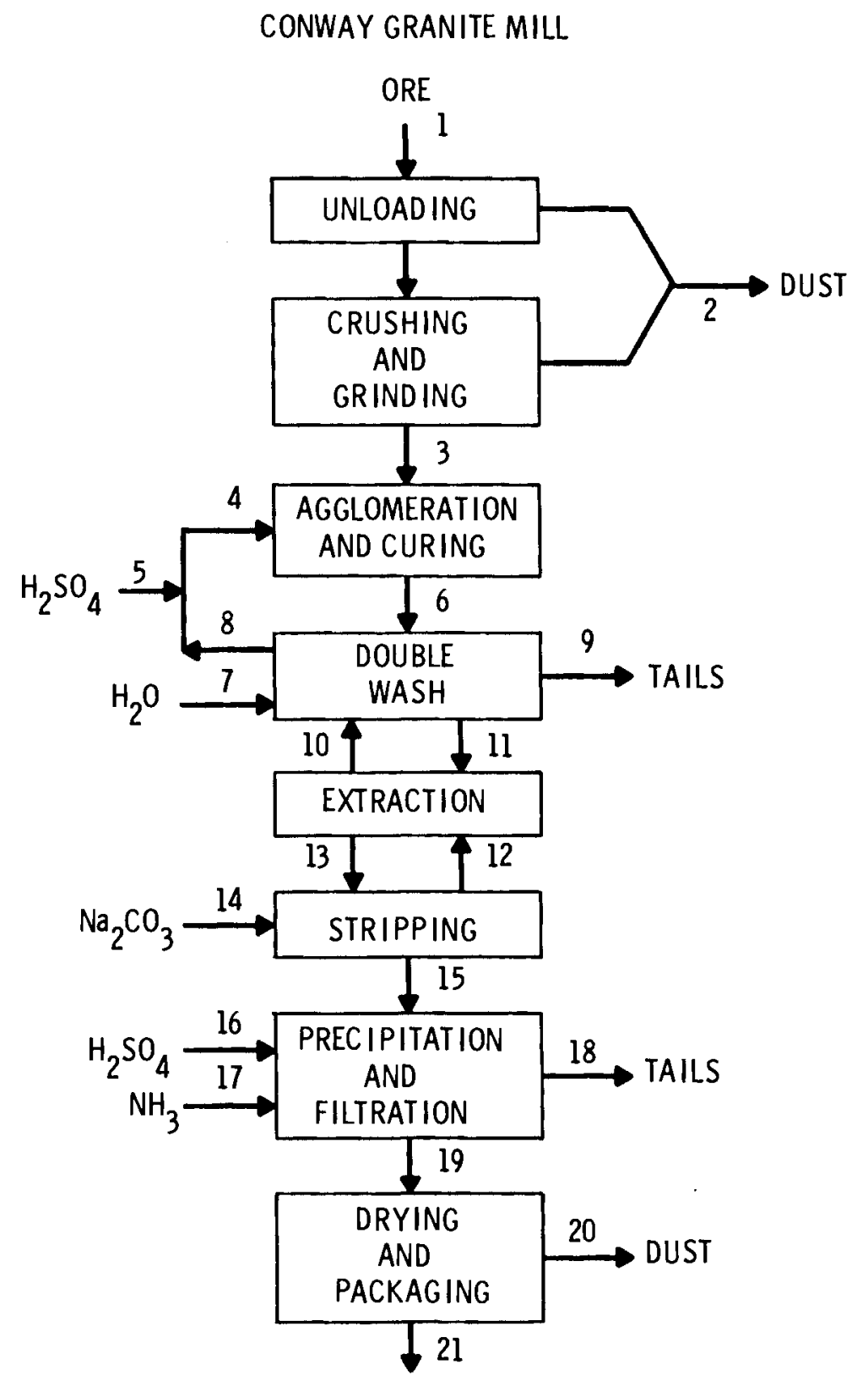

FIGURE D.9. Conway Granite Mill Flowsheet 
FIGURE D.9. Legend: Flow Streams for Conway Granite Mill

1. 4545.45 tons $/ \mathrm{hr}$ ore $\mathrm{w} / 480 \mathrm{lb} / \mathrm{hr}{ }^{232} \mathrm{Th}$

2. $454.5 \mathrm{lb} / \mathrm{hr} w / 2.4024 \times 10^{-3} \mathrm{lb} / \mathrm{hr}{ }^{232} \mathrm{Th}$

3. 4545.22 tons $/ \mathrm{hr} w / 480 \mathrm{lb} / \mathrm{hr}{ }^{232} \mathrm{Th}$

4. 800 tons $/ \mathrm{hr}$

5. 72.72 tons $/ \mathrm{hr} \mathrm{H}_{2} \mathrm{SO}_{4}$

6. 5345.22 tons $/ \mathrm{hr} \mathrm{w} / 480 \mathrm{lb} / \mathrm{hr}{ }^{232} \mathrm{Th}$

7. 1181.7 tons $/ \mathrm{hr} \mathrm{H}_{2} \mathrm{O}$

8. 727.28 tons $/ \mathrm{hr}$

9. 5799.46 tons $/ \mathrm{hr} w / 167.96 \mathrm{lb} / \mathrm{hr}{ }^{232} \mathrm{Th}$

10. 2908.8 tons $/ \mathrm{hr}$

11. 2908.98 tons $/ \mathrm{hr} w / 312.04 \mathrm{lb} / \mathrm{hr}{ }^{232} \mathrm{Th}$

12. 500 tons $/ \mathrm{hr}$ amine solvent

13. 500.18 tons $/ \mathrm{hr} w / 312.04 \mathrm{lb} / \mathrm{hr}{ }^{232} \mathrm{Th}$

14. 63.63 tons $/ \mathrm{hr} \mathrm{Na} \mathrm{Na}_{3}$

15. $63.81 \mathrm{tons} / \mathrm{hr} w / 312.04 \mathrm{lb} / \mathrm{hr}{ }^{232} \mathrm{Th}$

16. 2.73 tons $/ \mathrm{hr} \mathrm{H}_{2} \mathrm{SO}_{4}$

17. $909 \mathrm{lb} / \mathrm{hr} \mathrm{NH}$

18. 66.71 tons $/ \mathrm{hr} w / 23.999 \mathrm{lb} / \mathrm{hr}{ }^{232} \mathrm{Th}$

19. $574.24 \mathrm{lb} / \mathrm{hr} w / 288.04 \mathrm{lb} / \mathrm{hr}^{232} \mathrm{Th}$

20. $0.029 \mathrm{lb} / \mathrm{hr} w / 1.452 \times 10^{-2} \mathrm{lb} / \mathrm{hr}{ }^{232} \mathrm{Th}$

21. $574.21 \mathrm{lb} / \mathrm{hr} \mathrm{w} / 288.024 \mathrm{lb} / \mathrm{hr}{ }^{232} \mathrm{Th}$

\section{Tailings to Return to Mine}

In this stream, 5345.22 tons $/ \mathrm{hr}$ are to be dewatered and returned to the mine for disposal. Of this, $167.96 \mathrm{lb} / \mathrm{hr}$ are ${ }^{232} \mathrm{Th}$. The stream carries $36.75 \mathrm{lb} / \mathrm{hr}$ of uranium divided into two categories:

$$
\begin{aligned}
& 238 \mathrm{U}=36.49 \mathrm{lb} / \mathrm{hr} \\
& 235 \mathrm{U}=0.26 \mathrm{lb} / \mathrm{hr}
\end{aligned}
$$


The activity in the stream is:

$\begin{array}{lll}{ }^{232} \mathrm{Th} & 167.96 \mathrm{lb} / \mathrm{hr} & 8.387 \times 10^{-3} \mathrm{Ci} / \mathrm{hr} \\ 238 \mathrm{U} & 36.49 \mathrm{lb} / \mathrm{hr} & 5.520 \times 10^{-3} \mathrm{Ci} / \mathrm{hr} \\ 235 \mathrm{U} & 0.26 \mathrm{lb} / \mathrm{hr} & 2.53 \times 10^{-4} \mathrm{Ci} / \mathrm{hr} \\ 232 \mathrm{Th} \text { Daughters (9) } & \text { Trace } & 7.548 \times 10^{-2} \mathrm{Ci} / \mathrm{hr} \\ 238 \mathrm{U} \text { Daughters (13) } & \text { Trace } & 7.176 \times 10^{-2} \mathrm{Ci} / \mathrm{hr} \\ 235 \mathrm{U} \text { Daughters (10) } & \text { Trace } & 2.53 \times 10^{-3} \mathrm{Ci} / \mathrm{hr}\end{array}$

The above waste stream is to be dewatered and returned to the mine. If it is necessary, lime may be added before dewatering in order to neutralize the waste stream. About $350 \mathrm{lb} / \mathrm{hr}$ of 1 ime will be needed in order to completely neutralize the waste.

Liquid Waste To Tailings Pond

In this stream, 66.71 tons $/ \mathrm{hr}$ are to be sent to the tailings pond for disposal; of this, $23.999 \mathrm{lb} / \mathrm{hr}$ are ${ }^{232} \mathrm{Th}$. The stream also contains uranium in these amounts:

$$
\begin{aligned}
{ }^{238} U & =5.2087 \mathrm{lb} / \mathrm{hr} \\
{ }^{235} U & =3.68 \times 10^{-2} \mathrm{lb} / \mathrm{hr}
\end{aligned}
$$

The activity in the stream is:

$\begin{array}{lll}{ }^{232} \mathrm{Th} & 23.999 \mathrm{lb} / \mathrm{hr} & 1.1998 \times 10^{-3} \mathrm{Ci} / \mathrm{hr} \\ { }^{238} \mathrm{U} & 5.2087 \mathrm{lb} / \mathrm{hr} & 7.8791 \times 10^{-4} \mathrm{Ci} / \mathrm{hr} \\ { }^{235} \mathrm{U} & 3.68 \times 10^{-2} \mathrm{lb} / \mathrm{hr} & 3.581 \times 10^{-5} \mathrm{Ci} / \mathrm{hr} \\ { }^{232} \mathrm{Th} \text { Daughters (9) } & \text { Trace } & 1.0798 \times 10^{-2} \mathrm{Ci} / \mathrm{hr} \\ { }^{238} \mathrm{U} \text { Daughters (13) } & \text { Trace } & 1.0243 \times 10^{-2} \mathrm{Ci} / \mathrm{hr} \\ 235 \mathrm{U} \text { Daughters (10) } & \text { Trace } & 3.581 \times 10^{-4} \mathrm{Ci} / \mathrm{hr}\end{array}$




\section{D.10 GENERATED WASTES FROM CONWAY GRANITE REFINERY \\ Waste Sludge}

The waste sludge stream carries $663 \mathrm{lb} / \mathrm{hr}$ of sludge, which is $80 \%$ solids; of this, $5.72 \mathrm{lb} / \mathrm{hr}$ are ${ }^{232} \mathrm{Th}$. The amount of uranium in the entering milled product is $13.6 \%$ of the total or $77.43 \mathrm{lb} / \mathrm{hr}$. If the same ratio is assumed between $T h$ and $U$ in the waste sludge, the amount of uranium in the waste sludge is $1.55 \mathrm{lb} / \mathrm{hr}$. The amount of ${ }^{238} \mathrm{U}=1.54 \mathrm{lb}$ and the amount of ${ }^{235} \mathrm{U}$ is $1.00 \times 10^{-2} \mathrm{lb} / \mathrm{hr}$. The activity in the waste sludge stream is: ${ }^{232} \mathrm{Th}$
$238_{U}$
$5.72 \mathrm{lb} / \mathrm{hr}$
$2.86 \times 10^{-4} \mathrm{Ci} / \mathrm{hr}$
$235 \mathrm{U}$
${ }^{232}$ Th Daughters (9)
238 U Daughters (13)
$235 \mathrm{U}$ Daughters (10)
$1.55 \mathrm{lb} / \mathrm{hr}$
$1.00 \times 10^{-2} \mathrm{lb} / \mathrm{hr}$
Trace
Trace
Trace
$2.34 \times 10^{-4} \mathrm{Ci} / \mathrm{hr}$
$9.73 \times 10^{-6} \mathrm{Ci} / \mathrm{hr}$
$2.574 \times 10^{-3} \mathrm{Ci} / \mathrm{hr}$
$3.048 \times 10^{-3} \mathrm{Ci} / \mathrm{hr}$
$9.73 \times 10^{-5} \mathrm{Ci} / \mathrm{hr}$

This waste sludge is already concentrated to $80 \%$ solids and can be disposed of by proper burial techniques at an approved site.

Liquid Waste to Tailings Pond

As shown in Figure D.10, the following streams and respective loads are sent to a tailings pond:

Dewatering Stream - $1216 \mathrm{lb} / \mathrm{hr}$ containing $0.308 \mathrm{lb} / \mathrm{hr}{ }^{232} \mathrm{Th}$ with a total flow of $2.43 \mathrm{gpm}$.

Drying Stream - $56.85 \mathrm{lb} / \mathrm{hr}$, mainly $\mathrm{H}_{2} \mathrm{O}$, with a total flow of $0.114 \mathrm{gpm}$.

Extraction and Scrubbing Stream - $1254 \mathrm{lb} / \mathrm{hr}$ containing $0.264 \mathrm{lb} / \mathrm{hr}$ of ${ }^{232}$ Th with a total flow of $2.51 \mathrm{gpm}$.

Uranium Back Extraction and Scrubbing Stream - $318 \mathrm{lb} / \mathrm{hr}$ with no ${ }^{232} \mathrm{Th}$ and a total flow of $0.64 \mathrm{gpm}$.

Boildown and Evaporation Stream - $5351 \mathrm{lb} / \mathrm{hr}$ mainly $\mathrm{H}_{2} \mathrm{O}$, with a total flow of $1.07 \mathrm{gpm}$. 


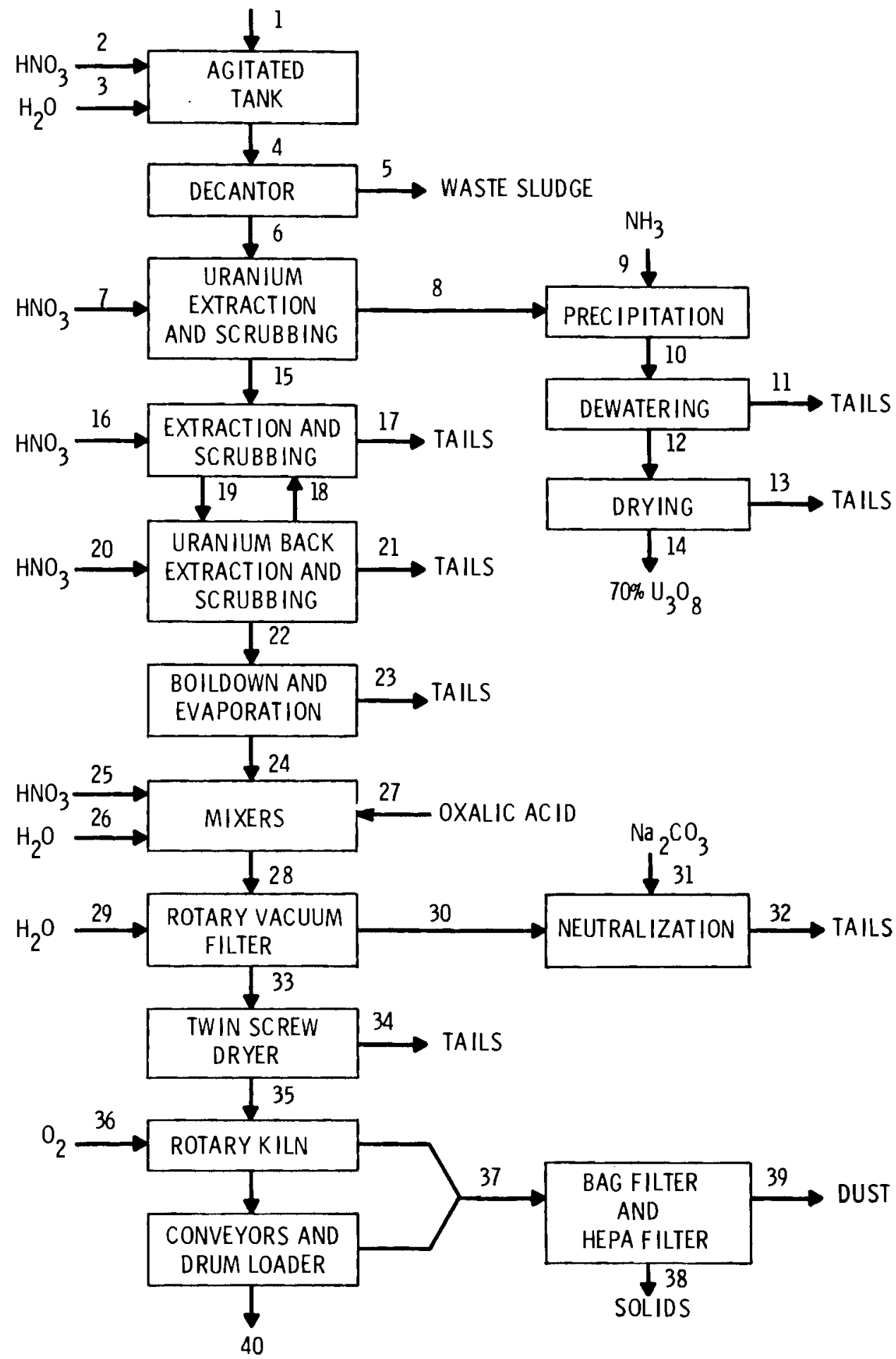

FIGURE D.10. Conway Granite Refinery Flowsheet 


\section{FIGURE D.10. Legend: Flow Streams for Conway Granite Refinery}

1. $570 \mathrm{lb} / \mathrm{hr} w / 285.9 \mathrm{lb} / \mathrm{hr}{ }^{232} \mathrm{Th}$

2. $299 \mathrm{lb} / \mathrm{hr} \mathrm{HNO}_{3}$

3. $491 \mathrm{lb} / \mathrm{hr} \mathrm{H}_{2} \mathrm{O}$

4. $1360 \mathrm{lb} / \mathrm{hr} w / 285.9 \mathrm{lb} / \mathrm{hr}^{232} \mathrm{Th}$

5. $663 \mathrm{lb} / \mathrm{hr} w / 5.72 \mathrm{lb} / \mathrm{hr}^{232} \mathrm{Th}$

6. $697 \mathrm{lb} / \mathrm{hr} w / 280.18 \mathrm{lb} / \mathrm{hr}{ }^{232} \mathrm{Th}$

7. $1367 \mathrm{lb} / \mathrm{hr} 4 \mathrm{M} \mathrm{HNO}$

8. $1367 \mathrm{lb} / \mathrm{hr} w / 0.308 \mathrm{lb} / \mathrm{hr}^{232} \mathrm{Th}$

9. $33 \mathrm{lb} / \mathrm{hr} \quad \mathrm{NH}_{3}$

10. $1400 \mathrm{lb} / \mathrm{hr} w / 0.308 \mathrm{lb} / \mathrm{hr}{ }^{232} \mathrm{Th}$

11. $1216 \mathrm{lb} / \mathrm{hr} w / 0.308 \mathrm{lb} / \mathrm{hr}{ }^{232} \mathrm{Th}$

12. $184 \mathrm{lb} / \mathrm{hr}$

13. $56.86 \mathrm{lb} / \mathrm{hr} \mathrm{H} \mathrm{O}$

14. $127.14 \mathrm{lb} / \mathrm{hr}\left(70 \% \mathrm{U}_{3} \mathrm{O}_{8}\right)$

15. $697 \mathrm{lb} / \mathrm{hr} w / 279.87 \mathrm{lb} / \mathrm{hr}{ }^{232} \mathrm{Th}$

16. $557 \mathrm{lb} / \mathrm{hr} \mathrm{HNO}_{3}$

17. $1254 \mathrm{lb} / \mathrm{hr} w / 0.264 \mathrm{lb} / \mathrm{hr}{ }^{232} \mathrm{Th}$

18. $6359 \mathrm{lb} / \mathrm{hr}$

19. $6677 \mathrm{lb} / \mathrm{hr} w / 279.606 \mathrm{lb} / \mathrm{hr}^{232} \mathrm{Th}$

20. $6677 \mathrm{lb} / \mathrm{hr}$ of $0.1 \mathrm{HNO}_{3}$

21. $318 \mathrm{lb} / \mathrm{hr}$
22. $6677 \mathrm{lb} / \mathrm{hr} w / 279.606 \mathrm{lb} / \mathrm{hr}{ }^{232} \mathrm{Th}$

23. $5351 \mathrm{lb} / \mathrm{hr} \mathrm{H}_{2} \mathrm{O}$

24. $1326 \mathrm{lb} / \mathrm{hr} w / 279.606 \mathrm{lb} / \mathrm{hr}^{232} \mathrm{Th}$

25. $74 \mathrm{lb} / \mathrm{hr} \mathrm{HNO}_{3}$

26. $87 \mathrm{lb} / \mathrm{hr} \mathrm{H}_{2} \mathrm{O}$

27. $112.6 \mathrm{lb} / \mathrm{hr}$ oxalic acid

28. $1599.6 \mathrm{lb} / \mathrm{hr} \mathrm{w} / 279.606 \mathrm{lb} / \mathrm{hr}{ }^{232} \mathrm{Th}$

29. $288.9 \mathrm{lb} / \mathrm{hr} \mathrm{H}_{2} \mathrm{O}$

30. $1070.9 \mathrm{lb} / \mathrm{hr} \mathrm{w} / 2.29 \mathrm{lb} / \mathrm{hr}^{232} \mathrm{Th}$

31. $309.7 \mathrm{lb} / \mathrm{hr} \mathrm{Na}_{2} \mathrm{CO}_{3}$

32. $1380.6 \mathrm{lb} / \mathrm{hr} \mathrm{w} / 2.29 \mathrm{lb} / \mathrm{hr}{ }^{232} \mathrm{Th}$

33. $817.6 \mathrm{lb} / \mathrm{hr} w / 277.316 \mathrm{lb} / \mathrm{hr}{ }^{232} \mathrm{Th}$

34. $326 \mathrm{lb} / \mathrm{hr} \mathrm{H} \mathrm{H}_{2} \mathrm{O}$

35. $581.6 \mathrm{lb} / \mathrm{hr} \mathrm{w} / 277.316 \mathrm{lb} / \mathrm{hr}{ }^{232} \mathrm{Th}$

36. $43.3 \mathrm{lb} / \mathrm{hr} \mathrm{O} \mathrm{O}_{2}$

37. $100.8 \mathrm{lb} / \mathrm{hr} \mathrm{H}_{2} \mathrm{O}$ and $205.8 \mathrm{lb} / \mathrm{hr}$ $\mathrm{CO}_{2} \mathrm{w} / 5.72 \mathrm{lb} / \mathrm{hr}{ }^{232} \mathrm{Th}$

38. $5.66 \mathrm{lb} / \mathrm{hr}{ }^{232} \mathrm{Th}$

39. $307.7 \mathrm{lb} / \mathrm{hr} w / 5.72 \times 10^{-2} \mathrm{lb} / \mathrm{hr}{ }^{232} \mathrm{Th}$

40. $311.8 \mathrm{lb} / \mathrm{hr} \mathrm{w} / 271.60 \mathrm{lb} / \mathrm{hr}^{232} \mathrm{Th}$ 
Plate-and-Frame Press Stream - $1380.6 \mathrm{lb} / \mathrm{hr}$ containing $2.29 \mathrm{lb} / \mathrm{hr}{ }^{232} \mathrm{Th}$ with a total flow of $2.76 \mathrm{gpm}$.

Twin-Screw Dryer Stream - $236 \mathrm{lb} / \mathrm{hr}$, mainly $\mathrm{H}_{2} \mathrm{O}$, with a total flow of $0.47 \mathrm{gpm}$.

The total amount sent to the tailings pond is $9812.46 \mathrm{lb} / \mathrm{hr}$, of which $2.86 \mathrm{lb} / \mathrm{hr}$ is ${ }^{232} \mathrm{Th}$. The total flow to the pond is $19.625 \mathrm{gpm}$. Uranium also enters the tailings pond in these amounts:

Uranium in tailings pond $=77.43-75.47-1.55=0.41 \mathrm{lb} / \mathrm{hr}$

$$
\begin{aligned}
& { }^{238} U=(0.993)(0.41)=0.407 \mathrm{lb} / \mathrm{hr} \\
& 235 U=(0.007)(0.41)=3.0 \times 10^{-2} \mathrm{lb} / \mathrm{hr}
\end{aligned}
$$

The activity in the tailings pond is:
${ }^{232} \mathrm{Th}$
$2.86 \mathrm{lb} / \mathrm{hr}$
$1.43 \times 10^{-4} \mathrm{Ci} / \mathrm{hr}$
$238 \mathrm{U}$
$0.407 \mathrm{lb} / \mathrm{hr}$
$6.16 \times 10^{-5} \mathrm{Ci} / \mathrm{hr}$
$235 \mathrm{U}$
$3.0 \times 10^{-3} \mathrm{lb} / \mathrm{hr}$
$2.92 \times 10^{-6} \mathrm{Ci} / \mathrm{hr}$
${ }^{232}$ Th Daughters
Trace
$1.122 \times 10^{-1} \mathrm{Ci} / \mathrm{hr}$
$238 \mathrm{U}$ Daughters
Trace
$1.3682 \times 10^{-1} \mathrm{Ci} / \mathrm{hr}$
$235 \mathrm{U}$ Daughters
Trace
$5.158 \times 10^{-3} \mathrm{Ci} / \mathrm{hr}$

Drying and Loading Dust

The drying and loading processes emit $100.8 \mathrm{lb} / \mathrm{hr} \mathrm{H}_{2} 0,205.8 \mathrm{lb} / \mathrm{hr}$ $\mathrm{CO}_{2}$, and $5.72 \mathrm{lb} / \mathrm{hr}{ }^{232} \mathrm{Th}$ into the dust stream. This stream is controlled by hoods connected to a $12,000-\mathrm{cfm}$ bag filter unit and HEPA filters, which remove $99 \%$ of the dust. This system captures $5.66 \mathrm{lb} / \mathrm{hr}$ of ${ }^{232} \mathrm{Th}$ in solids. The other $0.0572 \mathrm{lb} / \mathrm{hr}$ of ${ }^{232} \mathrm{Th}$ is emitted to the atmosphere. The activity in the streams is:
${ }^{232} \mathrm{Th}$ (solid)
${ }^{228}$ Th (solid)
$5.66 \mathrm{lb} / \mathrm{hr}$
$2.83 \times 10^{-4} \mathrm{Ci} / \mathrm{hr}$
${ }^{232}$ Th (air)
Trace
$2.83 \times 10^{-4} \mathrm{Ci} / \mathrm{hr}$
${ }^{228}$ Th (air)
$0.0572 \mathrm{lb} / \mathrm{hr}$
$2.86 \times 10^{-6} \mathrm{Ci} / \mathrm{hr}$
Trace
$2.86 \times 10^{-6} \mathrm{Ci} / \mathrm{hr}$ 


\begin{abstract}
APPENDIX E
CAPITAL COSTS FOR BASELINE ENVIRONMENTAL CONTROL TECHNOLOGY
\end{abstract}




\section{E.1 STOCKPILE REF INERY CAPITAL COSTS}

\section{Waste Sludge}

The waste sludge will be hauled to a clay lined landfill pit using a small dump truck or a forklift using dumpsters. The pit will be approximately $2-1 / 2$ acres in size on a 3 -acre tract.

\begin{tabular}{lr} 
Grub and clear 3 acres & $\$ 2,000$ \\
Excavate pit & 68,600 \\
Perimeter drainage & 4,000 \\
Finishing & 4,000 \\
Clay lining & 26,500 \\
\multicolumn{1}{|c|}{ Subtotal } & 105,100 \\
$20 \%$ Overhead & 21,000 \\
Truck and 2 dumpster hoppers & 25,000 \\
Land - 3 acres at $\$ 2,000$ & 6,000 \\
\hline Total Installed Cost & $\underline{\$ 157,100}$ \\
\hline
\end{tabular}

\section{Refinery Tailings Pond}

The tailings pond serves mainly as an evaporation pond because very little solids are contained in the liquid effluent. The pond will be approximately 4 acres in size and it will be lined with about $3 \mathrm{ft}$ of clay.

\begin{tabular}{lr} 
Grub and clear 5 acres & 3,300 \\
Excavate pond & 77,400 \\
Perimeter drainage & 4,000 \\
Pump and pipes & 2,800 \\
Finishing and miscellaneous & 4,000 \\
Clay lining & 36,800 \\
$\quad$ Subtotal & 128,300 \\
$20 \%$ Overhead & 25,700 \\
Land - 5 acres at $\$ 2,000 /$ acre & 10,000 \\
Total Installed Cost & $\$ 164,000$ \\
\hline
\end{tabular}


Drying and Packaging Dust

The dust in this area is more radioactive and requires the state-of-theart technology to control it. A baghouse filter and HEPA filter are used in series to collect the dust. An air demister unit is used to heat the bulk $6000 \mathrm{cfm}$ airstream well above the dew point and keep the water content below saturation.

$6000 \mathrm{cfm}$ Dust Control

\begin{tabular}{lr}
\hline $\begin{array}{l}\text { Baghouse filter }=\$ 126,000\left(\frac{6,000}{30,000}\right)^{0.85^{*}} \\
\text { HEPA filter system }\end{array}$ & 32,100 \\
Demister unit & 64,900 \\
Total Installed Cost & 6,700 \\
\hline$\quad 103,700$ \\
\hline
\end{tabular}

*Note - Scaling factors utilize Lemhi Pass costs as a basis in this study unless noted otherwise.

Pond Beach Dust

A portable sprayer is used to periodically spray chemicals on the shores of the tailings pond.

Equipment cost is estimated at

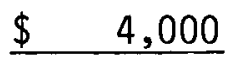

\section{Tailings Pond Cover}

At the conclusion of the refinery's life the pond will be allowed to evaporate. The residual solids will be covered by a minimum of $6 \mathrm{ft}$ of earth and 6 in. of rock.

$6 \mathrm{ft}$ earth and $6 \mathrm{in}$. rock cover $=920,000\left(\frac{4}{100}\right)^{0.8} \$ \quad \$ \quad 70,100$ 


\section{E.2. LEMHI PASS CAPITAL COSTS}

Mine Water

Use a 2-acre settling pond located on 3-acre tract.

\begin{tabular}{lr} 
Grub and clear 3 acres & 2,000 \\
Excavate pond & 19,300 \\
Trenches & 1,500 \\
Perimeter drainage & 2,000 \\
Finishing operations & 2,000 \\
\hline Subtotal & 26,800 \\
$20 \%$ Overhead & 5,400 \\
Land - 3 acres at $\$ 1,000 /$ acre & 3,000 \\
Total Installed Cost & $\$ 3,200$ \\
\hline
\end{tabular}

Controlled Mine Dust

Dust is sufficiently dilute, therefore, no waste control equipment is required.

$300,000 \mathrm{cfm}$ ventilation system, no control equipment

Total Installed Cost

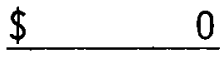

Uncontrolled Mine Dust

\begin{tabular}{cr} 
Water tank truck w/sprayer attachments & 30,000 \\
Storage pile barriers & 15,000 \\
Total Installed Cost & $\$ \quad 45,000$ \\
\hline
\end{tabular}

Loading, Crushing, and Grinding Dust

$26,000 \mathrm{cfm}$ cyclone $w /$ fans

Total Installed Cost

$\$ \quad 19,900$ 
Drying and Ignition Dust

21,000 cfm wet impingement scrubber $\mathrm{w} / \mathrm{fans}$ and pumps

Total Installed Cost

$\$ \quad 39,900$

Packaging Dust

4,000 cfm baghouse filter w/fans

Total Installed Cost

$\$ \quad 22,700$

Tailings Pond

100-acre clay core dam and reservoir

$\$ 2,401,000$

Distribution system, pumps, pipeline

220,000

Recycling system, pumps, pipe and 1-acre settling pond

320,000

Land - 125 acres at $\$ 1,000 /$ acre

125,000

Total Installed cost

$\$ 3,066,000$

Tailings Pond Beach Dust

Chemical spraying equipment (portable)

Total Installed Cost

$\$ 20,000$

Tailings Pond Cover

$1 \mathrm{ft}$ earth cover at $\$ 1,200 /$ acre

$\$ 120,000$

6 in. rock cover at $\$ 2,000 /$ acre 200,000

Total Installed Cost

$\$ 320,000$ 


\section{E.3. HALL MOUNTAIN CAPITAL COSTS}

Mine Water

(250 gpm, ${ }^{232}$ Th level below standard; use 1-acre settling pond on $1-1 / 2$-acre tract)

l-acre Settling Pond

Settling pond one-half size of Lemhi Pass Pond

$\therefore \$ 35,200\left(\frac{250 \mathrm{gpm}}{500 \mathrm{gpm}}\right)^{0.7}=$ Total Installed Cost $\$$

Controlled Mine Dust

Same as Lemhi Pass except ventilation air of $160,000 \mathrm{ft}^{3} / \mathrm{min}$ is required and ${ }^{232} \mathrm{Th}$ peak level is $2.78 \times 10^{-11} \mu \mathrm{Ci} / \mathrm{ml}$. No waste control equipment is needed.

Total Installed Cost

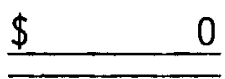

Uncontrolled Mine Dust

Same as Lemhi Pass except smaller spray equipment and barriers are used.

Water tank truck w/sprayer attachments

$\$ 17,300$

Storage pile barriers

8,700

Total Installed Cost

$\$ 26,000$

Loading, Crushing and Grinding Dust

Same as Lemhi Pass except a smaller 18,000 cfm cyclone is used.

$18,000 \mathrm{cfm}$ cyclone $w /$ fans

Total Installed Cost

$\$ 13,500$

Drying and Ignition Dust

25,000 cfm wet impingement scrubber $w /$ fans and pumps

Total Installed Cost

$\$ 46,200$

E.5 
Packaging Dust

4,400 cfm baghouse filter w/fan

Total Installed Cost

$\$ 24,700$

Tailings Pond

Use 15-acre clay core dam and reservoir. Recycle water.

15-acre clay core dam and reservoir

$\$ 636,000$

Distribution system, pump, pipes

172,000

Recycling system

137,000

Land - 25 acres at $\$ 1,000 /$ acre

25,000

Total Installed Cost

$\$ 970,000$

Tailings Pond Beach Dust

Same as Lemhi Pass except smaller equipment used.

Chemical spraying equipment (portable)

$$
\text { Total Installed Cost }=\$ 20,000\left(\frac{400}{1000}\right)^{0.6}
$$

\section{Tailings Pond Cover}

Same as Lemhi Pass except scaled down.

$1 \mathrm{ft}$ earth and 6 in. rock cover

$$
\text { Total Installed Cost }=\$ 320,000\left(\frac{15}{100}\right)^{0.8}
$$

$\$ 70,100$ 


\section{E.4 WET MOUNTAIN CAPITAL COSTS}

\section{Mine Water}

Same as Hall Mt. Flow $=250 \mathrm{gpm}$. The ${ }^{232} \mathrm{Th}$ level is the same. Use 1 -acre settling pond on 1-1/2-acre tract.

Total Installation cost

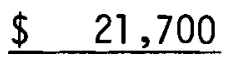

Controlled Mine Dust

Use $140,000 \mathrm{cfm}$ ventilation for peak level of $2.43 \times 10^{-11} \mu \mathrm{Ci} / \mathrm{ml}$. No waste control equipment is needed.

Total Installation Cost

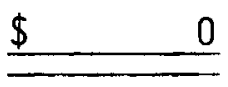

Uncontrolled Mine Dust

Same as Lemhi and Hall Mt. except smaller equipment is used.

Water truck $w /$ sprayer attachments

$\$ 16,000$

Storage pile barriers

Total Installation Cost

$\begin{array}{r}8,000 \\ \$ \quad 24,000 \\ \hline\end{array}$

Loading, Crushing and Grinding Dust

Same as Lemhi and Hall Mt. except different size cyclone is needed.

Use $13,000 \mathrm{cfm}$

Installed Cost $=\$ 22,500\left(\frac{13,000}{30,000}\right)^{0.85}$

$\$ 11,100$

Drying and Ignition Dust

Same as Lemhi and Hall Mt. except different size scrubber is needed. Use $20,000 \mathrm{cfm}$ wet impingement scrubber.

Installed Cost $=54,000\left(\frac{20,000}{30,000}\right)^{0.85}$

$\$ \quad 38,300$ 
Packaging Dust

Use $3,500 \mathrm{cfm}$ baghouse filter.

$$
\text { Installed Cost }=126,000\left(\frac{3,500}{30,000}\right)^{0.85} \$ \$ 20,300
$$

Tailings Pond

Use 14-acre clay core dam and reservoir. Recycle water.

14-acre clay core dam and reservoir

$\$ 606,300$

Distribution system, pumps, pipes

153,400

Recycling system

118,500

Land - 24 acres at $\$ 1,000 /$ acre

24,000

Total Installed Cost

$\$ 902,200$

Tailings Pond Beach Dust

Same as Lemhi Pass except smaller equipment is used.

Installed cost $=20,000\left(\frac{350}{1000}\right)^{0.6}$

$\$ \quad 10,700$

Tailings Pond Cover

Same as Lemhi, except scaled down.

$1 \mathrm{ft}$ earth and 6 in. rock cover

Installed cost $=320,000\left(\frac{14}{100}\right)^{0.8}$

$\$ \quad 66,400$ 


\section{E. 5 PALMER, MICHIGAN, CAPITAL COSTS}

Mine Water

Mine water will pass through a 3-acre settling pond and be pumped to the mi11/refinery complex to be used as process water. Excess water is discharged into surface waters.

\begin{tabular}{lr} 
Grub and clear 4 acres & 2,700 \\
Excavate pond & 46,500 \\
Trenches & 3,600 \\
Drainage around pond & 7,000 \\
Pumps & 52,500 \\
Piping & 79,200 \\
$\quad$ Subtotal & 191,500 \\
$20 \%$ Overhead & 38,300 \\
Land - 4 acres at $\$ 1,500 /$ acre & 6,000 \\
Total Installed Cost & $\$ 235,800$ \\
\hline
\end{tabular}

Uncontrolled Mine Dust

Procure spraying equipment and install wind barriers.

\begin{tabular}{lr} 
Water tank truck, sprayer w/attachments & $\$ 50,000$ \\
Miscellaneous, spray hoses, etc. & 10,000 \\
Storage pile barriers & 96,000 \\
$\quad$ Total Installed Costs & $\$ 156,000$ \\
\hline
\end{tabular}

Mill Unloading, Crushing, and Grinding Dust

Four 50,000 cfm cyclones will be used to collect this dust. 
Four $50,000 \mathrm{cfm}$ cyclones at $\$ 34,725$

Installed Cost $=34,725(4)$

$\$ 138,900$

Drying, Magnetic Separation, and Loading Dust

A $60,000 \mathrm{cfm}$ wet impingement scrubber will be used to collect dust from these operations.

Installed Cost

$\$ 108,000$

Mill Separation and Dewatering Liquid Waste

A 200-acre clay lined tailings pond will be used for settling out the solids. A distribution system will be used to spread the solids evenly throughout the pond. A recycling system, which consists of pumps, pipes and a smal1 auxilliary settling pond, will be used to return water to the mill for reuse.

Clay lined pond $=3,416,000\left(\frac{200}{100}\right)^{0.7}$

$\$ 5,551,000$

Distribution system $=320,000\left[\frac{(22)(900)}{5803}\right]$

0.7

Recycle system $=220,000\left(\frac{2372}{600}\right)^{0.7}$

755,500

Land - 225 acres at $\$ 1,500 /$ acre

575,800

Total Installed Cost

337,500

$\$ 7,219,800$

Refinery Unloading and Grinding Dust

A 10,000 cfm baghouse filter will be required.

$$
\text { Installed cost }=126,000\left(\frac{10,000}{30,000}\right)^{0.85}
$$

$\$ \quad 49,500$ 
Refinery Ignition and Drying Dust

A $16,000 \mathrm{cfm}$ low energy venturi scrubber will be used to collect the dust. Installed Cost

$\$ 36,900$

Packaging Dust

A 3,000 cfm baghouse filter will be used.

Installed cost

$\$ 17,800$

By-Product Recovery Dust

A $24,000 \mathrm{cfm}$ wet impingement scrubber will be used.

Installed Cost

$\underline{\$ 44,700}$

Refinery Tailings Pond

A 20-acre pond lined with $3 \mathrm{ft}$ of clay will be used to collect the solids and recycle the water to the refinery.

20-acre clay core dam and reservoir

$\$ 570,600$

Distribution system $=(320,000)(0.5)\left(\frac{4492}{5803}\right)^{0.7}$

128,700

Recycling system $=(220,000)\left(\frac{748}{600}\right)^{0.7}$

256,700

Land $=25$ acres at $\$ 1500 /$ acre

Total Installed Cost

$\$ 993,500$

\section{Refinery Tailings Pond Beach Dust}

Portable chemical spraying equipment will be used periodically to tie down dust on the shore.

Installation and Equipment cost is

$\$ \quad 6,500$ 
Refinery Tailings Pond Cover

After the refinery is permanently shut down a cover consisting of $6 \mathrm{ft}$ of earth and 6 in. rock will be used.

Estimated Cost

$\$ 253,900$ 


\section{E.6 BALD MOUNTAIN CAP ITAL COSTS}

\section{Mine Water}

A 2-acre settling pond with a pump and piping for transferring the water to the mill/refinery complex will be used for the base technology case.

\begin{tabular}{lr} 
Grub and clear 3 acres & $\begin{array}{r}2,000 \\
\text { Excavate pond }\end{array}$ \\
35,000 \\
Trenches & 2,400 \\
Drainage around pond & 4,500 \\
Pumps & 39,500 \\
Piping & 59,700 \\
$\quad$ Subtotal & 143,100 \\
$20 \%$ Overhead & 28,600 \\
Land - 3 acres at $\$ 1,000 /$ acre & 3,000 \\
$\quad$ Total Installed Cost & $\$ 174,700$ \\
\hline
\end{tabular}

Uncontrolled Mine Dust

Same methods as Palmer, Michigan. Cost is as follows:

Water tank truck w/attachments

$\$ 40,000$

Miscellaneous

7,000

Storage pile barriers

47,400

Total

$\$ 94,400$

Mill Unloading, Crushing, and Grinding Dust

One 50,000 cfm cyclone will be used for these operations. Installation Cost

$\$ \quad 34,700$

Drying, Magnetic Separation, and Loading Dust

A 30,000 cfm wet impingement scrubber will be used.

Installation Cost

$\$ 54,000$ 
Mill Separation and Dewatering Liquid Waste

A 40-acre clay lined pond will be used for settling out the solids. The liquid will be recycled through a settling pond and reused in the mill.

\begin{tabular}{|c|c|}
\hline Clay 1 ined pond $=(3,416,000)\left(\frac{40}{100}\right)^{0.7}$ & $\$ 1,798,700$ \\
\hline Distribution system $=(320,000)\left(\frac{4767}{5803}\right)^{0.7}$ & 278,900 \\
\hline Recycle system $=(220,000)\left(\frac{600}{600}\right)^{0.7}$ & 220,000 \\
\hline Land $=50$ acres at $\$ 1,000 /$ acre & 50,000 \\
\hline Total Installed Cost & $\$ 2,347,600$ \\
\hline
\end{tabular}

Refinery Unloading and Grinding Dust

A $10,000 \mathrm{cfm}$ cyclone is used.

Installation cost

$\$ \quad 8,800$

Refinery Ignition and Drying Dust

A $6,000 \mathrm{cfm}$ low energy venturi scrubber is used. Installed Cost

$\$ \quad 16,000$

Packaging Dust

A $1,200 \mathrm{cfm}$ baghouse filter is used.

Installed Cost

$\$ \quad 8,200$

By-Product Recovery Dust

A $15,000 \mathrm{cfm}$ wet impingement scrubber is used. Installed Cost

$\underline{\$ 30,000}$ 
Refinery Tailings Pond

A 6-acre clay lined pond is used to collect the solids and evaporate the liquid wastes. No recycle system is used.

6-acre clay core dam and reservoir

$\$ 201,300$

Land - 8 acres at $\$ 1,000 /$ acre

8,000

Total Installed Cost

$\$ 209,300$

Tailings Pond Beach Dust

A portable system will be used.

$\$ \quad 4,000$

Tailings Pond Cover

A $6 \mathrm{ft}$ earth with 6 in. rock cover will be used.

$\$ \quad 96,900$ 


\section{E.7 CONWAY GRANITE CAPITAL COSTS}

\section{Mine Water}

A settling pond of about 4 acres is required. The water is subsequently pumped to the mill where large quantities of water are needed. Excess water can be discharged into surface waters.

$$
\begin{aligned}
& 4 \text {-acre pond }=71,800\left(\frac{2000}{1500}\right)^{0.7^{\star}}, \$ 87,800 \\
& \begin{array}{ll}
\text { Pump and piping }=158,000\left(\frac{2000}{1500}\right)^{0.7 *} \quad 193,200
\end{array} \\
& \text { Land - } 6 \text { acres at } \$ 2,000 / \text { acre } \quad 12,000 \\
& \text { Total Installed Cost \$293,000 } \\
& \text { *Note - Palmer, Mich costs are basis. }
\end{aligned}
$$

Uncontrolled Mine Dust

Procure spraying equipment and insta 11 wind barriers.

Water tank truck and auxilliary spraying equipment

$\$ 60,000$

Miscellaneous

Storage pile barriers 150,000

Installation cost

$\$ 225,000$

Unloading, Crushing and Grinding Dust at Mill

Two 50,000 cfm cyclones will be used to collect this dust.

2 cyclones at $\$ 34,725$

Installed Cost $=34,725(2)$

$\$ \quad 69,500$ 
Mill Drying and Packaging Dust

Radioactivity level of this dust is relatively low. A 30,000 cfm wet impingement scrubber is used.

Installation Cost

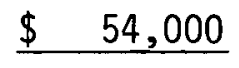

\section{Mill Tailings Pond}

A 20-acre clay lined pond is used to collect the solids by settling. The recycle water is passed through an auxilliary settling pond before being returned to the mill.

20-acre clay core dam and reservoir

$$
\begin{aligned}
& \text { Distribution system }=(320,000)\left(\frac{1467}{5803}\right)^{0.7} \\
& \text { Recycle system }=(220,000)\left(\frac{224}{600}\right)^{0.7} \\
& \text { Land - } 25 \text { acres at } \$ 2,000 / \text { acre } \\
& \text { Total Installed Cost }
\end{aligned}
$$

$\$ 686,800$

$$
61,100
$$

110,400 50,000

$\$ 908,300$

\section{Refinery Waste Sludge}

The sludge will be handled just the same as the stockpile refinery sludge. Sludge will be trucked to a 2-1/2-acre clay lined pit for landfilling.

$$
\text { Installation Cost }=\$ 157,100\left(\frac{350}{308}\right)
$$$$
\$ 178,500
$$

\section{Refinery Tailings Pond}

A 10-acre clay lined tailings pond is used with no recycle capability.

10-acre clay core dam and reservoir $\$ 300,800$

Land - 13 acres at $\$ 2,000 /$ acre 26,000

Total Installed Cost

$\$ 326,800$ 
Refinery Drying and Packaging Dust

Same as stockpile refinery except $12,000 \mathrm{cfm}$ baghouse filters and HEPA filters are required in series.

Baghouse filters

HEPA filters

Demister

Installed Cost
$\$ 57,800$

117,000

12,000

$\$ 186,800$

Refinery Pond Beach Dust

A portable sprayer is used periodically to spray chemicals on the pond shore.

$$
\text { Installed Cost }
$$

$\$ \quad 4,000$

Refinery Pond Cover

At decommissioning a $6 \mathrm{ft}$ earth and 6 in. rock cover will be placed over the residual solids.

$6 \mathrm{ft}$ earth and 6 in. rock installed

$\$ 145,800$ 
APPENDIX $F$

ANNUAL COSTS FOR BASELINE TECHNOLOGY 


\section{APPENDIX F: ANNUAL COSTS FOR BASELINE TECHNOLOGY}

\section{E.1 STOCKPILE REFINERY CAPITAL COSTS}

Waste Sludge

Truck to clay lined landfill onsite

\begin{tabular}{|c|c|c|}
\hline Capital charge $=(0.2338)(157,100)$ & $\$$ & 36,700 \\
\hline $\begin{array}{l}\text { Land and Working Capital Charge } \\
(L \& W C C)=(0.05)(36,700)\end{array}$ & & 1,800 \\
\hline Operations $=(616 \mathrm{mh})(20.13)$ & & 12,400 \\
\hline Maintenance $=(0.03)(157,100)$ & & 4,700 \\
\hline Miscellaneous and Fuel & & 2,000 \\
\hline Total & $\$$ & 57,600 \\
\hline
\end{tabular}

Refinery Tailings Pond

4-acre clay lined pond, no recycle

Capital charge $=(0.2338)(164,000)$

$\$ 38,300$

L\&WCC $=(0.05)(38,300)$

1,900

Operations $=(50 \mathrm{mh})(20.13)$

1,000

Maintenance $=(0.01)(164,000)$

1,600

Supplies and miscellaneous 300

Total

$\$ \quad 43,100$

Drying and Packaging Dust

$6,000 \mathrm{cfm}$ baghouse and HEPA filters w/conditioning

- Baghouse filter

Capital charge $=(0.2338)(32,100)$

$\$ 7,500$

L\&WCC $=(0.05)(7,500)$ 400

Operations cost 1,000

Maintenance

1,200

Miscellaneous 900

Power 2,400

Replacement bags 1,300

Subtota 1

$\$ \quad 14,700$


- HEPA Filter

Capital charge $=(0.2338)(64,900)$

$\$ 15,200$

L\&WCC $=(0.05)(15,200)$

800

Operating Cost

1,000

Maintenance

2,400

Miscellaneous

1,300

Power

700

Replacement filters

4,900

Subtota 1

26,300

- Conditioner, 1,000 cfm

Capital charge $=(0.2338)(6,700)$

$\$ 1,600$

L\&WCC $=(0.05)(1,600)$

100

Operations $=(0.02)(6,700)$

100

Maintenance $=(0.03)(6,700)$

200

Miscellaneous

500

Power

\section{Subtota 1}

2,000

Total Annual Cost $=\$ 14,700$

4,500

$$
+26,300
$$

$+4,500=\$ 45,500$

Tailings Pond Beach Dust

Spraying operations

Capital charge $=(0.2338)(4,000)$
L\&WCC $=(0.05)(900)$
Operations $=(50 \mathrm{mh})(20.13)$
Maintenance
Miscellaneous and Chemicals
$\quad$ Total

$\$ \quad 2,400$

Tailings Pond Cover

$6 \mathrm{ft}$ earth $\mathrm{w} / 6$ in. rock cover

Sinking Fund $=(0.00976)(70,100)$

$\$ \quad 700$ 
F.2 LEMHI PASS ANNUAL COSTS

Mine Water Settling Pond

$$
\begin{aligned}
& \text { Capital charge }=(0.2441)(35,200) \\
& \text { L\&WCC }=(0.05)(8,600) \\
& \text { Operations and Maintenance }=(0.06)(35,200) \\
& \quad \text { Total }
\end{aligned}
$$$$
\begin{array}{r}
8,600 \\
400 \\
2,100 \\
\hline \$ 11,100 \\
\hline
\end{array}
$$

\section{Controlled Mine Dust}

None

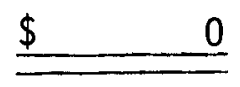

Uncontrolled Dust

Spraying Operation

$$
\begin{aligned}
& \text { Capital charge }=(0.2441)(30,000) \\
& \text { L\&WCC }=(0.05)(7,300) \\
& \text { Operators }=\left(16 \frac{\mathrm{mh}}{\mathrm{wk}}\right)(52 \mathrm{wk})(20.13) \\
& \text { Maintenance }=(0.06)(30,000) \\
& \text { Fuel and supplies }=(100,000 \mathrm{~kW}-\mathrm{hr})(0.03) \\
& \quad \text { Subtotal }
\end{aligned}
$$

$\begin{array}{r}7,300 \\ 400 \\ 16,700 \\ 1,800 \\ 3,000 \\ \hline \$ 29,200 \\ \hline\end{array}$

Storage Pile Barriers

\begin{tabular}{lr} 
Capital charge $=(0.2336)(15,000)$ & 3,500 \\
L\&WCC $=(0.05)(3,500)$ & 200 \\
Maintenance $=(0.02)(15,000)$ & 300 \\
Miscellaneous & 1,000 \\
$\quad$ Subtotal & $\$ \quad 5,000$ \\
\hline
\end{tabular}

$$
\text { Total }=\$ 29,200+5,000=\$ 34,200
$$




\section{Loading, Crushing, and Grinding Dust}

Cyclone

$$
\begin{aligned}
& \text { Capital charge }=(0.2336)(19,900) \\
& \text { L\&WCC }=(0.05)(4,600) \\
& \text { Operations }=(65 \mathrm{mh})(20.13) \\
& \text { Maintenance }=(0.03)(19,900) \\
& \text { Miscel laneous } \\
& \text { Power }=(133,300 \mathrm{~kW}-\mathrm{hr})(0.03) \\
& \quad \text { Total }
\end{aligned}
$$$$
\begin{array}{r}
\$, 600 \\
200 \\
1,300 \\
600 \\
900 \\
4,000 \\
\hline \quad 11,600 \\
\hline
\end{array}
$$

Drying and Ignition Dust

Wet impingement scrubber

$$
\begin{aligned}
& \text { Capital charge }=(0.2336)(39,900) \\
& \text { L\&WCC }=(0.05)(9,300) \\
& \text { Operations }=(110 \mathrm{mh})(20.13) \\
& \text { Maintenance }=(0.03)(39,900) \\
& \text { Miscellaneous } \\
& \text { Power }=(180,000 \mathrm{~kW}-\mathrm{hr})(0.03) \\
& \quad \text { Total }
\end{aligned}
$$$$
\begin{array}{r}
9,300 \\
500 \\
2,200 \\
1,200 \\
1,800 \\
5,400 \\
\hline \$ 20,400 \\
\hline
\end{array}
$$

\section{Packaging Dust}

$$
\begin{aligned}
& \text { Baghouse filter } \\
& \text { Capital charge }=(0.2336)(22,700) \\
& \text { L\&WCC }=(0.05)(5,300) \\
& \text { Operations }=(55 \mathrm{mh})(20.13) \\
& \text { Maintenance }=(0.03)(22,700) \\
& \text { Miscellaneous } \\
& \text { Power }=(43,300 \mathrm{~kW}-\mathrm{hr})(0.03) \\
& \text { Bag replacement } \\
& \quad \text { Total }
\end{aligned}
$$$$
\begin{array}{r}
\$, 300 \\
300 \\
1,100 \\
700 \\
500 \\
1,300 \\
700 \\
\hline \$ 9,900 \\
\hline
\end{array}
$$ 


\section{Tailings Pond}

100-acre clay core dam and reservoir and recycle Capital charge $=(0.2336)(3,066,000)$

$\$ 716,200$

L\&WCC $=(0.05)(716,200)$

35,800

Operations $=(2,250 \mathrm{mh})(20.13)$

45,300

Ma intenance manpower $=(4,000 \mathrm{mh})(20.13)$

80,500

Maintenance parts and supplies

12,100

Miscellaneous

9,000

Power $=(483,300 \mathrm{~kW}-\mathrm{hr})(0.03)$

14,500

Total

$\$ 913,400$

Tailings Pond Beach Dust

Spraying operations

Capital charge $=(0.2336)(20,000)$

$\$ 4,700$

L\&WCC $=(0.05)(4,700)$

200

Operations $=(832 \mathrm{mh})(20.13)$

16,700

Ma intenance $=(0.06)(20,000)$

1,200

Miscellaneous, chemicals, etc.

3,200

Total

$\$ 26,000$

Tailings Pond Cover

$1 \mathrm{ft}$ earth and 6 in. rock cover

Sinking Fund $=(0.00306)(320,000)$

$\$ 1,000$ 


\section{F.3 HALL MOUNTAIN ANNUAL COSTS}

Mine Water

Settling pond, 1 acre

$$
\begin{aligned}
& \text { Capital charge }=(0.3681)(21,700) \\
& \text { L\&WCC }=(0.05)(8,000) \\
& \text { Operation and maintenance }=(0.06)(21,700) \\
& \quad \text { Total }
\end{aligned}
$$

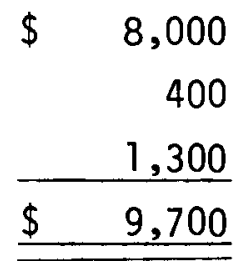

Controlled Mine Dust

None

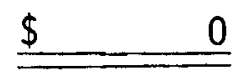

Uncontrolled Dust

Spraying

$$
\begin{aligned}
& \text { Capital charge }=(0.3681)(17,300) \\
& \text { L\&WCC }=(0.05)(6,400) \\
& \text { Operations }=(475 \mathrm{mh})(20.13) \\
& \text { Maintenance }=(0.06)(17,300) \\
& \text { Fuel and supplies } \\
& \quad \text { Subtotal }
\end{aligned}
$$

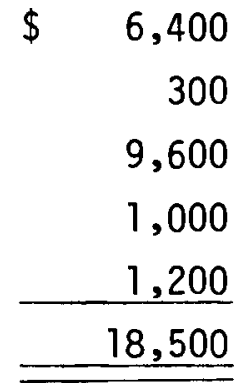

Storage pile barriers

$$
\begin{aligned}
& \text { Capital charge }=(0.3681)(8,700) \\
& \text { L\&WCC }=(0.05)(3,200) \\
& \text { Operations } \\
& \text { Maintenance }=(0.02)(8,700) \\
& \text { Misce1 laneous } \\
& \quad \text { Subtotal } \\
& \quad \text { Total }=\$ 18,500+4,200=\$ 22,700
\end{aligned}
$$

$\begin{array}{r}\$, 200 \\ 200 \\ 0 \\ 200 \\ 600 \\ \hline \$ 4,200 \\ \hline \hline\end{array}$


Loading, Crushing, and Grinding Dust

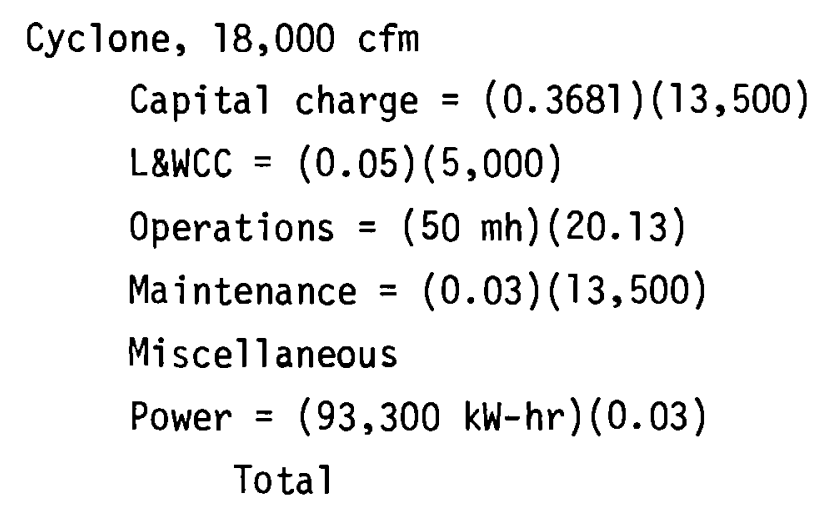

$\begin{array}{r}5,000 \\ 300 \\ 1,000 \\ 400 \\ 700 \\ 2,800 \\ \hline \quad 10,200 \\ \hline \hline\end{array}$

Drying and Ignition Dust

$25,000 \mathrm{cfm}$ wet impingement scrubber

\begin{tabular}{lr} 
Capital charge $=(0.3681)(46,200)$ & 17,000 \\
L\&WCC $=(0.05)(17,000)$ & 900 \\
Operations $=(130 \mathrm{mh})(20.13)$ & 2,600 \\
Maintenance $=(0.03)(46,200)$ & 1,400 \\
Miscellaneous & 2,100 \\
Power $=(216,700 \mathrm{~kW}-\mathrm{hr})(0.03)$ & 6,500 \\
$\quad$ Total & $\$ \quad 30,500$ \\
\hline
\end{tabular}

Packaging Dust

$4,400 \mathrm{cfm}$ baghouse filter

Capital charge $=(0.3681)(24,700)$

$\$ 9,100$

L\&WCC $=(0.05)(9,100)$

500

Operations $=(60 \mathrm{mh})(20.13)$

1,200

Maintenance $=(0.03)(24,700)$

700

Miscellaneous

600

Power $=(46,700 \mathrm{~kW}-\mathrm{hr})(0.03)$

1,400

Bag replacement 800

Total

$\begin{array}{r}600 \\ 1,400 \\ 800 \\ \hline \$ \quad 14,300 \\ \hline\end{array}$


Tailings Pond

15-acre clay core dam and reservoir and recycle

Capital charge $=(0.3681)(970,000)$

$\$ 357,000$

L\&WCC $=(0.05)(357,000)$

17,900

Operations $=(1,500 \mathrm{mh})(20.13)$

30,200

Ma intenance $=(0.03)(970,000)$

29,100

Miscellaneous

7,000

Power $=(283,300 \mathrm{~kW}-\mathrm{hr})(0.03)$

8,500

Total

$\$ 449,700$

Tailings Pond Beach Dust

Spraying operations

Capital charge $=(0.3681)(11,500)$

L\&WCC $=(0.05)(4,200)$

$\$ 4,200$

Operations $=(475 \mathrm{mh})(20.13)$

Maintenance $=(0.06)(11,500)$

600

9,600

700

Miscellaneous, chemicals, etc. 1,300

Total

$\$ \quad 16,000$

Tailings Pond Cover

$1 \mathrm{ft}$ earth and $6 \mathrm{in}$. rock cover

Sinking fund $=(0.14832)(70,100)$

$\$ 10,400$ 
F.4 WET MOUNTAIN ANNUAL COSTS

Mine Water

Settling Pond

Capital charge $=(0.3681)(21,700)$

$\$ 8,000$

L\&WCC $=(0.05)(8,000)$

400

Operations and maintenance $=(0.06)(21,700)$

1,300

Total

$\begin{array}{r}1,300 \\ \$ \quad 9,700 \\ \hline\end{array}$

Controlled Mine Dust

None

$\$$

Uncontrolled Dust

Spraying

Capital charge $=(0.3681)(16,000)$

$\$ 5,900$

L\&WCC $=(0.05)(5,900)$

300

Operations $=(440 \mathrm{mh})(20.13)$

8,900

Maintenance $=(0.06)(16,000)$

1,000

Fuel and supplies

1,100

Subtota 1

$\$ \quad 17,200$

Storage pile barriers

Capital charge $=(0.3681)(8,000)$

$\$ 2,900$

L\&WCC $=(0.05)(2,900)$

100

Operations

0

Maintenance $=(0.02)(8,000)$

200

Miscellaneous

500

Subtotal

Total $=\$ 17,200+3,700=\$ 20,900$

3,700 
Loading, Crushing, and Grinding Dust

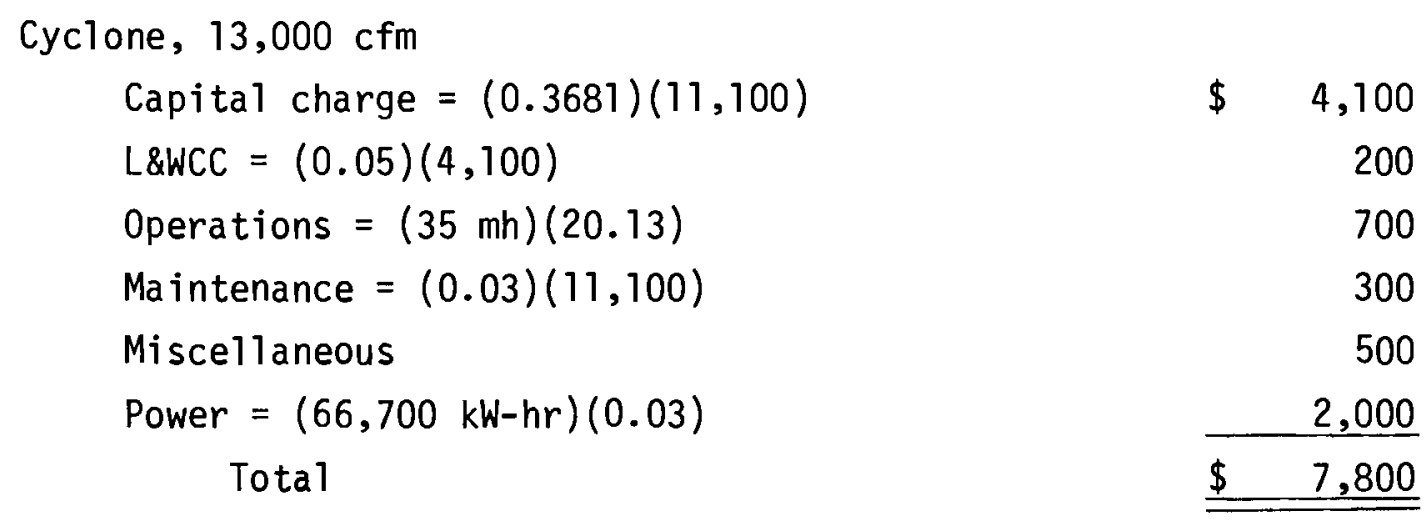

Drying and Ignition Dust

Wet impingement scrubber, $20,000 \mathrm{cfm}$

Capital charge $=(0.3681)(38,300)$

$\$ 14,100$

L\&WCC $=(0.05)(14,100)$

700

Operations $=(105 \mathrm{mh})(20.13)$

2,100

Maintenance $=(0.03)(38,300)$

1,100

Miscellaneous

1,800

Power $=(173,300 \mathrm{~kW}-\mathrm{hr})(0.03)$

5,200

Total

$\$ \quad 25,000$

Packaging Dust

Baghouse filter, $3,500 \mathrm{cfm}$

Capital charge $=(0.3681)(20,300)$

$\$ 7,500$

L\&WCC $=(0.05)(7,500)$

400

Operations $=(50 \mathrm{mh})(20.13)$

1,000

Maintenance $=(0.03)(20,300)$

600

Miscellaneous

500

Power $=(40,000 \mathrm{~kW}-\mathrm{hr})(0.03)$

1,200

Bag replacement

600

Total

$\$ 11,800$ 


\section{Tailings Pond}

14-acre clay core dam and reservoir and recycle

$$
\text { Capital charge }=(0.3681)(902,200)
$$

$\$ 332,100$

L\&WCC $=(0.05)(332,100)$

16,600

Operations $=(1,400 \mathrm{mh})(20.13)$

28,200

Maintenance $=(0.03)(902,200)$

27,100

Miscellaneous

6,000

Power $=(230,000 \mathrm{~kW}-\mathrm{hr})(0.03)$

6,900

Total

$\$ 416,900$

Tailings Pond Beach Dust

Spraying operations

Capital charge $=(0.3681)(10,700)$

$\$ 3,900$

L\&WCC $=(0.05)(3,900)$

200

Operations $=(440 \mathrm{mh})(20.13)$

8,900

Maintenance $=(0.06)(10,700)$

600

Miscellaneous, chemicals, etc.

1,100

Total

$\$ \quad 14,700$

\section{Tailings Pond Cover}

$1 \mathrm{ft}$ earth and 7 in. rock cover

Sinking fund $=(0.14832)(66,400)$

$\$ \quad 9,800$ 
F.5 PALMER, MICHIGAN, ANNUAL COSTS

\section{Mine Water}

3-acre settling pond and pumping system

Capital charge $=(0.2338)(235,800)$

$\$ 55,100$

$L \& W C C=(0.05)(55,100)$

2,800

Operations $=(235 \mathrm{mh})(20.13)$

4,700

Maintenance $=(0.03)(235,800)$

7,100

Power $=(1,033,000 \mathrm{~kW}-\mathrm{hr})(0.03)$

31,000

Total

$\$ 100,700$

Uncontrolled Dust

Spray equipment and storage pile barriers

\begin{tabular}{lr} 
Capital charge $=(0.2338)(156,000)$ & 36,500 \\
L\&WCC $=(0.05)(36,500)$ & 1,800 \\
Operations $=(1,560 \mathrm{mh})(20.13)$ & 31,400 \\
Maintenance $=(0.03)(156,000)$ & 4,700 \\
Fue1, chemicals and miscellaneous & 30,000 \\
\hline Total & $\$ 104,400$ \\
\hline
\end{tabular}

Unloading and Crushing Dust

4-50,000 cfm cyclones

Capital charge $=(0.2338)(138,900)$
L\&WCC $=(0.05)(32,500)$
Operations $=(545 \mathrm{mh})(20.13)$
Maintenance
Miscellaneous
Power $=(1,173,000 \mathrm{~kW}-\mathrm{hr})(0.03)$
$\quad$ Total

$\$ 32,500$

1,600

11,000

5,000

7,400

35,200

$\$ \quad 87,700$ 
Drying, Magnetic Separation, and Loading Dust

2-30,000 cfm wet impingement scrubbers

\begin{tabular}{lr} 
Capital charge $=(0.2338)(108,000)$ & 25,300 \\
L\&WCC $=(0.05)(25,300)$ & 1,300 \\
Operations $=(412 \mathrm{mh})(20.13)$ & 8,300 \\
Maintenance & 4,400 \\
Miscellaneous & 6,900 \\
Power $=(683,000 \mathrm{~kW}-\mathrm{hr})(0.03)$ & 20,500 \\
$\quad$ Total & $\$ \quad 66,700$ \\
\hline
\end{tabular}

Separation and Dewatering Liquid Waste

200-acre clay lined pond $\mathrm{w} / \mathrm{recycle}$

Capital charge $=(0.2338)(7,219,800)$

$\$ 1,688,000$

L\&WCC $=(0.05)(1,688,000)$

84,400

Operations $=(6,000 \mathrm{mh})(20.13)\left(\frac{330}{240}\right)$

166,100

Maintenance $=(8,000 \mathrm{mh})(20.13)\left(\frac{330}{240}\right)$

221,400

Supplies, parts, etc.

55,000

Power $=(2,627,000 \mathrm{~kW}-\mathrm{hr})(0.03)$

78,800

Total

$\$ 2,293,700$

Unloading and Grinding Dust

$10,000 \mathrm{cfm}$ baghouse filter

Capital charge $=(0.2338)(49,500)$

$\$ \quad 11,600$

L\&WCC $=(0.05)(11,600)$

600

Operations $=(160 \mathrm{mh})(20.13)$

3,200

Maintenance $=(0.04)(49,500)$

2,000

Miscel1aneous

1,600

Power $=(147,000 \mathrm{~kW}-\mathrm{hr})(0.03)$

4,400

Bag replacement

2,300

Total

$\$ 23,900$ 
Ignition and Drying Dust

$16,000 \mathrm{cfm}$ low energy venturi scrubber

Capital charge $=(0.2338)(36,900)$

L\&WCC $=(0.05)(8,600)$

$\$ 8,600$

Operations $=(180 \mathrm{mh})(20.13)$

400

Maintenance $=(0.04)(36,900)$

3,600

1,500

Miscellaneous

2,400

Power $=(287,000 \mathrm{~kW}-\mathrm{hr})(0.03)$

8,600

Total

$\$ 25,100$

\section{Packaging Dust}

3,000 cfm baghouse filter

Capital charge $=(0.2338)(17,800)$

4,200

L\&WCC $=(0.05)(4,200)$

200

Operations $=(45 \mathrm{mh})(20.13)$

900

Maintenance

500

Miscellaneous

400

Power $=(33,300 \mathrm{~kW}-\mathrm{hr})(0.03)$

1,000

Bag replacement

500

Tota 1

7,700

By-Product Recovery Dust

$24,000 \mathrm{cfm}$ wet impingement scrubber

Capital charge $=(0.2338)(44,700)$

$\$ 10,400$

L\&WCC $=(0.05)(10,400)$

500

Operations $=(164 \mathrm{mh})(20.13)$

3,300

Ma intenance

1,800

Miscellaneous

2,700

Power $=(273,000 \mathrm{~kW}-\mathrm{hr})(0.03)$

8,200

Total

26,900 


\section{Liquid Waste to Tailings Pond}

20 -acre pond $w / 3 \mathrm{ft}$ clay liner $w /$ recycle

Capital charge $=(0.2338)(993,500)$

$\$ 232,300$

L\&WCC $=(0.05)(232,300)$

11,600

Operations $=(3,000 \mathrm{mh})(20.13)$

60,400

Maintenance $=(4,000 \mathrm{mh})(20.13)$

80,500

Supplies, parts, etc.

20,000

Power $=(603,000 \mathrm{~kW}-\mathrm{hr})(0.03)$

18,100

Total

$\$ 422,900$

Tailings Pond Beach Dust

Spraying Operations

Capital charge $=(0.2338)(6,500)$

$\$ 1,500$

L\&WCC $=(0.05)(1,500)$

100

Operations $=(156 \mathrm{mh})(20.13)$

3,200

Maintenance $=(0.06)(6,500)$

400

Miscellaneous, chemicals, etc.

600

Total

$\$ \quad 5,800$

\section{Tailings Pond Cover}

$6 \mathrm{ft}$ earth $\mathrm{w} / 6$ in. rock cover

Sinking fund $=(0.00976)(253,900)$

$\$ \quad 2,500$ 


\section{F.6 BALD MOUNTAIN ANNUAL COSTS}

Mine Water

2-acre settling pond and pumping system

$$
\begin{array}{lr}
\text { Capital charge }=(0.2668)(174,700) & \$ 4,600 \\
\text { L\&WCC }=(0.05)(46,600) & 2,300 \\
\text { Operations }=(175 \mathrm{mh})(20.13) & 3,500 \\
\text { Maintenance }=(0.03)(174,700) & 5,200 \\
\text { Power }=(690,000 \mathrm{~kW}-\mathrm{hr})(0.03) & 20,700 \\
\quad \text { Total } & \$ \quad 78,300 \\
\hline
\end{array}
$$

Uncontrolled Dust

Spraying and storage pile barriers

$$
\begin{aligned}
& \text { Capital charge }=(0.2668)(94,400) \\
& \text { L\&WCC }=(0.05)(25,200) \\
& \text { Operations }=(1,090 \mathrm{mh})(20.13) \\
& \text { Maintenance }=(0.03)(94,400) \\
& \text { Fuel, supplies, miscellaneous } \\
& \quad \text { Tota } 1
\end{aligned}
$$

$$
\begin{array}{r}
25,200 \\
1,300 \\
22,000 \\
2,800 \\
20,000 \\
\hline \quad 71,300 \\
\hline
\end{array}
$$

Unloading and Crushing Dust

$$
\begin{aligned}
& 50,000 \mathrm{cfm} \text { cyclone } \\
& \text { Capital charge }=(0.2668)(34,700) \\
& \text { L\&WCC }=(0.05)(9,300) \\
& \text { Operations }=(159 \mathrm{mh})(20.13) \\
& \text { Maintenance }=(0.04)(34,700) \\
& \text { Miscellaneous } \\
& \text { Power }=(340,000 \mathrm{~kW}-\mathrm{hr})(0.03) \\
& \text { Total }
\end{aligned}
$$$$
\begin{array}{r}
\$, 300 \\
500 \\
3,200 \\
1,400 \\
2,100 \\
10,200 \\
\hline \quad 26,700 \\
\hline
\end{array}
$$ 
Drying, Magnetic Separation, and Loading Dust

$30,000 \mathrm{cfm}$ wet impingement scrubber

\begin{tabular}{lr} 
Capital charge $=(0.2668)(54,000)$ & 14,400 \\
L\&WCC $=(0.05)(14,400)$ & 700 \\
Operations $=(204 \mathrm{mh})(20.13)$ & 4,100 \\
Maintenance & 2,200 \\
Miscellaneous & 3,400 \\
Power $=(340,000 \mathrm{~kW}-\mathrm{hr})(0.03)$ & 10,200 \\
$\quad$ Total & $\$ \quad 35,000$ \\
\hline
\end{tabular}

Separation and Dewatering Liquid Waste

40-acre clay lined pond $w /$ recycle

Capital charge $=(0.2668)(2,347,600)$

$\$ 626,300$

L\&WCC $=(0.05)(626,300)$

31,300

Operations $=(2,250 \mathrm{mh})(20.13)\left(\frac{330}{240}\right)$

62,300

Maintenance $=(.03)(626,300)\left(\frac{330}{240}\right)$

25,900

Maintenance parts, supplies, miscellaneous

28,900

Power $=(663,000 \mathrm{~kW}-\mathrm{hr})(0.03)$

19,900

Total

$\$ 794,600$

Unloading and Grinding Dust

10,000 cfm cyclone

Capital charge $=(0.2668)(8,800)$

$\$ 2,400$

L\&WCC $=(0.05)(2,400)$

100

Operations $=(40 \mathrm{mh})(20.13)$

800

Maintenance

300

Miscel laneous

500

Power $=(66,700 \mathrm{~kW}-\mathrm{hr})(0.03)$

2,000

Total

$\$ \quad 6,100$ 
Ignition and Drying Dust

$6,000 \mathrm{cfm}$ low energy venturi scrubber

Capital charge $=(0.2668)(16,000)$

$\$ 4,300$

L\&WCC $=(0.05)(4,300)$

200

Operations $=(75 \mathrm{mh})(20.13)$

1,500

Maintenance $=(0.04)(16,000)$

600

Miscellaneous

1,000

Power $=(80,000 \mathrm{~kW}-\mathrm{hr})(0.03)$

2,400

Total

$\$ 10,000$

Packaging Dust

$1,200 \mathrm{cfm}$ baghouse filter

Capital charge $=(0.2668)(8,200)$

$\$ 2,200$

L\&WCC $=(0.05)(2,200)$

100

Operations $=(25 \mathrm{mh})(20.13)$

500

Maintenance $=(0.04)(8,200)$

300

Miscellaneous

300

Power $=(17,000 \mathrm{~kW}-\mathrm{hr})(0.03)$

500

Bag replacement

300

Total

$\$ \quad 4,200$

By-Product Recovery Dust

$15,000 \mathrm{cfm}$ wet impingement scrubber

Capital charge $=(0.2668)(30,000)$

$\$ 8,000$

L\&WCC $=(0.05)(8,000)$

400

Operations $=(110 \mathrm{mh})(20.13)$

2,200

Maintenance $=(0.04)(30,000)$

1,200

Miscellaneous

1,800

Power $=(170,000 \mathrm{~kW}-\mathrm{hr})(0.03)$

5,100

Tota 1

$\$ \quad 18,700$ 
Liquid Waste to Tailings Pond

6-acre pond w/clay liner, no recycle

\begin{tabular}{lr} 
Capital charge $=(0.2668)(209,300)$ & 55,800 \\
L\&WCC $=(0.05)(55,800)$ & 2,800 \\
Operations $=(70 \mathrm{mh})(20.13)$ & 1,400 \\
Maintenance $=(0.01)(209,300)$ & 2,100 \\
$\quad$ Total & $\$ 62,100$ \\
\hline
\end{tabular}

\section{Tailings Pond Beach Dust}

Spraying operations

\begin{tabular}{lr} 
Capital charge $=(0.2668)(4,000)$ & 1,100 \\
L\&WCC $=(0.05)(1,100)$ & 100 \\
Operations $=(50 \mathrm{mh})(20.13)$ & 1,000 \\
Maintenance $=(0.04)(4,000)$ & 200 \\
Miscellaneous, chemicals, etc. & 200 \\
$\quad$ Total & $\$ \quad 2,600$ \\
\hline
\end{tabular}

\section{Tailings Pond Cover}

$6 \mathrm{ft}$ earth $\mathrm{w} / 6$ in. rock cover

Sinking fund $=(0.04925)(96,900)$

$\$ \quad 4,800$ 


\section{F.7 CONWAY GRANITE ANNUAL COSTS}

Mine Water

4-acre settling pond and pumping system

Capital charge $=(0.2338)(293,000)$

$\$ 68,500$

L\&WCC $=(0.05)(68,500)$

3,400

Operations $=(418 \mathrm{mh})(20.13)$

8,400

Maintenance

12,600

Power $=(2,010,000 \mathrm{~kW}-\mathrm{hr})(0.03)$

60,300

Total

$\$ 153,200$

Uncontrolled Dust

Spraying and storage pile barriers

Capital charge $=(0.2338)(225,000)$

$\$ 52,600$

L\&WCC $=(0.05)(52,600)$

2,600

Operations $=(2,340 \mathrm{mh})(20.13)$

47,100

Ma intenance $=(0.03)(225,000)$

6,800

Fuel, Chemicals, etc.

60,000

Total

$\$ 169,100$

Unloading, Crushing, and Grinding Dust

2-50,000 cfm cyclones

Capital charge $=(0.2338)(69,500)$

$\$ 16,200$

L\&WCC $=(0.05)(16,200)$

800

Operations $=(338 \mathrm{mh})(20.13)$

6,800

Maintenance

3,100

Miscellaneous

4,500

Power $=(720,000 \mathrm{~kW}-\mathrm{hr})(0.03)$

21,600

Total

$\$ \quad 53,000$ 
Mi11 Drying and Packaging Dust

$30,000 \mathrm{cfm}$ wet impingement scrubber

\begin{tabular}{lr} 
Capital charge $=(0.2338)(54,000)$ & 12,600 \\
L\&WCC $=(0.05)(12,600)$ & 600 \\
Operations $=(220 \mathrm{mh})(20.13)$ & 4,400 \\
Maintenance & 2,400 \\
Miscellaneous & 3,600 \\
Power $=(375,000 \mathrm{~kW}-\mathrm{hr})(0.03)$ & 11,300 \\
$\quad$ Total & $\$ \quad 34,900$ \\
\hline
\end{tabular}

Liquid Waste to Tailings Pond

20-acre clay 1 ined pond $w /$ recycle system

Capital charge $=(0.2338)(908,300)$

$\$ 212,400$

L\&WCC $=(0.05)(212,400)$

10,600

Operations $=(2,500 \mathrm{mh})(20.13)$

50,300

Maintenance

70,500

Supplies

Power $=(253,000 \mathrm{~kW}-\mathrm{hr})(0.03)$ 11,000

Total

7,600

$\$ 368,400$

Refinery Waste Sludge

Truck to clay lined landfill

Capital charge $=(0.2338)(178,500)$

$\$ 41,700$

L\&WCC $=(0.05)(41,700)$

2,100

Operations $=(700 \mathrm{mh})(20.13)$

14,100

Maintenance

5,300

Miscellaneous and fuel

2,300

Total

$\$ \quad 65,500$ 
Refinery Drying and Packaging Dust

$12,000 \mathrm{cfm}$ baghouse and HEPA filter w/conditioning

- Baghouse filter

\begin{tabular}{lr} 
Capital charge $=(0.2338)(57,800)$ & 13,500 \\
L\&WCC $=(0.05)(13,500)$ & 700 \\
Operations cost & 3,900 \\
Maintenance & 2,400 \\
Miscellaneous & 1,900 \\
Power & 5,500 \\
Replacement bags & 2,900 \\
$\quad$ Subtotal & $\$ 30,800$ \\
\hline
\end{tabular}

- HEPA filter

Capital charge $=(0.2338)(117,000)$

L\&WCC $=(0.05)(27,400)$

$\$ 27,400$

Operations

1,400

Maintenance

2,100

Miscellaneous

4,900

Power

2,600

Replacement filters

1,700

Subtotal

11,200

$\$ 51,300$

- 2,000 cfm conditioner

Capital charge $=(0.2338)(12,000)$

$\$ 2,800$

L\&WCC $=(0.05)(2,800)$

100

Operations $=(0.02)(12,000)$

200

Maintenance $=(0.03)(12,000)$

400

Miscellaneous

1,000

Power

Subtotal

4,000

$\$ \quad 8,500$

Total Annual Cost $=\$ 30,800$

$+51,300$

$+8,500=\$ 90,600$ 
Refinery Tailings Pond

10-acre clay lined evaporation pond, no recycie

Capital charge $=(0.2338)(326,800)$

$\$ 76,400$

L\&WCC $=(0.05)(76,400)$

3,800

Operations $=(100 \mathrm{mh})(20.13)$

2,000

Ma intenance $=(0.01)(326,800)$

3,300

Supplies and miscellaneous

500

Total

$\$ 86,000$

Refinery Tailings Pond Beach Dust

Spraying operation

Capital charge $=(0.2338)(4,000)$

$\$ 900$

L\&WCC $=(0.05)(900)$

100

Operations and maintenance

2,100

Total

3,100

Refinery Tailings Pond Cover

$6 \mathrm{ft}$ earth w/ 6 in. rock cover

Sinking fund $=(0.00976)(145,800)$

$\$ 1,400$ 


\section{DISTRIBUTION}

No. of

Copies

OFFSITE

A.A. Churm

DOE Patent Division

9800 S. Cass Ave.

Argonne, IL 60439

R.W. Ramsey

DOE Division of Environmental

Control Engineering

Washington, DC 20545

W.E. Mott

DOE Division of Environmental

Control Enginnering

Washington, DC 20545

J. Counts

DOE Division of Environmental

Control Enginnering

Washington, DC 20545

27 DOE Technical Information Center

U.S. Department of Commerce

5285 Port Royal Rd.

Springfield, VA 22161

W.W. Ballard

Nuclear Power Development Division

Department of Energy

Washington, DC 20545

Bobby $\mathrm{Clark}$

Flanders Filters

P.0. Box 1219

Washington, NC 27889

J.H. Cavendish

National Lead Company

of Ohio

P.0. Box 39158

Cinc innati, OH 45239
No. of

Copies

Frank E. Driggers

El DuPont

Savannah River Laboratories

Aiken, SC 29801

D.R. Everhart

Manager

Grand Junction Operation

Office

U.S. Dept. of Energy

Grand Junction, CO 81502

Dr. T.W. Offield

U.S. Geological Survey

Federal Center

Box 25046

Mail Stop 916

Denver, CO 80225

J.A. Patterson

Director of Resource

Assessment Operations

12 th \& Pennsylvania Ave. N.W.

Mail Stop 6521, RA 224

Washington, DC 20461

Roy Post

University of Arizona

Department of Nuclear

Engineering

Tucson, AZ 85721

W.M. Shaffer III

Acfg. Director

Fuel Cycle Project Office

Savannah River Operations

Office

P.0. Box A

Aiken, SC 29801

M.H. Staatz

U.S. Geological Survey

1711 Illinois Street

Room 327

Golden, CO 80401 
No. of

Copies

ONSITE

2 DOE Richland Operations Office

H.E. Ransom

P.A. Craig

34 Pac if ic Northwest Laboratory

D.E. Blahnik (5)

C.H. Bloomster (5)

D.E. Deonigi

R.M. Fle ischman

L.H. King

M.A. Lewallen

R.C. Liikala

S.A. Weakley (5)

L.D. Williams

J.K. Young (5)

Technical Information Files (5)

Publishing Coordination KE (2) 